\title{
A MANAGEMENT MODEL FOR CLOSED-LOOP SUPPLY CHAINS OF REUSABLE ARTICLES
}

\author{
by \\ Ruth Carrasco-Gallego \\ Submitted to the Departament of Industrial Engineering, Industrial Management and \\ Statistics \\ in partial fulfillment of the requirements for the degree of \\ Doctor by the Technical University of Madrid (UPM) \\ at the \\ ESCUELA TÉCNICA SUPERIOR DE INGENIEROS INDUSTRIALES.
UNIVERSIDAD POLITÉCNICA DE MADRID
}

September 2010

(C) Escuela Técnica Superior de Ingenieros Industriales. Universidad Politécnica de Madrid 2010

Signature of Author ...

Departament of Industrial Engineering, Industrial Management and Statistics September 1st 2010

Accepted by

Dr. Eva Ponce-Cueto

Associate Professor. Technical University of Madrid (UPM). 


\begin{abstract}
This PhD dissertation is framed in the emergent fields of Reverse Logistics and ClosedLoop Supply Chain (CLSC) management. This subarea of supply chain management has gained researchers and practitioners' attention over the last 15 years to become a fully recognized subdiscipline of the Operations Management field. More specifically, among all the activities that are included within the CLSC area, the focus of this dissertation is centered in direct reuse aspects.
\end{abstract}

The main contribution of this dissertation to current knowledge is twofold. First, a framework for the so-called reuse CLSC is developed. This conceptual model is grounded in a set of six case studies conducted by the author in real industrial settings. The model has also been contrasted with existing literature and with academic and professional experts on the topic as well. The framework encompasses four building blocks. In the first block, a typology for reusable articles is put forward, distinguishing between Returnable Transport Items (RTI), Reusable Packaging Materials (RPM), and Reusable Products (RP). In the second block, the common characteristics that render reuse CLSC difficult to manage from a logistical standpoint are identified, namely: fleet shrinkage, significant investment and limited visibility. In the third block, the main problems arising in the management of reuse CLSC are analyzed, such as: (1) define fleet size dimension, (2) control cycle time and promote articles rotation, (3) control return rate and prevent shrinkage, (4) define purchase policies for new articles, (5) plan and control reconditioning activities, and (6) balance inventory between depots.

Finally, in the fourth block some solutions to those issues are developed. Firstly, problems (2) and (3) are addressed through the comparative analysis of alternative strategies for controlling cycle time and return rate. Secondly, a methodology for calculating the required fleet size is elaborated (problem (1)). This methodology is valid for different configurations of the physical flows in the reuse CLSC. Likewise, some directions are pointed out for further development of a similar method for defining purchase policies for new articles (problem (4)).

The second main contribution of this dissertation is embedded in the solutions part (block 4) of the conceptual framework and comprises a two-level decision problem integrating two mixed integer linear programming (MILP) models that have been formulated and solved to optimality using AIMMS as modeling language, CPLEX as solver and Excel spreadsheet for data introduction and output presentation. The results obtained are analyzed in order to measure in a client-supplier system the economic impact of two alternative control strategies (recovery policies) in the context of reuse. In addition, the models support decision-making regarding the selection of the appropriate recovery policy against the characteristics of demand pattern and the structure of the relevant costs in the system.

The triangulation of methods used in this thesis has enabled to address the same research topic with different approaches and thus, the robustness of the results obtained is strengthened. 


\section{Resumen}

Esta tesis doctoral se enmarca en los campos emergentes de la logística inversa y las cadenas de suministro de bucle cerrado (CLSC). En los últimos quince años, estas subáreas de la gestión de redes de suministro han ido recibiendo una mayor atención tanto desde el mundo académico como desde el empresarial, hasta convertirse en una disciplina totalmente reconocida dentro del área de Dirección de Operaciones. De forma más específica, de entre todas las actividades que se incluyen dentro de las CLSC, esta tesis se centra en los aspectos relacionados con la reutilización.

La contribución principal de esta tesis al conocimiento existente es doble. En primer $\underline{\text { lugar}}$, se desarrolla un marco conceptual para las llamadas "CLSC de reutilización" (reuse CLSC). Este modelo conceptual se apoya empíricamente en un conjunto de seis casos de estudio reales, elaborados por la autora, relativos a varias empresas industriales de distintos sectores. El modelo ha sido contrastado con la literatura científica existente sobre el tema así como con expertos internacionales del ámbito empresarial y académico. El modelo conceptual está constituido por cuatro bloques. En el primer bloque se propone una tipología para los artículos reutilizables: elementos de transporte y manutención retornables (RTI), envases reutilizables (RPM) y productos reutilizables (RP). En el segundo bloque, se identifican un conjunto de características particulares que dificultan la gestión logística en este tipo de sistemas, a saber: pérdida de activos, inversión y visibilidad limitada. En el tercer bloque, se analizan los principales problemas que surgen en la gestión logística de las "CLSC de reutilización", como son: (1) dimensionar el tamaño adecuado de la "flota" (fleet) de artículos reutilizables, (2) definir indicadores para el control de tiempo de ciclo y establecer medidas que fomenten la rotación de los artículos en el sistema, (3) definir indicadores para el control de la tasa de retornos y establecer medidas para evitar la pérdida de artículos, (4) establecer políticas para la compra de nuevos artículos, (5) planificar y controlar el proceso de reacondicionado de artículos usados, y por último, (6) equilibrar el número de artículos en inventario en cada nodo de la red logística de reutilización.

Finalmente, en el cuarto bloque se proponen soluciones a varios de estos problemas. En primer lugar, los problemas (2) y (3) se abordan mediante un análisis comparativo de las alternativas existentes para el control del tiempo de ciclo y la tasa de retornos. En segundo lugar, para el problema (1) se propone una metodología para el cálculo del tamaño de flota, que es válida para todo tipo de configuraciones de la red logística. Asimismo, se indican direcciones para desarrollar en el futuro una metodología similar para la definición de políticas de compra de nuevos artículos (problema (4)).

La segunda contribución principal de la tesis se encuentra encajada en el bloque 4 del marco conceptual y consiste en la formulación de un problema de decisión en dos etapas, que integra dos modelos de programación lineal entera mixta (MILP) interrelacionados. Ambos modelos se resuelven usando una herramienta informática que integra el modelador AIMMS, el solver CPLEX y la hoja de cálculo Excel para la 
introducción de datos y presentación de resultados. El análisis de los resultados obtenidos a partir de los modelos cuantitativos permite medir el impacto económico que tiene en el sistema cliente-proveedor el uso de dos alternativas diferentes de recuperación de artículos en el contexto de la reutilización. Asimismo, permite decidir qué política de recuperación de productos es más adecuada en función de las características de la señal de demanda de entrada y la relación entre los costes relevantes del sistema.

La triangulación de métodos empleada en esta tesis ha permitido acercarse a un mismo problema desde diferentes perspectivas, lo que fortalece en cierta medida los resultados obtenidos. 


\section{Contents}

$\begin{array}{ll}\text { Contents } & 4\end{array}$

$\begin{array}{ll}\text { List of Figures } & 9\end{array}$

List of Tables $\quad 11$

1 Introduction: motivation and objectives of this dissertation 12

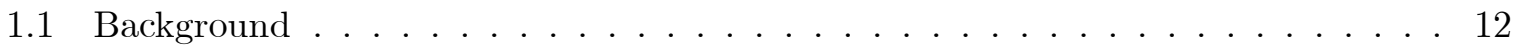

1.2 Research goal and objectives . . . . . . . . . . . . . . . . 14

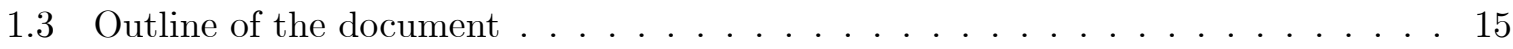

2 Theoretical framework: reverse logistics and closed-loop supply chains $\quad 18$

2.1 Introduction . . . . . . . . . . . . . . . . . . . . . . . . . 18

2.2 Evolution of the reverse logistics concept . . . . . . . . . . . . . . . . . . 19

2.2.1 Definitions: from reversed channels to closed-loop supply chains . . . . . . 19

2.2.2 Exploring the boundaries of reverse logistics term . . . . . . . . . . . . . 22

2.3 Literature on reverse logistics and closed-loop supply chains . . . . . . . . . . . . 24

2.3.1 $\mathrm{PhD}$ dissertations on reverse logistics in Spain . . . . . . . . . . . . 24

2.3.2 Conceptual frameworks in reverse logistics . . . . . . . . . . . . . . 27

2.4 Activities carried out in reverse logistics systems. Reverse flows typology . . . . . 32

2.4 .1 Commercial returns _ . . . . . . . . . . . . . . . . . . 34

2.4.2 Repairs, warranties and after-market (after-sales) services . . . . . . . . 36

2.4 .3 Product recalls . . . . . . . . . . . . . . . . . . . . . 36 
2.4 .4 Reuse. Fuctional returns . . . . . . . . . . . . . . . . . . . . 37

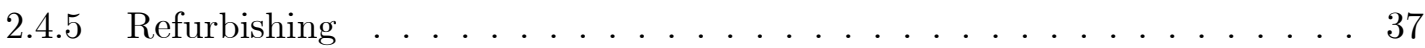

2.4 .6 Remanufacturing . . . . . . . . . . . . . . . . 38

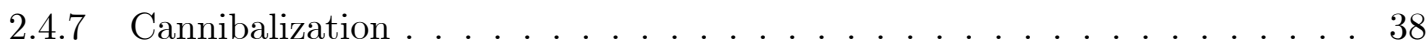

2.4 .8 Recycling . . . . . . . . . . . . . . . . . . . . . . . 39

2.4 .9 Production scrap, rework and by-products . . . . . . . . . . . . . 39

2.4.10 Waste Management and Energy Recovery . . . . . . . . . . . . . . . . . 39

2.5 Decision-making categorization in reverse logistics systems and closed-loop supply chains . . . . . . . . . . . . . . . . . . . . . . 4 41

2.5.1 Strategic decision-making . . . . . . . . . . . . . . . . . . 42

2.5.2 Tactical decision-making . . . . . . . . . . . . . . . . . . 43

2.5.3 Operational decision-making . . . . . . . . . . . . . . . 43

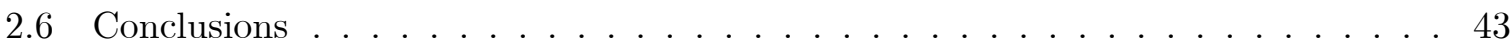

3 Research problem positioning and methodological approach $\quad 45$

3.1 Introduction . . . . . . . . . . . . . . . . . . . . 45

3.2 Thesis scope and research problem positioning . . . . . . . . . . . 46

3.3 Research methodologies in Operations Management . . . . . . . . . . . . . 50

3.3.1 Research methods in Operations Management: characteristics . . . . . . . 51

3.3.2 Comparative analysis of research methods in Operations Management: a selection guide . . . . . . . . . . . . . . . . . . 5 57

3.3.3 A holistic conception of the research process in the area of Operations Management . . . . . . . . . . . . . . . . . 59

3.3.4 Methodological framework in OM: Conclusions . . . . . . . . . . . . . 65

3.4 Methodological approach used in this thesis $\ldots \ldots \ldots$. . . . . . . . 66

4 Reusable articles: a typology grounded on case studies $\quad 69$

4.1 Introduction . . . . . . . . . . . . . . . . . . . . . . 69

4.2 The need for a framework on reusable articles systems $\ldots \ldots \ldots \ldots$. . . . . 71

4.3 Reusable articles: structuring the field . . . . . . . . . . . . . . . 73

4.3.1 A definition and a typology for reusable articles . . . . . . . . . . . . 73 
4.3.2 Characteristics of reusable articles networks . . . . . . . . . . . . 75

4.3.3 Differences between RTI, RPM and RP . . . . . . . . . . . . . . 78

4.3.4 Types of reusable articles networks: star systems vs. multi-depot systems 79

4.4 Empirical evidence: case studies . . . . . . . . . . . . . . . . . 80

4.5 Case studies detailed description . . . . . . . . . . . . . . . . . 87

4.5.1 Case 1: Gas cylinders in a multinational chemical company (MedGas) . . 87

4.5.2 Case 2: LPG cylinders in a petrochemical company . . . . . . . . . . . . . 91

4.5.3 Case 3. Surgical material at Erasmus MC . . . . . . . . . . . . . . . . 94

4.5.4 Case 4. Service tools . . . . . . . . . . . . . . . . . . . . 95

4.5.5 Case 5. Shopping carts in retail shops . . . . . . . . . . . . . . . 96

4.5.6 Case 6. Flora Holland . . . . . . . . . . . . . . . . . . . . . . . . . 98

4.6 Conclusions . . . . . . . . . . . . . . . . . . . . . . . . 99

5 Development of a conceptual model for the management of closed-loop sys$\begin{array}{ll}\text { tems of reusable articles } & 100\end{array}$

5.1 Introduction . . . . . . . . . . . . . . . . . . . 100

5.2 Building block 1: Common problems found in reuse closed-loop supply chains . . 102

5.2 .1 Fleet shrinkage . . . . . . . . . . . . . . . . . . . . 102

5.2 .2 Significant investment . . . . . . . . . . . . . . . . . . . . . 104

5.2 .3 Limited visibility . . . . . . . . . . . . . . . . . . . . . . . 105

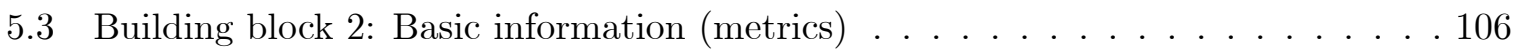

5.4 Building block 3: Management issues . . . . . . . . . . . . . . . . . . . . . . 109

5.4 .1 Issue 1: Define the fleet size dimension. . . . . . . . . . . . . . . . . 111

5.4.2 Issue 2: Control cycle time and promote articles rotation. . . . . . . . . . 112

5.4.3 Issue 3: Control the return rate and prevent shrinkage. . . . . . . . . . . . 114

5.4.4 Issue 4: Define purchase policies for new articles. . . . . . . . . . . . . 114

5.4.5 Issue 5: Plan and control reconditioning activities. . . . . . . . . . . 115

5.4.6 Issue 6: Balance inventory between depots. . . . . . . . . . . . . . . 116

5.5 Solutions proposal: control strategies . . . . . . . . . . . . . . 117

5.5 .1 Economical recovery incentives . . . . . . . . . . . . . . . . 118 
5.5.2 Non-economical recovery incentives . . . . . . . . . . . . . . . . . . . . . 119

5.5.3 User accountability . . . . . . . . . . . . . . . . . . . . . . . 120

5.6 Solutions proposal: a methodology for calculating the fleet size . . . . . . . . 121

5.6.1 Addenda 1. Methods available for return rate assessment. . . . . . . . . . 126

5.6.2 Addenda 2. Methods available for cycle time assessment. . . . . . . . . 127

5.7 Solutions proposal: purchase policies . . . . . . . . . . . . . . . 131

5.7.1 Addenda 3. Inventory control models with product returns Are they suitable for reuse CLSC $? \ldots \ldots \ldots$. . . . . . . . . . . . . . . . . . . . .

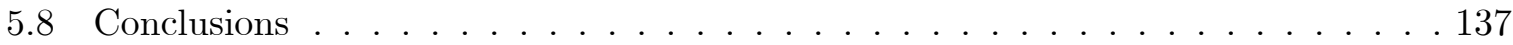

6 The impact of using the equal exchange recovery strategy in reuse CLSC 139

6.1 Introduction . . . . . . . . . . . . . . . . . . . . . . . . . . . . . 139

6.2 Literature review . . . . . . . . . . . . . . . . . . . . . . . . 142

6.2.1 Characteristics of the equal exchange recovery strategy . . . . . . . . . . . 142

6.2.2 Positioning the research problem: related work . . . . . . . . . . . . . 145

6.3 Problem conceptualization . . . . . . . . . . . . . . . . . . 146

6.3.1 The two-level decision problem description . . . . . . . . . . . . . 146

6.3.2 Model assumptions . . . . . . . . . . . . . . . . . . . . . . . 148

6.4 Customer model . . . . . . . . . . . . . . . . . . . . . . . . . . 151

6.4.1 List of variables. Customer model . . . . . . . . . . . . . . . . . . 151

6.4.2 List of parameters. Customer model. . . . . . . . . . . . . . . . . . . . 152

6.4.3 Sequence of events. Customer model . . . . . . . . . . . . . . . . . . 152

6.4 .4 Customer model formulation . . . . . . . . . . . . . . . . 157

6.5 Supplier model . . . . . . . . . . . . . . . . . . . . . . 159

6.5.1 List of variables. Supplier model. . . . . . . . . . . . . . . . . . . . 159

6.5.2 List of parameters. Supplier model. . . . . . . . . . . . . . . . . 160

6.5.3 Sequence of events. Supplier model . . . . . . . . . . . . . . . . . . . 161 
6.5.4 Supplier model formulation . . . . . . . . . . . . . . . . . . . 164

6.6 Alternative equal exchange control strategy . . . . . . . . . . . . . . . . . 171

6.6.1 Alternative control strategy description . . . . . . . . . . . . . 171

6.6 .2 Models reformulation . . . . . . . . . . . . . . . . . . . . 172

6.7 Numerical experiments . . . . . . . . . . . . . . . . . . . . . . . . 174

$6.7 .1 \quad$ Experimental design . . . . . . . . . . . . . . . . . . . 175

6.7 .2 Calculations . . . . . . . . . . . . . . . . . . 180

6.7 .3 Results analysis . . . . . . . . . . . . . . . . . . 186

6.8 Conclusions . . . . . . . . . . . . . . . . . . . . . . . 191

7 Conclusions, original contributions and future research lines 192

7.1 Conclusions of this $\mathrm{PhD}$ dissertation . . . . . . . . . . . . . . . . 192

7.2 Original contributions . . . . . . . . . . . . . . . . . . . . 202

7.3 Future research lines . . . . . . . . . . . . . . . . . . . . . . 204

$\begin{array}{ll}\text { Bibliography } & 206\end{array}$ 


\section{List of Figures}

2-1 Reverse flows typology. Adapted from Thierry et al. (1995). . . . . . . . . . . . . 28

2-2 Product recovery networks. Adapted from Fleischmann et al. (2000). . . . . . . . . . 29

2-3 Tipology of product recovery networks. Adapted from Fleischmann et al. (2000) . . . 30

2-4 The five basic dimensions of reverse logistics. Adapted from De Brito (2004). . . . . . 33

2-5 Activities framed in the sphere of reverse logistics. Own development. . . . . . . . . 34

2-6 Decision-making problems typology. Own development. . . . . . . . . . . . . 42

3-1 Positioning of the research problem adressed in this thesis. Own development. . . . . . 48

3-2 Action-Research cycles. Adapted from Coughlan and Coughlan (2002) . . . . . . . . . 53

3-3 A holistic conception of the research process in the Operations Management area: methodologies. Own development based on Mitroff et al. (1974). . . . . . . . . . . . . . . . . 61

3-4 Methodological approach used in this thesis. Own development. . . . . . . . . . . . 68

4-1 Reusable Articles (RA): RTI, RPM and RP (own development). . . . . . . . . . . . . 74

4-2 Reusable articles CLSC: cycle time, return rate and unobservable part of the supply chain (own development). . . . . . . . . . . . . . . . . . . . 77

4-3 Star network vs. multi-depot network (own development). . . . . . . . . . . . . . 80

4-4 Closed-loop supply chain of medical oxygen cylinders. . . . . . . . . . . . . . . 89

5-1 Cycle time distribution (includes a finite probability of not return). Own development. . 107

5-2 A management model for reuse CLSC: common problems and basic information (metrics). Own development. . . . . . . . . . . . . . . . . . . . . . . 109

5-3 A conceptual management model for reuse CLSC. Own development. . . . . . . . . . . 110 
5-4 A methodology for determining the fleet size in reusable articles networks. Own development. . . . . . . . . . . . . . . . . . . . . . . 123

6-1 The simplified container network. Own development. . . . . . . . . . . . . . . 147

6-2 Periods definition. Own development. . . . . . . . . . . . . . . . . . . 148

6-3 Event sequence in a generic time period $t$. Customer model. Own development. . . . . . 153

6-4 Event sequence time period $t=0$. Customer model. Own development. . . . . . . 155

6-5 Event sequence time periods $T$ and $T+1$. Customer model. Own development. . . . . 156

6-6 Event sequence in a generic time period $t$. Supplier model. Own development. . . . . . 161

6-7 Event sequence initial time periods of the planning horizon. Supplier model. Own development. . . . . . . . . . . . . . . . . . . . . . 164

6-8 Event sequence at the end of the planning horizon. Supplier model. Own development. . 165

6-9 Decision variables in the two alternative two-level decision models. Own development. . 173

6-10 A sample Excel table: customer model, strict equal exchange recovery strategy, demand pattern D2. Own development. . . . . . . . . . . . . . . . . . . 182

6-11 A sample Excel table: supplier model, strict equal exchange recovery strategy, demand pattern D2. Own development. . . . . . . . . . . . . . . . . 183

6-12 A sample Excel table: customer model, relaxed equal exchange recovery strategy, demand pattern D2. Own development. . . . . . . . . . . . . . . . . . . 184

6-13 A sample Excel table: supplier model, relaxed equal exchange recovery strategy, demand pattern D2. Own development. . . . . . . . . . . . . . . . . . . 185 


\section{List of Tables}

2.1 PhD dissertations on reverse logistics elaborated in Spanish universities. Own development base on information contained in TESEO (Ministry of Science data-

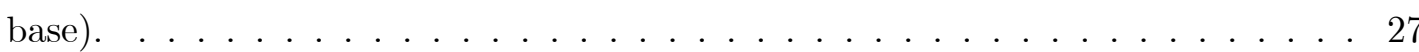

3.1 A selection guide for research methods strategy in Operations Management area.

Source: own development. . . . . . . . . . . . . . . . . . . . 60

4.1 Features of reuse closed-loop supply chains. Own development. . . . . . . . . . 76

5.1 System-wide investment in reusable articles fleet. Own development. . . . . . . . 104

5.2 Stochastic inventory control models with returns: some relevant contributions.

Own development. . . . . . . . . . . . . . . . . . . . 136

6.1 Demand patterns considered in the numerical experiments. Own development. . . . . . 177

6.2 Cost values for Cost Experiment 1 (CE1). Own development . . . . . . . . . . . . . 179

6.3 Cost values or Cost Experiment 2 (CE2). Own development . . . . . . . . . . . . . . 180

6.5 Results Analysis. Stage 1. Part I . . . . . . . . . . . . . . . . . . . . . . 187

6.6 Results Analysis. Stage 1. Part II . . . . . . . . . . . . . . . . . . . . . 188

6.7 Results Analysis. Stage 3. Part I . . . . . . . . . . . . . . . . . . . . . . . . . 189

6.8 Results Analysis. Stage 3. Part II _ . . . . . . . . . . . . . . . . . . . 190 


\section{Chapter 1}

\section{Introduction: motivation and objectives of this dissertation}

\section{$1.1 \quad$ Background}

Civil society worldwide is growingly becoming conscious that the resources and capacities of our planet are limited. In this sense, in order to maintain the socio-economical achievements that industrialized countries enjoy, and to favor their extension, especially in the countries of the so-called Third World, it is crucial that our resources and capacities are used in a responsible way, that is to say, without jeopardizing the development capacities of future generations. The increasing concern to reach a sustainable development, which includes the triple economical, environmental and social perspective (with a special focus on the two former bottom-lines), has caused since the mid -nineties the flourishing of an emergent discipline in the area of Operations Management: Reverse Logistics.

This discipline is in charge of studying the materials, information and financial flows that run backwards in the supply chain network, from the customers to the suppliers. The "vectorial" sense of Reverse Logistics is opposite to the traditional forward flow considered in supply chain networks, that have traditionally focused in the downstream flow, from raw materials (suppliers) to end users (customers).

Since the mid-nineties, the European Union has introduced as an important element of its environmental policy the notion of "producer responsibility": manufacturers, importers and 
sellers (companies either making or commercializing a product) are hold liable for the costs derived from the whole life-cycle management of their products, an especially, at the end-of-life phase. In this respect, several European directives have been introduced in order to force takeback schemes for different waste streams, such as packaging and packaging waste (Directive 94/62/EC), end-of-life vehicles (ELV, Directive 2000/53/EC), waste electrical and electronic equipment (WEEE, Directive 2002/96/EC) or more recently, batteries (Directive 2006/66/EC). As a result, there is a growing number of companies and industrial sectors that have an interest in managing the backward flow in supply chain networks.

In the first few years of the decade 2000-2010, the academic vision in reverse logistics evolves towards the concept of closed-loop supply chains (Guide and van Wassenhove, 2003). Within this concept, the necessary coordination of the forward and reverse chains is emphasized, providing a holistic vision of the logistical system which integrates both flows in a closed-loop system. This natural evolution of the reverse logistics concept is very much in the line with what has been the evolution of the business logistics area from World War II to the present time. This new vision also connects with the new paradigms arising in product design, such as the Cradle-to-Cradle concept (McDonough and Braungart, 2002). All in all, all these frameworks move in the same direction of advocating for the change from a unidirectional, one-way economy to a cyclical, closed-loop economy.

In any case, reverse logistics and closed-loop supply chains are still disciplines in exploration process. The academic community has been able to establish common activities that are developed in the reverse supply chains, but these activities can enormously change in complexity and management importance from one scenario to another. The understanding that has been reached from those activities is still incomplete. In addition, products can be returned throughout the service life of a product (direct reuse, commercial returns, repairs), after use (end-of-use) and at the end of its useful lifetime (end-of-life). Each type of return requires a reverse chain that considers the characteristics of the product and its actual life-cycle stage.

In particular, it is the integration of the forward and reverse flows in a closed-loop system which brings new logistics decision problems to the managerial arena. The difference between one-way reverse logistics and the traditional "forward" logistics is not that much a matter of "direction" or "vectorial sense". The differences between distribution and collection, between 
assembly and disassembly, between procurement and recovery appear to be rather limited and do not lead essentially to different logistics decision problems (Fleischmann, 2001). However, when the boundaries of the system are widened in order to integrate the reverse flow as the inbound flow of the forward direction, a new challenge has to be considered: how to coordinate the demand (forward flow) and the supply (reverse flow) side? What can be done to make meet the return flow (a supplier over which firms have limited control) with the demand stream coming from the market?

In this dissertation we focus in the logistical aspects of a closed loop supply chain type that, in spite of its contribution to the economical and environmental sustainability of productiondistribution systems, has not been widely researched for the moment: closed-loop supply chains (CLSC) of reusable articles or, from now on, "reuse CLSC". In this type of supply chain, the above-mentioned issue (new logistical problem) of making demand meet with returns is central because, as will be presented in the remainder of the dissertation, in reuse CLSC most demand is fulfilled with used products that reintegrate the forward flow via returns.

\subsection{Research goal and objectives}

This $\mathrm{PhD}$ dissertation is framed in the emergent fields of reverse logistics and closed-loop supply chain management. This subarea of supply chain management has gained researchers and practitioners attention over the last 15 years to become a fully recognized subdiscipline of operations management field (Guide and van Wassenhove, 2009). More specifically, among all the activities that are included within the CLSC area, the focus of this dissertation is centered in direct reuse aspects.

The core research goal of this dissertation is to develop a management model for closed-loop supply chains of reusable articles. The model we put forward includes a conceptual framework that identifies and synthesizes the main problems and managerial issues that arise in the context of reuse. Next, a set of qualitative approaches and quantitative tools and techniques are used to develop practical solutions to some of these issues.

More precisely, the general aim of this thesis can be broken down into the following objectives: 
1. To explore/survey and structure the field of reverse logistics and closed-loop supply chains in order to provide a general understanding of this subarea of supply chain management.

2. To position the research problem addressed in this thesis in the general body of RL and CLSC literature.

3. To develop a methodological framework for research in the Operations Management area, and to elaborate the particular methodological approach used in this thesis.

4. To elaborate six own development case studies carried out in real industrial settings on which the theories and concepts proposed in this thesis are grounded through inductive reasoning.

5. To sharpen the reusable articles concept definition and to propose a typology for reusable articles classification, providing an integrated view of RTI, RPM and RP.

6. To elaborate a conceptual model that synthesizes the common problems detected in reusable articles systems, the basic information and metrics required to deal with this set of problems and the managerial issues that practitioners will specifically encounter in the context of reuse.

7. To propose several solutions to some managerial issues, such as an analysis of different recovery control strategies, a methodology for determining the reusable articles feet size in star networks and the corresponding replenishment purchasing policies.

8. To elaborate and solve a mixed-integer linear programming (MILP) model to quantitatively analyze the impact of different recovery control strategies on reusable articles management.

The methods used to tackle each objective and the overall methodological framework supporting this thesis will be presented in detail in Chapter 3 .

\subsection{Outline of the document}

The $\mathrm{PhD}$ dissertation document is structured as follows: 
In Chapter 2, the reader is introduced to Reverse Logistics and Closed-Loop Supply Chain Management fields through an overall presentation of this Operations Management subarea.

In Chapter 3, the scope of this thesis is defined and the research problem positioned: we go from the generals to the specifics to center the focus in reuse CLSC. Then the problem dealt with in this dissertation is positioned among the related academic work. In addition, the methodological framework elaborated to support this thesis is presented. First, we put forward a general framework for the research process in the Operations Management area and we position the suitable methodologies corresponding to each stage of this process. Second, we explain how the methodological framework we have elaborated is used in the particular context of this thesis.

Chapter 4 constitute the first cornerstone of the management model defended in this thesis. In this chapter, the case studies that empirically support the management model are described. From these case studies, using a bottom-up (inductive) process for generating theory, we sharpen our definition of reusable articles and we propose a typology that integrates under the reusable articles term different types of articles that had been considered separately in the past. The common characteristics of reusable articles, as well as the differences that motivate three different categories are highlighted. Chapter 4 lays out the foundations of the reusable articles model proposed in this thesis. It has been labelled as "building block 0 " in our framework for reusable articles: the other building blocks in the model are built upon it.

Chapter 5 is the second cornerstone of the management model. In this part we present three extra building blocks of the framework. Building block 1 introduces the common problems found in reuse CLSC. Building block 2 identifies the basic information and metrics required to manage the problems identified in building block 1 . The common problems translate in a set of managerial issues or decision problems that have to be faced by practitioners confronted with reusable articles systems. The set of managerial issues constitute building block 3 . Then, we propose solutions to the managerial issues identified in building block 3 . In this chapter, two solutions are completely developed: control strategies analysis and a methodology for calculating the fleet size. A third solution related to purchasing policies is pointed out.

In Chapter 6 we focus in one of the solutions proposed (control strategies) and more precisely in one particular recovery strategy, the so called equal exchange policy. In this chapter, we adopt 
a purely quantitative focus in order to determine the effects of using one particular recovery strategy (equal exchange strategy) in reuse CLSC. In order to measure this impact, we formulate a two-stage decision model made up of two linked mixed-integer linear programming (MILP) models that jointly represent the behaviour of a two-echelon closed-loop supply chain comprising one customer and one supplier. Models' formal structure has been developed in AIMMS 3.9.4 while CPLEX 12.1. was used to solve the models. The results of the different numerical experiments carried out are presented and analyzed in order to discern the consequences of using two different recovery control strategies in a reusable articles system.

In Chapter 7 the overall conclusions of this dissertation are presented, our original contributions are highlighted and we point out further developments of the research lines we have initiated within this thesis. 


\section{Chapter 2}

\section{Theoretical framework: reverse logistics and closed-loop supply chains}

\subsection{Introduction}

In this chapter, the reader will be introduced to the main basic concepts and frameworks that will support the discussion throughout the remainder of the dissertation. The goal is to provide a general overview of Reverse Logistics (RL) and Closed-Loop Supply Chain (CLSC) fields, that will theoretically frame the results presented in this thesis. In the first section, different definitions of RL and CLSC will be provided, and the evolution from one term to the other will be analyzed. The precise position of RL and CLSC in the Operations Management literature will be determined by exploring the border fields of the RL term. Next, some key contributions to RL and CLSC literature are reviewed, with a special focus on $\mathrm{PhD}$ dissertations on the topic elaborated by other doctoral students in the Spanish context. In section 3 , the activities encompassed in the reverse flow are listed and briefly explained. Section 4 discusses the motivations that act as facilitators or drivers of reverse flows. Finally, section 5 identifies the more relevant logistic decision-making problems arising in the RL and CLSC field and classifies them according to their strategic, tactical or operational nature. 


\subsection{Evolution of the reverse logistics concept}

\subsubsection{Definitions: from reversed channels to closed-loop supply chains}

Given that the scientific study of reverse logistics is relatively recent, the terminology and the concepts associated to the discipline are still in process of homogenization and acceptance within the academic community. The concept of reverse logistics has evolved throughout the years and it is still in consolidation process. As the following paragraphs will detail, initially the notion of "reverse logistics" focused on the backwards direction of the materials flow, in opposition to the habitual one. In the nineties, the focus turned to the environmental aspects of the term, to return later on to the original pillars of the concept. Finally, in the last years the horizon of the discipline has extended to integrate with a holistic vision the forward and backward flows in the concept of closed-loop supply chains.

Reverse logistics activities in industrial settings are probably as old as industrial development is (scrap dealers, rework of defective production). However, from an academic standpoint, the first references to the reverse logistics concept date from the seventies decade, when some authors start to refer to "reverse channels" or "reverse flows" (Guiltinan and Nwokoye, 1975; Ginter and Starling, 1979). During the eighties, the backwards or "wrong" movement of goods is emphasized in the definition, as the wording used by Lambert and Stock (1981) shows:

"[...] going the wrong way on a one-way street because the great majority of product shipments flow in one direction"

- These authors already identify some problems linked to the upstream material flow in the supply chain, namely:

- Most logistic systems are not designed for handling the backwards flow of products.

- The costs of reverse distribution can be up to nine times higher than those of forward distribution from manufacturers to consumers, for the very same product.

- Frequently, returned items cannot be transported, stocked or handled in the same way as done in the forward channel. 
In the same decade, Murphy (1986) emphasizes the direction of the materials flow in his definition of reverse logistics or reverse distribution as:

"Reverse logistics or reverse distribution is the movement of goods from a consumer towards a producer in a channel of distribution" (Murphy, 1986).

He identifies three drivers or initiatives in the origin of reverse flows:

- Customer initiative - voluntarily retumed goods

- Industry initiative - recycling

- Government initiative- product recalls

At the beginning of the nineties, the Council of Logistics Management (CLM), institution whose name afterwards changed (2005) to the Council of Supply Chain Management Professionals (CSCMP), published in a white paper the first formal definition of the term reverse logistics explicitly linked to environmental aspects:

"[...]...the term often used to refer to the role of logistics in recycling, waste disposal, and management of hazardous materials; a broader perspective includes all issues relating to logistics activities to be carried out in source reduction, recycling, substitution, reuse of materials and disposal." (Stock, 1992).

This definition positions the term reverse logistics mainly in an environmental management context, as it does not provide any reference to the flows direction in the supply chain. A similar definition, edited by the CLM as well, is provided by Kopicki et al in 1993:

"[...] término que se refiere a las capacidades y actividades de la gestión logística involucradas en la reducción, gestión y eliminación de materiales, peligrosos o no, desde embalajes a productos finales. Incluye la distribución inversa, como se acaba de definir, la cual provoca el flujo de productos e información en dirección opuesta a las actividades normales" 
Within this definition, although the focus is centered in the environmental aspects of the term, an explicit mention is done to the flow direction, which is "opposite" to the "normal" one. Other contemporary authors to Kopicki and Stock, such as Pohlen and Farris (1992), keep the concept of the "opposite direction" in their definition, even if the focus of their research is plastic recycling.

Carter and Ellram's (1998) definition keeps relating the reverse logistics concept to environmental issues:

"the process whereby companies can become environmentally efficient through recycling, reusing, and reducing the amount of materials used."

In the late nineties, Rogers and Tibben-Lembke (1999), again in a publication from the CLM, put forward a new definition that unveils the prominence that the "process" approach was gaining at that time:

"The process of planning, implementing, and controlling the efficient, cost effective flow of raw materials, in-process inventory, finished goods, and related information from the point of consumption to the point of origin for the purpose of recapturing value or proper disposal." (Rogers and Tibben-Lembke, 1999)

The European Working Group on Reverse Logistics (RevLog), takes Rogers and TibbenLembke's definition as a departure point, and provides a wider view by replacing "point of consumption" by "manufacturing, distribution or use point" and "point of origin" by "point of recovery or point of proper disposal".

From year 2000 onwards, more and more authors make reference to the impossibility of considering the forward and the reverse logistic chain as independent entities. The concept of closed-loop supply chain emerge at that time. Guide and Van Wassenhove (2003) put forward the following definition:

"... closed-loop supply chain include traditional forward supply chain activities and the additional activities of the reverse supply chain"

In other words, closed-loop supply chains integrate forward and reverse supply chains, in an attempt to avoid the functional approach that considers both chains as independent systems 
and adopting a holistic "process" vision. As Lebreton (2007) emphasizes, closed-loop supply chains are those supply chains that carry out, simultaneously, "forwards" and "backwards" movements.

\subsubsection{Exploring the boundaries of reverse logistics term}

Since reverse logistics is a relatively new discipline in the Operations Management area, similar terms can be found in the scientific literature that refer more or less to the same thing. To the commonly accepted "reverse logistics", similar terms such as "reversed logistics", "return logistics", "retro logistics", "reverse channels" o "reverse distribution" can also be encountered.

There are several disciplines that have common borders with Reverse Logistics. This subsection aims at clarifying the breadth and meaning of each of them.

\section{Waste Management}

Waste Management discipline focuses in proposing desirable practices for the collection and final disposal of waste, i.e. products and materials that have been discarded. Waste Management includes activities such as waste handling and transport, incineration, landfilling, recycling, energy recovery, biological reprocessing, etc. While in waste management, the process typically ends with waste elimination, reverse logistics puts more emphasis on those flows where there is some type of value to be recaptured (such as, for instance, recycling).

Regarding waste management, the definition of the term waste has important legal implications regarding international agreements on the import and export of waste (c.f. Basel Convention on the Control of Transboundary Movements of Hazardous Wastes and their Disposal www.basel.int).

\section{Green Logistics}

This discipline puts the focus on the study of the negative externalities (mainly environmental) stemming from business logistics, such as greenhouse gas (GHG) emissions, other air pollutants emissions, nonrenewable natural resources depletion (fossil fuels, for instance), acoustic pollution, etc. The measurement of the carbon footprint in a given supply chain is an example of the typical activities of interest in green logistics. As the business logistics discipline itself, green 
logistics has been traditionally more focalized on the manufacturers-to-consumers direction of the materials flow.

\section{Industrial Ecology}

Industrial Ecology focuses on the interaction between industrial systems and the environment. The underlying idea is that industrial processes need to evolve from a linear conception of the system (open-loop systems) towards a circular or cycle conception (closed-loop systems). Within the first conception, resources and capital investments linearly move throughout the system to finally produce a waste output that needs to be disposed of. Within the latter conception, waste and by-products generated in a particular industry become inputs for industrial processes in other sectors.

The origins of Industrial Ecology reside in the following proposition: if natural ecosystems do not produce waste per se, because waste is reintroduced in the trophic cycle as raw material for other natural processes, why should industrial systems produce waste? As the waste produced by some species constitute precious valuable resources for others, could not the valueless outputs of an industry be used as inputs for the productive processes in others, reducing this way the resources consumption, pollution and the need to properly treat industrial wastes? An effort should be in done in order to achieve industrial systems designed to operate like natural ecosystems do, if we want them to be sustainable (Frosch and Gallopoulos, 1989; Jelinski et al., 1992). The Danish industrial park of the city of Kalundborg constitutes a remarkable example of industrial ecology. In this park, a thermal power plant, a refinery, a pharmaceutical plant, a plasterboard factory, an enzyme producer, a soil remediation company (SoilRem) and the Kalundborg municipality, use on the basis of commercial agreements the residues or byproducts of the other companies. For instance, the process of water purification that is carried out in the plant of water treatment of Kalundborg, of municipal ownership, results in muds as a by-product. These muds are used by SoilRem like nutrients in the process of bio-remediation of contaminated soils. Another example is the refrigeration water of the thermal power plant, which is used by a nearby fish farm of trout and salmon. The growth conditions of these species improve if water temperature is risen a few degrees. The global outcome is a he outcome is reduced consumption of resources and a significant reduction in environmental strain (The 
Kalundborg for Center Industrial Symbiosis, 2007).

The following topics are considered within the Industrial Ecology area (International Society for Industrial Ecology, 2007):

- material and energy flows studies ("industrial metabolism")

- technological change

- dematerialization and decarbonization

- life cycle planning, design and assessment

- design for the environment (eco-design)

- extended producer responsibility ("product stewardship")

- eco-industrial parks ("industrial symbiosis")

- product-oriented environmental policy

- eco-efficiency

\subsection{Literature on reverse logistics and closed-loop supply chains}

\subsubsection{PhD dissertations on reverse logistics in Spain}

A search in TESEO was conducted for doctoral theses defended in Spain on the topic addressed in this dissertation. As the result, the following authors and works were identified. None of previous works identified in this search explicitly dealt with reuse aspects of packaging and products in a comprehensive way. To the best of our knowledge, this $\mathrm{PhD}$ dissertation is the first attempt in this direction.

González Torre (2001) defended the first doctoral thesis in Spain focused on reverse logistics issues. She addresses different aspects of the reverse logistics activities in the glass bottling industry. Four actors were identified in this logistic cycle:

- Consumers: they should enable selective waste collection 
- Waste management companies: they provide the infrastructure for selective waste collection

- The glass manufacturing industry: they use either virgin or recycled raw materials in order to provide glass packaging.

- The food and drink industry: they use glass packaging to deliver their products to end consumers.

Different aspects were analyzed in each link of chain. Regarding consumers, a comparative analysis on the recycling habits in Asturias region (Spain) and El Paso (USA) was elaborated. The two regions used different recovery systems for glass products. Regarding waste management companies, a multi-objective linear programming model was developed for decisionmaking on the location of collection containers. The objective is to maximize the amount of collected glass while logistic costs are minimized. Regarding the glass manufacturing industry, a comparative case study analysis is developed for assessing downcycling effects when using recycled raw materials in glass production. The comparison was established between companies located in Belgium and Spain. Finally, regarding the food and drink industry, a postal survey was conducted intending to analyze their supplier-client relationship for glass products and the firms characteristics form a reverse logistics standpoint.

Rubio Lacoba (2003) presents an in-depth state of the art on reverse logistics, to progressively concentrate, as the dissertation advances, on the quantitative aspects of the discipline. He uses discrete-event simulation on Excel spreadsheet to analyze three (s, Q) inventory control models with return flows: forward model (null return flow), reuse model and remanufacturing model. Within each model, the behavior of the system (in terms of cost and service levels) is analyzed against variations of the parameters, namely; reorder point, lot size, lead times for original and remanufactured articles, and the time the product remain in the market before being returned. The author introduces uncertainty in product recovery through a product return rate defined as a binomial distribution which is a function of sales in previous periods and a return probability for which three levels are considered: optimistic, normal and pessimistic.

De la Fuente Aragón (2003) highlights the need for integration of the forward and the reverse supply chains when both are organized around the same manufacturing company. She devel- 
ops a methodology for analyzing and improving the processes comprising both chains, which emphasizes especially two needs: collaboration in the extended supply chain (manufacturers, suppliers, wholesalers, retailers, clients) and paying attention not only to physical flows, but also to informational ones. The thesis describes an application case in the metal-mechanical industry.

Fernandez Quesada (2004) contributes to develop reverse logistics theoretical framework and provide real application cases. The methodologies she employed include: (a) focus groups, with business experts on the topic. This stage enabled her to direct the initial research questions towards the most interesting problems for the industry; (b) case studies; (c) milti-criteria decision making, and more precisely, AHP (Analytical Hierarchy Process).

Soto Zuluaga (2005) initially focuses his research in commercial returns in the publishing industry in Spain. He elaborates an exploratory study on this topic based on Yin's case study research methods (Yin, 1983). Data collection involved participation in expert working groups, field visits to companies and interviews with experts. The Spanish publishing sector shows very high return rates, with almost one book returned for every two sent to the market. In the second part of the thesis, he puts forward a linear programming model for production planning in collaborative environments with remanufacturing, which considers the return flow of recovered parts, and sets out three particular cases of the model. Two solving techniques are suggested for this model. First, a branch and bound algorithm is used for obtaining the optimal solution, which quickly requires too long computational times as model complexity grows. Second, a heuristic algorithm combining optimization routines with a local search technique is introduced, which provides more reasonable computational times for industrial applications.

The PhD dissertation from Gonzalez Torre (2004) deals with product design aspects from the perspective of "Design for the Environment" (DfE) and "Life Cycle Analysis" (LCA) approaches. In addition, based on data stemming from a bottom-up analysis of products Bill of Materials (BOM), she develops new algorithms for product disassembly at their end-of-life stage.

Ortega Mier (2008) addresses the design of reverse logistics networks oriented towards recycling. He puts forward two plant location problems, of dynamic and stochastic nature, and solves them using metaheuristics, and more precisely, genetic algorithms and scatter search. 
Table 2.1: PhD dissertations on reverse logistics elaborated in Spanish universities. Own development base on information contained in TESEO (Ministry of Science database).

\begin{tabular}{|l|c|l|}
\hline Author & Year & Institution \\
\hline \hline González Torre, Pilar L & 2001 & Universidad de Oviedo \\
\hline Rubio Lacoba, Sergio & 2002 & Universidad de Extremadura \\
\hline de la Fuente Aragón, M. Victoria & 2003 & Universidad Politécnica de Cartagena \\
\hline Fernández Quesada, Isabel & 2003 & Universidad de Oviedo \\
\hline González Torre, Beatriz Almudena & 2004 & Universidad de Oviedo \\
\hline Soto Zuluaga, Juan Pablo & 2005 & Universidad Pompeu Fabra \\
\hline Ortega Mier, Miguel & 2008 & Universidad Politécnica de Madrid \\
\hline Barba Gutierrez, Yolanda & 2009 & Universidad de Oviedo \\
\hline
\end{tabular}

The solving method is tested with a practical application using real data coming from the province of Guipúzcoa (Basque Country, Spain).

Barba Gutierrez (2009) reviews the decisions of strategic and operational nature to be taken in reverse supply chains. Several tools are developed in the thesis for supporting decision-making in the particular case of Waste Electric and Electronic Equipment (WEEE). More precisely, Life Cycle Analysis (LCA) is used to assess the eco-efficiency of several home appliances. In addition, new algorithms are developed for the disassembly planning of process, incorporating new characteristics to the problem that remained unsolved in literature.

Table 2.1 summarizes the characteristics of the PhD dissertations defended in Spain in the Reverse Logistics area:

\subsubsection{Conceptual frameworks in reverse logistics}

Since reverse logistics is a relatively new discipline, where basic concept are still under development, almost all the authors who have made relevant contributions in this field have tried to settle down or to clarify the type of logistic flows that can be found when dealing with a reverse supply chain and to provide conceptual frameworks that allow to "put order" in the field. The contributions of Thierry et al. (1995), Fleischmann et al. (2000) and De Brito (2004) are highlighted in this dissertation.

The first author presents an integrated supply chain that includes the following activities: direct reuse, after-sales service, product recovery management and waste management (Figure 


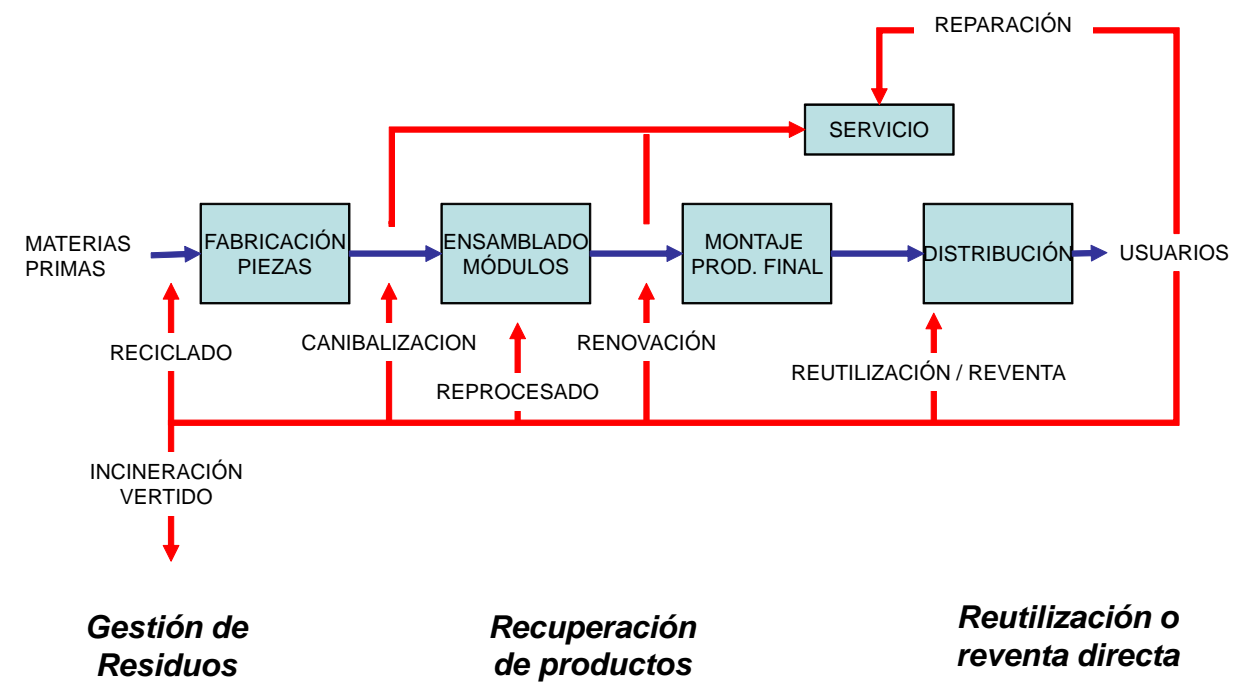

Basado en Thierry et al. (1995)

Figure 2-1: Reverse flows typology. Adapted from Thierry et al. (1995).

thierry.fig). Five different product recovery options are identified, depending on the point where used products re-enter the forward chain: repair, refurbishing, remanufacturing, cannibalization and recycling.

Fleischmann et al. (2000) analyze nine case studies for providing the main characteristics or logistics networks for product recovery. As happens in forward networks, where three basic activities take place: supply, production and distribution, five general activities are identified product recovery networks, namely: collection, inspection/selection, reprocessing, redistribution and disposal. All these activities are represented in the figure 2-2 .

The five common activities found in reverse logistic processes are later on grouped in three upper-level stages (figure 2-3), in analogy to the supply, production and distribution stages of the forward supply chains. These stages are:

- Collection, where flows show a convergent configuration from multiple collection points at the disposer market to a few recovery facilities. 


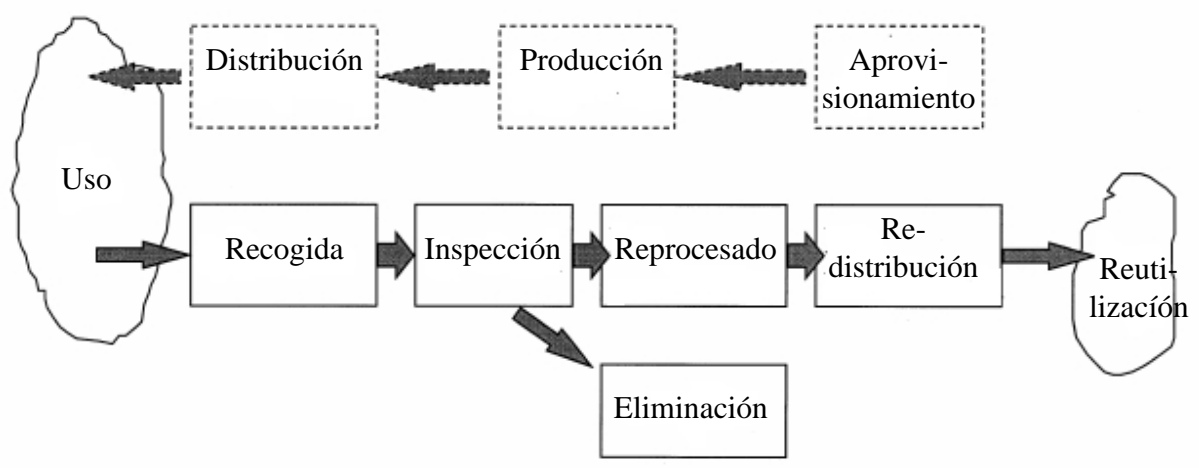

Figure 2-2: Product recovery networks. Adapted from Fleischmann et al. (2000). 


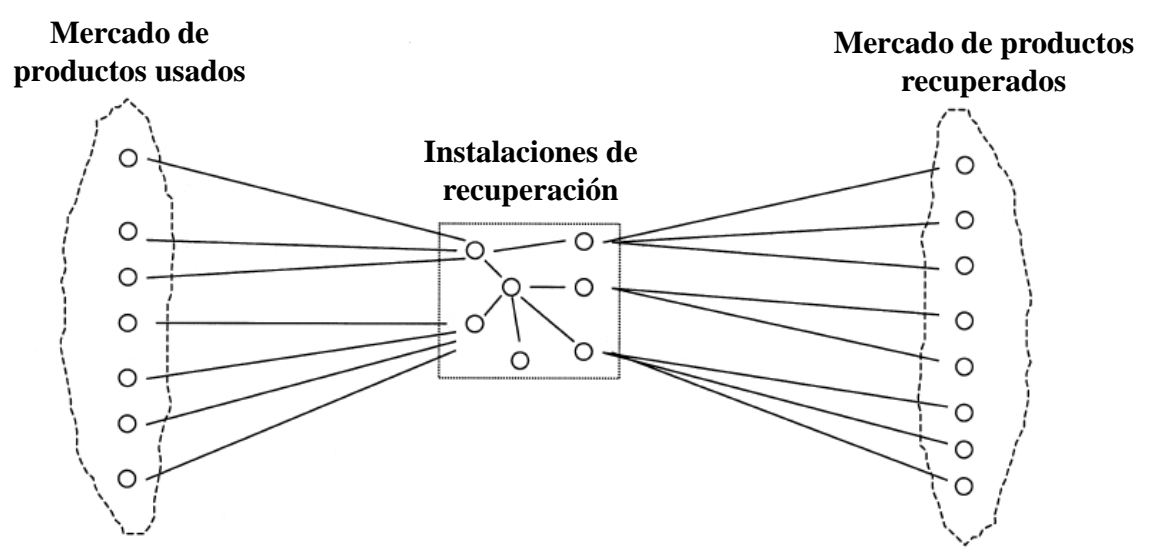

Figure 2-3: Tipology of product recovery networks. Adapted from Fleischmann et al. (2000)

- Recovery, where the complexity of recovery network configuration is determined by how complex is the process that brings the product considered into a usable product again (how many steps and actors are involved in the recovery process).

- Redistribution, where flows are diverging from a few recovery facilities to multiple delivery points in the reuse market.

The main difference between the traditional production-distribution networks and product recovery networks stands in the supply side. Indeed, the high degree of uncertainty in the supply side regarding the quantity of products that will be collected, the quality condition of the collected products and the timing when the returns will effectively take place, is a distinguishing characteristic between product recovery networks and traditional forward supply chains. This uncertainty is the root of the inspection and disposal activities, generally not included forward supply chains. Likewise, a high number of low volume input streams in the recovery facility is also typical in product recovery networks (a higher number of sources of used products, which 
points that typically smaller volumes than in the traditional setting).

Product recovery networks can be classified in three types:

\section{Recycling networks}

In these networks, the objective is material recovery from discarded products (and therefore, of low value). The network is usually configured in the form of open-loop systems, since the recovered materials are not necessarily used in the manufacturing process of the original product. Given the fact that the investments in recycling equipment are generally substantial, it is necessary to reach economies of scale for rendering the recycling activity profitable. As a consequence, sectorial organizations such as SIGs are generally in charge of recycling activities within a given industry. This is the case for packaging and packaging waste, car wreck recycling (end of life vehicles ELV) or Waste Electric and Electronic Equipment (WEEE). In this way, recycling networks adopt a centralized configuration (only a few plants carry out recycling activities) in order to exploit economies of scale.

Some examples of this type of networks are: sand recycling, plastic recycling, paper recycling, recycling of by-products of steel production, carpet recycling, WEEE recycling, packaging and packaging waste recycling, ELV recycling.

\section{Remanufacturing networks}

The objective in these networks is to reuse parts of a product that has relatively high value. This is the case of copiers remanufacturing, for instance. The main driver for the development of these networks is economic, since equipment manufacturers are interested in recovering the value that still remains in the discarded product. Since the recovery activities require of a deep knowledge of the product, the original manufacturer of the product (Original Equipment Manufacturer, OEM) usually is in charge of the remanufacturing activities. Nevertheless, in certain activities where the entrance barriers are low (tyres retreading, toner cartdriges) third-party actors interested in the business may appear. In addition, product remanufacturing implications from the marketing standpoint need to be considered, since the market for original products (primary market) and the remanufactured ones (secondary market) can show overlapping areas.

\section{Reusable items networks}

These networks arise in the direct reuse of packaging items. They are directly re-usable elements without needing complicated operations of remanufacturing, would be enough with 
inspection and cleaning. It includes the reuse of packaging elements such as palets, the returnable bottles, plastic crates or containers.

De Brito (2000) puts forward a theoretical framework for reverse logistics based on the analysis of five dimensions that are required to characterize a reverse flow (Figure 2-4), namely:

- Why receiving? Driving forces behind the adoption of reverse logistics practices in the organizations.

- Why returning? Reasons that explain why the products are returned or discarded

- What? Characteristics of the returned product

- How? The way in which the products are recovered: recovery options and recovery processes.

- Who? Actors taking part in the collection/recovery process and the role adopted by each of them.

\subsection{Activities carried out in reverse logistics systems. Reverse flows typology}

In section 2.2 of this chapter, it was stated that reverse logistics arise whenever a there is an upstream materials flow in the supply chain that runs in the opposite direction of the usual forward flow. This definition is in fact extremely ample, and allows including within the reverse logistics term a wide variety of different logistics flows. Therefore, we can find under the same "reverse logistics" label very different situations.

With respect to the motivations or drivers that trigger the reverse flow, we can find situations where it is economically profitable to recover a product or its parts at the end-of-life or endof-use stages (e.g. copiers refurbishing), whereas in other cases the "backwards" movement is justified for only for legal (e.g. product recalls or collection of urban waste) or commercial reasons (commercial returns).

With respect to the configuration adopted by the supply chain network, we can find networks that adopt a closed or cyclical configuration (closed-loop), where product, parts or materials 


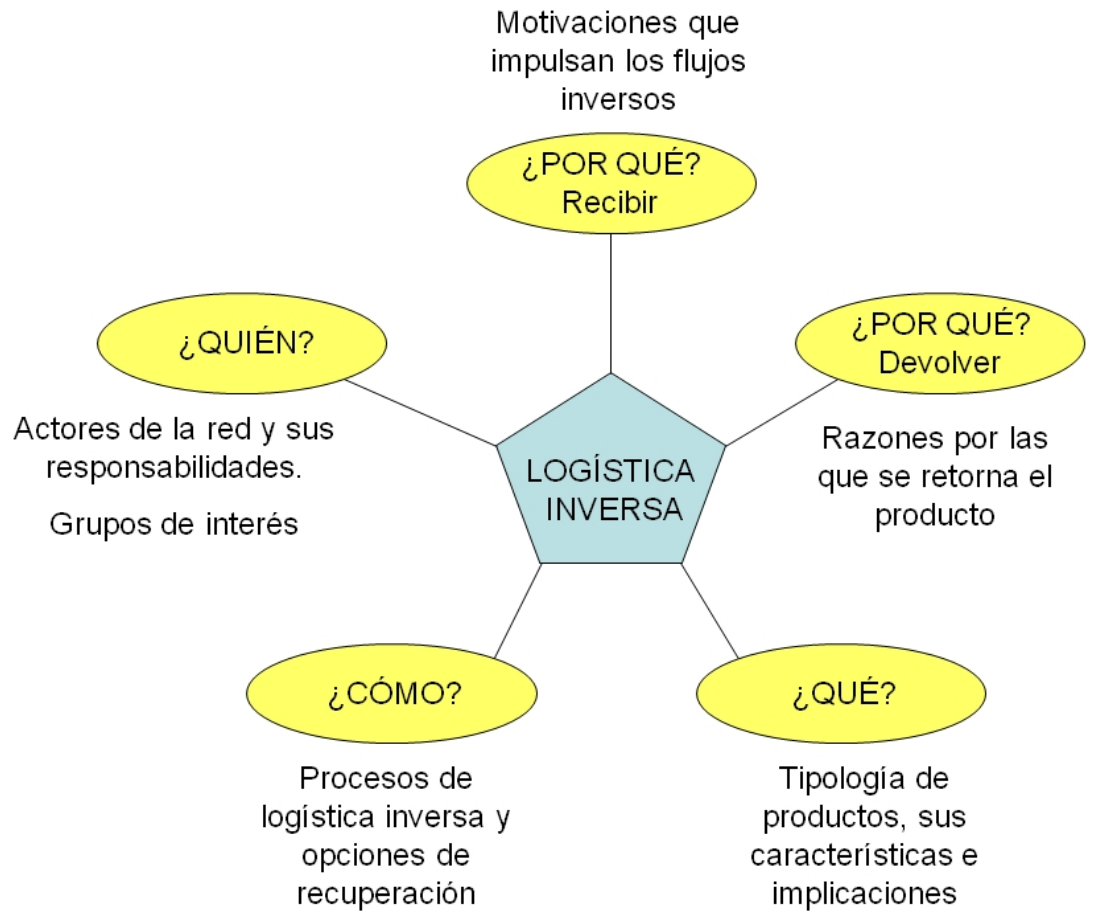

Figure 2-4: The five basic dimensions of reverse logistics. Adapted from De Brito (2004). 


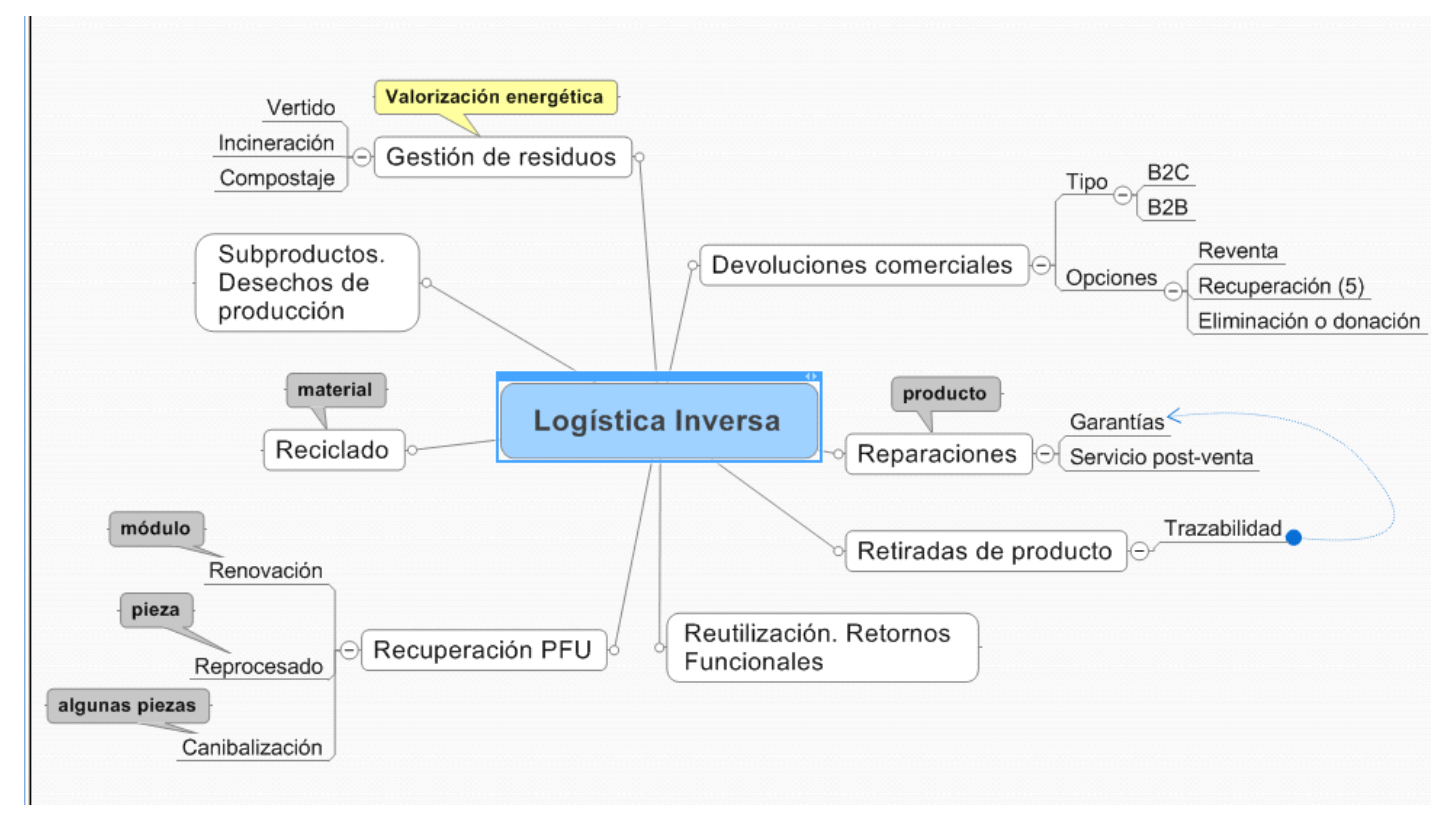

Figure 2-5: Activities framed in the sphere of reverse logistics. Own development.

return to the same original supply chain at the end-of-life or end-of-use stages (e.g. pallets), or networks that adopt a linear configuration (open-loop), where the recovered products, parts or materials do not return to the original supply chain. The reverse flow is reintegrated to another supply chain independent from the previous one (waste packaging recycling).

In the following subsections, the reverse flows identified in this dissertation are described. They are all mapped in Figure 2-5.

\subsubsection{Commercial returns}

This category comprises those product returns that imply the cancellation of previous commercial transaction, which generates the corresponding financial flow from the supplier to the customer. It is the customer who triggers the commercial return, usually because the product does not satisfy its needs or expectations. Firms find themselves growingly forced to accept these returns, either because of legislative reasons (consumers rights) or due to commercial reasons (since to be competitive in the market, companies are forced to offer more and more aggressive returns policies). 
Commercial returns constitute a financial threat for the retailer and its suppliers, especially in products subject to a fast obsolescence, due to their seasonal nature or their short lifecycle: perishable products, clothes, complements, suntan lotions, etc. In this sense, a good management of the returns, for example, in terms of rapidity of reaction of the supply chain can contribute to limit the losses by commercial returns. Firms have several options available for the management of this type of returns.

Resale. If the product is in good condition, it can be reintroduced again in the market, either in the same channel or in alternative channels, such as, for instance, sales for employees. This option is only really effective if critical attention is given to time factor. Resales is a very interesting option for the company from the financial point of view, because it allows to obtain some revenue for the returned products.

Refurbishing, remanufacturing, cannibalization, recycling or repair. If direct resale is not possible, because the product is not in "as-new" condition, firms can use some of the recovery options described in previous sections. Consumer goods subject to fast technological obsolescence (e.g. personal computers) constitute an example. After an upgrade of the outdated modules, the product could be sent again for sale. It is possible that before reintroducing the product in the market, it needs some type intervention of the technical service (repair). In any case, the last option would be recycling the materials of the returned product.

Disposal or donation. In this case, return products do not undertake any recovery process, they are directly sent to landfill or incineration. Few years ago this was the most used option and in some sectors, such as the agro-food industry, it still constitutes the most employed option (Rubio Lacoba, 2003). Another option available, when there is no possibility of recovering any value from the returned products, is their donation to charities, NGOs or foundations. Through this option, the firm can receive the tax benefits linked to this type of operations in some countries, such as Spain.

It should be highlighted that returns do not only happen between the end consumer and retailers. They can take place between all the partners in the supply chain network. In fact, retailers typically transfer their suppliers the financial burden linked to the commercial returns of their products, thanks to their higher bargaining power in the extended supply chain network (Kuik, goes Nunen and Coenen, 2005). Commercial returns can also encompass returns of excess 
raw material or the returns of parts and materials that have not approved in quality controls at reception. The return of unsold inventories of goods pushed to the market can also be included under the commercial returns term.

According to Rogers and Tibben-Lembke (1999), commercial returns reach up to $6 \%$ of the total amount of articles sold in the United States, where these types of practices enjoy a long tradition. However, there are sectors where that return rate is rather more significant, such as the publishing sector (up to $30 \%$ ) or the computers manufacturers sector (up to $20 \%$ ). In the case of the catalog sales or electronic commerce, return rates can reach up to $35 \%$ and in addition, a good return policy for the consumers and a suitable logistic management of returns are key success factors in this type of businesses.

\subsubsection{Repairs, warranties and after-market (after-sales) services}

Return flows due to warranty or repair concern products which are defective in origin or have been damaged during the distribution phase or during the use phase of the article. Damaged articles are sent to the manufacturer for repair. After the technical intervention of the after-sales service, the article should recover its initial functionality. According to Thierry et al. (1995), repair implies fixing or replacing a small and limited number of pieces (so that repair does not become an economically less interesting option than replacing the damaged product

Although repair has been typically carried out by the technical service of the manufacturer, outsourcing to third-party logistics providers (3PL) not only the physical movement of goods to be repaired but also the repair service itself is becoming more and more common. It can be cited, for instance, the Toshiba and UPS partnership in the united States for repairing laptops. The new process has reduced the average collection-repair-delivery cycle time from 10 days to 4 days or even less. (UPS, 2005).

\subsubsection{Product recalls}

Product recalls take place when a manufacturer notices problem in a batch or set of batches and decides to retire these product fraction from the market. In the case of the pharmaceutical or the agro-food industries, European legislation forces companies to undertake a traceability system that enables them to quickly recall from the market all suspicious batches. The manufacturer 
should maintain a registry enabling to reconstruct the history, route and final destination of a certain product, identifying the origin of its raw materials or parts, the history of the processes applied, the circumstances of its distribution, as well as the location of the delivery point to the final client. In this way, in case of noticing a problem in a raw material batch or in a particular workstation, the company must be able to quickly identify and locate the clients quickly who have bought affected products and to conduct the appropriate actions.

In modern manufacturing systems, it is not conceived to have a product without its traceability. For this reason, many other industries not legally forced to adopt traceability systems, have adopted this type of management practices, such as the aeronautics industry, the tires industry or the civil works construction. Some authors, like Fleischmann (2001), include product recalls in the previous category. (repairs and warranties), though product recall flows are triggered by the supplier and not by the customer.

\subsubsection{Reuse. Fuctional returns}

This type of flows concerns items such as returnable packaging and distribution equipment, which are reintroduced in physical distribution processes, either directly, without any intermediate treatment, or after small cleaning and repair operations. It is the case of pallets, returnable glass bottles or the re-usable containers. These items are designed for supporting the distribution of other products and their main function is to move forwards and backwards in supply chains in consecutive reuse cycles. For this reason this type of flows are also named functional returns (De Brito, 2004).

\subsubsection{Refurbishing}

Refurbishing consist of bringing used products up to a given quality standard after undertaking a recovery process, in order to improve their quality and extend their service-life. However, the quality standard for refurbished products does not need to be as flawless than those for new products, and therefore the average service-life of a refurbished product is typically shorter than those of brand new products. Products subject to refurbishing are disassembled and their critical modules inspected. Next, these modules can be either repaired or replaced by completely new ones and then re-assembled in the refurbished product. Refurbishing typically implies a 
technological update of the product, since the obsolete modules and parts can be replaced by others which are technologically superior or with a more recent design. Aircrafts constitute the typical example of products that undertake refurbishing processes.

\subsubsection{Remanufacturing}

Remanufacturing consists of bringing used products up to a quality standard that is as rigorous as those for brand new products. Used products are completely disassembled and all modules and parts are exhaustively inspected. Worn out or obsolete parts and modules are replaced by new ones. Repairable parts or modules are fixed, tested and undertaken a quality test. If they reach the quality standard, parts and modules are later on assembled to shape the remanufactured product.

Thierry et al. (1995), citing Heeb (1989), point out that a used machine tool can be upgraded to a "as-new" quality and technological standard by only the $50-60 \%$ of the cost of a new machine.

Remanufacturing involves a true production process that implies parts disassembly of the used product and their re-assembly as in new products manufacturing. Therefore, the wellknown techniques for planning and scheduling production in forward flows can also be used for the re-assembly process of remanufacturing. However, the disassembly process requires adapting these techniques to its own specific characteristics.

\subsubsection{Cannibalization}

Cannibalization seeks to obtain a limited set of parts from the used products, with the purpose of using them in the new product manufacture or in the repair, refurbishing or remanufacturing of used equipment. While in repair, refurbishing or remanufacturing processes, firms make use a great proportion of the used product, cannibalization only recovers a small proportion of parts. Cannibalization involves selective disassembly of used products and inspection of the potentially re-usable pieces.

The quality standard that cannibalized parts must meet depends on the process where they are going to be used. Parts for remanufacturing must fulfill stricter quality criteria than those directed to repair or refurbishing. 


\subsubsection{Recycling}

Recycling aims at recovering the materials of used parts and products. The recycled product does not preserve its identity or functionality, but its materials are reused in the manufacturing of another type of parts or products.

The recycling process starts with the disassembly of product parts and its further separation and classification based on the material to be recovered. Later on, the recycled materials can be used in the manufacture of new parts.

Recycling is common practice nowadays in many industries in the developed countries, such as the paper and plastic industries, the automotive industry, the electronic industry and so on.

\subsubsection{Production scrap, rework and by-products}

In many cases, the scrap material of some industrial process, such as the trimming waste, can be reintroduced in the production process, limiting the amount of new raw materials required. Likewise, raw materials that do not fulfill quality standards can undertake an additional process that brings them up to needed requirements. Since this type of internal return flows involve savings, they are usually motivated by their intrinsic economic yield. An example of production scrap reuse is exemplified by the wood shaving generated in furniture manufacturing processes. Wood shaving can be reused in the very same factory or by others for the elaboration of wood agglomerate (Ortega Mier, 2002).

By-products are usually transferred to alternative supply chains, as described in subsection 2.2.2 (Industrial Ecology).

\subsubsection{Waste Management and Energy Recovery}

When no recovery option is available for a product, its final disposal has to be managed. The most common processes for waste disposal are dumping, landfilling, incineration and composting. In addition, in some disposal processes, energy can be obtained from waste products in the so-called energy recovery processes. Next, different final disposal options are briefly described. 


\section{Dumping}

Open dumping designates a land disposal site where of waste is open-air accumulated without any type of treatment. Although it is the oldest and most inexpensive form of waste disposal, it is unacceptable neither from the environmental nor from the human health points of view, and therefore, dumping is legally forbidden in most developed countries. Insects, rodents and microorganisms proliferate in these dumps. Garbage decomposition generates substances that pollute soil, air and water. Other problems related to open-air dumps are the bad smell, the visual impact on landscape and the fire risk, that they would release toxic smoke.

\section{Landfilling}

Landfilling is the waste disposal method most used in Europe, since it allows final and complete disposal, enabling also the possibility of using complementary recycling practices in the nearby areas of the landfill. It consists of the storage of waste in pre-treated site, where land is previously digged and then filled up with alternative layers of compacted garbage and clay. It is fundamental to choose a site located in geologically and topographically appropriate area in order to avoid polluting surface or underground water. Since the anaerobic decomposition of the organic waste generates gases (biogas), the sanitary landfill must be properly ventilated to avoid explosions. Landfill walls are waterproofed with polyethilene to avoid filtrations towards inferior layers. After completion, the landfill is covered with a clay layer that waterproofs the ground to avoid bad smell and rain filtration, and several layers of sand and humus that allow the growth of the vegetation, so that the site can be turned into a recreational area or industrial zone. The combustion of the biogas generated in the landfill can be used for the electrical power generation, which allows in certain way the energy recovery of the waste disposed of in the landfill.

\section{Incineration}

Incineration consists of a controlled, high-temperature combustion process of waste, which is transformed into inert ash-gray and gases. During the combustion process, a great amount of heat is generated, that can be used for urban heating or for power generation. Incineration is not a method of complete disposal, since it generates ashes, dregs and gases, but provides an 
important reduction in weight $(70 \%)$ and volume (80-90\%) of original waste (FECYT, 2002).

The main disadvantage of the incineration method is the generation of highly polluting and hardly foreseeable elements, given the variable composition of the incinerated waste. Heavy metals (such as Zinc (Zn), Lead (Pb), Chromium (Cr), Nickel (Ni), Cadmium (Cd) and, mainly, Mercury (Hg, due to its low evaporation point)), dioxines, furans, organo-chloride compounds: and acid gases such as $\mathrm{HCl}, \mathrm{SO} 2, \mathrm{HF}, \mathrm{HBr}, \mathrm{NOx}$ are generated during the incineration process. This makes necessary a purification process of the incineration gases

\section{Composting}

Composting is a process of aerobic biological decomposition (in the presence of oxygen) of organic waste. The process takes place at controlled temperature (between $50-70^{\circ} \mathrm{C}$ ) in order to assure the sanitary safety of the resulting product, the so-called compost, that can be used as an organic regenerator of soils.

In Spain there are 24 composting plants that produce up to 2,3 million Tm/year.. Approximately, $80 \%$ of the facilities are located in the East and the South of Spain (Valencia, Murcia, Andalusia and Catalonia).

\subsection{Decision-making categorization in reverse logistics systems and closed-loop supply chains}

The design and operation of reverse logistics systems entails a series of decision problems of strategic, tactical and operational nature that researchers in the area are trying to solve. Eventually, some decision-making models already developed for forward supply chains can be directly applied. However, many times, the structure of the problem is new and calls for appropriate specific modeling and solving techniques.

The analysis of scientific literature conducted in this thesis has enabled us to identify the types of decision- making problems that are consider in reverse logistics. They are schematically depicted in Figure 2-6. 


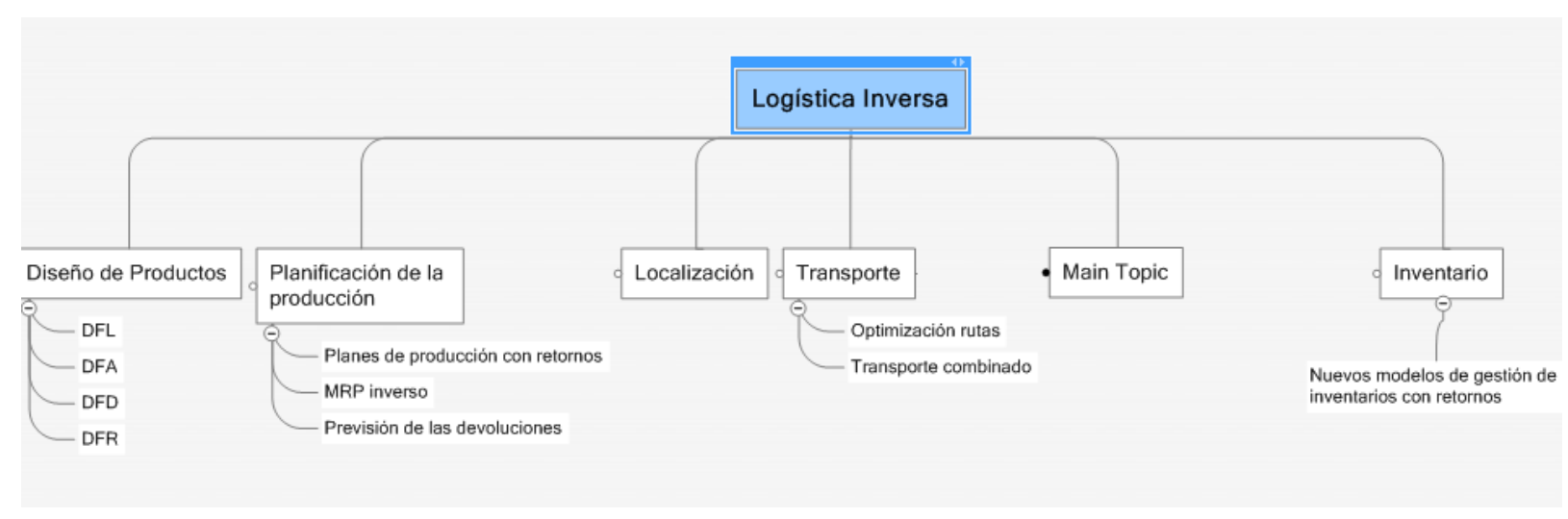

Figure 2-6: Decision-making problems typology. Own development.

\subsubsection{Strategic decision-making}

\section{Product design}

The best way to reuse products or parts and to avoid unnecessary waste generation is to design products oriented towards this aim. In this sense, the increasing importance of the recycling, remanufacturing and refurbishing activities demand simple product disassembly in modules or parts. This fact motivates the development of product designs based on modularity. In the last few years, new concepts that advance in this line, such as Design for Logistics (DFL), Design for Assembly (DFA), Design for Disassembly (DFD) or Design for Reciclability (DFR), have emerged.

\section{Reverse network design}

Decision-making regarding the reverse networks design constitute a lively research field in reverse logistics area. The main difference between forward and reverse networks resides on the multiple collection points from which returns takes place. According to Fleischmann et al. (2000), reverse network structures is A "many-to-one" type, whereas in forward logistics networks adopt a "one-to-many" configuration. Another important aspect is the uncertainty inherent to return process. With respect to facilities location and network design, models try provide answers regarding the number of steps necessary to take to end recovery operations, the number and location of facilities and the way to integrate the activities of forward and reverse 
supply chains.

\subsubsection{Tactical decision-making}

\section{Production planning}

When reverse logistics is involved somehow in the input of a manufacturing process, production planning is rendered more complex. It involves the generation of production plans that integrate the return flow of materials and in the introduction of reverse MRP systems, designed for disassembly in remanufacturing operations (bills of materials where the input reference "explodes" in several references). Returns forecasting can also be required for proper production planning.

\section{Transport planning}

The movement of products, modules or parts coming from the consumers or load consolidation centers towards the recovery facilities eventually requires new models decision making in transport, such as route planning decisions or selection of logistic operators. Another relevant aspect in transport arises when forward and reverse flows are combined in a unique transport, the so-called combined transport (Fleischmann, 2001).

\subsubsection{Operational decision-making}

\section{Inventory control}

New inventory management models have been developed in the academic literature that include the more complex situation of incorporating returns and the output of disassembly operations. In literature, we can either find models based on exact methods (De Brito, 2004) lor simulation models (Rubio Lacoba, 2002).

\subsection{Conclusions}

The main conclusion of this chapter is that Reverse Logistics (RL) and its natural extension, Closed-Loop Supply Chains (CLSC), are still in their infancy as academic disciplines, especially 
when compared with the enormous amount of scientific literature focusing on the forward supply chain. Throughout the chapter, it was showed that the academic community has been able to determine:

- Different types of product recovery options for used or discarded products, components and materials. Thierry et al (1995) distinguish between (a) direct reuse / resale (distribution items and commercial returns), (b) product recovery management, which includes the following options: repair, refurbish, remanufacture, cannibalization, recycle; and finally, (c) waste management (landfilling or incineration).

- Different kind of activities that are generally carried out when dealing with reverse flows, namely: collection, inspection/separation, re-processing, disposal, re-distribution , and in addition different types of product recovery networks: recycling networks, value-added remanufacturing networks, and reusable items networks. (Fleischmann et al. 2000)

- A wide variety of return flow types (Flapper et al., 2005) that depending on the product life-cycle stage in which the product is returned, enable to classify closed-loop supply chains in: production-related returns (rework), distribution returns (reusable articles), commercial returns, repair-related returns, end-of-use returns or end-of-life returns. In the same line, Krikke at el. (2004) distinguish between end-of-life(EoL) returns, end-ofuse returns (EoU), commercial returns and reusable items. This diversity in return flows entails different levels of complexity and management importance.

However, the actual academic (and practical) knowledge on RL and CLSC is quite limited and its extension and level of deepness varies depending on the type of closed-loop supply chain, the activities involved and the type of decision-making problems addressed. For instance, remanufacturing supply chains and, more recently, commercial returns, have received a fair amount of scientific attention. Network design, inventory management with returns or disassembly planning and scheduling are decision-making problems that constitute well-established research clusters in CLSC field. On the contrary, production-related closed-loop supply chains, direct reuse closed-loop supply chains or decision-making problems dealing with production plans that integrate the forward and the reverse material flows have been much less studied and provide opportunities to researchers in order to make new contributions in the field. 


\section{Chapter 3}

\section{Research problem positioning and methodological approach}

\subsection{Introduction}

The goal of this chapter is twofold: on the one hand, the first objective is to sharpen and position the research problem addressed in this thesis. On the other hand, the second objective is to define the methodological approach that will be used to tackle this research problem. These two objectives necessarily have to be addressed sequentially. Only once the thesis problem has been precisely delimited, it becomes possible to define the methodological approach to be used. As it will be presented throughout the second part of the chapter, the suitable research methods and techniques depend on the research problem at hand, as well as on the research objectives considered.

In the first part of the chapter, the current state-of-the-art on Reverse Logistics and ClosedLoop Supply Chains, developed in Chapter 2, is taken as a departure point. Then we go from generals to specifics, narrowing the scope of our research in order to focus in one particular activity carried out in CLSC: reuse. We justify the importance of reuse activities, which have been under-researched in the body of literature of CLSC. We also position reuse CLSC in the general framework of CLSC research.

The second part of the chapter adresses the methodological approach that will give support to the results obtained in this thesis. First, in section 3.3, methodology aspects are adressed 
from an Operations Management general point of view Next, in section 3.4, it is explained how the methodological framework elaborated in 3.3 is applied to the particular context of this thesis. Section 3.3 is subdivided in three corresponding subsections. Subsection 3.3 .1 characterizes the main research methods that are typically used in Operations Management, namely: case study research, action research, survey research and quantitative modelling. The four methods are compared in order to discern the type of research questions that are best addressed with each different method in subsection 3.3.2. Finally, in subsection 3.3.3, a framework is proposed in order to position each research methodology within a research cycle representing how different research methods contribute to the advancement of scientific knowledge generated around a specific research problem. The framework put forward in section 3.3. constitute the first net contribution to knowledge arising in this $\mathrm{PhD}$ thesis.

\subsection{Thesis scope and research problem positioning}

The literature review presented in Chapter 2 introduced the different types of product recovery options, the different types of activities and the different types of return flows that had been determined by the RL and CLSC academic community. Thierry et al. (1995) distinguish among direct reuse/resale, repair, refurbish, remanufacture, cannibalization and recycle as recovery options. Likewise, Flapper et al. (2005) classify closed-loop supply chains in productionrelated returns (rework), distribution returns (reusable articles), commercial returns, repairrelated returns, end-of-use returns or end-of-life returns. In the same line, Krikke at el. (2004) distinguish between end-of-life (EoL) returns, end-of-use returns (EoU), commercial returns and reusable items. Even if most authors point out the existence of a particular subtype of closedloop supply chains related with reuse, this type of closed-loop supply chains have not been extensively researched in academic literature. Most research in CLSC area has focused in the last few years in areas such as inventory control with product returns, remanufacturing issues or commercial returns aspects (Rubio et al., 2006, Guide and van Wassenhove, 2009). However, other areas have received much less attention, even if their contribution to achieving sustainable industrial systems, especially from the environmental and economical point of view, is not to be neglected. One of these areas is constituted by closed-loop supply chains dealing with the 
so-called "reusable articles". The term "reusable articles" is proposed in this dissertation to integrate under a single expression different types of items that are frequent in the context of reuse. A definition of the "reusable articles" term and a typology is presented in Chapter 4, but for the sake of clarity in this section, some examples of reusable articles are provided ahead, namely:

- transport items (load carriers, distribution items), such as pallets, crates, maritime containers;

- packaging materials, such as refillable glass bottles, cylinders, kegs or containers for chemicals (containers), refillable cartdriges, reusable cameras or special packaging in direct contact with the product (wind farm spare parts, special boxes for medical equipment, automotive racks, ...

- reusable products (what is reused is not a packaging element but the product itself), such as service tools, surgical instruments, rental cars, public rental bikes system, etc.

The focus of this dissertation is on closed-loop supply chains of reusable articles (from now on, "reuse CLSC"), in contrast to other recovery options such as repair, remanufacturing or recycling. Figure 3-1 narrows the scope of this thesis from the general framework of reverse logistics and closed-loop supply chains to the specific position of this thesis on reuse. What makes different reuse CLSC to other types of CLSC is the level of disassembly or disaggregation required in product recovery activities. Reuse activities only require minor repairs or reconditioning (sterilization, filling, cleaning) to have a functional product ready to be used again. Then, the dissagregation level corresponds to the item level (product is not dissasembled). Repair requires the fixing or the replacement of some broken parts. The product is partially dissasembled in order to replace damaged spare parts, so the disaggregation level is at spare part level. In remanufacturing, disaggregation takes place at part level: the complete product is disassembled and the resulting parts and subassemblies are tested. The worn out parts are substituted and replaced by new ones and approved parts are used to re-assembly the product, which has to meet the standards of as-new products. Finally, recycling can be considered as dissasembly at the material level: parts and products lose their identity and functionality in order to enable the reuse of its materials in the manufacturing processes of new products 


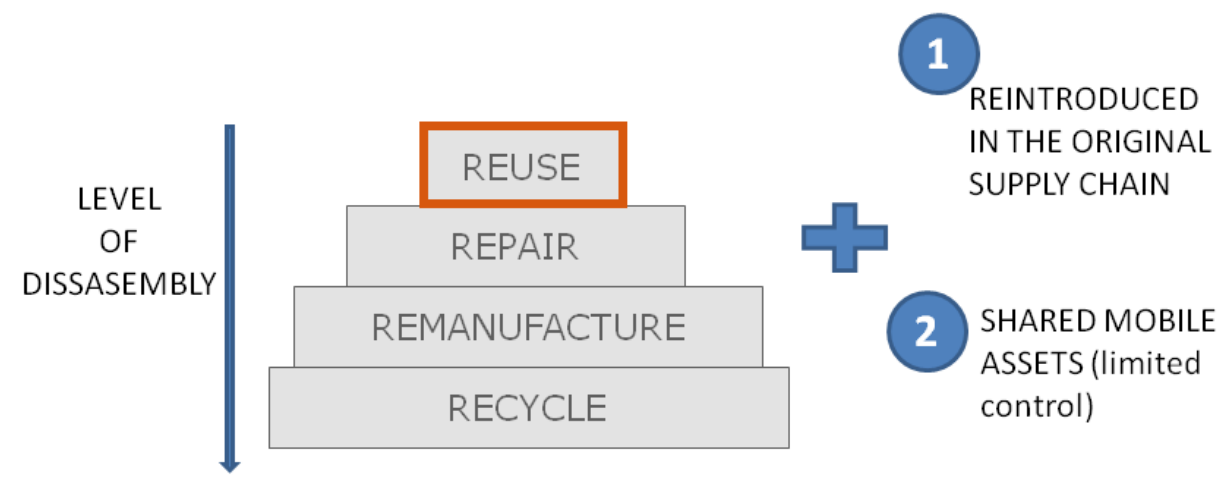

Figure 3-1: Positioning of the research problem adressed in this thesis. Own development.

Besides the level of disassembly required to recover value from the product, another two additional important features are required to position reuse CLSC in the general body of literature of reverse logistics and CLSC.

First, in reuse CLSC the used articles are reintroduced in the same original forward supply chain or a very similar one. Used and brand new products are perfect substitutes and serve the same markets. This feature (marked with 1 in Figure 3-1) makes closed-loop supply chains of reusable articles (reuse CLSC) different from end-of-use closed-loop supply chains (EoU CLSC). This latter type of CLSCs deal with functional products not having reached their end-of-life phase, but which are discarded by the first user because of end of lease, trade in or product replacement (due to, for instance, fashion or marketing reasons). Discarded products do not enter the same original supply chain but a different one; typically, a secondary market that may cannibalize some sales in the primary market. Sales cannibalization and remarketing problems (Debo et al., 2006, Atasu et al., 2008) are not an issue in reuse CLSC, whereas they constitute a quite important aspect in EoU CLSC. In addition, the problem of making the demand and the return flow meet is critical in reuse CLSC (most demand is fulfilled with used products, which are perfect substitutes of brand new products). In this sense, EoU CLSC resemble traditional one-way supply chains, as returns are not the main source of supply catering demand in the original market. Examples of EoU returns include mobile phones, second hand white and brown goods, second hand textiles, etc... This type of re-use, linked to 
EoU returns, is out of the scope of this dissertation. Our focus is on products that are conceived since their design phase for durability and for being reused.

The second feature (marked with 2 in Figure 3-1) is that reuse CLSC deal with assets that travel along the supply chain network and constitute a (mobile) shared resource for different supply chain partners. In reuse CLSC, articles travel across the boundaries of the organizations that made up the supply chain network, so in some stages of article life-cycle, the supply chain hub (the pool operator, the owner of reusable articles) has very limited or none control over a part of the articles. Therefore, fixed assets that do not "travel" along the value chain, such as for instance hotel rooms, are also out of the scope of our research.

Design and management of reusable articles systems are likely to be more important in the near future, as a result of the growing concern on natural resources' depletion. We cannot rule out that in medium-term, industries which currently are choosing disposable packaging elements or single use instrumentation (recycle), can reorient their policy towards reuse. As the new sustainability paradigm gains momentum, the need of switching our use-and-dispose model (one-way economy) to a closed-loop economic model, where a packaging element or a durable article can have multiple lives, will become more and more evident.

However, from the academic point of view, reusable articles have not been widely researched (see section 4.2). On the other hand, from practitioners' point of view, management of closedloop systems of reusable articles is not straightforward (see Chapter 5). In our interaction with organizations dealing with reusable elements, managers have reported difficulties in orchestrating these logistics systems. These operational challenges are also remarked in existing literature, where several authors point out that managing reusable articles systems can become trickier than expected (McKerrow 1996; Twede and Clarke 2005). The identification of the management difficulties arising in reusable articles systems constitutes a first step in order to avoid that these troubles become a hindering factor to the adoption of reusable articles when confronted with single use articles, thus contributing to a more sustainable (from the economic and environmental point of view) production and distribution system. 


\subsection{Research methodologies in Operations Management}

Methodology-related aspects are gaining importance in the research activity of the Operations Management academic community. This is because, to a certain extent, the scientific community implicitly assumes that if a researcher is capable of describing the method used in written reports, this is a sign that the research has been conducted according to some supposedly appropriate plan or method, which, in turn, is a sign that the results achieved are backed up by certain quality standards. On the other hand, knowledge can hardly be considered scientific if some previously designed plan or method has not been followed to generate such knowledge. As Karlsson (2002) points out, methodology as a part of research activity is a way to ensure the quality of that research and guarantee the reliability of the results.

The area of Operations Management has not paid a great deal of attention to methodological considerations, maybe because the traditional research paradigm in this area, based on quantitative models, can be easily framed within what is typically known as scientific knowledge due to its inherent formal (mathematical) nature. However, since the discipline first saw light at the beginning of the 20th century, it has steadily expanded its "focus", which was initially centred on the organisation of production systems, to gradually include topics such as the study of the human factor in socio-technical systems, new product development (concurrent engineering), the design and global management of logistic networks or systems, organisational change, business strategy, or more recently, issues related to ethics and social responsibility. This opening-up of approach brings with it the need to take on other methods of research (case studies, research by means of surveys or action-research) frequently used in social sciences, such as psychology or sociology, and to incorporate them into the "more traditional" quantitative model-focused set of methodologies of the discipline.

Improving methodological aspects in the area of Operations Management may lead to a wider acceptance of this discipline in academic circles. Compared to other academic subjects of a more long-standing tradition, Operations Management is relatively new. It cannot boast a long-standing research tradition or methods that have the mutual agreement of the whole scientific community in its area, which, to the contrary, is the case with other subjects touching on our context, such as Chemical Engineering or Electronic Engineering, to name but two examples. When the academic community in the area finally reaches an agreement as to the 
most appropriate methods for each piece of research and the methodologically-related aspects of private research work are improved, a contribution will have been made to spreading the "academic recognition" of Industrial / Organization Engineering and, most particularly of Operations Management, in university and scientific circles.

The main aim of this section is to review the different research methods that are currently considered as standard in the area of Operations Management and then go on to furnish a decision-making or guidance tool that will enable the researcher to orient the choice of methodology or the combination of methods that best fit a specific piece of scientific research, in line with the issues to be approached.

For this purpose, the four research methodologies that have been identified as the most habitual in the context of Operations Management are characterised in section 3.3.1: case study research, action-research, survey research and the use of quantitative models. Further on, in section 3.3.2, a comparative analysis is made of the four methodologies. In this same section we propose a tool for selecting the most appropriate methodology or set of methodologies for the research questions it is intended to approach. Finally, in section 3.3.3, a model is put forward that conceptualises the scientific knowledge generation procedure from a systemic point of view and places each of the methods studied in the corresponding stages of the process.

This conceptual framework, which integrates the guidelines for choosing the research strategy as well as the model representing the scientific research process concerning a specific problem, constitutes the first net contribution to knowledge provided by this $\mathrm{PhD}$ dissertation.

\subsubsection{Research methods in Operations Management: characteristics}

\section{Case studies}

Case study research is a research method based on empirical data (obtained from a field study) which study a phenomenon while taking into account the context in which the phenomenon occurs, since the borders separating the phenomenon and the context are not clearly defined. By means of case studies new theories can be generated and already existing theories can be tested or refined by using an inductive process based on diverse document and reference sources. These sources can be of a qualitative or quantitative nature: direct observation, interviews, questionnaires, files, economic series, etc. 
There are various major works in some way related to case study research. One of them is the work by Glaser and Strauss (1967) on grounded theory ("teoría fundamentada" in Spanish, see Andreu Abela et al., 2007), which is a methodological approach oriented towards theory building (conceptualising) by taking qualitative data analyses, where data are systematically gathered and analysed. At the beginning of the 80s, Yin (1984) made a significant contribution by clarifying the methodological basis of case studies. He analysed the multiple weaknesses and stereotypes applied at that time to case study research in social sciences and put forward some strategies, which right from the design stage of research, enable consistency, internal validity and external validity to be increased as well as the reliability of the results obtained through case studies. He also suggested a typology for designing case studies, established what analytical generalisation and replication logic consisted of, and detailed the kind of research that was most suited to the use of case studies.

We can also highlight the works of Miles and Huberman (1984), who proposed various techniques for structuring and observing relationships in quantitative data analysis, and the renowned paper by Eisenhardt (1989), which consists of a synthesis of the previous works and contributes a multistage process for generating new theories from case studies. Finally, the contributions made by Ellram (1996) and Voss et al. (2002) are also relevant within an Operations Management focus. The first contribution show how case study method can be used in business research and more specifically, in business logistics research. The second contribution falls within the context of the methodology training seminars for $\mathrm{PhD}$ students that have been held annually since 1998 as part of the annual EurOMA conference.

\section{Action-Research}

The term action-research, coined in the 40s by the director of the "Center for Group Dynamics" at the MIT, Kurt Lewin, denotes a research method that combines a process of participation on the reality being researched with the generation of new knowledge. To achieve this, he conscientiously and deliberately used a cyclical process, a "spiral of steps" (Figure 3-2), consisting in: planning, acting, evaluating the action, start planning again and so on, successively.

Lewin (1946) argues in favour of the need to use this methodological approach based on the idea that everything connected with the human and social factor, when it becomes an object of 


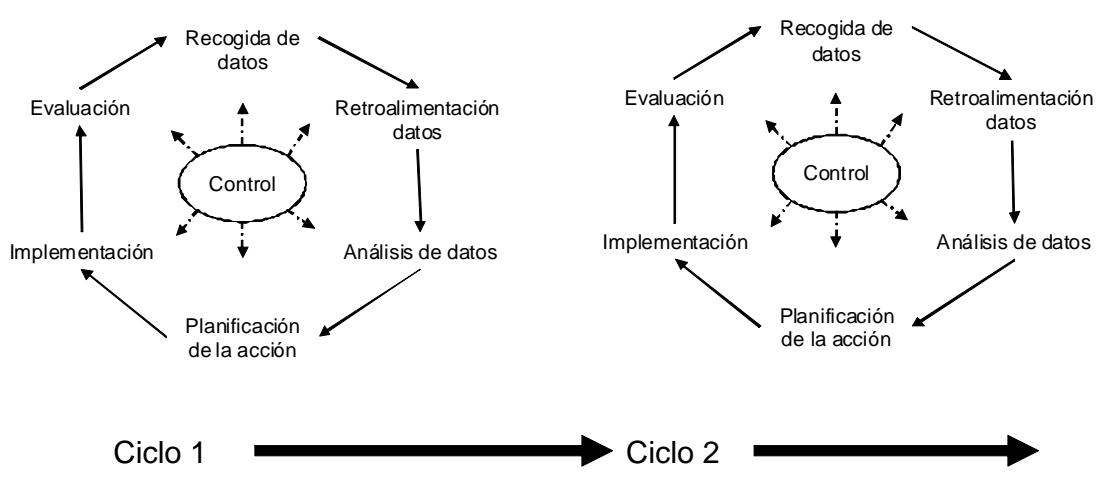

Figure 3-2: Action-Research cycles. Adapted from Coughlan and Coughlan (2002)

study, exhibits a series of special characteristics (interiority, non-determinism and uniqueness of each human being) that require a different methodology from that traditionally adhered to in the "hard" sciences. In the research construction process, action-research must involve both the researchers and the actors taking part in the experience.

Lewin's work had a large influence on the founders of the Tavistock Institute and, particularly, on Eric Trist. For this institution, the action-research approach was a core component of the work method they used with industry and business. Trist's works and the 1961 Norwegian Industrial Democracy Project jointly provided the seed for the founding of a network of research centres to promote action-research in various European countries. This was a major contribution to the spread of action-research approaches and experiences, some of the most marked being the works of Trist and Bamforth (1951), Emery and Trist (1965 and 1972), Emery and Thorsrud (1976), Hill (1976), Herbst (1974) and Davis and Cherns (1975).

Combining the generation of new knowledge with the participation in a given reality, on the one hand, requires quality criteria that are different from those traditionally used in a positivist approach to science (Susman and Evered, 1978). On the other hand, researchers need to become aware of their dual role in action-research. Apart from generating new knowledge, the 
researcher acts as an agent of change by facilitating action and reflection from the inside of the organisation. As a consequence of this dual focus, action-research has sometimes been labelled as "consultancy dressed up as research". Gummesson (2000) presents various characteristics that differentiate action-research from consultancy, such as the rigour of the research process and its documentation, the use of theoretical evidence (in consultancy empirical evidence is sufficient) or the cyclical process of action-research (in consultancy the process is usually linear: approach the problem, take action and finish).

\section{Survey research}

This method of research basically consists in gathering information from a specific sample in a population and submitting the information obtained to appropriate statistical processing with the purpose of contributing to knowledge on a particular area of interest (typically, by generalizing by statistical inference the results observed in the sample to the population as a whole). Gathering information implies that it is necessary to make contact with a set of individuals through postal or electronic questionnaires, telephone calls, personal interviews, etc, and formulating a set of questions about themselves or about the organisations of which they are part

Forza (2002) describes the steps to be followed during a research project that uses surveys as a base method. As a prior step to this design, a theoretical model or conceptual framework on the phenomenon under study is required. The first step should consist in transferring concepts and proposals from the conceptual framework to the survey design. The second step is to design the research. This includes drawing up the questionnaire and choosing the sampling method to be used. When the tools required to conduct the research have been designed (sample questionnaire), it is advisable to fine-tune this design using a pilot test, which, in addition, will let the procedures be set up for managing the questionnaires submitted. Once the samples and final questionnaire are available, the next step is to collect the definitive data, then analyse the data and write the report to publicise the findings.

In Operations Management, many of the difficulties that arise from survey research are due to the sampling process (selecting the population elements that will be part of the sample), either because not enough elements have been selected (sample size), or because care has not 
been taken to take a sufficiently representative sample (randomness). An unsuitable sample design limits the possibility of generalising results (Kotzab, 2005). Obtaining a sufficient sample size to ensure the required level of statistical significance is often a question of increasing the questionnaire's response rate. Frohlich (2002) presents several strategies for this purpose, such as sponsorship by professional associations or the sending of periodic reminders. Distributing the questionnaires via email and the use of Web questionnaires makes it easier to complete the questionnaire and avoids manual data having to be entered for their subsequent automatic processing. To ensure that the sample is representative there are various probabilistic and nonprobabilistic sampling techniques, like simple random sampling, systematic sampling, stratified sampling and convenience sampling. Only probabilistic sampling techniques allow extending (through statistical inference) the results observed in the sample to the population as a whole.

Survey research has become increasingly important in the area of Operations Management. On the one hand, this is taken as a positive symptom for the area for two reasons. Firstly, because the availability of different research methodologies and particularly field-based research methodologies (cases and surveys), traditionally less widely used in the area of Operations Management than mathematical models and simulation, is an indicator of the discipline having reached maturity (Malhorta and Grover, 1998). Secondly, because one of the main applications of survey research is to test the validity of pre-existing theory models with empirical data. Although Operations Management is a relatively new discipline and nowadays there is a greater need to construct new theories than to test already existing ones, the growth of survey-based research is indicative of the extent to which theory has moved forward in the area (Filippini, 1997). However, it should also be pointed out that badly planned and badly implemented survey research contributes little or is even a handicap to the advancement of knowledge in this area. Therefore, it is would appear essential to enhance the quality of this kind of research in the area of Operations Management. Many authors consulted coincide in the opinion that, in general, there is room for improvement in the application of survey research methods.

\section{Quantitative models}

The use of analytical approaches or models for solving problems related to managerial decisionmaking form the basis of the most longstanding research method in the area of Operations 
Management. These models are representations or idealisations of reality which enable us to predict and explain phenomena with a high degree of accuracy, but by performing in a way that is less complex and less difficult to control than reality (Ackoff and Sasieni, 1968). In order to make them tractable from a mathematical point of view, the models are necessarily simpler than reality. They are made up of abstractions or idealisations of reality that highlight how the major variables of the problem are related from the viewpoint of the researcher constructing the model (Ackoff, 1971; Sagasti and Mitroff, 1973). Hax (2007) emphasises the impact that operational research has (and still has) on the design and control of the most operative processes. This is because operational research techniques adapt particularly well to the context of "programmable" decisions, that is to say, decisions where the problem presents a high level of structuring and the influence of the human factor is negligible, such as production planning and control or resource allocation.

Depending on their ultimate purpose, quantitative models have traditionally been classified as normative models and descriptive models. Normative models allow the partial capture of the decision-making problems that arise in actual production and logistic processes. They consist of techniques that select the best or the preferred solution from the different alternatives (which may be infinite) by considering a set of criteria elected by the decision-maker. The normative models are so-called because this type of technique gives the manager a norm or standard on which to base decision-making, a rule for choosing a particular policy. Included in this category are mathematical programming models, either deterministic (Kantorovich, 1939; Dantzig, 1963) or stochastic models, decision-theory models (Raifa, 1968; Schlaifer, 1969), multicriteria decision techniques (Zeleny, 1975) and goal programming (Ignizio, 1976).

Descriptive models characterise and explain the structure of a specific phenomenon. Their interest lies in the fact that if the causes behind a specific phenomenon are understood its future behaviour can be predicted. Descriptive models are also used to choose the most advisable solution from a set of alternatives. However, instead of it being the model itself that points to the choice in accordance with some predefined criteria, with descriptive models it is the decisionmaker who chooses the best alternative according to the predictions made by the the descriptive model. The category of descriptive models includes demand forecasting techniques based on time-series (Box and Jenkins, 1976), system dynamics models (Forrester, 1961), queueing theory 
and discrete event simulation models (Law and Kelton, 1991).

\subsubsection{Comparative analysis of research methods in Operations Management: a selection guide}

Having briefly reviewed the research strategies identified as the usual ones in Operations Management, in this section we shall go on to conduct a comparative analysis of the different techniques.

Case study is one of the most appropriate methodological strategies for addressing a phenomenon that has undergone little research up to the present or when it is wished to address an already studied phenomenon from a new perspective. So, case studies can be: (a) of an exploratory nature when little is known about the phenomenon and the research is looked on as an initial approach to the object of study; (b) of a descriptive nature when on completion of the study the phenomenon has been characterised; and (c) of an explanatory nature when case study involves such a thorough examination of the phenomenon and its context that the researcher can infer the underlying causes of the phenomenon under study. Therefore, case study is a highly suitable strategy when research questions are of the type, How? (description of a phenomenon that has been little researched up to present) or Why? (explanation of the underlying causes behind a specific phenomenon). Since case study encourages a direct contact between the researcher and the reality being researched, it constitutes an appropriate strategy when it is wished to move forward to generate new knowledge regarding a specific phenomenon.

Likewise, action-research generates direct interactions between the researcher and the reality being researched. For the same reasons, (in-depth knowledge of the phenomenon in its real context), the action-research approach is a good method to generate new knowledge. However, let us not forget that action-research has a dual aim and the research project not only seeks to increase the corpus of scientific knowledge but also aims at intervening in the studied reality to cause its transformation (to trigger a process of change). From an academic point of view, the action-research approach can be used to tackle the same research questions as case study research: How? (describe) and Why? (explain). The main difference between the two research methods lies in the researcher's level of participation. While in action-research the researcher is part of the reality under study and intervenes in that reality in order to bring 
about change (agent of change), in case study research, researchers are "passive" entities: their role is that of an outside observer, who, from the boundaries of the organisation, examines how the phenomenon unfolds without intervening and without triggering any change with their research (at least, not deliberately). The role of the researcher is therefore very different in one or other of the research strategies. In case study, the researcher has no control whatsoever over the events or the acts of the persons in the organisation, while in action-research it is to some extent possible to steer the course of events and observe if the resulting behaviour is indeed what was to be expected. For this reason, action-research is more akin to a clinical experiment where the researcher maintains a certain control over the system under study and changes some parameters of the experiment to confirm that the system does indeed perform as expected.

Therefore, it may be concluded that case study as well as action-research are appropriate strategies for addressing research of a descriptive or exploratory nature. As both strategies are based on an in-depth examination of a specific phenomenon within a real context, both methods subsequently present difficulties when it comes to generalising the results, as such results are understood to be specific and embedded in the context. The challenge to be faced by the researcher in both cases is the way to overcome the barriers that are restricting the possibility of extending the proposed theories and attempt to generalise the results to the highest possible number of circumstances. In whatever case, the results provided by well-designed case study research or action research projects constitute pieces of empirical evidence contributing to support the postulated theories.

Survey research is a method based on quantitative techniques provided by statistics. Processing the information in line with well established fixed rules agreed by the scientific community lets the researcher generalise the findings from a limited set of observations to the population as a whole (statistical inference). Survey research can also have various objectives. It may be: (a) of an exploratory nature when a better understanding of the chosen topic is sought on which there is no prior theoretical framework; (b) of a confirmatory nature when there is an existing theoretical framework and it is simply a question of checking the concepts and relationships postulated, by measuring to what extent the variables are interrelated; and (c) of a descriptive nature when the distribution of a phenomenon in a population is described. In this case, instead of being directed towards "How?" or "Why?", the research question is more oriented towards 
quantifying either the intensity of the relationship among variables in confirmatory-type studies or the frequency with which a specific phenomenon is found in a population in descriptive-type studies. Therefore, the research questions that are best adapted to survey research are questions that ask "How much?"

The other quantitative approach research strategy is related to the models and techniques inherent to operational research. In this case, it is sought to construct mathematical models that will explain (at least partially) the behaviour of the processes arising in the area of operations or which will allow detecting (at least partially) the decision-making problems that managers have to confront in real life. A model is used to try to predict the future behaviour of the system (descriptive models) or to capture the essence of the decision-making problems and provide rules to facilitate decision-making in the organisation (normative models). Therefore, quantitative models are an adequate strategy in research projects that approach design decisions (what-if) or that aim at furnishing a rule for making a decision when faced with a particular situation.

The main difference between quantitative models and survey research lies in the fact that the former can be used to predict the future state of the modelled processes. That is to say, they are not confined to describing and explaining the observations made on reality, as is the case with surveys.

The Table 3.1 summarises the issues approached in this sub-section. The Table also serves as a guide to orient the researcher towards the most appropriate methodology or combination of methods in accordance with the questions initially asked in the research.

\subsubsection{A holistic conception of the research process in the area of Operations Management}

The previous section identified the type of research questions that can best address each of the research techniques studied. The questions set by the research will typically depend on the amount of progress reached by the scientific community in respect of a specific phenomenon. The aim of this section is to present a conceptual model for characterising the scientific research process in the area of Operations Management from a systemic and holistic approach. Each of the strategies analysed in the previous sections regarding the process for creating new knowledge in the chosen area can be placed in this model, as figure 3-3 shows. In doing so, we aim at 


\begin{tabular}{|l|l|l|}
\hline \multirow{2}{*}{ Methodology } & \multicolumn{2}{|c|}{ Type of Research Project } \\
\cline { 2 - 3 } & \multicolumn{1}{|c|}{ Research questions } & \multicolumn{1}{c|}{ Purpose } \\
\hline \hline \multirow{3}{*}{ Case Study } & How? & Describe \\
\cline { 2 - 3 } & Why? & Explain \\
\cline { 2 - 3 } Action-Research & \multicolumn{1}{|c|}{ The researcher does NOT have direct control over the experience } \\
\cline { 2 - 3 } & Wow? & Describe \\
\cline { 2 - 3 } & \multicolumn{2}{|c|}{ Explain } \\
\hline \hline \multirow{3}{*}{ Survey Research } & The researcher HAS direct control over the experience \\
& \multicolumn{2}{|c|}{ Intervention over reality } \\
\cline { 2 - 3 } & \multicolumn{2}{|c|}{ Relationships intensity $\Longrightarrow$ Confirm theories } \\
\hline \hline Quantitative models & What to do? & Decide: decision-making rules \\
\cline { 2 - 3 } & How will the system evolve? & Predict: describe system's future behaviour \\
\hline \hline
\end{tabular}

Table 3.1: A selection guide for research methods strategy in Operations Management area. Source: own development.

making it clear that all forms of scientific activity have their typical strengths and weaknesses that make one method more suitable than another depending on the stage of research cycle that has been reached.

The model set out in Figure 3-3 shows the stages that arise in research processes that typically occur in the area of Operations Management. In the model, any scientific research "would begin" with the existence of a problematic situation set in a real context. In order to solve this problem, the first step is to formulate a conceptual model of the chosen problem. This conceptual model includes a definition of the problem in question, a specification of the variables relevant to the study and the level of analysis of these variables (a macro or micro level, for example). In this conceptualisation stage, although the problem and its context are real objective entities, the researcher's subjectivity comes into play to some extent. As Ackoff (1971) argues, when faced with the same phenomenon different researchers will abstract different systems or "mental images" according to their interests and experience.

When the conceptual model has been decided, formal (mathematical) models can be approached. This enables a series of causal relationships among variables to be expressed analytically. In the model construction process, not only must the causal relationships among the relevant variables be established, but also the measurements that will allow the parameters in- 


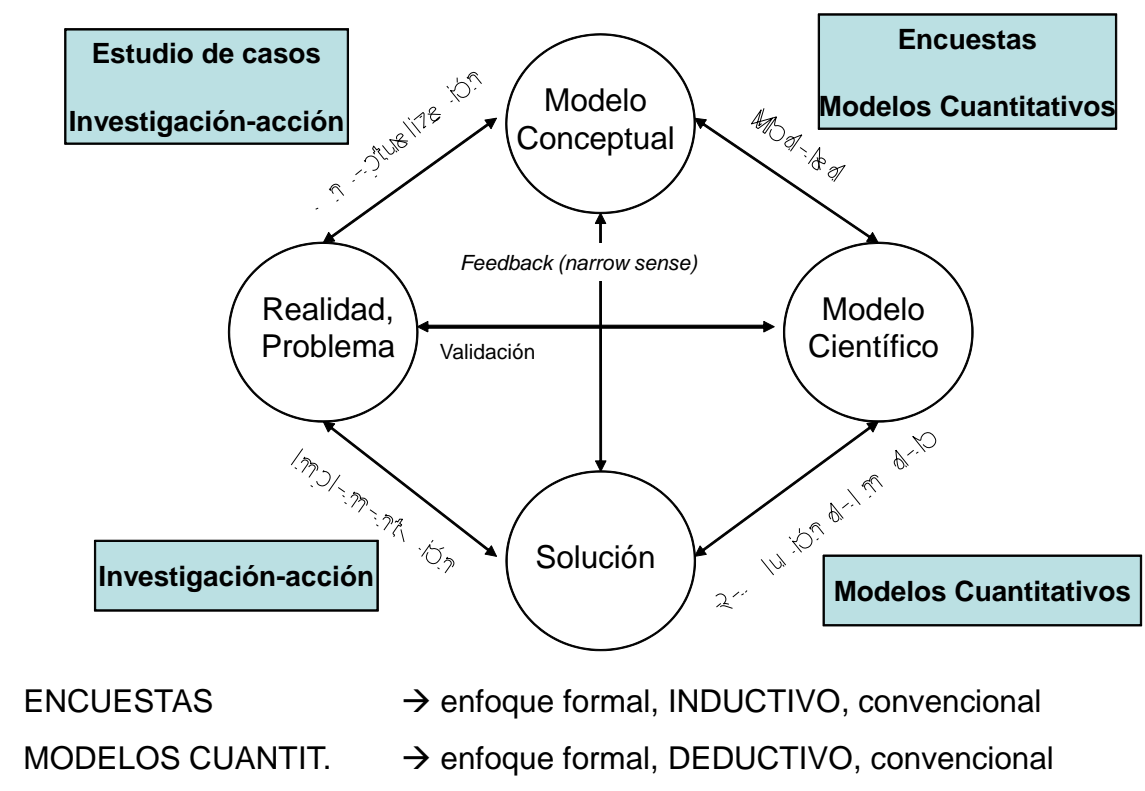

Figure 3-3: A holistic conception of the research process in the Operations Management area: methodologies. Own development based on Mitroff et al. (1974). 
volved in the model to be estimated. On occasions, the non-availability of data, its poor quality or the impossibility of measuring certain parameters may lead the researcher to reformulate the model, but maybe somewhat less accurately than first intended. The availability of data and the model construction process interact in such a way that, typically, the final mathematical formulation is to be attained after several cycles of mathematical modelling and data searches. Each model constructed leads to a search for the corresponding data; if the search does not come up with the required data, model formulation is changed in order to fit the available data sets.

When the model has been finally expressed in mathematical terms, we go on to the solutionfinding stage. Finally, the solution resulting from the model is implemented in the reality under study in order to solve the problem initially set. Implementation, therefore, means intervening in the reality and changing it in the light of the solution. When the solution has been implemented, a new research cycle is begun. It should be pointed out that the research cycle has no initial or final stages. As remarked in Mitroff et al. (1974), the process can begin and end at any point of the diagram.

So, in view of the table for selecting the most appropriate methodology to fit the questions set in the research (Table 3.1), it would appear reasonable to use techniques such as case studies or action-research in the conceptualisation stage. In the modelling tasks, depending on the research goal, techniques such as surveys or quantitative models can be used. Surveys will allow setting relationships among variables that can then be compared to reality in the validation stage (confirmatory surveys). Therefore, survey research only works in the upper part of the diagram, because as it is a mainly descriptive technique it does not allow any "solutions" to be generated that will mean a subsequent modification of reality. It would appear logical then to apply action-research in the stages where the solution is implemented. Every one of the research strategies suggested in this model is governed by its own criteria of excellence. For example, in quantitative modelling priority is given to researchers' ability to formulate appropriate models and derive solutions from them, while in action-research a criterion of excellence is the capability to bring about relevant social change.

It is also worth pointing out that researchers do not need to cover the full loop represented in figure 3-3 for their research to be considered complete. Indeed, many research projects only 
focus on one of the stages in the diagram: conceptualisation, modelling, solving the model or implementing it. However, although a specific scientific researcher may start out from any point in the diagram without needing to run the full course for the research to be deemed complete, it is necessary to point out that the overall scientific knowledge could not be deemed complete if the entire conceptualisation - modelling - solving -implementation cycle (that is, starting out from reality and returning with a new solution) is not carried out by the scientific community as a whole. This is particularly true in the context of applied sciences, such as engineering disciplines, where the ultimate purpose is to solve problems. That is to say, if problems are solved, but they are not in touch with the real problems, or if the reality is analysed in depth in order to understand the problems that need solving, but these problems are never solved, this ultimate purpose of solving major problems or problems that are of relevance to humankind would never be satisfied.

Therefore, the scientific system must be prevented from falling into the right-hand loop (Conceptual Model-Scientific Model-Solution), where the actions performed are not contrasted with reality, as well as into the left-hand loop (Reality-Conceptual Model-Solution), where conceptual models are confused with formal models.

\section{a) Right-hand loop}

Two of the most prevalent forms of scientific activity fall into this loop. Both act as if the goal of the scientific research cycle was to solve problems. The goal of problem-solving is simply to iterate in order to derive better scientific solutions from ever bigger and better devised models. These kinds of activity never go back to reality in order to question the initial hypotheses and simplifications. On the one hand, the initial conceptualisation of the problem (to a large extent implicit in the model) is taken for granted. On the other hand, there is no interest in implementing the solution or involving the models and solutions in social action.

According to Churchman (1961), one of these forms of scientific activity is the "formal, deductive, conventional" approach of science. The other form is the "formal, inductive, conventional" approach. The first approach places the emphasis on formal models and their axiomatic solving, the demonstration of theorems, etc. The second approach is centred on comparing hypotheses and data gathering. Both approaches are formal in the sense that the hypotheses are established a priori before the research work begins, remain unalterable during the course of the 
research and are tested using well-established fixed rules. The approach would be "non-formal" if emphasis were placed on discovering the hypotheses and not on testing them, that is to say, when the aim of the research is to discover new ideas and not to test the existing ones.

Both approaches are conventional to the extent that there is an agreement in the scientific communities that are "users" of both approaches regarding the legitimacy of both forms of scientific activity. The act of researching under these methodologies assumes the membership of a specific scientific community. On occasions, even the members of these scientific communities may act as if they believe that these are the only valid models of scientific work. In addition, the approaches are conventional in another sense. They trust in conventions that are unquestioningly accepted: some things are taken for granted. One example of this kind of convention is the use of a 0.05 level of significance in hypothesis testing.

\section{b) Left-hand loop}

In the same way that the right-hand loop represents research focused on model construction activities and deriving solutions from them, the left-hand loop represents research focused on conceptualisation and implementation activities. The conceptual model should not be confused with the formal model: no matter how rich and elaborated a conceptual model is, it is no substitute for the power of formal models when it comes to creating innovative solutions or solutions not previously foreseen.

Two loops at the top and the bottom of the diagram can also be considered (RealityConceptual Model-Scientific Model and Reality-Scientific Model-Solution).

\section{c) Top loop}

This research loop focuses on the validation activities: conceptual and formal models need to be continuously revised to check that they do indeed reflect the studied reality. Survey research not complemented by some other research method would be confined to this loop, as the technique by itself would not be able to offer any possibility of creating solutions from the model.

\section{d) Bottom loop}

This research loop places an excessive focus on finding solutions and on action. It ignores conceptualisation and modelling activities. This happens when not fully developed ideas are put into practice or in research that is excessively practical. 
The advantage of this systemic conception of the scientific knowledge creation process is that it brings out the risk entailed in considering some system element to be more important than the others or dealing with it as an entity that is independent of the other system elements. However, on occasions, the scientific community has only looked at the right-hand part of the diagram, taking the left-hand part to be irrelevant for scientific knowledge. The left-hand part is the "discovery context", the part where ideas originate, where inductive-type approaches (bottomup) are used; the right-hand part is the "verification context", where ideas are tested; on this side of the diagram a greater use of deductive reasoning is usually made. More importance is given to validating theories (or rather to invalidating them, as Falsificationists would put forward (Popper, 1934)) rather than to creating new knowledge. This fact arises from the concern to explain science by using the terms of Logic. The right-hand part of the diagram, almost by definition, can be modelled in logical terms and, in this sense, it meets the rigorous formal criteria set for a certain piece of knowledge to attain the "status" of scientific knowledge. However, the left-hand part of the diagram containing the origin of ideas is much more difficult to model in formal terms, but its impact on scientific knowledge (in terms of new ideas generation and conceptualization) also needs to be recognised.

\subsubsection{Methodological framework in OM: Conclusions}

As an initial conclusion from the conceptual framework presented in this section, it can be stated that the area of Operations Management has at hand various research methodologies. However, the main conclusion to be drawn from our model is how the different techniques presented complement one another. The four approaches analysed should not be considered as disjoint alternatives but rather as complementary approaches that researchers have at their disposal to generate new knowledge. The most appropriate research techniques are dependent on the research problem and the research goals set (Jankowicz (1991), quoted by Ponce and Prida (2004)), for which reason, a top quality researcher must be able to handle various techniques. Not all need to be used at once, either one, another, or a combination of them can be chosen depending on the problem that arises. Likewise, reviewers must be prepared to assess works that include the techniques that are most appropriate for the problems being addressed.

In any research project, including a doctoral thesis, it would seem advisable to use vari- 
ous complementary research methodologies to address the same problem (what is known as a triangulation of methods). If similar findings and conclusions can be reached by using various techniques, the internal consistency and validity of the research is reaffirmed. Also, using diverse research methods is usually positive and a sign that a certain maturity has been reached in the area (Malhorta and Grover, 1998). The progressive broadening of the "focus" undergone by Operations Management since its origins as a scientific discipline brings with it a need to consider making new techniques and research methods a part of research projects.

\subsection{Methodological approach used in this thesis}

The research object of this thesis are reuse CLSC. In Chapter 2 and Section 3.2, it was argued that: 1) RL and CLSC are subjects of study in the Operations Management area that still need important amounts of exploration and conceptualization; 2) Within this general exploration context, reuse aspects have been under-researched in the newly emerging field of closed-loop supply chains, especially when compared to other types of CLSC (remanufacturing, commercial returns). Given the novelty of reuse CLSC topic, conceptualization of the reuse phenomena from real data coming from the field appear to be necessary. The reserch process started with field studies intending to acquire deeper insights into the reuse processes. The results from the conceptualization process are presented in Chapters 4 and 5 of this dissertation. The conceptual model that is put forward there is generated through an inductive process (bottomup approach) based on several case studies that have been carried out in real industrial settings, in close contact with several partner companies or organizations (Figure 3-4) Case Study 1 (Industrial and Medical Gases, IMG) and Case Study 2 (Liquified Petroleum Gases, LPG) had an exploratory nature and enabled to identify the main managerial issues that are are related with reuse CLSC. The concepts and ideas generated in Cases 1 and 2 were afterwards confirmed and refined with cases 3, 4, 5 and 6 (and also with evidence coming from literature). The four confirmatory case studies enabled to ratify the emerging theory stemming from the two first case studies, to redefine the scope of this theory (that encompasses three different categories of reusable articles (such as reusable products, RP)) and to sharpen the concepts and ideas included in the conceptual model. The model was finally validated by managers involved in 
some of the companies that had been analyzed during the case studies.

The first case study (Case Study 1: Medgas) is partially based on the past professional experience of the $\mathrm{PhD}$ candidate as logistics manager in the medical branch of Air Liquide Spain. In addition, some interaction was also established with the main competitor of Air Liquide Spain (Carburos Metálicos) in the industrial and medical gases market. This second interaction for case study 1 came to confirm that the problems associated with cylinder reuse observed in Air Liquide were not company-specific, but common to other companies operating in the same sector.

The second case study was the result of a one-year research project conducted in Repsol GLP, the liquiefied petroleum gases (LPG) branch of Repsol group in Spain. The managerial issues observed in Case Study 1 were also observed in the Repsol case. The complexities arising in both cases were not linked to the product but to the reuse of product containers (cylinders).

Cases 3, 4, 5 and 6 were carried out during a research visit in the Netherlands (Erasmus University Rotterdam) and enabled to extend the emerging managerial model to different types of reusable articles, which resulted in the typology which is presented in Chapter 4.

After the conceptualization phase, the main managerial issues arising in reuse CLSC had been identified. The solutions proposal stage was then addressed. Part of the solutions proposed are based in purely quantitative modelling methods, as shown in Chapter 6 .

Therefore, in the research trajectory described in this dissertation, most phases of whole process for generating scientific knowledge (Fig. 3-3) have been accomplised. More precisely, throughout the $\mathrm{PhD}$ trajectory the conceptualization, modelling and solving phases have been undergone. The validation phase has only been partially adressed through model validation by industrial practitioners. It is interesting to remark that different stages in the process of scientific knowledge generation have been adressed with this thesis. Each stage required its own methods, as explained in section 3.3: at first, case study research was used, as deeper insights on the research problem were required. Once the real problem had been modellized and structured, it was possible to formulate and solve the MILP models that will be presented in Section 6 (quantitative modelling). A complementary research technique used throughout all the PhD trajectory is systematic literature review. 


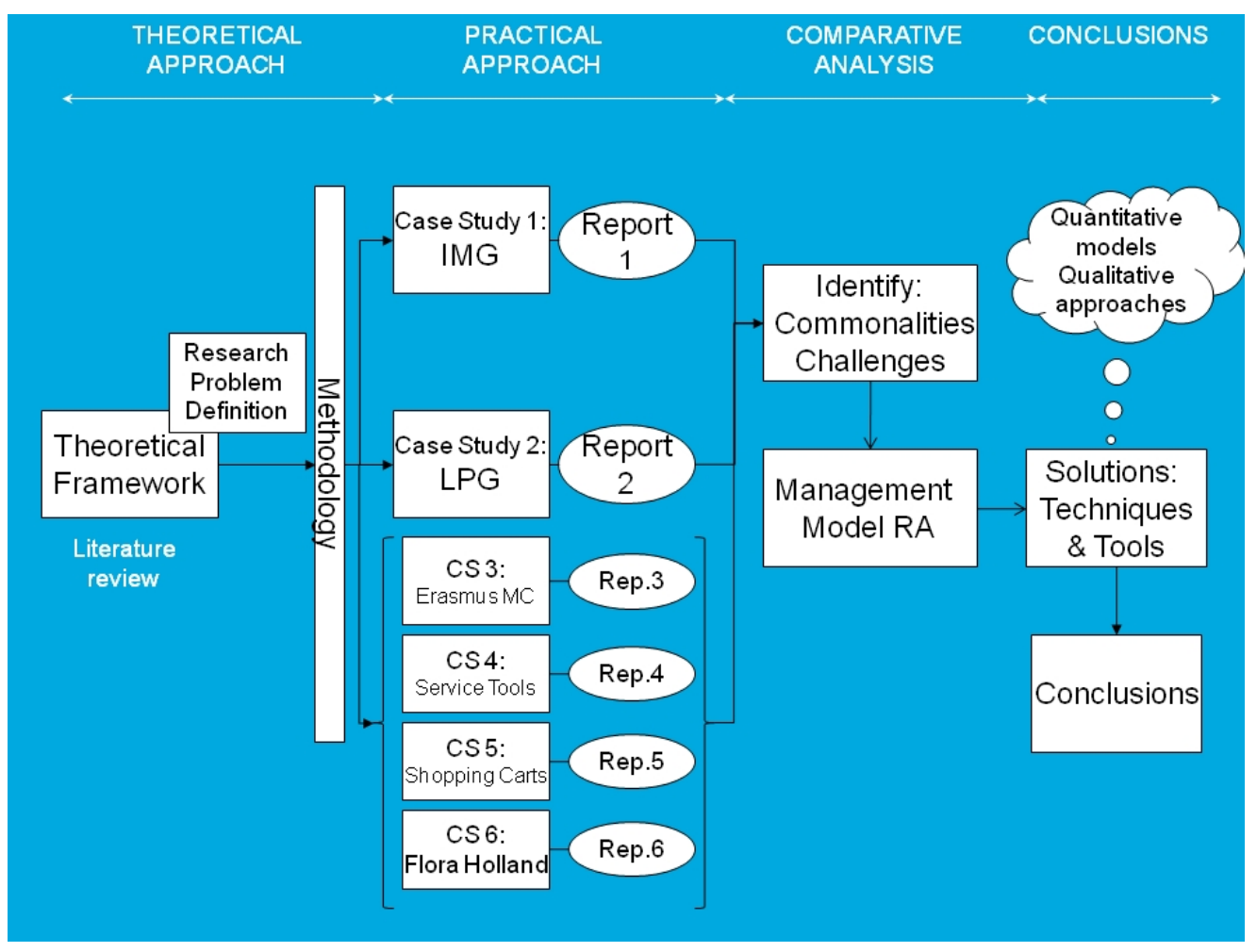

Figure 3-4: Methodological approach used in this thesis. Own development. 


\section{Chapter 4}

\section{Reusable articles: a typology grounded on case studies}

\subsection{Introduction}

In section 3.1 the scope of this thesis was defined and the research problem at hand was positioned among the related work. The research problem sharpening process showed up that, in spite of the contribution of reuse practices to the environmental and economical sustainability of production and distribution systems, reuse closed-loop supply chains (CLSC) have not been widely researched for the moment. From this chapter onwards, we start to bridge this gap by proposing the different puzzle pieces that make up the management model for reusable articles presented as the overall research goal of this thesis.

In this chapter, the core cornerstone of the management model is adressed. More specifically, the reusable articles term is defined, the characteristics of reusable articles are identified and a typology integrating different categories of articles (transport items, packaging materials, tools) is proposed. This results are grounded in set of case studies carried out in real industrial settings, which are also presented within this chapter.

Chapter 5 builds on the emerging theory stemming from chapter 4 and presents additional building blocks that are added up to the management model (common problems found in reuse CLSC, basic information (metrics), management issues, solutions proposal). The results of chapter 5 are also partially based on the case studies presented here. 
Chapter 4 and chapter 5, considered as a whole, constitute the above-mentioned general and comprehensive conceptual model for the management of CLSC of reusable articles. Later on, in chapter 6 , the focus will be narrowed to a particular type of solutions in the general model in order to quantitatively analyze its effects on cost performance of the closed-loop system.

In Chapter 4, the specific objectives are:

- To define the reusable articles term and to propose a standard terminology in the reusable articles field.

- To build a typology for reusable articles that integrates under the same term three different articles categories. Combining several classes under the same concept enables us to extend results obtained for one type of reusable articles to the other categories.

- To identify and characterize the common features that distinguish reuse CLSC from other types of CLSC

- To identify the differences existing between the different categories. The differences enable to establish the boundaries for results generalization among categories.

- To characterize different types of reusable articles networks.

- To provide the empirical evidence stemming from the case studies that grounds the results presented in this chapter.

- To describe the case studies used for generating the emerging theory provided in this chapter.

The contribution we present in this chapter seeks to develop new theory useful for the operations management academic community and for industrial practitioners. Our methodological choice for building new theory is basically inductive: our results are grounded (Glaser and Strauss 1967; Strauss and Corbin 1990; Glaser 1992) in conceptualization on the different case studies (Eisenhardt 1989) we have carried out in real industrial settings, the knowledge we have acquired through these different research projects and the contrast with existing literature. For validating the emerging theory we used a deductive approach, using empirical evidence also coming from our case studies, validation by managers we interacted with during our field work 
and contrasting again with existing literature. Hence, the contribution of chapters 4 and 5 is conceptual and empirically supported by case studies.

The remainder of the chapter is organized as follows. In section 2, we justify the need for deepening in our knowledge on reusable articles, through an analysis of the academic literature related with the topic. In section 3, the emerging theory proposed in this chapter is presented: we sharpen our definition of RA and we present our typology for RA: three different types of RA are identified and we make clear which are the similarities and differences among them. In addition, two different types of reusable articles networks (depending on how the physical flows in the system are organised) are introduced. Next, in section 4, we condense the empirical evidence (stemming from the case studies) that supports the statements put forward in chapters 4 and 5 . Section 5 provide an structured detailed description of the case studies that were carried out throughout this thesis. Finally, in section 6 the conclusions of this chapter are presented.

\subsection{The need for a framework on reusable articles systems}

Scientific literature on the topic of reusable articles is quite scarce. Fleischmann et al. (2000) point out that the number of references on the topic is limited. According to Kärkkäinen et al. (2004), the scarcity of literature on the management practices of reusable articles, given their increased importance, is startling. Johansson and Hellström (2007) also remark that empirical research on reusable articles management is surprisingly scarce.

Besides, most of the previous scientific literature has just dealt with some particular subclasses of reusable articles, such as some types of packaging, focusing either on returnable transport items, on refillable containers, on reusable cameras, etc. To our knowledge, none of the current academic publications considers simultaneously different classes of reusable articles. In addition, terminology in the field of reusable articles is not always consistent. We found a multiplicity of terms to designate similar concepts depending on the author(s). This lack of an agreed-upon wording is sometimes misleading.

Kroon and Vrijens (1995), McKerrow (1996) and Twede and Clarke (2005) focus on the organizational design of returnable containers systems. The first paper explores different network design alternatives and proposes a MILP plant location model for deciding where container 
depots should be located. McKerrow (1996) focuses on the benefits of standardized reusable packaging and presents different ways of organizing an equipment pool network. Twede and Clarke (2005) identify the supply chain relationships that favour the introduction of reusable packaging systems.

Some firms substitute disposable for reusable packaging elements in order to obtain a more sustainable supply chain (waste reduction), among other reasons. Thus, much academic research concerning reusable packaging has focused on assessing the costs and savings to be considered when evaluating a potential shift from one-way to reusable distribution items. Flapper (1996), Dubiel (1996), Rosenau et al. (1996), Mollenkopf et al. (2005) and, also, Twede and Clarke (2005), propose cost evaluation models for supporting this choice between reusable or disposable packaging systems.

Another group of previous contributions focuses on operational aspects of reusable packaging systems and primarily, on techniques for forecasting future article returns. This topic is central in Goh and Varaprasad (1986); Kelle and Silver (1989a\&b) and Toktay et al. (2000). Returns forecasting is closely related with the value of item-level tracking information. The two latter papers also deal with this topic. Besides, Van Dalen et al. (2005), Johansson and Hellström (2007) and De Brito and Van der Laan (2009) also contribute in this line. Regarding production and distribution planning and control considering a closed-loop system of refillable bottles we only found Del Castillo and Cochran (1996).

Most of the papers we reviewed allude to the operational problems that typically arise in particular subclasses of reusable articles. Specifically, Duhaime et al. (2001), Rudi et al. (2000), Young et al. (2002) or Breen (2006), deal respectively with the management challenges of postal monotainers, reusable medical devices (wheelchairs), chemical railcars or a diverse variety of distribution items (pallets, totes, trays, kegs, trolleys, bins).

For a more extensive literature review on this topic, we refer the reader to the Appendix I of this chapter, where we provide for each of the references cited in this section the topics dealt with, the main contribution of the paper and the subclasses of reusable articles specifically considered.

As a result of our literature review, we conclude that knowledge on CLSC of reusable articles is fragmented, scattered and terminology in the field needs to be standardized. The analyzed 
papers deal with particular types of reusable articles or particular problems or issues related with them. To our knowledge there is no existing paper considering together different types of reusable articles and identifying with a holistic approach the management issues arising in the context of reuse. This motivates this conceptual chapter that provides an empirical analysis of real case studies in this area.

\subsection{Reusable articles: structuring the field}

\subsubsection{A definition and a typology for reusable articles}

The term reusable articles (RA) refers to products that are used multiple times by different users. This definition implies that the use by each user is of relatively short duration (compared with article lifetime) and does not deteriorate the product. It also implicitly states that RA require a reconditioning process which should remain short and simple, in order to enable quick utilization by the next user. We define reconditioning, in line with Guide and Van Wassenhove (2002), as the necessary processes required to bring a used RA to a condition in which it can be safely reused again. Another feature essential to RA is the fact of having multiple different users: so, articles have to go back to a reconditioning facility where they are made available for the next user. RA are returned and reintroduced in a closed-loop system to be reused in multiple use cycles.

Reusable packaging is a natural example of RA, but is not the only class that can be included under this term. Other articles also exhibit the same characteristics, as will be explained in the following paragraphs. Then, we put forward the following typology for RA, which is depicted in Figure 4-1:

- returnable transport items (RTI),

- returnable packaging materials (RPM),

- reusable products $(\mathrm{RP})$.

The RTI acronym, coined by Johansson and Hellström (2007), is used in this paper to designate secondary and tertiary packaging materials (Stock 1992) which are used for assembling 


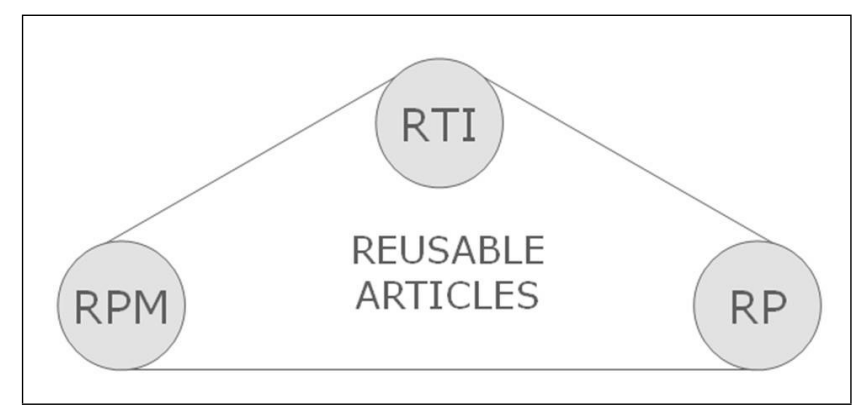

Figure 4-1: Reusable Articles (RA): RTI, RPM and RP (own development).

goods in material handling and transportation in the supply chain and then returned for further usage. RTI are not in direct contact with the product consumed by the end customer. Examples of RTIs include pallets, maritime containers (Crainic et al. 1993), railcars (Young et al. 2002), standardized vessels for fluids transportation, crates, totes, collapsible plastic boxes, trays (Duhaime et al. 2001), roll cages (Carrasco-Gallego and Ponce-Cueto 2009), barrels, trolleys, pallet collars, racks, lids, etc. Most RTI are used in B2B settings, although they can also appear in B2C contexts with elements such as supermarket trolleys, baggage trolleys in airports and train stations and wheeled bins arranged by local councils (Breen, 2006).

We use the RPM acronym, coined by Van Dalen et al. (2005), for denominating primary packaging materials designed to directly protect and hold the product that the end consumer really wants. Examples of RPM are refillable glass bottles for beverages (Goh and Varaprasad 1986; Del Castillo and Cochran 1996), gas cylinders (Kelle and Silver 1989a\&b), kegs (Swinkels and Van Esch 1998), containers for chemicals, toner cartridges (Guide and Van Wassenhove 2003), single-use cameras (Toktay et al. 2000), medical equipment protection, windmill parts equipment protection or steel coils packaging (Rubio et al. 2009).

Finally, we use the reusable products (RP) term for a third category where products themselves are used multiple times. We refer, for instance, to sterilized surgery instruments, wheel chairs or other types of medical equipment lent by National Health Services to patients (Rudi et al. 2000), systems for borrowing of books, video tapes or sport equipment (Yuan and Cheung 1998) or the service tools (Vliegen and Van Houtum 2009) required to perform maintenance actions that are borrowed from a central unit. It is essential in the RP category to consider 
articles being utilized by different users. Rechargeable batteries, for instance, are excluded from this category because they are typically utilized by a single user. Batteries do not need to return to a reconditioning facility to make them available for the next user. It should be noted that reuse by different agents is related with the usage pattern of the article and not with the article itself. Consider for instance, books. Library books are included under the RP term while personal books are not, because they are not acquired with the intention of being reused by multiple different users.

The rationale for considering together these three types of items as reusable articles resides in the fact that the three categories share the same logistical characteristics (see subsection 3.2). Hence, the results obtained from the analysis of an individual class (RTI, RPM or RP) can be extended to all classes of reusable articles. This allows generalizing the results obtained in the RTI literature (which, although scarce, is the more abundant in the three types of reusable articles) to a wider number of situations in which reuse is involved. Our claim for generality also enables us to "learn" from other classes and transfer best practices developed for one particular category to the others. For instance, management models used for RTI can be extended to service tools or other types of RP.

When confronted with disposable articles, we find that reusable articles reduce purchase costs in the long run $^{2}$ and article disposal costs, if they exist. RA contribute to reduce firms' ecological footprint through a reduction of the amount of waste they generate. On the other hand, RA add extra costs related with return transportation, reconditioning and management of the closed-loop of reusable articles. The latter cost element includes the administrative effort and the cost of acquiring the necessary information for effective management.

\subsubsection{Characteristics of reusable articles networks}

In this subsection, the objective is to identify and describe the features distinguishing reusable articles networks from other types of CLSC, such as rework, commercial returns, repairs and warranties, end-of-use returns or end-of-life returns. These features or contingency factors as they were coined by Woodward (1965) are summarized in Table 4.1.

\footnotetext{
${ }^{2}$ Although the acquisition cost of one unit of a single-use article is usually lower than its reusable homologue, the cost per use is typically lower in the reusable version.
} 
(a) New and reused products are treated as the same.

(b) Simple reconditioning activities. Quick reintroduction in the forward supply chain.

(c) The fraction of returned products is high (most demand is fulfilled with used products).

(d) Many units in circulation of low-medium unitary value each.

(e) Main operational challenge: balancing demand and returns.

Table 4.1: Features of reuse closed-loop supply chains. Own development.

(a) One of the main characteristics of RA when confronted with other types of CLSC is that users do not make a difference between brand new and reused articles. Both have the same cost for the end consumer and they provide the same functionality. New and used products are mixed in the logistic channel and serve the same markets.

(b) Simple reconditioning processes enable RA to be quickly reintroduced in the forward supply chain. This makes reuse CLSC different from other types of CLSCs, such as those involving repair, refurbishing or remanufacturing, which typically entail to some extent the disassembly of the used product. Reconditioning in reuse CLSC include activities such as inspection, testing, cleaning, minor repairs, filling, sterilization, etc. Reconditioning lead times are usually short (we do not include in this lead time the time articles spend in inventory waiting to be reconditioned or waiting to be shipped as new after reconditioning). Reconditioning does not entail a major cost compared with the acquisition cost of a new product (that is the rationale for reuse of many of these articles).

(c) When compared with other closed-loop flows, the volume of RA return flows is substantial. The fraction of returned articles is high, even if some articles would be lost or irreparably damaged in the logistic channel. However, quantifying exactly the percentage of reusable articles that effectively return is not straightforward, as will be explained in section 5 . In general terms, it can be said that in CLSC of RA, most demand is fulfilled with previously used articles. The return percentage is usually above $80 \%$.

(d) The number of units circulating in the system tends to be considerable, varying from large (RP) to very large (RTI, RPM). Hence, even when the unitary value of each article is limited, the complete fleet of RA should be considered assets, rather than expensed items. The relative inexpensiveness of each article sometimes leads to a lack of tight control over each unit.

(e) Despite the high return volumes, it is still a challenge in these systems to ensure equilib- 
rium between demand and return rates. As some RA would have to be replaced due to leakages or permanent damages, even in the case of an even demand pattern, new articles have to be purchased from time to time. Even if the number of articles circulating in the CLSC is enough, it is still necessary to assure that the articles are returned and reconditioned at the right time in order to fulfil demand. Balancing demand and returns becomes even more complex when transhipments between depots are allowed, as articles need to be located in the right point of the supply chain in order to fulfil demand.

Next we present the characteristics of reusable articles return flow, which is depicted in Figure 4-2.

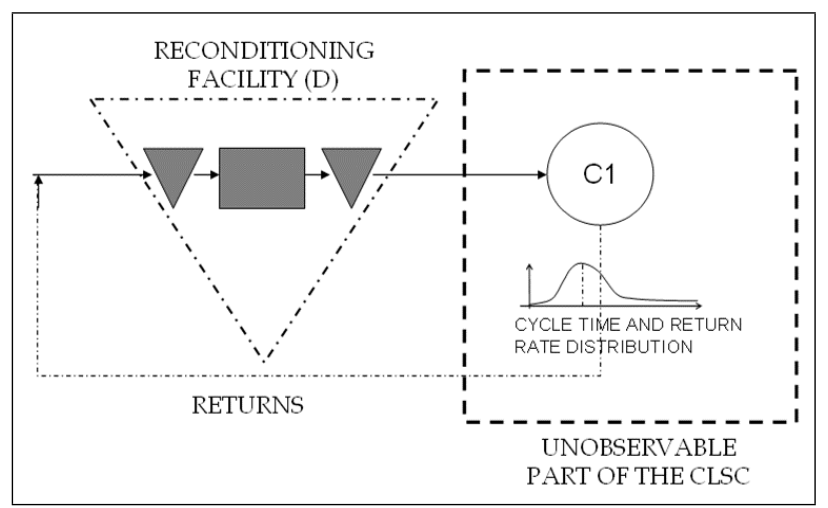

Figure 4-2: Reusable articles CLSC: cycle time, return rate and unobservable part of the supply chain (own development).

RTI, RPM and RP have similar characteristics in their return flows. As in many other CLSC, the return flow features in reusable articles systems are conditioned by the past behaviour of sales (forward flow). RA are launched to the market and, after a certain unknown time they will return to the central facility to be reconditioned and, next, reused. This unknown time may be described by a statistical distribution, although a non-stationary description may be necessary. A number of RA will not return due to uncontrolled leakages (losses) or irreparable damage. Hence, the time from issue to return of each $\mathrm{RA}$ is a random variable with a distribution that includes a finite probability of never being returned (Kelle and Silver 1989a; Toktay et al. 2000). In this dissertation, we use the term cycle time to designate this random variable. The same variable has been referred to in literature with different names such as turnaround time 
or trip duration (Goh and Varaprasad 1986), return delay (Toktay et al. 2000) sojourn time (Fleischmann et al. 2002), time until return (De Brito and Dekker 2003), lead time (Kiesmüller and Van der Laan 2001) or circulation time (Van Dalen et al. 2005). The probability of a sale yielding a return is the return rate. Note also that there is a part of the supply chain, when RA are at "customer-use" stage, which is unobservable for the organization in charge of RA reconditioning. During this phase, the central organization loses control over their assets. The return rates of RTI, RPM and RP are remarkably high when compared with other types of CLSC, such as remanufacturing or commercial returns. It can be said that return rates in the context of reuse tends to fluctuate between 80-99\% (as most demand is fulfilled with used products). However, precise figures of return rates are usually not available, due to lack of visibility over the unobservable part of the supply chain.

\subsubsection{Differences between RTI, RPM and RP}

Although RTI, RPM and RP share many logistical characteristics, there are also differences between them that led us to establish three different categories. In this subsection we will point out these differences in order to establish boundaries for the generalization of results between categories.

The main difference between RTI (secondary and tertiary packaging) and RPM (primary packaging) is that the latter are in direct contact with the product the end customer really wants. As a result, while RTI tend to be standardized, RPM are less. Many well-known operational benefits can be derived from standard material handling units: more efficient cube utilization, enabler for material handling automation (unique dimensions for material handling equipment), potential productivity improvements in handling operations, enhanced product protection, etc. The direct contact of the RPM element and the "real" product makes it more difficult to achieve the standardization of RPM, mainly because of marketing or technical reasons. For instance, beverage manufacturers maintain different glass bottles for different brands: bottles constitute a means to differentiate each brand product from its competitors and are a very important marketing element. Industrial gas cylinder connections are gasspecific (for security reasons) and sometimes even installation-specific (a given instrumentation requiring a special type of cylinder). Packaging protecting products entailing special dimensions 
(medical equipment, windmill parts, steel coils) is difficult to standardize. These are examples of technical reasons hindering standardization of RPM. In addition, RPM's reconditioning tends to be more difficult than RTI's, because of the direct contact of the product. More thorough cleaning is usually required for RPM.

The main difference between RP (tools, instrumentation, etc.) and the two previous RA categories is that RTI or RPM are somehow a packaging holding the product that the end customer will consume (gas, ink, photo film, ...) while in this latter category what is reused is the product itself. RP are rarely standardized and their reconditioning operations complexity varies from very simple activities (e.g. library books) to more somewhat complex actions (e.g. sterile surgery instruments).

Standardization (articles interchangeability) is a necessary condition for the management of RA in pool ${ }^{3}$ systems. Hence, while RTI pools are relatively frequent, this organizational design is less common for RPM or RP.

\subsubsection{Types of reusable articles networks: star systems vs. multi-depot systems}

Depending on the configuration of the physical flows involved, logistics networks entailing reusable articles returns can be broadly classified in two categories: star systems and multidepot systems. Figure 4-3 depicts the difference between the two network models. In star systems, RA return to the same plant or depot from where they were originally issued once they have been used. In multi-depot systems, it is not compulsory for RA to return to the issuing depot.

In star systems, the central facility D can directly supply end customers (C1) or use intermediate distributors $(\mathrm{d} 1, \mathrm{~d} 2)$ that serve the end customers in a given region ( $\mathrm{C} 2$ to $\mathrm{C} 6)$. Even if the network comprises several tiers, RA always return to the same central facility D (the filling plant, the sterilization unit, etc.) where they receive specialized reconditioning operations (filling, sterilization, etc).

\footnotetext{
${ }^{3}$ In pool systems, a group of suppliers and/or customers agree to participate in an exchange program, where the same collection of interchangeable RTI -the pool- is used by them all. The pool can be jointly owned by the pool participants (i.e., Dutch flower auctions) or can be owned by an independent third party (i.e., Chep pallet pool).
} 


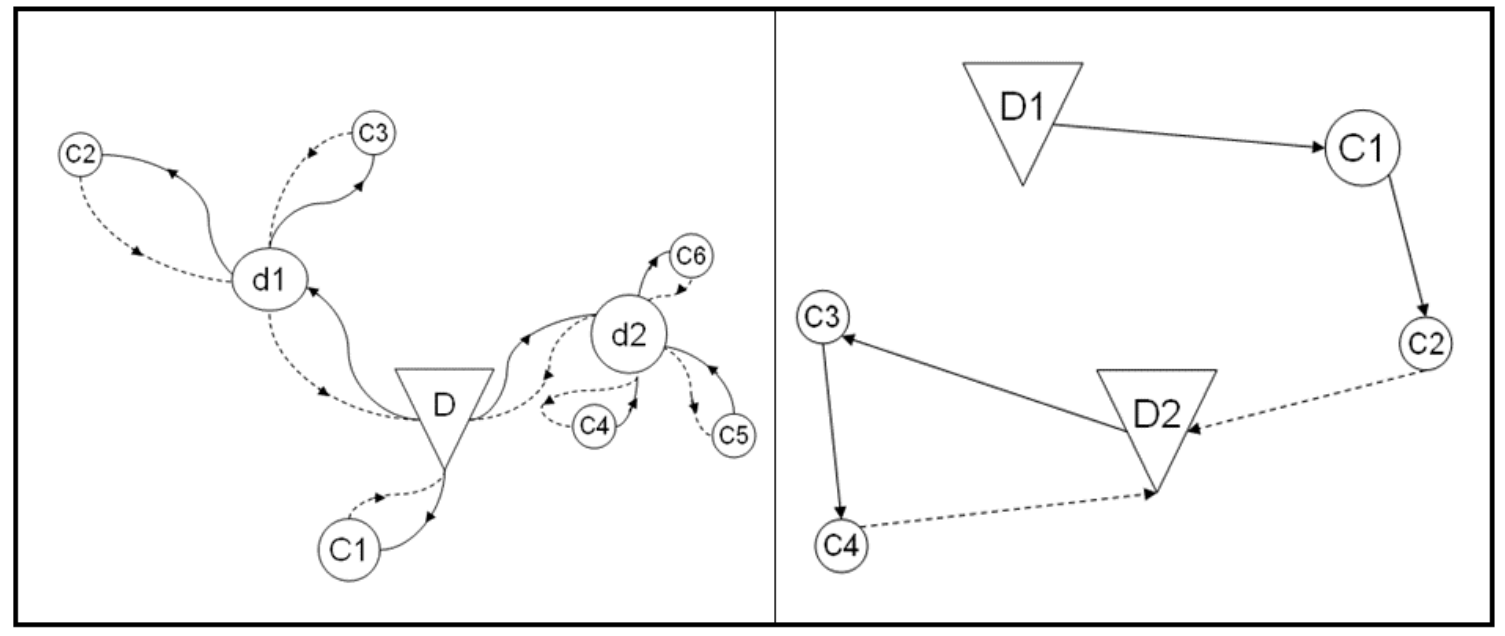

Figure 4-3: Star network vs. multi-depot network (own development).

In multi-depot systems, RA can be utilized by different agents of the supply chain $(\mathrm{C} 1, \mathrm{C} 2)$ before returning to a depot that can be different from the original sender. Only eventually will RA return to their original sender (D2). In the multi-depot network, all depots must be able to perform the reconditioning tasks necessary to bring RA into a usable condition again. Thus, the simpler the reconditioning activities, the more favoured is a multi-depot structure. This is usually the case of RTI, whose reconditioning tends to include only inspection, cleaning and minor repairs.

In literature, the difference between the two network models has been suggested but not clearly established. Kroon and Vrijens (1995) underscore the differences between transfer systems, depot systems and switch pool systems. Dubiel (1996) distinguishes between individual exchanges, multilateral exchanges and pool systems. Twede and Clarke (2005) use the terms closed-loop applications and supply chain system-wide applications.

\subsection{Empirical evidence: case studies}

The generation of new theory that we have presented in section 4.3 is the result of our involvement in different field works in the context of reusable articles. Therefore, the statements presented in section 4.3 are supported by a set of ten case studies. Six of them have been devel- 
oped by the authors in real industrial settings. The interested reader is referred to an extensive structured description for each of them provided in the following section (section 4.5). The other four cases are available in the scientific literature. They were selected because they have been described extensively in previous papers. In this section, the objective is to carry out an analysis of the features we have identified in subsection 4.3.2 ( (a) new and reused products are treated as the same, (b) simple reconditioning, ....) within each case study. This analysis is summarized in Table 4.2 .

Our first case study (MedGas) concerns the Spanish subsidiary of a multinational company that produces and distributes gases for the industrial and medical sectors, such as oxygen, nitrogen or carbon dioxide. More precisely, we interacted with the healthcare branch of the firm. For small consumption levels, gases are compressed and distributed by means of cylinders. Inside the cylinder, gas is compressed and packaging has to withstand pressures of around 200 bars, so cylinders are typically manufactured in steel or aluminium alloys. A standard $50 \mathrm{l}$ cylinder has an estimated unitary cost of $€ 100$, making cylinder reuse the only economically viable option.

Medical oxygen is distributed in the so-called compact cylinders. The company owns an estimated fleet of compact cylinders for this particular product of roughly 20,000 units ( $€ 2$ million investment). When they return to oxygen filling plants, cylinders have to be checked in order to determine if they can be safely reused. If the hydraulic test ${ }^{4}$ has expired for a particular cylinder, it is put aside in order to be taken to a special testing facility. If the cylinder is suitable for reuse, it enters an automated circuit where it is cleaned and refilled with oxygen. Physical flows in the medical oxygen supply chain are organized following a star model, as cylinders return to the originally issuing filling plant. Regarding losses, the company controls the number of cylinders that are scrapped due to their bad condition and these assets are retired from the account balance. Nevertheless, there is a lack of control over the cylinders that are lost in the unobservable part of the supply chain.

The second case study was developed within a Spanish oil company that delivers Liquified Petroleum Gases (LPG), mainly butane and propane, to households and industrial customers.

\footnotetext{
${ }^{4} \mathrm{~A}$ periodical test that cylinders pass every 2, 5 or 10 years in order to check if they can resist high working pressures (testing pressure is at least 1.5 times cylinder working pressure).
} 
The firm holds a fleet of 30 million LPG cylinders for supplying the Spanish market. Assuming a unitary price of $€ 20$ per cylinder, this represents a value of $€ 600$ million. Cylinders have a very long technical life, so much of the cylinder fleet financial value has been written down a long time ago. However, LPG in Spain is a declining market and management acknowledges that their cylinder fleet size is now overdimensioned for their current operational needs. Maintaining such a big fleet of cylinders has financial and economic consequences, not only in terms of space and handling, but also in terms of maintenance and opportunity costs (see complete case in Appendix II). Regarding losses, the firm just controls the cylinders scrapped due to their bad condition. They cannot control the losses happening in the unobservable part of the supply chain. Physical flows are organized around a star network: end customers are assigned to a particular distributor. Distributors are assigned to a particular filling plant. Therefore, cylinders return to the filling plant from where they were originally issued.

Our third case study concerns the central sterilization department (CSD) of Erasmus MC, an important clinical institution in the Netherlands. The hospital holds a stock of durable surgical instruments that are sent to sterilization to the CSD after each use. CSD management could not quantify exactly the amount invested in the total instrument inventory, but they established the magnitude order in millions of euros. Typical figures dealt with in the case were $€ 100$ per single instrument and $€ 10,000$ for a complete surgical net comprising around a hundred instruments. The reconditioning of surgical instrumentation involves checking the completeness of the net, replacing the missing or defective instruments in case it is needed, and instruments sterilization in autoclaves. All sterilization operations in the hospital are done in the CSD, so the physical flows follow a star model necessarily.

The fourth case study is related with service tools used for maintenance purposes. Typically, Original Equipment Manufacturers (OEMs) hold local inventories of expensive service tools that are required for assuring customers' equipment maintenance in a given region. Service engineers borrow these tools from the warehouse when needed. After use, tools are taken back to the warehouse for further use. Before reintegrating the tools stock, instruments are checked and consumable parts (welding material, for instance) are replaced. Lateral transhipments between tool warehouses are allowed in case of emergency, but tools always return to the original issuing warehouse, so physical flows follow the star model. The amount invested in service 
tools inventories could not be exactly quantified but the firm participating in this case study estimated it in the millions of euros for each warehouse. The percentage of lost tools because of misplacement or irreparable damage is considered to be very low by OEM management.

Our fifth case study concerns the shopping carts of a retailer in the Netherlands. The trolley inventory for a typical medium-size retailing surface in this country varies between 200 and 400 units. The price of each cart fluctuates between $€ 152$ and $€ 174$. In small retail centres, where there is only one service point where customers retrieve and take back the carts, physical flows follow a star model. Big retailing surfaces typically have several service points (depots) and in that case, physical flows follow the multi-depot model: carts can be returned at any available depot. Management issues in this context include determining the required cart fleet size in order to provide the right service level even in intense-demand periods (weekends), preventing trolley losses (3 per cent of the fleet is lost or irreparably damaged annually) and rebalancing cart inventory between locations when the retailing surface has more than one trolley service point. Note that the term "fleet size" refers to the total number of RA in circulation in the system. It includes, for instance, RA stocked in the reconditioning facilities, RA stocked in other parts of the supply chain and also RA in transit.

In our last case study, we have analyzed the use of stapelwagen or metal carts in the cut flowers and plants supply chain within Flora Holland, a Dutch company in charge of flower auction houses in the Netherlands. Metal carts are used by all the agents of the floricultural supply chain (growers, auction houses, buyers) in order to reduce unnecessary product handling. Carts are property of Flora Holland and growers and buyers rent them for supplying/retrieving products to/from the auction house. Once they have been used, metal carts can return to any of the six auction houses that Flora Holland runs in the Netherlands. Carts just require very simple reconditioning operations (mainly cleaning) and are available to be reused very quickly. Physical flows follow a multi-depot model, so rebalancing carts inventory levels among auction houses is an issue in this case. The total inventory levels of carts are estimated by Flora Holland in roughly 50,000 units, with a unitary price of $€ 500-600$ per cart (involving an investment of around $€ 30$ million).

Our analysis also includes four relevant case studies described in the academic literature. We have selected case studies concerning four different industries utilizing reusable articles: a 
brewery (Van Dalen et al. 2005), a dairy producer (Johansson and Hellström 2007), a furniture retailer (Hellström 2009) and the automotive industry (Roseneau et al. 1996).

The Heineken case (Van Dalen et al. 2005) describes the closed-loop supply chain of reusable packaging used in a Heineken brewery, which includes RPM such as glass bottles, crates and kegs. The total replacement value of RPM (kegs, bottles, crates) within Heineken Europe is estimated at $€ 550$ million. The inventory of crates in one particular brewery is estimated at 3.57 million crates, each of them having a unitary cost of $€ 3.5$. In the case, a tracking experiment on crates is described, and authors conclude that return percentages on crates are very high, close to $100 \%$. However, an exact return percentage for crates is not provided in the case. Periodically, a certain amount of crates, bottles and kegs are replaced because their image is no longer acceptable from the marketing point of view. In the case it is acknowledged that Heineken maintains large amounts of RPM in stock in order to avoid disruptions in the bottling processes. The firm's investments on new RPM have been traditionally based on experience and simple calculations. Physical flows in the analyzed brewery considered in the case are organized around a star network: all the crates labelled with that particular brand return to the same central facility.

In the Arla Food case, Johansson and Hellström (2007) describe the operations of a Swedish diary producer that distributes their products to retailers using different types of RTI, such as roll containers. The firm experiences difficulties in managing and controlling RTI. The information concerning how many units of RTI are in circulation or how much inventory is available in each location does not exist. Management estimates that they own roughly 120,000 units of RTI and that 10 per cent of the RTI fleet is lost annually due to theft and misplacement. $€ 2$ million are invested annually in order to substitute the lost RTIs. Each roll container has an estimated unitary cost of $€ 120$. Their reconditioning is simple as they just require inspection, cleaning and in some cases, minor repairs. Regarding physical flows, roll containers are exchanged between the dairy distribution centres and the retailers following the star model.

Ikea (Hellström 2009) uses steel containers for delivering products directly home to endconsumers. Steel containers consist of two components: a platform and side bars. Depending on the products to be delivered, different side bars are placed in different positions on a platform. The steel containers loaded with products are issued from IKEA distribution centres (DC) to 
the logistics hubs of the third-party logistic providers (3PLs). Then, 3PLs deliver the products to the end-customers and return the empty containers to the original IKEA's DC (star network). Reconditioning in this case consists of cleaning and assembly / disassembly of platforms and side bars. The fleet of platforms and side bars for one DC comprises 16,000 and 64,000 units, respectively. The estimated value of each component is $€ 170$ for a platform and $€ 20$ for a side bar. The total investment on RTI fleet for one DC is around $€ 4$ million. Roughly 10 per cent of the steel containers are lost annually.

Finally, we consider a case study on the use of returnable containers in the automotive industry (Roseneau et al. 1996). Ten vehicle assembly companies participated in the study. The assembly companies receive parts from their components suppliers in returnable containers built of steel (racks) or of plastic, high-density polyethylene. Each individual container is relatively inexpensive $(\$ 100-\$ 600)$ but the amounts invested in the complete fleet for one single assembly plant are astounding. The authors give figures of $\$ 16.3$ million and $\$ 35$ million for two different assembly plants. Containers are designed to resist harsh industrial environments and their reconditioning usually requires simply cleaning. Regarding the return rate, it is assumed in the automotive industry (Mollenkopf et al. 2005) that $5 \%$ of the container fleet will have to be replaced due to loss and damage every year. Management difficulties with reusable containers systems are acknowledged. As remarked by Twede and Clarke (2005): "Companies that excel at inbound and outbound logistical arrangements, such as the US automobile manufacturers, have not been so successful when it comes to managing their container fleets. Containers are routinely misdirected, inappropriately reused or lost and they are rarely tracked in system-wide information systems. [... JThe automotive industry's frustration with container control [...] led to outsourcing it to a third party". Regarding the organization of the physical flows, both star and multi-depot networks are possible in the automotive industry.

The three types of RA arise in this analysis. Shopping carts, Flora Holland, Arla Foods, Ikea and the automotive case studies deal with RTI. MedGas, LPG and Heineken cases concern RPM. Erasmus MC and service tools cases involve RP. In the ten cases, we deal with durable articles, designed for sustainability. Articles are used during short times, compared with their lifetime, enabling multiple use cycles. End users do not make distinctions between brand new and reused articles. Depending on the article being considered, reconditioning operations require different 
levels of complexity, but they remain simple when compared with repair, remanufacturing or recycling, as dissasembly of the RA is not required in any case. RTI's reconditioning tends to be simpler than RPM's. RP's reconditioning complexity varies depending on the article type. Firms assume that the volume of articles returning is very high (typically above $90 \%$ ), as most of the demand is fulfilled with used articles. However, it is very difficult for the companies to provide precise quantifications of the return rates. Usually, only losses due to damage are controlled (because they fall under the observable part of the supply chain) while losses due to misplacement or alternative use of RA by other supply chain agents are not controlled (these losses take place in the unobservable part of the supply chain). In all the cases, new articles have to be bought from time to time in order to replace misplaced, lost or irreparably damaged articles. The RA fleet is constituted by many units of relatively inexpensive articles. Nonetheless, the amounts invested in RA fleets are remarkable in the ten cases. Besides, all the organizations we analyzed were dissatisfied with their performance when it came to management of RA. In order to avoid problems to make demand and returns of RA meet, many firms tie-up large amounts of capital in high inventories of RA.

\subsection{Case studies detailed description}

Case studies description is organized as follows. After a short introduction to the context in which each case study has been developed, we address the reusable articles' characteristics (special features, reconditioning process, etc.), the dimensions of the RA fleet size in each case, the organizational design of the RA system, issues related with RA losses (fleet shrinkage) and the more relevant management challenges within each case.

\subsubsection{Case 1: Gas cylinders in a multinational chemical company (MedGas)}

Context. The first case concerns a multinational company producing and distributing industrial and medical gases. Our interaction took place with the Spanish subsidiary of this corporation. The firm's main productive process consists in liquefying and then distilling atmospheric air in order to obtain oxygen, nitrogen and some noble gases (argon, helium). Through a different chemical process, carbon dioxide and hydrogen are also obtained. All this gases have multiple 
applications in industry and healthcare and can be delivered to the final customer by different means: pipelines, bulk (using cryogenic tank trucks) or cylinders.

Reusable article's characteristics. Inside the cylinder, gases are compressed and the vessel reaches an internal pressure of around 200 bars. Cylinders are designed to resist high pressures: typically manufactured in steel or aluminium alloys, a standard $50 \mathrm{l}$ cylinder has an estimated unitary cost of $€ 100$, making cylinder reuse the only economically viable option. Vessel owner is legally responsible to test them every 2,5 or 10 years, depending on the physical-chemical characteristics of the gas contained. These periodic tests include an hydraulic test (in which the cylinder shall withstand a given test pressure, which is usually 1,5 times the working pressure) and eventually, some complementary tests, such as ultrasonic inspection. This periodic test requires specific instrumentation and needs to be carried out in a focused facility.

The focus of this case study is on the healthcare branch of the company, where the more important cylinder-delivered gas product is medical oxygen compressed in the so-called compact cylinders. This product presents a marked seasonality, as consumption during winter months is around a $50 \%$ higher than in the low season (summer), due to the higher incidence of respiratory diseases in winter.

Fleet size. Cylinders are owned by the gas company. The compact cylinder fleet size is estimated in roughly 20,000 units for serving the Spanish market. This represents an investment of $€ 2$ million only for this particular product. Each individual cylinder does not represent an important investment, but the enormous amount of them in circulation make that, collectively, cylinders constitute a relevant amount of tied-up capital. This calls for considering the cylinder fleet an asset.

Investments in cylinders are gas specific: filling a vessel prepared for oxygen with a different gas is not allowed, due to security reasons. Therefore, unfortunately, sharing the same cylinder fleet for different gas products is not possible.

Organizational design. The structure of the closed-loop process followed by medical oxygen cylinders is depicted in Figure 4. The solid grey coloured elements in the upper part of the figure represent the full cylinders, whereas the stripped ones in the lower part represent the empties. The four agents participating in the closed-loop system are depicted in columns (filling plants, distributors, customers and testing centers). 


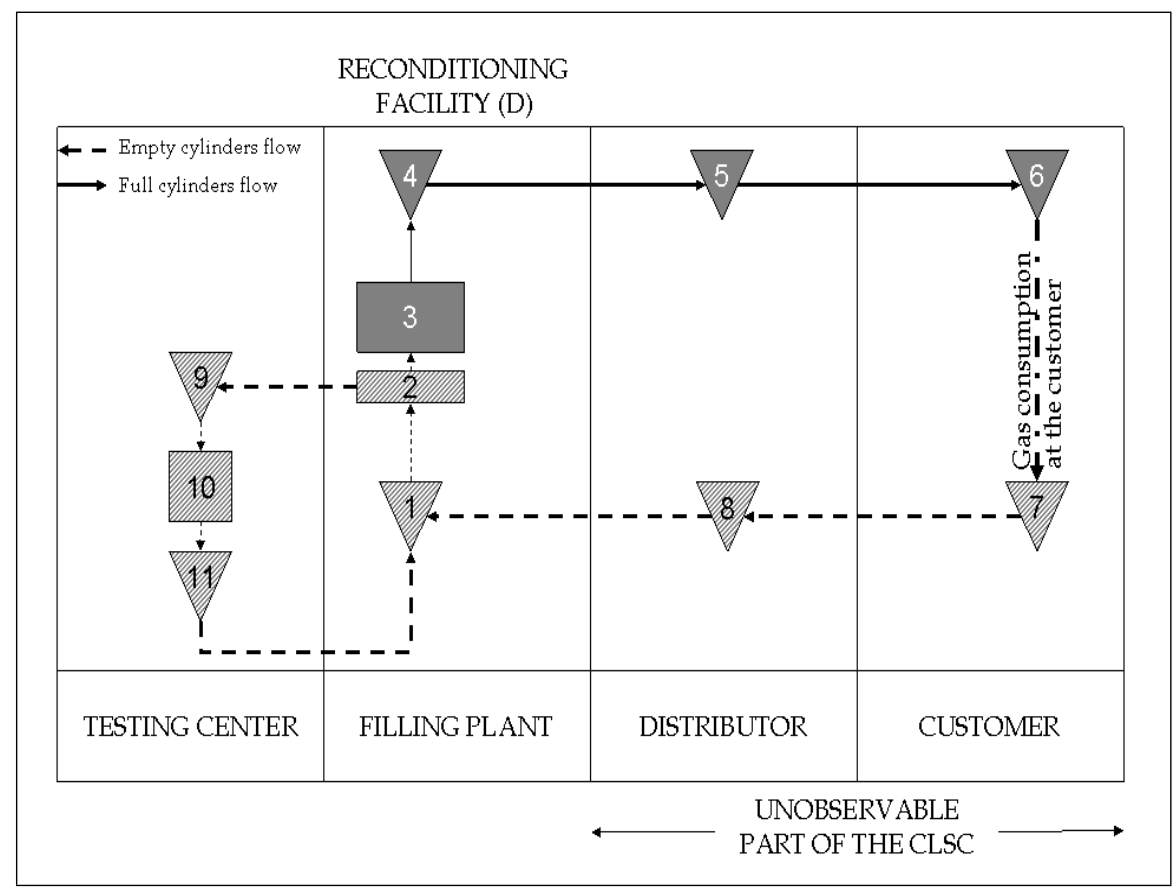

Figure 4-4: Closed-loop supply chain of medical oxygen cylinders.

Stock number 1 represents the stock of empty cylinders at the filling plant. At their arrival, cylinders are visually inspected (2) in order to separate those for which the hydraulic test has expired and need to be sent to retest $(9,10,11)$. Cylinders found suitable for refilling go into the automatic filling installation (3) and enter the stock of full cylinders (4), from which customers orders are retrieved. Depending on their size and geographical proximity to the filling plant, end customers are served from an intermediate distributor (5) or directly from the filling plant (in that case, stocks 5 and 8 do not apply). Once the contents of the cylinder is used up (7), the vessel can return to the filling plant using the same logistic circuit used for delivering full units (7-8-1). Empty cylinder recovery takes place at the same moment of full cylinders delivery. Typically, customers are delivered only as many full cylinders as empty units they can give in exchange. The company call this practice full-for-empty swapping or equal exchanges policy. As the same logistic circuit is used for deliveries and returns, empty cylinders always return to the same filling plant, so the physical flows in this case follow a star model. Integrating in the same vehicle forward and reverse flows of cylinders enables the company to obtain transportation 
cost savings by using the backhauls of the delivery routes.

Fleet shrinkage. Regarding losses, the company controls the number of cylinders that are scrapped due to their bad condition and these assets are retired from the account balance. Nevertheless, the control over cylinders lost in the unobservable part of the supply chain (customers, distributors) is very limited. In order to ensure cylinder recovery, the firm only relies on incentives aiming at inducing the desired behaviour in supply chain partners. Two control mechanisms are applied in this supply chain. First, the above mentioned equal exchanges of full-for-empty swapping policy (a). Second, account management with periodical payments (b). The (b) control mechanism consists in registering in the information system (ERP) the incoming and outgoing cylinder quantitites from a given customer. This information, which is available in the delivery notes, enables us to re-build the RA inventory at the customer at any given time. Then a dialy rental is charged to the customer depending on the number of RA in inventory each day. The payment for this daily rental is reclaimed at the end of each invoicing period (the month).

These control policies are useful for preventing cylinder losses ((a) and (b)) and enhancing cylinder rotation (only (b)), but they do not provide any information about the number of cylinders lost outside the filling plant. Hence, the return rate is not known with accuracy. Besides, the two control policies are not always applied. Some big customers, such as hospitals, have a greater bargaining power and do not accept clauses in their contracts involving payments for cylinder tenancy. In such cases, management has reported a worse behaviour of cylinders in terms of return rate (more cylinders are lost by these customers) and cycle time (these customers do not have any incentive to return cylinders as soon as they are used up).

Management challenges. Operations management department executives acknowledge that uncertainty about the cylinders returns (timing, quantity, quality) makes difficult to match oxygen demand with empty cylinders returns. The balance between demand and returns is ensured by mantaining large amounts of cylinders in stock.

The role of the high inventory levels of cylinders in RA systems is shown up in this case study. When new governmental regulations classified medical oxygen as a medicament, additional requirements were introduced regarding quality assurance and traceability for medical oxygen filling and distribution. Top management decision was then to separate industrial and medical 
oxygen flows, and concentrate medical oxygen filling in a set of new facilities especially conceived for fulfilling the new legal requirements. This meant a complete reorganization of the logistics flows for medical oxygen, which introduced extra travelling distances between the reconditioning facilities (the filling plants) and the customers. Cylinder's cycle times increased (in general) in the new scenario. The number of required cylinders in the new situation (a new fleet size dimension) was not, however, reconsidered in the redesign of the logistical system. When the new system went live, multiple operational troubles were encountered because of the lack of cylinders. Availability of empty cylinders to be refilled became a major bottleneck which had to be solved by adding extra production shifts or by delivering and collecting at customers more frequently. In the long term, investments in new cylinders had to be done. The larger cycle times called for a larger cylinder fleet. As new investments in cylinders were not foreseen in the new medical logistic system, the cylinder inventory level was not sufficient to mitigate the lack of information about cylinders returns. This experience shows the existence of an industrial need for deepening in the understanding of design and management of reusable articles systems.

\subsubsection{Case 2: LPG cylinders in a petrochemical company}

Context. The second case concerns Repsol GLP, the liquefied petroleum gas (LPG) division of Repsol group. The LPG division has operations in Spain (where it holds a market share of roughly $80 \%$ ) and the neighbouring countries (France, Portugal) and several iberoamerican countries (Ecuador, Peru, Argentina, Chile and Brazil). While LPG consumption grows in the developing countries, in the advanced economies LPG is a very mature or even declining market, where domestic use of LPG is being strongly substituted by safer or cleaner alternatives such as natural gas or renewable energies.

Reusable article's characteristics. In this case study we focus in LPG for domestic uses delivered in cylinders. LPG cylinders are similar to the vessels described in the previous case (MedGas), but their security specifications are less demanding. The pressures inside the LPG vessel do not exceed 20 bars (propane and butane are liquefied inside the cylinder), so the constructive steel of the LPG cylinder do not need to be as resistant as in the previous case. Therefore, the value of the LPG cylinders is lower than the value of oxygen cylinders. The unitary price of each LPG cylinder is estimated in $€ 20$. LPG cylinders are also periodically 
tested in order to check the vessel's resistance to working pressure's stress. Like in the previous case, the hydraulic test for LPG cylinders takes place in specialized plants. Then, regular empty cylinder transfers between filling and testing plants are required.

Fleet size. For serving the Spanish LPG market, Repsol holds a fleet of 30 million cylinders. Assuming a unitary price of $€ 20$ per cylinder (estimated figure provided by Repsol management), this represents a value of $€ 600$ million. Of course, as cylinders technical life is very long, much of the cylinder fleet book value has been written down in the balance sheet a long time ago. LPG in Spain is a declining market and new investments in cylinders are not expected for this market. Repsol management acknowledges that their cylinder fleet size is currently overdimensioned for the company's operational needs. Maintaining such a big fleet of cylinders has financial-economic consequences, not only in terms of space and handling, but also in terms of maintenance. As LPG cylinders need to pass their hydraulic test every 10 years, every year some 3 or 3.5 million cylinder are sent to the testing plants in order to receive specialized maintenance (hydraulic test and painting). After this maintenance, the cylinder is as new, and in fact a new serial number is engraved in the body of the cylinder. Maintenance has an estimated cost of $€ 3$ per cylinder, so the maintenance invoice roughly represents annually around $€ 9$ million. A smaller fleet would require fewer units to be sent to maintenance. There is also an opportunity cost, as the exceeding fleet could be scrapped and then recover the value of the constructive material (steel). Cylinders can also be sold to countries where LPG is a growing market, such as for instance, the Indian market or the markets in other developing economies. With annual growth rate figures of up to $9 \%$ for LPG, companies operating in these countries need to invest in new cylinders for covering the growing demand.

Organizational design. The logistical scheme used for distributing Repsol LPG cylinders is very similar to the one depicted in Figure 4 for the previous case. The agents in the supply chain are again the filling plant, its distributors, the end customers and the testing center. In this case, the filling plant do not directly deliver any end customer, distributors are always used instead, so stocks (5) and (8) always apply.

As in the previous case, empty cylinder recovery follows the same logistic circuit used for full cylinders delivery. The full-for-empty swapping or equal exchanges policy also applies in this case for cylinder exchanges between filling plants / distributors and distributors / end- 
customers. The same vehicle route delivers full LPG cylinders and recovers the empty ones. As cylinders are heavy packaging elements, is important to achieve transportation cost reductions by using the equal exchanges policy. Cylinders always return to the same filling plant, so the physical flows are organized following a star model.

Regarding the exchanges with the testing center, empty cylinders that need to be tested (expired hydraulic test) are put aside in the filling plant. When a sufficient transportation lot size is achieved, a vehicle is shipped to the testing center. Tested cylinders ready to enter the filling circuit are sent in the return leg of this trip.

Fleet shrinkage. Cylinders are scrapped when their repair is not economical anymore. This decision is taken in the filling plant. Scrapped cylinders (assets) are written down of the balance sheet. However, cylinders are also lost at the distributor and end customer stages, but these leakages in the unobservable part of the channel are not controlled. The exact LPG cylinder return rate is then unknown.

Control mechanisms are also introduced in this case in order to incentivate cylinders returns from end-customers and distributors. First, the equal exchanges policy, that has already been explained. Second, the use of deposits. The first time a customer is delivered with LPG a certain amount (between $€ 10-€ 20$ ) has to be paid to the distributor for each of the cylinders delivered. Customers can reclaim the deposit once they do not need to use LPG anymore. Deposits only apply in the distributor / end-customer exchanges.

Management challenges. The cylinder fleet owned by Repsol is currently oversized for the LPG demand in the Spanish market. Thanks to this large cylinder inventory, Repsol filling operations run quite smoothly, even in the peak demand periods of the year (winter). Management is concerned with the financial-economical consequences of mantaining such a huge amount of cylinder inventory in the system, not only in terms of space and handling, but also in terms of manteinance. However, in order to reduce their cylinder fleet size, Repsol needs to define the number of cylinders that suits their current demand and operational requisites. Management affirm that the lack of a methodology for determining the cylinder fleet size dimension (and also the lack of information on cylinders' life-cycle parameters) are the main factors hindering the readjustment of the cylinder fleet size. 


\subsubsection{Case 3. Surgical material at Erasmus MC}

Context and reusable article's characteristics. Erasmus MC is a large academic hospital in the Netherlands. As many other clinical institutions, Erasmus MC holds a stock of durable surgical instruments that are sent to sterilization after each use. A closed-loop flow is established between the operating theatres and central sterilization department of the hospital, who manages the inventory of used and sterilized instrumentation and is in charge of performing all the reconditioning operations required to leave instrumentation ready for the next use. Surgical instruments are typically grouped in the so-called "nets", a set of tools specific for a particular type of surgery.

In this case we are not considering a reusable packaging element but an article itself that is reused by multiple different users $(\mathrm{RP})$.

Fleet size. Although Erasmus MC central sterilization department could not provide exact figures, they acknowledge that the amount invested in the total instrument inventory has a magnitude order of millions of euros. Approximate values we worked with in this case were $€ 100$ per single instrument and then $€ 10,000$ per a complete net with 100 items.

Organizational design. The sterilization cycle comprises the following phases. The sterile instruments/nets are stored near the operating theatres. Some time before every operation (as prescribed in the corresponding protocol) the required instruments are retrieved from the sterile inventory and brought to the operating theatre. After the operation, the used instruments are placed in a non-sterile inventory from which they are collected and brought to the central sterilization department (CSD). Upon receipt, the instruments are registered in the information system and then washed and disinfected in autoclaves. Before going to sterilization, the nets are checked for completeness. Any missing or defective instrument is replaced or repaired at the CSD. When nets are complete and sterile they are registered in the information system and finally taken to the sterile storage near the operating theatres. Being the CSD the only sterilization unit in the hospital, the physical flows for the surgical instruments follow a star model.

Fleet shrinkage. Along this cycle some tools can get lost or result irreparably damaged. Although the percentage of losses could not be exactly determined by CSD management, they do not consider instruments leakage as a problematic issue; annual losses are estimated to be 
below $5 \%$ of the total inventory.

Management challenges. Even if instrument losses do not seem problematic, CSD management is not satisfied with their current performance regarding the management of instrument inventory. For some types of instruments there are substantial under- stock (and hence, a serious need for additional instruments) while for other instruments types there are serious over-stock. Many sterilization orders are placed as rush orders, which are five times more costly than regular orders.

\subsubsection{Case 4. Service tools}

Context. This case study is framed in the context of the Service Logistics Forum (SLF, 2009), a knowledge platform in the Netherlands comprising several Original Equipment Manufacturers (OEMs) and some Dutch universities. The aim of the SLF is to develop and share knowledge on Service Logistics topics.

OEMs perform preventive and corrective maintenance actions in order to fulfil the service contracts agreed upon with their customers. In order to carry out these maintenance actions, firms need spare parts, service engineers and service tools. The OEM has to decide the stock levels of spare parts and service tools at each service location, as well as how many service engineers have to be hired, in order to meet the service target while the systems costs are minimized.

In the context of this case, the analyzed firm stored service tools in local warehouses near the customer factories. Each of these warehouses gives service to several machines installed in a region. When tools are needed, they are taken from this local warehouse and sent to the factory needing a maintenance action. After use, the service tools are returned to the warehouse.

Reusable article's characteristics. Service tools collection includes a wide variety of instruments of heterogeneous characteristics. The complexity of the reconditioning operations depends on the type of tool considered. Many tools just require cleaning while others, such as welding equipment, need to have their consumables replaced. The price of service tools is also variable and ranges from very cheap to very expensive. Cheap tools that are demanded very often are usually available in the standard tool boxes service engineers carry with them(one single user). Hence, these cheap tools cannot be considered RP as we defined them in section 
3.1. More expensive tools are stocked in the local warehouses from where they are lent to multiple different service engineers. The focus of our case is then on this borrowing system, which fulfills the requisites to be included under the RP category.

Fleet size. If service tools stock levels in the local warehousesare are not optimized, they may lead to large investments for the OEM. The amount invested in service tools inventories is estimated in the millions of euros, but it could not be exactly quantified by OEM management. The inventories of service tools have traditionally received little managerial attention and information about them is scarce and not always reliable.

Organizational design. Each customer location is assigned to a service tools local warehouse. When manteinance is needed, service engineers borrow the required instruments from the corresponding local warehouse. After use, the service tools are returned to the issuing warehouse. Obtaining service tools from other warehouses (emergency supply) is also possible but, after use, service tools return to the warehouse they belong to. Then, the physical flows of service tools are organized in this case following a star network.

Fleet shrinkage. Eventually, some service tools may return damaged after a manteinance action. Local warehouse personnel decides if damaged tools can be repaired or they are discarded (quality losses). Discarded tools are written off and replaced. Some tools are lost because of misplacement or opportunistic usage by other parties. All in all, the percentage of lost tools is very small and OEM mangement did not find it a burdensome aspect.

Management challenges. OEMs participating in the SLF consider that service tools inventories have received much less attention than other parts of the business, such as the inventories of spare parts. Given the large amounts invested in service tools inventories, managers have expressed their interest in developing models and methods for determining the optimal "fixed circulation stock level" for each service tool With this term, we refer to the total inventory of service tools (either on stock at the warehouse or at the machine for repair purposes) required for providing a given service level.

\subsubsection{Case 5. Shopping carts in retail shops}

Context. This case study was developed after our interaction with a large retailing chain in the Netherlands. 
Reusable article's characteristics. Trolleys used in retail shops constitute one of the few examples of RTI use in B2C settings. The recovery incentive typically used in this case is a deposit that the customer recovers once the shopping cart is back in one of the service points (the "depots"). When taken back to the service points by customers, carts are "reconditioned" and ready for the next use. Cleaning operations and minor repairs are carried out periodically by the retail shop personnel, too.

Fleet size. The unitary price of a shopping cart in the Netherlands varies between $€ 152$ and $€ 175$, depending on the model. A trolley fleet size between 200 and 400 units is considered within the regular limits for a medium-size retailing surface in this country.

Organizational design. Small retail shops generally have only one service point for retrieving and taking back the carts. In this case, trolleys physical flows follow a star model. In big retail centres, where more than one trolley service point is available, carts are managed in a multidepot network, as they can be returned at any available depot.

Fleet shrinkage. In this particular case, involving a retailer in the Netherlands, roughly 3 per cent of the cart fleet is lost annually. This figure includes not only quality losses (which are controlled by the retailer and correspond to the carts taken out of the system because of irreparable damage), but also incidental and structural losses. These two latter losses types remain out of retailer's control and include cart misplacement, alternative usage by customers, etc. In other markets, trolley fleet shrinkage may represent a more problematic aspect: Breen (2006) reports that UK retailers lose 16-18 per cent of their trolley fleet every year.

Management challenges. Retailer management highlighted three main questions related to the operation of the trolley system. First, how can trolley losses be prevented. Second, how to assure that the number of shopping carts in the depots is sufficient to meet cart demand. In other words, management needs to define the required cart fleet size. Note that demand in this case presents weekly seasonality, with peak periods on weekends. Trolley fleet size has to be adjusted to these intense-demand periods. Finally, a last issue arising, particular of the multi-depot trolley networks, is the need for rebalancing shopping carts between locations so that the inventory level in all the depots is sufficient to meet cart demand in each of them. 


\subsubsection{Case 6. Flora Holland}

Context. Flora Holland is a Dutch firm operating flower auctions in the Netherlands. Given the predominant role the Netherlands play in the horticultural sector at international level, Flora Holland has become the leading matchmaker and intermediary between worldwide demand and supply of cut flowers and plants.

Flora Holland runs six auction houses where growers supply their production and buyers bid in the so-called auction clocks (which follow the reverse auction or Dutch auction bidding system). In order to reduce the number of handling operations that such delicate products as cut flowers and plants have to undergo during the horticultural supply chain, growers, buyers and transporters use an industry-wide packaging standard. The use of standard RTIs avoid unnecessary repackaging operations when product ownership changes. As the central actor of the flower supply chain, Flora Holland is in charge of managing the pool of RTIs for the floricultural industry. Growers and buyers rent the packaging equipment they need from Flora Holland.

Reusable article's characteristics. The stapelwagen (aluminium metal cart) constitute the most important logistical carrier for plants and flowers within the floricultural sector and has positioned itself as a industry-wide standard. These metal carts are specially designed for the transportation and storage needs of the floricultural industry. The stapelwagen has three moveable shelves which the user may position at various heights. Its reconditioning operations are very simple, requiring just cleaning and sometimes minor repairs.

Fleet size. Each cart has an approximate price of $€ 500-€ 600$ and Flora Holland owns a stock of roughly 50 thousand carts (involving an investment of around 30 million $€$ ).

Organizational design. Flower and plant growers supply their products to one of the six auction houses already packed in stapelwagens. When received, products are exhibited to potential buyers in clock conveyors constituted by chains of these metal carts. Once the stapelwagen has a new owner, it is sent the buyers address. The buyer can return the empty stapelwagen to any of the six auction houses Flora Holland operates. Growers rent the empty stapelwagens from their nearest auction house. Hence, the physical flows in this closed-loop supply chain are organized following the multi-depot model.

Fleet shrinkage. When stapelwagens are irreparably damaged they are retired from the 
circuit and replaced by new units. Other types of losses are not tightly controlled, but Flora Holland management do not consider them problematic neither in the grower's part of the supply chain nor in the buyers' side. The stapelwagen return rate is not known with exactitude.

Management challenges. Regular rebalancing shipments have to be carried out between auction houses so that the stapelwagens inventory levels correspond to demand in each auction house. Linear programming models can be used to determine the intensity and sense of rebalancing flows among auction houses.

\subsection{Conclusions}

In this chapter we have provided a conceptual structure for deepening our understanding of CLSC of reusable articles. After exploring the literature related with this topic, we concluded that empirical research on reusable articles management is quite scarce. Knowledge on reuse CLSC is fragmented and scattered and only considers some particular situations in which reuse is involved. We have proposed a definition and a typology for RA, which integrates three different categories of RA (RTI, RPM and RP). Our framework highlights the similarities and differences between the three categories. We have also defined two different models for physical flows

configuration in RA networks (star and multi-depot models).We claim that the commonalities found between RTI, RPM and RP's logistics characteristics enable us to generalize results and best practices obtained for one particular category of RA to the others. Our claim is grounded on a set of 10 case studies comprising different industrial situations in which reuse is involved.

This chapter contributes to scientific literature by integrating the view of RTI, RPM and RP As our case studies indicate, reusable articles involve management difficulties that do not arise in supply chains utilizing single-use articles. But on the other hand, reusable articles contribute to natural resources preservation by reducing the amount of waste that firms generate. When well managed, RA also provide interesting cost reductions. Mitigation of the management difficulties related with RA contributes to facilitate the shift from a use-and-dispose model to a reuse one. 


\section{Chapter 5}

\section{Development of a conceptual model for the management of closed-loop systems of reusable articles}

\subsection{Introduction}

Management of closed-loop supply chains of reusable articles (reuse CLSC) is not straightforward. Many companies that have turned into reusable packaging from disposable packaging materials have encountered difficulties in managing their fleets of reusable articles. In the automotive industry -a sector widely recognized for the excellence of their logistics procedures- many assemblers have decided to finally outsource the ownership and management of the reusable packaging they use (crates, racks, etc.) to a third party, given the problems encountered when substituting disposable packaging elements for reusable ones (Roseneau et al., 1996, Witt, 2000). Other industries where reuse has been practiced for a long time, such as beer brewers or sterilization centres, report similar management difficulties (Breen, 2006; Wyld, 2009). Reusable articles constitute a shared resource in the supply network: they travel beyond the boundaries of the organization and their control involves several actors (suppliers, manufacturers, distributors, end customers) having different objectives and incentives. Their management requires a good amount of coordination and incentives alignment, as well as information sharing. 
In this chapter, we build upon the the results presented in chapter 4 and propose a conceptual structure that condenses the management issues arising in reuse CLSC. The model includes three additional building blocks: common problems, basic information requirements and management issues. In addition we propose in the chapter several solutions to some of the issues: we analyze different control strategies available and we propose a methodology for calculating the fleet size; we also point out further research opportunities regarding inventory control models for reuse CLSC. The complete model made up with the elements provided in chpater 4 and 5 intends to contribute to academic knowledge and to industrial practice by providing a conceptual model for the management of closed-loop supply chains of reusable articles. This framework intends to be a guideline for practitioners in order to identify the more relevant management issues in which they have to focus on. In addition, we propose several solutions for helping managers to deal with these issues.

The empirical support for the results presented in this chapter includes two cornerstones: (a) our direct experience about the managerial concerns involved in reusable articles CLSC, and (b) the contrast of our understanding with existing related literature. The first element -(a) experience-, has been acquired through our past professional career (dealing with reusable cylinders) in industry and through our involvement in six case studies conducted in real industrial settings (cases 1 to 6 ). The second element, (b) contrast with literature, includes four additional case studies that other authors have reported with enough detail in the academic literature (cases 7 to 10). Besides, we also support our statements throughout the text on the results from other researchers published in the general literature review about reuse CLSC that we have carried out simultaneously. The management model proposed in this chapter has been contrasted and enriched with the comments from operations managers in some of the companies where case studies have been carried out (more specifically, MedGas company, case \#1, and LPG company, case \#2).

Case studies detailed description can be found in Chapter 4, section 4.5.

The reminder of the chapter is organized as follows. In section 5.2, we identify and describe the three common problems found in reuse CLSC. Next, in section 5.3 we present the basic information required to manage a CLSC of reusable articles. The main issues in which managers have to focus on in order to achieve more efficient operations in reuse CLSC are listed and 
explained in section 5.4. Section 5.5 presents some of the solutions that have been analyzed. More precisely, we propose and analyze a set of control strategies aiming at the prevention of fleet shrinkage and the promotion of rotation in reusable articles systems. In section 5.6, we propose a methodology for determining the fleet size in reusable articles networks (star and multi-depot). Section 5.7 analyzes some preliminar developments on purchasing policies. Finally, in section 5.8we present the conclusions of this chapter.

\subsection{Building block 1: Common problems found in reuse closed- loop supply chains}

\subsubsection{Fleet shrinkage}

Typically, in reuse CLSC the fraction of articles returning and being reintroduced into the system is high, when compared with other types of CLSC, such as those involving commercial returns or remanufacturing. For commercial returns, an average return rate of $12 \%$ in catalog sales is a standard (Toktay et el., 2004), with return rates varying by product category (up to $35 \%$ for high-fashion apparel). In retail sales, large retailers such as Home Depot, can have return rates of $10 \%$ of sales, or higher, because of liberal returns policies (Guide and Van Wassenhove, 2009). Regarding remanufacturing CLSC, we can cite the example of Volkswagen. In their automotive parts remanufacturing program, the firm reports a material reuse quote, from the share of original engines and transmissions recovered from the market, ranging between $50 \%$ and $80 \%$ depending on part type (50\% of the recovered cylinders heads are remanufactured while in the case of camshafts the percentage reaches 80\%) (Momberg, 2009). In contrast, in reuse CLSC, returns rates are very high, typically ranging between 80-99\% (Carrasco-Gallego et al. 2009a) and many articles are almost directly reusable. Although the return rate is not always easy to quantify with precision (section 5.3), we can provide some approximations coming from literature and our case studies: wooden pallets loss rate: 9-10\% annually (Ilic et al., 2007), beer kegs loss rate: 4-6\% annually (Fluensee, 2010), Medgas cylinders loss rate: 5\% annually (Case \# 1). A return intensity not too far away from 1 is one of the particular characteristics that make reuse CLSC different from other CLSC (c.f., for instance, Fleischmann et al. 2002).

However, even if in reuse CLSC most demand is fulfilled with used products (which are a 
perfect substitute for all-new ones), all the RA sent to the market will not return to the system in order to enter in a new reuse cycle (the system cannot be considered exactly as a closed system). The fact that there are "leakages" in the fleet of reusable articles is widely recognized either in academic and practitioners-oriented literature (Academic literature: Kelle and Silver, 1989a; Roseneau et al., 1996; Fleischmann et al., 2000; Breen, 2005; Mollenkopf et al., 2005; Twede and Clarke, 2005; Johansson and Hellström, 2007; Hellström, 2009; Thoroe et al., 2009; Ilic et al., 2009; Martinez-Sala et al., 2009. Business-oriented literature: Witt, 2000; Bryson, 2005; Wyld, 2009; Fluensee, 2010).

Fleet shrinkage arises when some articles are irreparably damaged, misplaced or stolen. Hence, we classify shrinkage causes in quality losses, incidental losses or structural losses.

Quality losses refer to RA that have resulted so damaged during their use phase that their reconditioning is not economically viable anymore. How relevant quality losses are depends on the characteristics of the RA considered and more precisely, on its durability. Steel cylinders and kegs can last more than 50 years if properly maintained and checked (Case studies \#1 \& \#2). Plastic crates and containers can have an expected operational lifespan of more than 10 years (Roseneau et al., 1996; Martinez-Sala, 2009). On the contrary, electronic medical devices lent by national health services (Rudi et al., 2000) have short average life cycles due to technological obsolescence and to articles inherent fragility. Geyer et al. (2007) discuss reusable components limited durability and provide for some reusable articles their maximum number of lives (glass bottle: 25 cycles; wooden pallet: 50 cycles; crates for bottles: 120 cycles).

Incidental losses refer to RA that do not return to the system for unexpected or "nonorganized" reasons, such as fortuitous misplacement or loss by customers or other supply chain agents. These RA are subject to return back to the system after a having been declared as lost articles, if they are finally found.

Structural losses refer to articles not returning due to deliberate fraud to the owner. For instance, industries that use metallic containers (such as kegs or cylinders) know that their loss rates are linked to the steel and aluminium prices in the commodities markets. Some metallic containers will not return to the owner, because they are stolen for their scrap value (Bryson (2005), Breen (2006), Wyld (2009), Case studies \#1 \& \#2). The existence of an illegal secondary market for pallets (RTI that are theft for resale) is also documented in literature 


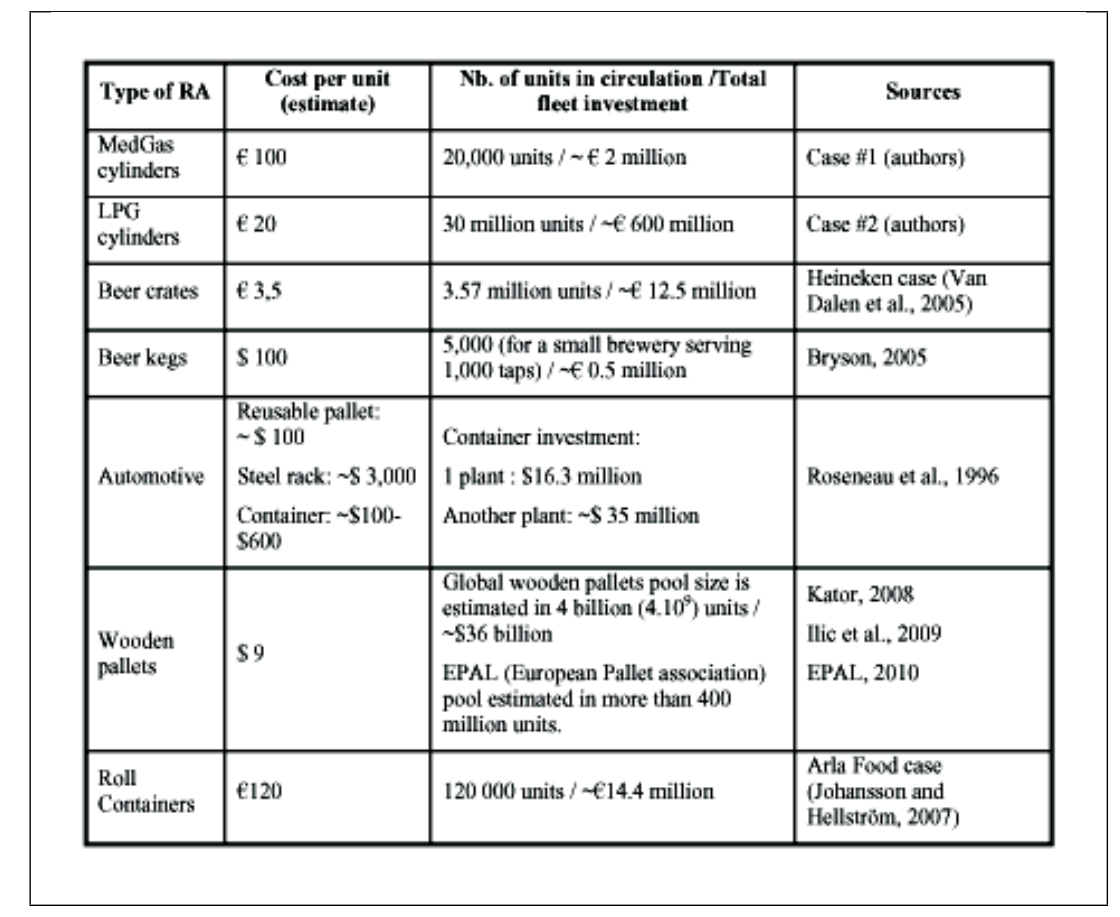

Table 5.1: System-wide investment in reusable articles fleet. Own development.

(Breen (2006), Ilic et al. (2009)).

\subsubsection{Significant investment}

The cost of one RA unit can range from relatively inexpensive articles that are $€ 3.5$ worth (beer crate) to high-value items costing thousands of euros (automotive racks). It is not exceptional that the value of a reusable packaging element (RTI or RPM) surpasses the value of its contents. It is also typical that enormous amounts of low, medium or yet high value units are required to run operations. Therefore, even in the case of relatively inexpensive reusable articles units, when the system is considered as whole, the amount of capital immobilized in the form of a fleet of RA can become really significant. For instance, Roseneau et al. (1996) reported of investments in reusable containers for a single automotive assembly plant of up to $\$ 35$ million, where each container was $\$ 100-\$ 600$ worth. Table 2 lists some selected examples extracted from our own case studies and literature.

Given the impressive amounts invested in the whole fleet, reusable articles should be considered as corporate assets. However, the fact that each individual article is relatively inexpensive 
leads them to be considered many times as expensed items. (Roseneau et al., 1996; Guintini and Andel, 1994). Internally, many times reusable articles do not meet the minimum value for the accounting department to be considered a corporate asset. In addition, the fact that the investment in reusable articles is usually phased, making many little purchases over a long period of time, also contributes to consider them internally as an expensed item instead of an asset. Besides, supply chain partners often do not realize of reusable articles' intrinsic value and tend to neglect their caring and quick return.

\subsubsection{Limited visibility}

Reusable articles are not kept in a single location. They constitute a shared resource that can be located either in the sites of different supply chain partners or in transit between locations. During the "customer-use" stage, articles remain out of the control of their owner (Bryson, 2005; Inaba, 2008; Ilic et al., 2009; Thoroe et al., 2009). However, the relative low unitary value of reusable articles has rendered difficult to justify a tight monitoring over each unit in the past (Kelle and Silver, 1989a, Toktay et al., 2004). The benefits derived from enhanced visibility (value of information: Ferrer and Ketzenberg, 2004; Ketzenberg et al., 2006) over the "customer-use" phase did not overcome in many cases the costs of obtaining such information (administrative workload, IT investments). When the value of each unit justified the costs derived from individual tracking, item-level monitoring has been eventually implemented with the technology available at the moment. Note that although modern item-level monitoring systems are supported by automatic identification technologies, such as radio-frequency identification (RFID) or bar codes, tracking can also rely on "manual/visual" recognition of a serial number which is then simply registered with pen and paper or in a spreadsheet. Think for instance in the check-in and check-out data registered by car rental companies (Edelstein and Melnyk, 1977; Fink and Reiners, 2006; Hertz et al., 2009).

As a result, historically, in business practice reusable articles were not serialized nor itemlevel tracked and their monitoring was based only on account management. Account management consists on registering aggregate issues and returns of articles in a given location (plant, distributor, customer) over the course of time, but without identifying which particular article has been issued or returned. We refer the reader to Swinkels and van Esch (1998), Kärkkäinen 
et al. (2004), Case Study \#1 (Medgas) and Case Study \#2 (LPG) in order to delve into how account management works. Although this type of aggregate data is useful for some purposes, the lack of item-level monitoring results in very limited visibility in the customer use stage of RA life cycle (unobservable part of the supply chain) (Bryson, 2005; Johansson and Hellström, 2007; Inaba, 2008; Ilic et al., 2009, Thoroe et al., 2009; Wyld, 2009). Lack of visibility makes difficult to obtain accurate information about how many articles are lost in the unobservable part of the supply chain, how long does it take for a reusable article to return to a depot and be ready for reuse again or how many articles are available at each location of the supply chain.

In the last few years, however, the cost of tracking technologies (RFID, bar codes, associated software) has steadily decreased. As advocated in McFarlane and Sheffi (2003) and Sheffi (2004), many companies have started to experiment with RFID technology by launching pilot applications in their reusable articles fleets (sub-conveyances in the terminology used by the authors). Besides, new stricter regulations on food and medicines (Regulation (EC) No. 178/2002, Regulation (EC) No 726/2004) have forced many companies operating in those sectors to reengineer their business processes in order to assure product traceability (and proper product recall if needed). As a result, the number of item-level tracking applications for medium value reusable articles has been increasingly growing in the last few years. Some recent case studies include Hellström (2009), Ilic at al. (2009), Thoroe et al. (2009), Martínez-Sala et al. (2009) or Carrasco-Gallego and Ponce-Cueto (2009c) with the description of "Leche Pascual" case (a Spanish company from the agro-food sector). In all these experiences, authors coincide to highlight that enhanced visibility over the customer-use stage of RA lifecycle (accompanied by proper actions and continuous management attention) results in a reduction in the number of units in circulation (fleet size downsizing) and in a cutback of fleet shrinkage rates.

\subsection{Building block 2: Basic information (metrics)}

Beside articles demand characteristics, three metrics have been identified as the basic information required for managing a CLSC of reusable articles: return rate, cycle time and on-hand inventory in each location. We discuss them in turn.

Return rate is defined as the probability that a RA will eventually return to the depot after 


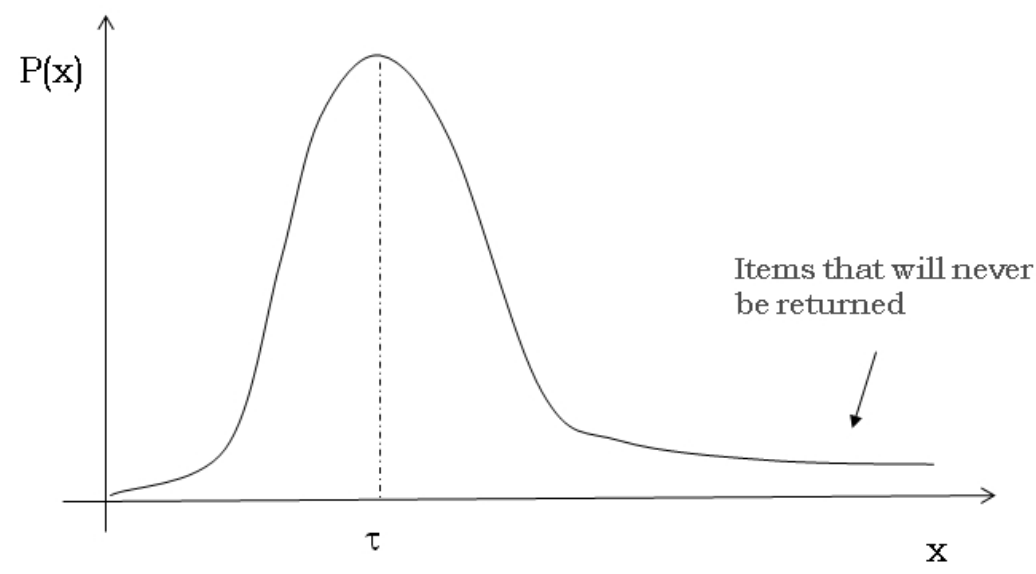

Figure 5-1: Cycle time distribution (includes a finite probability of not return). Own development.

having been issued to the market.

Cycle time is defined as the time elapsed between the issue of an article and its return to the depot in condition to be reused again. Cycle time comprises: (a) the time spent in storage in all the stages of the forward and reverse supply chain (manufacturer, distributors, retailers, etc.), (b) the time required for transportation between the different locations, (c) the time spent in the use stage at the customer, and also, (d) the time spent in reconditioning operations. Reconditioning refers to all necessary processes required to bring a used RA to a condition in which it can be safely reused again. Typical reconditioning activities for RA include inspection, cleaning, minor repairs, sterilization or filling.

Cycle time and return rate may be described by a statistical distribution, as depicted in Figure 1. $P(x)$ represents the probability that an article returns to depot when a time-interval $\mathrm{x}$ has elapsed since its issue. The finite probability that an article will never be returned due to fleet shrinkage (infinite cycle time) is represented by the right asymptote in the probability distribution. $\tau$ represents the average cycle time. To be noted that a non-stationary description may be necessary for $P(x)$ : the average cycle time $\tau$ and its dispersion can vary depending on demand season, for instance.

Note that the cycle time concept depends on the way reusable articles physical flows are 
arranged. Two physical flow models are possible: star systems and multi-depot systems. In star systems, reusable articles return to the same plant or depot from where they were originally issued. Physical flows follow a one-to-many configuration, as depicted in Figure 4-3 (chapter 4) . In this case, cycle time definition is clear, as it refers to the time elapsed between the issue and the return of an article to the depot (D in figure 4-3), including the time required for reconditioning. In multi-depot systems, reusable articles can be returned to a depot which is not the original sender (figure 4-3 shows an article issued from D1 and returned to D2). Multi-depot physical flows follow a many-to-many configuration. Cycle time refers in this case to the time elapsed between the reusable article issue from a given depot and its return to the sender depot or to another depot in the network, including the operations to make the article ready to be used again.

Finally, the on-hand inventory in each location metric refers to how many RA units are available in each stage of the supply chain, both in usable (new, full) and unusable (old, empty) conditions.

The three metrics (return rate, cycle time, on-hand inventory) are usually difficult to quantify, due to the limited visibility firms have over the supply chain stages which are not under their direct control. For instance, the metric for the on-hand inventory in a given location can be extracted from the account management system (registration of the incoming and outgoing quantities) when item-level tracking is not available or not economically justified. However, as will be explained in 6.1.3., this method is not exempt of some shortcomings: in order to obtain reliable figures for the on-hand reusable articles inventory, periodical inventory audits in supply chain partners (distributors, customers) locations are required. Inventory audits at customers and distributors premises involve a non-neglectable workload and their execution is not always possible or allowed. Similar challenges that arise in industrial practice for determining cycle time and return rate metrics, will be presented throughout the remainder of the paper.

Figure 3 depicts the two first building blocks of the conceptual model we propose in this paper: common problems in reuse CLSC (fleet shrinkage, significant investment, limited visibility) around a nucleus containing the basic information (metrics) that managers need to handle the common problems block. 


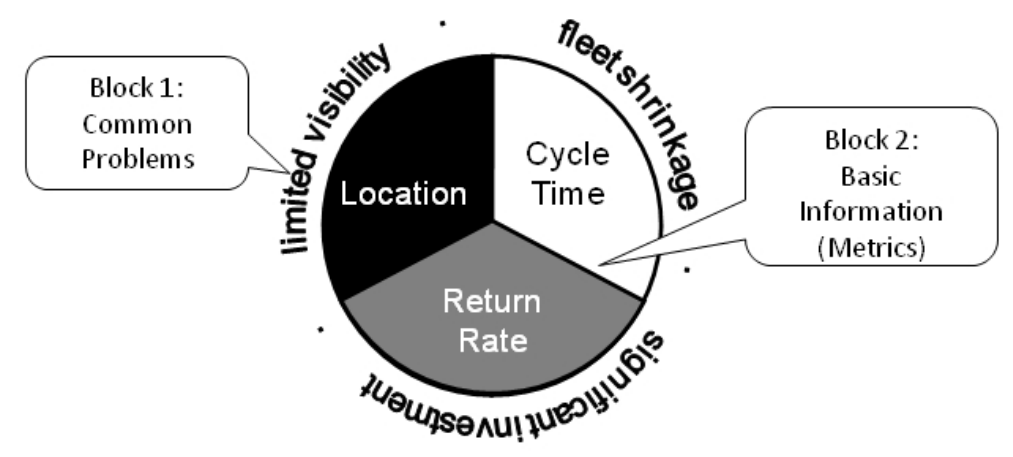

Figure 5-2: A management model for reuse CLSC: common problems and basic information (metrics). Own development.

\subsection{Building block 3: Management issues}

Management of reuse CLSC is not a simplistic task. Depots need to assure that they are able to fulfil demand depending heavily on returned articles (return volumes are typically over $90 \%$ and most demand is fulfilled with reused articles). But in the meanwhile, returns are subject to a high degree of uncertainty in their timing, quantity and quality. Limited visibility on the customer-use stage of the supply chain renders difficult to know when a given article will return, how many articles will return in a particular time period and in which condition will they be returned (will the articles need extensive reconditioning operations or will they be in very good condition an almost ready for the use of the next user), as explained in subsection 3.3.

In order to match reusable articles demand and returns, firms deal with the challenges depicted in Figure 4. The following six management issues constitute the third building block in our framework. Note that the scope of this framework is to synthesize the main managerial aspects (tactical and operational issues) in a system that is already in place. Design aspects of the system, such as network design, actors involved in the supply chain, relations and cost allocation between these agents, etc. are not the main focus of this chapter. 


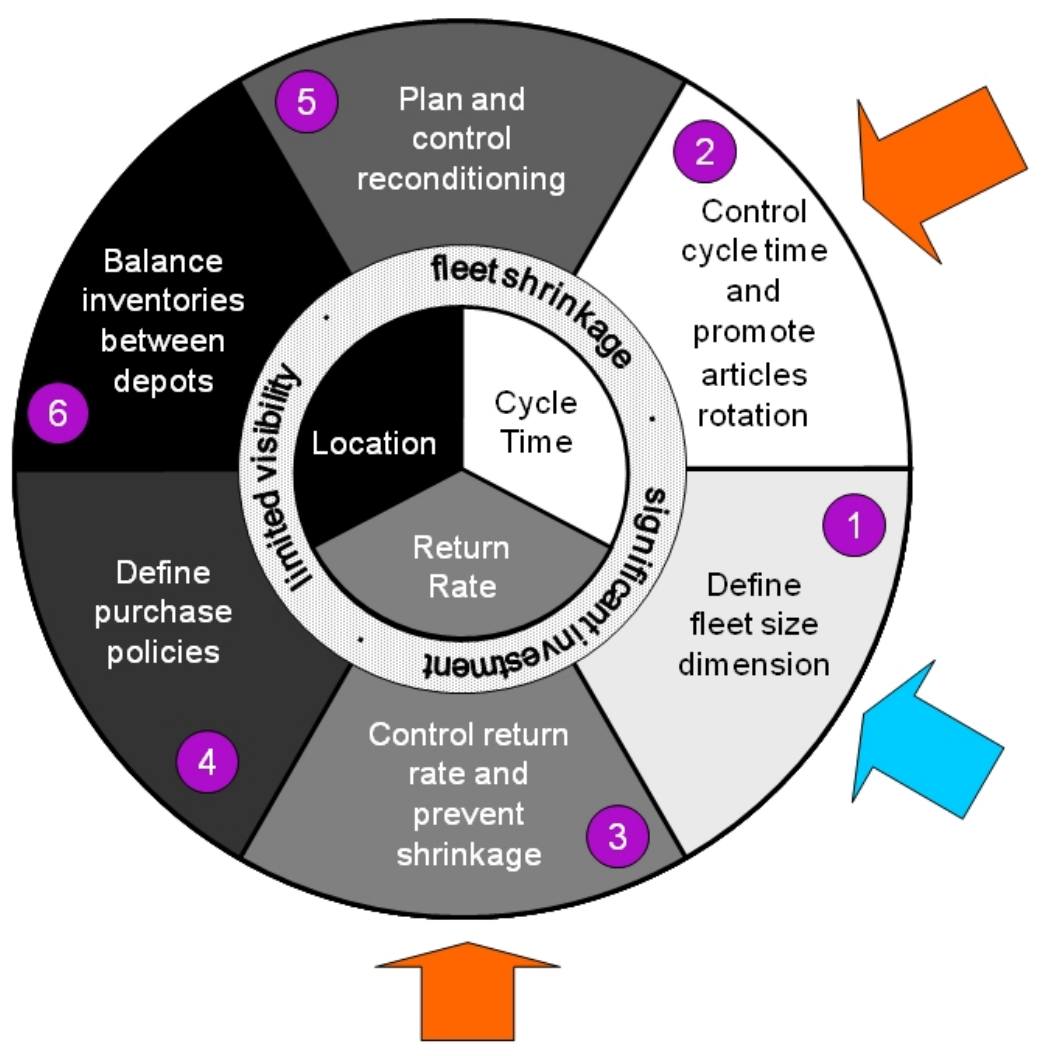

Figure 5-3: A conceptual management model for reuse CLSC. Own development. 


\subsubsection{Issue 1: Define the fleet size dimension.}

One of the first questions that managers need to deal with when implementing a system of reusable articles is the number of units in circulation required to keep operations running smoothly (Goh and Varaprasad, 1986; Fleischmann et al., 2000; Johansson and Hellström, 2007). As noted in subsection 3.2, the purchase of the initial RA fleet generally constitutes an important initial investment. An overdimensioned RA fleet unnecessarily ties up capital and adds holding costs. On the other hand, an undersized RA fleet will cause unsatisfied demands and costly stockouts.

Note that we use the term fleet size to refer to the total number of RA that are in circulation in the whole supply chain, including reusable articles inventory levels at supply chain partners and RA in transit (forward and reverse) between locations. There is not a standard term in literature to refer to this system-wide number of articles. In the beer business, practitioners use the term "float" (Bryson, 2005; Wyld, 2009). However, in other practitioners' oriented papers with a more general scope (Aberdeen, 2004, BRIDGE, 2007) and in academic papers (Turnquist and Jordan, 1986, Roseneau et al., 1996, Johansson and Hellström, 2007), the term "fleet" is mostly used, so is the one we adopt in this paper.

The number of articles needed in circulation in the whole system depends on the demand for RA and the time a RA requires for completing the whole logistics cycle (from its issue to the moment in which it is ready for reuse again). Long cycle times require larger fleet sizes. Surprisingly, our own case studies and the review of literature have shown that there is not a clear methodology in industry for calculating the fleet size. Investments in RA are usually based in experience and simple calculations (van Dalen et al., 2005, Hellström, 2009). For instance, in the beer industry, the "rule-of-thumb" is that for every keg on tap in the customer another extra seven kegs are required to cover kegs in transit, in maintenance, in stock in the wholesalers, distributors, etc (Bryson, 2005; Wyld, 2009). Therefore, for every pouring tap, eight kegs are required. Similar rules of thumb are used in the MedGas (Case \#1) and LPG industries (Case $\# 2$ ). Of course, such simple criteria should vary with the particular characteristics of the supply chain: number of middlemen (echelons), average time spent in each stock location, average time articles are in use at the customer, geographical distances, etc.

To be noted that the typical safety stock formula for gaussian approximations of demand 
$(\mu+k \cdot \sigma, \mu$ is the expected demand for RA, $\sigma$ represents RA demand dispersion and $k$ represents the service level; Johansson and Hellström, 2007) is not valid for determining the required system-wide fleet size. The issue here is not determining how much stock must be kept in a isolated location but to decide the total number of units that need to be circulating in the whole supply chain (multiple locations) in order to guarantee the satisfaction of a pre-established service level (avoid stockouts). The above formulation $(\mu+k \cdot \sigma)$ just takes into account the demand for RA, ignoring the fact that the same unit of RA can be used for satisfying a set of demands during the time horizon of analysis.

This situation calls for clarifying which are the magnitudes of interest in fleet size calculations and for proposing a methodology for its computation, as will be done in section 7 .

\subsubsection{Issue 2: Control cycle time and promote articles rotation.}

The economical efficiency of the RA system directly depends on the velocity with which RA travel around the supply chain. The faster articles circulate in the system, the smaller is the required fleet size. A short cycle time renders a high number of article uses per time unit. As far as cycle time is concerned, managers have to deal with two main challenges. First, how can cycle time metric be measured and controlled. Second, which managerial actions can be implemented in order to reduce cycle time (encourage as much as possible the turnover (rotation) of RA in the system).

The first challenge (metric measurement) is related with the limited visibility available in the customer use stage of the CLSC. Unless some type of item-level tracking is put in place, accurate information about the average cycle time, a measure of its dispersion and the cycle time distribution shape would be at least complicated to obtain. However, as noted in 3.3, most closed-loop systems of reusable articles have been traditionally managed without itemlevel tracking. At best, only account management (aggregate issues and returns in a period of time) information has typically been available. With no serialization of RA it is not possible to obtain empirical observations of the turnaround process of RA and its cycle time. Nevertheless, academic literature cover a few applications of statistical methods (Goh and Varaprasad (1986) and Toktay et al. (2000)) that claim to draw from models relevant cycle time distribution parameters, while circumventing the need of serialization and item-level tracking. In both 
applications, a dynamic regression (Pankratz, 1991) is established between aggregate issues and returns time series. Cycle time distribution parameters are drawn from the dynamic regression model estimation. However, as we discuss in Table 3 of section 7 , some estimation problems have been reported regarding the application of this statistical methods, especially if cycle time distribution shows non-stationarity (which is typically the case of articles with seasonal demand). Then, when a non-stationary description of cycle time distribution is necessary, itemlevel tracking seem to be the only realistic option to obtain information about the turnaround process. For these purposes, as we also discuss in Table 3 (section 7), serialization and item level tracking does not need to be implemented in the whole fleet, but just on a sample of reusable articles.

Once the cycle time distribution has been estimated (cycle time metric is measured), the second challenge introduced at the beginning of this subsection can be dealt with: which managerial actions can be undertaken in order to reduce cycle time metric? While managers will have direct control over some stages contributing to the total cycle time, in the unobservable part of the supply chain, the return velocity depends on supply chain partners' behaviour. The desired behaviour can be induced through the recovery incentives we will present in section 6 . In the stages under firm's direct control, different courses of action can be adopted in order to reduce long cycle times, such as accelerating reconditioning lead times, bypassing unnecessary waiting times in inventory locations or delivering/collecting more frequently at distributors and customers. For this purposes, keeping in mind some factors that contribute to increasing the cycle time in RA CLSC can be useful:

- large stock quantities of used and reconditioned articles at depots

- long reconditioning lead times (for filling, repair, sterilize, etc.)

- long transportation distances

- infrequent deliveries and collections at distributors and/or customers

- long supply chains with a high number of intermediaries

- excessive customer holding time 


\subsubsection{Issue 3: Control the return rate and prevent shrinkage.}

Regarding return rate, two challenges analogous to the ones presented in 5.2 arise. First issue is how to determine a metric for measuring the current return (loss) rate in system. Once the current return (loss) rate is known, the second issue is to determine which management controls can be introduced for preventing loss and increasing returns (Fleischmann et al., 2000; Toktay et al., 2004). The economical efficiency of the system improves if less RA have to be purchased in order to replace the lost or irreparably damaged articles.

As far as return rate control is concerned, quality losses can be regularly measured because damaged articles are rejected in the part of the supply chain which is under depots' control. On the contrary, incidental and structural losses are difficult to monitor and measure because they happen in the unobservable part of the supply chain.

As a result, obtaining the overall return rate (including the three types of shrinkage causes: quality, incidental and structural losses) is not straightforward. The six case studies we conducted in the field and the results published by other researchers show that most firms dealing with reusable articles are not able to quantify with precision their current return rates. In section 7 (Table 2) we inventarise different methods used in practice in order to estimate the return rate under different informational levels: account management and item-level tracking.

Once the current return rate of the system is measured, managers can focus in the courses of action to be launched for obtaining higher return rates. Recovery incentives, which will be further discussed in section 6 , are powerful tools for discouraging article leakage. Visibility in the unobservable part of the CLSC, at least to an extent that enables to know where in the system there are more leakages, can also provide good results.

\subsubsection{Issue 4: Define purchase policies for new articles.}

Fleet shrinkage has consequences both in the finance and operations functions. Lost assets have to be written off from the balance sheet. In addition, even in the case of a level demand pattern, new reusable articles (assets) will have to be purchased from time to time in order to substitute the irreparably damaged, lost or theft articles. In this "replacement" situation, managers need to determine the optimal procurement policies (for new articles) and their optimal control parameters (purchase orders quantities and timing). In Appendix I, inventory control models with 
product returns have been reviewed in order to check their suitability to the particular characteristics of this purchase policies definition problem in reuse CLSC: determining the timing and quantity of new articles purchasing batches aiming at the replacement of lost or irreparably damaged articles. We concluded that that, to the best of our knowledge, the particular characteristics of reuse CLSC (high return rates not too far away from 1, new and used articles are perfect substitutes, firms have a limited control over returns timing) have not been grasped in any of the inventory models described in the academic literature. Therefore, development of specific inventory management models for reuse CLSC constitute an opportunity of further research for the operational research and operations management research communities.

In addition, managers need to bear in mind that procurement of new articles not only needs to take place in a steady-state replacement situation. Besides the initial acquisition of the fleet, new articles (assets) also have to be purchased when the fleet size has to be redefined due to structural changes in demand or cycle time. More RA units are required in circulation if there is an increase in RA demand (that can be either a sudden increase, because of, for instance, the addition of new markets to be served from the same plant; or a gradual growth, due to an increasing trend in demand). More RA units are required also if there is an enlargement of cycle time motivated, for instance, by longer travelling distances. This type of situations requiring a redesign of the fleet size are not to be addressed through inventory control models but through the fleet size dimension methodology proposed in the first part (fleet size design) of section 7 .

\subsubsection{Issue 5: Plan and control reconditioning activities.}

Even if the number of RA in circulation in the network is accurate, depots need to assure that articles are returned and reconditioned at the right time in order to fulfil demand. In real industrial settings, the reconditioning capacity is not infinite (Kelle and Silver, 1989a; Koh et al., 2002) and therefore, "reconditioning" plans (similar to manufacturing plans) have to be carried out for the necessary activities that put the RA into a usable condition again. This planning involves forecasting the expected demand and the expected returns in a given time period. If the reconditioning capacity is not enough to match the forecasted demand and returns then some course of action has to be undertaken, such as buying new reusable articles 
or searching for extra reconditioning capacity.

Using the available capacity for reconditioning activities was found to be a management issue in several of our case studies (Case \#1: MedGas; Case \#2: LPG; Case \#3: Erasmus MC). Giuntini and Andel (1994) also remarked this issue:

"In most organizations, fewer than $50 \%$ of returnable containers are available for use at any one time. The rest are floating around customer sites or stacked in the warehouse in some unusable condition".

\subsubsection{Issue 6: Balance inventory between depots.}

This challenge only concerns multi-depot networks, where RA do not have to return to the originally issuing depot. In this case, periodical rebalancing of the number of RA among facilities is required, so that the inventory in each depot is sufficient to cope with the demand for RA it faces (note that demand in each depot is dynamic - changes over the time - and uncertain). Rebalancing involves transhipments between depots from time to time in order to relocate RA from locations with an excess of inventory to locations that can eventually experience a stockout.

Linear programming models and network flow models can be used to provide norms for carrying out inventory rebalancing between depots at the minimum costs. The use of this type of models has been widely reported in the transport sector (railcars, trucking operations, maritime container systems, rental cars). Models were firstly formulated within the classical transportation construction (Misra, 1972). Next, the transportation models were extended into the transhipment formulation in order to include the dynamic characteristics of demand using time-space networks (White, 1972; Herren, 1977). Later on, stochastic demands were included as well (Jordan and Turnquist, 1983; Powell, 1986). More recent references on the same topic include Crainic et al. (1993), Erera et al. (2009) or Dong and Song (2009). However, few examples are found in literature for the application of this type of models for rebalancing reusable articles' systems different from maritime containers and railcars. Duhaime et al. (2001) constitute an exception.

Interesting research opportunities arise from these six issues for the operations management academic community. Issue 1 can be addressed through stochastic inventory control models. 
Obtaining information about cycle time distribution is critical for these purposes. Issues 2 and 3 call for methodologies for return rate and cycle time quantification and for analyzing the effect the different recovery policies that will be presented in section 6 (deposits, rental, equal exchanges, etc.) have on fleet shrinkage prevention and on articles' cycle time. Issue 4 points out a need for defining optimal purchasing policies for new articles that replace the lost or irreparably damaged articles. Issue 5 calls for developing techniques for forecasting future returns under different levels of information availability. Issue 6 can be addressed by linear programming models providing norms for carrying out inventory rebalancing between depots.

\subsection{Solutions proposal: control strategies}

In the previous section we have pointed out the main issues faced in the management of a reuse CLSC. In this section and the next one, we provide some approaches and techniques that can be useful for dealing with the above mentioned issues. More specifically, in this section we present several control strategies (incentives) aiming at reducing fleet shrinkage and accelerating articles cycle time.

Reusable articles constitute a shared resource in the supply network: they travel beyond the boundaries of the organization and their control involves several supply chain partners having different objectives and incentives. In order to obtain the desired behaviour from supply chain partners, reusable articles' owners can use a variety of control strategies. The objective of the control strategies should be twofold: (a) Prevent fleet shrinkage and (b) Promote articles rotation. Control strategies simultaneously address two management issues, as depicted in Figure 5-3 (orange arrows).

In turn, we explain and analyze different alternatives of control strategies that are used in real industrial practice. We classify the collection of control strategies in three categories: (a) Economical recovery incentives: deposit, rental, account management; (b) Non economical recovery incentives: equal exchanges, immediate retrieval, direct return after use; (c) User accountability. 


\subsubsection{Economical recovery incentives}

\section{Deposits}

Within this control strategy, the quantity paid as a deposit acts as a guarantee that customers will meet their obligation of returning back the RA to the owner. Many examples of deposit use can be found in B2C settings such as deposits for beverage packaging (case \# 7: Heineken), for LPG cylinders (case \# 2) or the $€ 1$ deposit for using trolleys at supermarkets (case \# 5).

The deposit system has the advantage that, in case of loss, the owning organization gets at least partially compensated. However, especially in B2B settings, the deposit system can be perceived as a sign of mistrust between the parties and an opportunity for the owner to make cash. Deposit customer acceptance decreases in the case of a high deposit in relation to a low product price. The extra administrative effort related with the deposit system management has also to be taken into account. The effect of deposits on cycle time control is limited because the only penalty for excessive customer holding time is deposit depreciation.

\section{Rental}

The customer has to pay a daily rent for each RA the customer has in use. Rental systems are typical in maritime containers (Kärkkäinen et al., 2004) or railcar fleets (Young et al., 2002).

Using rental as a control strategy constitute an effective way of speeding up cycle time in reuse CLSC, as customers would tend to return the RA as soon as they do not need it anymore. However, not all industries and products can suit to such a recovery strategy: rental requires articles to be serialized (and item-level tracked) and therefore, is typically only applied in reusable articles with a high unitary value.

\section{Account management with periodical payments}

Account management with periodical payments can be used as a substitute of rentals when item-level tracking information is not available (e.g. oxygen cylinders, case \# 1). Incoming and outgoing RA quantities from the customer have to be carefully registered in the information system of the company. Then, it is possible to re-build the inventory at the customer at any given time and charge a daily fee depending on the number of RA in inventory each day. The 
payment is done at the end of a pre-agreed period, such as the month.

The main shortcoming with account management systems is that any transactional error in the incoming or outgoing quantities leads to inaccuracies in the customer inventory record (Heese (2007) show how inventory discrepancies between "information system" and "physical" inventory arise in the operations of many organizations. We also refer the reader to Raman et al. (2001), Sahin (2004), Rekik et al. (2008), Rekik et al. (2009) and Nachtmann et al. (2010) for further explanations on this issue). The application of this control strategy requires periodical inventory audits in the customer inventory in order to correct discrepancies.

As rental systems, reliable account management systems also constitute an effective way of speeding up cycle time in RA CLSC, as customers have an incentive to return the articles as soon as possible in order to decrease their daily inventory.

\subsubsection{Non-economical recovery incentives}

\section{Equal exchanges (swapping)}

Equal exchanges consist in the following rule to be observed by supply chain partners: the supplier will hand over $\mathrm{n}$ full RA only if the customer is able to give back exactly $\mathrm{n}$ empty units at the moment of delivery. This equal exchange of full-for-empty (or new-for-old) is a quite extended control mechanism in reuse CLSC. We found this strategy in many case studies (cases \#1, \#2, \#6, \#8: Medgas cylinders, LPG cylinders, flower roll cages, roll containers) and also in other studies published in academic literature (Del Castillo and Cochran, 1996; Roseneau et al., 1996; Twede and Clarke, 2004; Karkkäinen et al., 2004; Breen, 2006, Privé et al., 2006, Ilic et al., 2009).

This control strategy results advantageous because it constitutes a simple mechanism for preventing losses (no administrative efforts are required) and also because its application simplifies transport organization integrating forward and reverse flows. Vehicle routing is done attending to forward flows and articles for reconditioning (old, empties) are returned in the backhauls of delivery routes. Nevertheless, the equal exchanges policy doesn't have any positive effect in cycle time, and in fact, it can even have a negative effect. Using equal exchanges implies that return flows pass through all the stages (echelons) of the forward supply chain. By-passing some stages for the return flow would lead to shorter cycle times. Moreover, in the 
case of seasonal products, the use of this control strategy requires a wider fleet size than the strictly necessary. Other disadvantages include the exceptions that have to be done the first and last time a customer is delivered.

\section{Immediate retrieval}

The immediate retrieval control strategy can only be applied to secondary or tertiary packaging materials used for material handling and transportation (RTI type). This strategy consists in immediately removing the delivered goods, so that material handling element can be taken back by the transporter right away. It constitutes a very simple mechanism for preventing losses and achieving fast circulation of RTIs, but on the other hand, requires extra handling and extra waiting time for the delivering vehicle. It is used, for instance, with the racks used for engine transportation in the automotive sector.

RPM (primary packaging) or RP always require some time at the customer while the article (contents or directly the product) is in use. Some specific cases of RTI, such as the display pallets used in retail surfaces, present the same limitation. Hence, the immediate return of the RA to its owner is not possible.

\subsubsection{User accountability}

In some cases, the structure of the supply chain (in terms of product type and partners relationships) advice against introducing neither economical incentives nor equal exchange policies. The RA owner has to rely in the goodwill of the supply chain partners for recovering the articles. In such a context, where no return incentives are applied, the only action that owners can undertake for keeping fleet shrinkage under control is making users accountable for the articles they handle.

Monitoring reusable articles in the "customer-use" stage of the CLSC is a necessary condition for implementing users' accountability policies. As explained in subsection 3.3., RA tracking can be done "by hand" (manual serial number identification and registration in paper or a spreadsheet), but the use of automatic identification technologies such as bar codes or RFID, renders this task less-labour intensive and the information obtained is less prone to human error. Tracking information enables to point out which partners or customers are ac- 
countable for article losses or longer cycle times. Just the communication of this information to non-compliant partners seems to have positive effects in return rates and cycle times (Hellström, 2009). If required, penalties can be introduced in contracts or verbal arrangements in B2B settings.

It should be emphasized that the introduction of tracking technologies in itself is a necessary condition, but not sufficient, to establish user accountability as a control strategy. Continuous management attention (making users really "accountable" for their losses) is required to obtain benefits in terms of reduced shrinkage and cycle time acceleration. RFID or bar codes just provide data about articles status and whereabouts, but firms need to know how to use this data for undertaking the proper managerial actions (Johansson and Hellström, 2007).

\subsection{Solutions proposal: a methodology for calculating the fleet size}

Another central issue in reuse CLSC management is determining how many articles should be circulating in the network so that operations run smoothly (blue arrow in Figure 5-3). During our involvement in the six case studies we have developed, practitioners have remarked the importance of this issue. However, as explained in issue 5.1., there is not a clear methodology in industry for defining the required fleet size. Investments in RA are usually based in experience and simple calculations (Van Dalen et al. 2005; Hellström, 2009). This situation calls for clarifying which are the variables of interest in fleet size calculations and for proposing a methodology for its computation.

There are two variables that determine the fleet size: demand and cycle time. The total number of RA required in circulation in the system is the number of expected uses in a given time horizon (demand) divided by the number of uses each RA is given in the same time horizon. However, neither demand nor cycle time take deterministic values: both are random variables subject to stochasticity. Therefore, we put forward the following yardstick (1) for fleet size calculation:

$$
N=\frac{D}{T} \cdot\left(1+S_{D}\right) \cdot\left(1+S_{T}\right)
$$


Where $N$ represents the fleet size dimension, $D$ is the average demand (in units of RA) during time period $t, T$ is the average number of times a RA is used during time $t$, and $S_{D}$ and $S_{T}$ are safety factors for protecting the system against demand and cycle time inherent variability.

Note that in the above expression, the function of the safety factors is to "protect" against unpredictable changes in demand or cycle time in a stationary situation. Structural trends in the values of the variables, such as seasonality in demand or in cycle time (which involve changes throughout time in the average value, the dispersion or the shape of the statistical distribution of demand or cycle time) have to be addressed in a different way, involving the recalculation of the adequate fleet size

Demand is a well-controlled variable in most organizations, but this is not characteristically the case of cycle time. Then, the methodology we propose aims at obtaining the basic data requirements for cycle time distribution characterization under different information levels (account management or item-level tracking). Figure 5-4 depicts the steps we propose to follow for fleet size calculation.

A previous step is to identify the data structure available (what is registered). We consider two possible informational levels: account management (only aggregate issues and returns are registered) or item-level tracking (each article is followed univocally). Outlying observations due to measurement or transactional errors need to be identified and excluded if possible.

First step consists in representing the demand time series in order to get insights into the reusable articles demand process. The first output expected from this stage is the identification of basic demand pattern characteristics: is demand a continuous random variable (that can be approximated by a normal distribution, for instance) or is it an intermittent demand (random demand with a large proportion of zero values, will be typically represented by a Poisson process)? First type of demand (normal continuous demand) is expected to be found in packaging elements (RTI and RPM) as demand for this type of articles will be directly linked to contents' (the real product) market demand. The second type of demand (intermittent demand) is expected to be observed mainly in RP, such as service tools, books or rental articles. The identification of which demand type (continuous vs. intermittent) is being dealt with will enable us to apply the adequate inventory control models for future replacement purchases of 


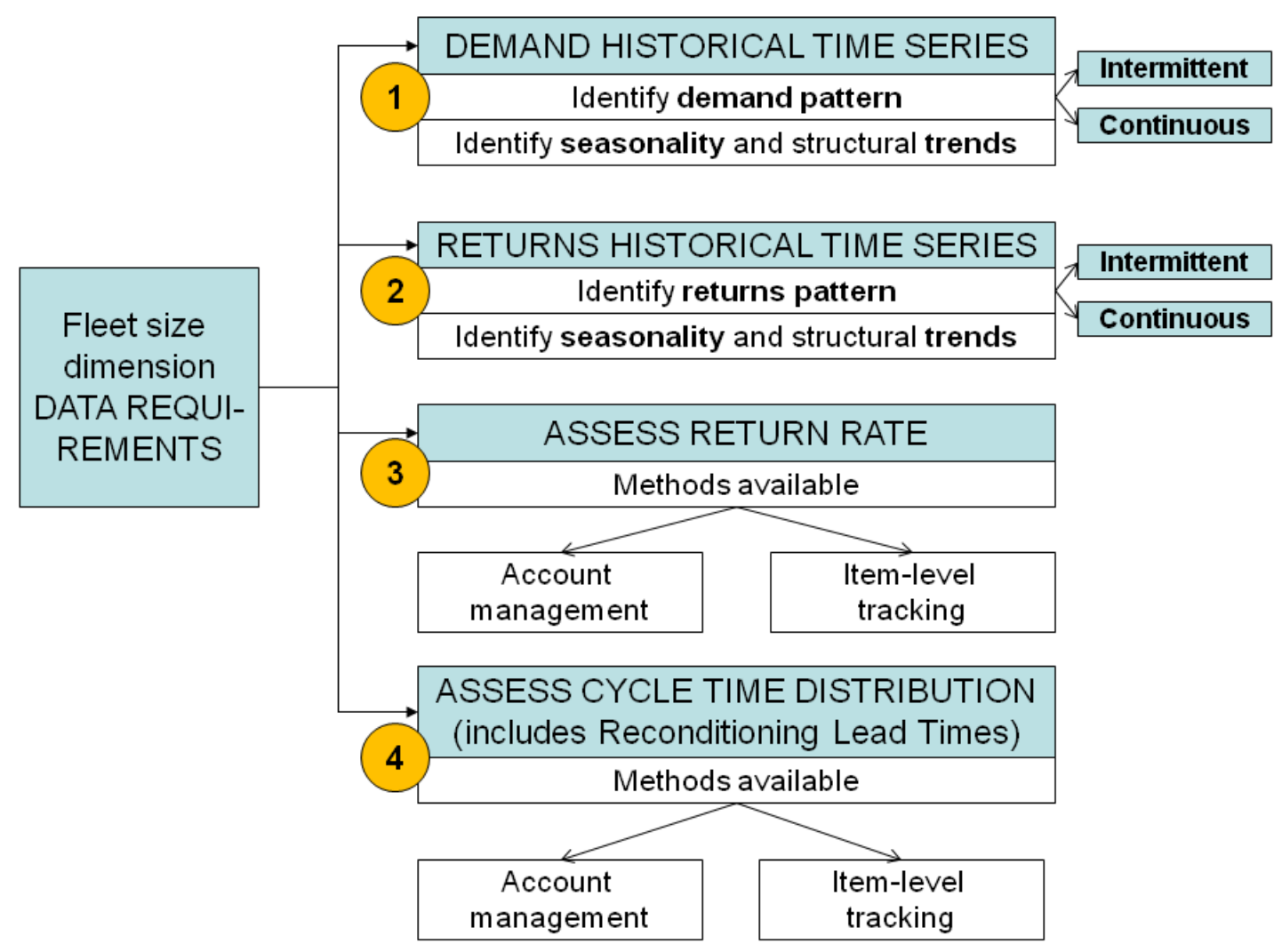

Figure 5-4: A methodology for determining the fleet size in reusable articles networks. Own development. 
new articles. Additionally, a second output to be obtained from this stage involves the identification of the main characteristics of demand time-series: seasonal patterns (more sales in winter (case \#1: Medgas, case \#2: LPG) or in summer (case \#7: beer)), structural trends (such as an increasing or decreasing tendency in sales), or cycles.

Second step involves carrying out the same time series analysis over returns historical data. The same two outputs are also expected for this second stage: ¿continuous or intermittent returns? and seasonality, trends or cycles in returns time-series identification. The objective of the second output in the two first steps is to identify non-stationarity in demand and returns, in case it exists. Faster cycle times are expected in high-demand seasons, for instance. Thus, cycle time distribution might be non-stationary if demand is also non-stationary.

Third and fourth step consist in trying to assess the statistical distribution representing cycle time and return rate (the distribution intuitively depicted in Figure 1). Depending on the informational level available, different methods can be used. We survey the available methods in Addenda 1 and Addenda 2. Some situations have been already described in literature while others are our own contribution.

The data collection and analysis carried out throughout steps 1, 2, 3 and 4 should enable managers to characterize the behavior of demand and cycle time and, more specifically, their average values, the dispersion and shape of their statistical distributions, and the way these distributions evolve with time. The completion of these four steps provides the required information to accurately use the yardstick we put forward in (1) for calculating the fleet size. Additionally, the demand will have been categorized as continuous (normal approximation) or intermittent demand, in order to apply in the dya-to-day operations of the facility the adequate inventory control models (providing purchase orders quantities and timing) for fleet size "maintenance".

Calculation of the target fleet size has to be carried out not only the first time the reusable articles system is put in place, but also when structural changes in demand or cycle time distributions take place. Therefore, how well the target fleet size suits current business conditions in terms of demand and cycle time has to be periodically checked. If demand trend in the long term is decreasing (declining markets, case \#2: LPG), the fleet size $\mathrm{N}$ has to be readapted to the new situation and be downsized. In such a case, firms can suspend replacement purchases 
of new articles or, in extreme situations, scrap or sale part of their fleet. Inversely, an increasing demand (growing markets, case \#1: MedGas, case \#2: LPG in developing countries) requires an uprise of the required fleet size (new RA have to be purchased not only for replacing lost or damaged articles but also for enlarging the dimension of the fleet size (N). Symmetrically, variations in cycle time have to be considered. In front of a fixed demand (ceteris paribus), if cycle time has become shorter (managerial actions, such as new recovery incentives or a reduction in the length of the supply chain, have achieved a cut down of cycle time metric), the fleet size dimension can be trimmed. If cycle time metric shows an increase, the fleet size dimension $\mathrm{N}$ needs to be increased as well.

Note that, like happens with "manufacturing capacity", the system-wide fleet is somehow rigid: investments on new articles in order to adjust the fleet size to demand and cycle time behaviour are not always immediate (capital unavailability, long purchasing lead times for new RA). In contrast, demand may rapidly evolve throughout seasons or along the months/years. In order to cope with seasonality in demand, in business practice, the fleet size is dimensioned for the high-demand season. When demand abates in the low season a part of the fleet is stored in the facility in order to be released when needed during the high season (van Dalen et al., 2005, case \#2: LPG). Another possible approach for coping with sudden increases of demand when fleet size is forced to remain constant is to launch managerial actions that can eventually accelerate cycle times while new investments : temporary shortening of reconditioning lead times (accelerate inspections/testing processes or subcontract extra reconditioning capacity), especial recovery campaigns of reusable articles at customer premises, etc. (case \#1: MedGas).

Finally, a remark intending to clarify how this methodology is applied in the case of multidepot networks. In star networks (one-to-many configuration), cycle time variable is defined as the time elapsed between issue and return to the "central" depot. In multi-depot networks (many-to many configuration), cycle time concept is more "fuzzy" and we defined it in section 4 as the time elapsed between the issue of an article and its return to the originally sender depot or another depot in the network. With both definitions, the inverse variable of cycle time in multi-depot networks is the number of uses an article is given in the time period of analysis. Then, in multidepot networks, yardstick (1) is also applied for determining the system-wide fleet size. In this case, it is important to note the term "system-wide": what is calculated 
is the total number of RA in circulation in the whole system, including all the depots that exchange articles and their corresponding customers. In such a system, one single depot cannot be considered in isolation from the rest of depots and customers with which reusable articles are exchanged. Fleet size dimension in multi-depot networks has to be defined for the whole system, taking into account the global demand in all depots (use the aggregate demand for all depots in the numerator of yardstick (1)) and the number of uses an article is given during the period of analysis. Then, rebalancing movements (as explained in section 5, issue 5.6) enable to adapt the inventory in each depot to the short term demand the depot will face.

\subsubsection{Addenda 1. Methods available for return rate assessment. Informational level: account management}

If reusable articles are not serialized and item-level tracked, it is not possible to determine when one particular article has been lost. When only account management data is available, firms can use ratios based on aggregate issues and returns in order to approximate their return rates.

Goh and Varaprasad (1986) and Toktay et al. (2000) report the use in industry of the formula (2) ratio:

$$
\text { Return rate }=\frac{R_{a}}{I_{a}}
$$

where:

$R_{a}$ : number of articles that return in a given time period (such as the year)

$I_{a}$ : number of articles issued to the market in the same time period.

This formulation for the recovery rate has the following shortcomings:

- it does not take into account that articles utilization can span several time periods,

- the returns received in this year (period) can be originated from issues from previous years (periods),

- there are returns that will take place in future periods as a result of issues taking place in this period. 
Bojkow (1991) also reports the use of the formula (3) ratio:

$$
\text { Re turn rate }=\frac{R_{\infty}}{I_{\infty}}
$$

where:

$R_{\infty}$ : cumulative number of articles returned since the first day of operation of the facility.

$I_{\infty}$ : cumulative number of articles issued since the first day of operation of the facility.

In this formulation the main shortcoming resides in the fact that not always the information remounting to the first operative day of the depot or plant is available. The possible fluctuation in the value of the return rate probability along the time in such a long period is also neglected, as the method does not provide information about which were the periods (years, months, etc.) with a lower recovery rate (more losses) or how this metric has evolved throughout time.

\section{Informational level: item-level tracking}

When articles are tracked on an individual basis, it is possible to determine which specific articles have not been returned to the depot. However, an extra issue arises when defining a return rate in presence of item-level monitoring: which criteria will be defined for declaring an article definitively lost? A limit must be set on return time after which the article is considered lost.

\subsubsection{Addenda 2. Methods available for cycle time assessment.}

\section{Informational level: account management}

Most closed-loop systems of reusable articles have been traditionally managed without itemlevel tracking. At best, only account management (aggregate issues and returns in a period of time) information has typically been available. Based only on aggregate issues and returns as input information, some statistical methods have been developed in literature in order to draw some relevant cycle time distribution parameters, such as Bojkow (1991) (Method 1), Goh and Varaprasad (1986) (Method 2a) and Toktay et al. (2000) (Method 2b).

\section{- Method1}


Bojkow (1991) compiles different methods used for "trippage" calculation. Trippage is a concept closely related to cycle time; it measures the total number of trips made by a reusable article in its life-time (cycle time measures the duration of one trip). Bojkow defines the trippage number with (4) ratio:

$$
\text { Trippage }=\frac{I_{a}}{I_{a}-R_{a}}
$$

where:

$I_{a}$ : number of articles issued in a given time period (such as the year).

$I_{a}-R_{a}$ : represents the number of "lost" articles in the same time period.

This ratio provides an order of magnitude of trippage figures, but suffers from gross inaccuracies which invalidate its use as input in the estimation of reusables fleet size. As it does not take into account that articles utilization can span several time periods, the same shortcomings identified for ratio (2) in Table 2 are also present here.

\section{- Method 2}

A dynamic regression model (Pankratz, 1991) can be formulated to establish the relationship between issues and returns. Returns in period $t$ are a function of sales in past periods:

$$
y_{t}=v_{0} x_{t}+v_{1} x_{t-1}+v_{2} x_{t-2}+\ldots+N_{t}
$$

Where:

- $\quad$ - The set of parameters $\left(v_{0}, v_{1}, v_{2}, \ldots v_{\infty}\right)$ represent the probability that an article issued on period $t$, returns to the system either on the same period $t$, on the next period $t+1$, on period $t+2$, and in general, $i$ periods afterwards, $i=0,1,2, \ldots$, provided that the item will ever be returned.

- $v_{\infty}$ represents the probability that an article will never be returned $\left(v_{\infty}=1-r\right.$, represents the loss rate).

- $N_{t}$ can either be gaussian white noise $\left(N_{t}^{\sim} N(0, \sigma)\right)$ or not. 
The model (5) can be estimated using historical data (time-series) of articles' issues and returns. This estimation consists in calculating the values of the set of parameters $\left(v_{0}, v_{1}, v_{2}, \ldots v_{\infty}\right)$ which provides a good approximation to cycle time distribution (including a return rate estimate) while (theoretically) circumventing the need of tracking individual items for obtaining such information.

Goh and Varaprasad (1986) (Method 2a) estimate the dynamic regression model in (5) using a transfer function model approach. Model (5) can be rewritten as indicated in (6), where the (potentially) infinite parameters to be estimated in (5) are expressed by the quotient of two finite polynomials:

$$
y_{t}=v(B)+N_{t}, \quad y_{t}=\frac{w_{0}-w_{1} B-w_{2} B^{2}-\ldots-W_{s} B^{s}}{1-\delta_{1} B-\delta_{2} B^{2}-\ldots-\delta_{r} B^{r}} x_{t-b}+N_{t}, \quad v(B)=\frac{w(B) B^{b}}{\delta(B)}
$$

The Box-Jenkins procedures of transfer function identification, model estimation and diagnostic checking are carried out to estimate model (6) parameters, using a sample of the past values of the issues $\left\{x_{t}\right\}$ and returns $\left\{y_{t}\right\}$ time-series.

In Toktay et al. (2000) (Method 2b), model estimation is done using a distributed lag model approach (Bayesian inference), where a specific form, based on theoretical considerations, is assumed for lag ( $v_{i}$ coefficients). Typical assumptions are geometrically distributed lags (coefficients that decline exponentially) or Pascal (negative binomial) distributed lags. A distributed lag model has the same form expressed in (5), but in this case, $N_{t}$ necessarily has to be gaussian white noise $N_{t} \sim N(0, \sigma)$. The disadvantage of this second approach is that a pre-specified distribution is imposed on the data, while the advantage resides in the relatively parsimonious form of the model: as less parameters are to be estimated, smaller sample sizes are required for estimation.

Method 2 is presumed to provide an approximation to cycle time distribution and return rate while eluding the need of empirically observing reusable articles turnaround behaviour through item-level tracking. However, few attempts have been made to estimate the relationship between returns and past sales using actual data from industry. The method is not reported to be used in practice in none of the industrial case studies we have dealt with. When brought to practice, 
the estimates of cycle time distribution and return rate obtained through model (5) are reported to be not always realistic. Estimation problems are reported in Goh and Varaprasad (1986) (daily and weekly counts), Fleischmann et al. (2002), Van Dalen and Van Nunen (2009) and Carrasco-Gallego and Ponce-Cueto (2009b).

We have identified three main shortcomings in this method:

- $\quad$ - First, method 2 assume that cycle time distribution is stationary $\left(\left(v_{0}, v_{1}, v_{2}, \ldots v_{\infty}\right)\right.$ parameters are constant values to be determined), while empirical observations show that the turnaround process duration may evolve throughout time. Cycle time average value varies also with the product demand seasonality (Van Dalen et al., 2005, Van Dalen and Van Nunen, 2009; Carrasco-Gallego and Ponce-Cueto, 2009b, Case \#1 (Medgas) and Case \#2 (LPG)). Then, a non-stationary description of cycle time distribution might be necessary. are not constants but functions of time.

- Second, dynamic regression models used in method 2 rely on the assumption that that causality is unidirectional from the input variable $\left\{x_{t}\right\}$ (sales) to the output $\left\{y_{t}\right\}$ (returns). Feedback from the output to the input is ruled out. If returns timing and quantity influence somehow sales figures, the use of dynamic regression models for drawing cycle time and shrinkage rates parameters would be invalidated.

- Third, in practice, returns timing does not depend only on sales timing and the time required for products consumption but also on other operational factors, such as the way transportation is organized between depots. Used articles are usually stocked for some time in order to achieve economies of scale in transportation. Articles do not "freely" return to plant just after use, as suggest the impulse response functions in model $(5)\left(v_{i}\right.$ coefficients).

\section{Informational level: item-level tracking}

Item-level tracking systems provide real empirical data that can be used to obtain information about the average cycle time, a measure of its dispersion and the cycle time distribution shape. In order to explore cycle time behaviour, item-level tracking can be implemented either in the whole fleet or just in a sample of articles. The resulting cycle times and other turnaround 
process parameters empirically observed in the sample can be inferred (if experiments are well designed) to the reusable articles population (van Dalen and van Nunen, 2009). The technology used to track individual articles can range from human observations registered with pen and paper or in spreadsheets to bar code or RFID tagging. Regardless of the tracking technology used, articles need to be serialized in order to follow cycle times.

Within this informational level, the data obtained through the tracking application can be used by managers for observing the behaviour of the turnaround process and the way it varies over the time.

\subsection{Solutions proposal: purchase policies}

After the completion of the four steps of the methodology presented in section 6 , the target fleet size $(N)$ is calculated, given current demand and cycle time conditions. Next, in the day-to-day operations, purchasing policies for new articles replacing the irreparably lost ones need to be set (issue 5.4). To establish a purchasing policy for "fleet maintenance", managers need to take into consideration:

- the target fleet size $(N)$, which depends on reusable articles demand and cycle time

- the return rate $(r)$

To maintain the fleet size dimension in the appropriate level, $N \cdot(1-r)$ articles will have to be reinjected in system in the time horizon of reference. Firms will periodically determine the number of lost articles since the last system-wide inventory levels review (including articles in circulation and at customer use stage) and will replace them till the target fleet size is reached again. The objective of the purchasing policy is to determine the timing and quantity of new articles purchasing batches so that total costs (holding costs, acquisition costs...) are minimized.

We surveyed inventory control models with product returns and analyzed their applicability in the context of reuse CLSC. The results are presented in Addenda 3. As a result of this analysis, we obtained the following conclusions:

1. Inventory control models need to take into account the characteristics of the demand pattern the reusable articles system faces in each case (continuous vs intermittent demand, 
first output of steps one and two in figure 5). RTI and RPM articles (packaging elements) are expected to show a normal continuous demand, linked to the demand pattern of the real product: the contents. RP articles (surgical instruments, service tools, books, rental articles) are expected show intermittent demand, linked to the usage pattern of the article in each case (operations theatre scheduling, preventive maintenance operations planning (preventive actions) and breakdown occurrence pattern (corrective actions), etc.).

2. In the context of reuse CLSC (high return rates not too far away from 1 , new and used articles are perfect substitutes), inventory control models with product returns need to adopt a "system-wide" view: the inventory level to be taken into account includes not only the inventory at the facility under study (the depot) but also the inventory available in the rest of the system (customers, distributors, other depots in the case of multi-depot networks). A substantial part of this inventory (80-99\%), which is not on-hand at the moment in the depot under study, will come back to the facility after the completion of corresponding cycle time. Then, if in purchasing policies we do not take into account the available inventory in the system (and focus only on the on-hand inventory in the unit-of-analysis: a single depot), we will systematically over-estimate of the replacement needs, resulting in high inventory holding costs.

3. To the best of our knowledge, very few inventory control models adopt this "system-wide" view of the inventory system, as most models work with decoupled issues and returns and do not consider the inventory available in other locations of the system that will eventually come back. We have identified the few contributions that explicitly model the dependency between demand and returns (consider system-wide inventory levels) in the second row of Table 5 (embedded in table 4).

4. For the sake of mathematical tractability of the problem, all the models in the second row of table 5 use net demand (demand-returns) in their inventory model expressions. Netting implicitly assumes that returns occur exactly when needed, which in frequently not the case in reuse CLSC. Netting translates in an underestimation of the replacement needs, causing costly stockouts.

5. The final conclusion is that particular characteristics of reuse CLSC (high return rates 
not too far away from 1, new and used articles are perfect substitutes, firms have limited control over returns timing) have not been grasped in any of the inventory models described in the academic literature, constituting an opportunity of further research for the operational research and operations management academic communities.

\subsubsection{Addenda 3. Inventory control models with product returns Are they suitable for reuse CLSC?}

As most supply chain management areas, inventory management has traditionally focused on the forward supply chain, developing appropriate control mechanisms for consumables inventory systems. However, due to the increased importance that reverse logistics and closed-loop supply chains are gaining in the last few years, new developments have been made in the field of inventory management with product returns. Inventory management is one of the most lively researched areas in CLSC: the incorporation of an exogenous return flow to inventory control models complicates the management of the inventory system. The issue is to verify if traditional inventory control methods are still valid in CLSC context. In the following we review inventory models with product returns .Our intention is not to be exhaustive but to identify if the already available body of theory can be directly applicable to reuse CLSC and in case not, detect what is missing.

Inventory control models with products returns can be classified in the following categories:

1. Recoverable Item Control (Multi-echelon models). Repairable inventory theory.

2. Inventory control with product returns. Imperfect correlation between demand and returns.

1) Recoverable Item Control (Multi-echelon models). Repairable inventory theory.

This stream of research stems mainly from METRIC model (Sherbrooke, 1968), originally developed in the military context. METRIC objective is to set the optimal levels of systemwide inventory distributed at bases (forward locations) and a central depot. At the depot, failed articles returned from the subsidiary bases are repaired, while a pre-specified service level 
(minimize the number of stockouts) is assured. Recoverable articles (weapons) are demanded at the bases and returned to the depot for repair after use with a given probability. Bases inventory is resupplied from its corresponding depot.

METRIC model and its extensions try to minimize system-wide inventory, as problem is formulated as a multi-echelon model (the total investment in inventory, which is distributed in the depot and its corresponding bases is considered). However, some of the assumptions made in these models make their application to reuse CLSC somehow unrealistic:

- First, recoverable items demand follow a Poisson distribution. Therefore, METRIC models would only suit for RA following an intermittent demand. When articles' demand is better described by a continuous random (and probably non-stationary) variable, METRIC models would not be suitable anymore.

- Second, METRIC models assume that there is perfect correlation between demand and returns. That is, a return (weapon failure) will automatically generate a demand for a replacement item. In reusable articles system this strong assumption is not typically fulfilled. Mathematically, perfect correlation between demand and returns implies that the inventory level is a monotonic decreasing function. In real reuse CLSC, the total inventory of articles may also increase over time when the return flow exceeds demand in the current period.

- Third, METRIC models assume that the system is closed, that is, that no condemnation of recoverable items occur. The total number of units in stock in the whole system is constant. No plans are required then for new articles procurement quantities and timing.

We refer the reader to Guide and Srivastava (1997) for a comprehensive review of METRIC models and its extensions.

\section{2) Inventory control with product returns. Imperfect correlation between de- mand and returns.}

1. Most inventory control models with product returns developed in the last few years do not assume that a return will automatically generate a simultaneous demand for a replacement 
item. Returns represent an exogenous inbound flow causing loss of monotonicity of stock levels. Models' mathematical formulation involves higher complexity in this case. Hence, it is not strange that research has been focused for the moment in the more simple approach of finding the optimal inventory management policy from the point of view of a single facility (single-echelon models, although some authors distinguish a two-level inventory structure of returned and serviceable items). The main shortcoming of this "narrow-view" (one facility) approach when applied to star reusable article systems is that the resulting inventory optimization is local, focused in the central facility, while system-wide inventory levels (including inventory at customers, distributors, etc), owned by the firm but not at hand (they are in the customer -use stage) are not considered. An exception is represented by themulti-echelon models developed in DeCroix et al., 2005; DeCroix and Zipkin, 2005 and DeCroix, 2006, which explicitly consider a system-wide multi-echelon structure. However, their application to the case of reuse is limited because, as it is explained beneath, independent processes for demand and returns are considered in these three papers.

Inventory control models with product returns can be further classified in deterministic and stochastic models.

Deterministic models extend the classical EOQ theory to the case where a return flow exists. This type of models concentrate in finding the optimal procurement batch for replacing worn out (irrecoverable) articles or the optimal batch size for repairing used articles. Some relevant examples of this type of deterministic models include Schrady (1967), Richter (1996), Koh et al. (2002), Teunter (2004) or Thoroe et al. (2009). All these deterministic models assume independent demand and returns processes (no explicit consideration is done of reusable articles that are at customer use stage).

In the case of stochastic models, most papers assume that the demand and returns processes are independent (De Brito and Dekker, 2003). In addition, many papers explicitly assume that demand and return processes are Poisson, which is most suitable to intermittent demand patterns. In Table 5, we classify some relevant stochastic inventory control models with items returns depending on: 


\begin{tabular}{|c|c|c|}
\cline { 2 - 3 } \multicolumn{1}{c|}{} & Poisson demand & $\begin{array}{c}\text { Continuous random demand } \\
\text { (or no explicit assumptions) }\end{array}$ \\
\hline $\begin{array}{c}\text { Independent demand } \\
\text { and returns }\end{array}$ & $\begin{array}{c}\text { Fleischmann et al. (2002) } \\
\text { Fleischmann and Kuik (2003) }\end{array}$ & Inderfurth (1997) \\
\hline $\begin{array}{c}\text { Dependent demand } \\
\text { and returns }\end{array}$ & $\begin{array}{c}\text { Yuang and Cheung (1998) } \\
\text { Kiesmüller and Van der Laan (2001) }\end{array}$ & $\begin{array}{c}\text { Kelle and Silver (1989a,b) } \\
\text { Buchanan and Abad (1998) }\end{array}$ \\
\hline
\end{tabular}

Table 5.2: Stochastic inventory control models with returns: some relevant contributions. Own development.

- the type of assumptions made for the demand process:

- Poisson - models suitable for articles presenting an intermittent demand pattern

- continuous random variable (or no explicit assumption) on demand process - models suitable for articles with a continuous demand pattern.

- the explicit modeling of the dependency between demand and returns.

Inventory control models assuming independent demand and return processes seem to be realistic when the return intensity is not too close to 1 , as happens with commercial returns or in remanufacturing settings. However, when dealing with reuse CLSC, where most demand is fulfilled with used products (return rate ranging between 80-99\%) and new and reused products are perfect substitutes, the demand and returns independence assumption in inventory models needs to be revisited as suggest the results shown in Fleischmann et al. (2002). When returns intensity is close to 1 , the on-hand inventory "explodes" when the optimal parameters of an $(s, Q)$ policy are calculated and applied. Similar results are obtained in Fleischmann and Kuik (2003) with the optimal $(s, S)$ order policy.

Therefore, inventory models assuming independent demand and return processes (first row in Table 5.2) may not be directly applicable for setting new articles purchasing policies in the context of reuse CLSC. There is a queuing effect when returns rates are high that cannot be eluded in inventory management models aiming at establishing the optimal procurement policies for new reusable articles replacing the irreparably lost ones.

Second row models, which show explicit modeling of the relationship between demand and returns, can be useful for establishing new articles procurement policies. Nevertheless, articles demand pattern has to be taken into account: right-hand cell models are suitable for articles 
with a random continuous demand pattern (packaging elements whose demand is linked to contents demand). Left-hand cell models seem more suitable for articles showing intermittent demand which is the case of many RP: video rentals, tools, books in a library, etc. A common shortcoming arising in the four models is the very simple relationship established between sales and returns, as a result of firms little knowledge on cycle time statistical distribution. Buchanan and Abad (1998) and Yuang and Cheung (1998) postulate exponentially distributed cycle times. Kelle and Silver (1989a,b) assume that cycle time distribution is known (return probability in each period is constant (stationary)). Kiesmüller and Van der Laan (2001) assume a constant cycle time.

However, the main shortcoming of the four bottom-row models resides in the fact that, for the sake of simplicity, the net demand (demand minus returns) is used in the inventory models expressions. This netting approximation seems to work well for small return ratios. However, netting implicitly assumes that returns occur exactly when they are needed which is not always true in reality. As a result of this analysis we can conclude that there are still room for generating appropriate inventory control models for the specific case of reuse CLSC (returns intensity close to 1$)$.

\subsection{Conclusions}

In this chapter we have presented a framework (conceptual model) that synthesizes the main aspects involved in the management of a reuse CLSC. The model contributes to a better understanding of the main factors that make the management of a reuse closed-loop supply chain more complex than the management of the classical one-way supply chain (use-and-dispose model). Besides, we described in the chapter several solutions for helping industrial practitioners to deal with the new issues arising with reuse. From the academic point of view, chapters 4 and 5 cover a gap detected in the body of literature pertaining to reverse logistics and closed-loop supply chains. Most research in this knowledge area has focused in remanufacturing or commercial returns activities whereas reuse CLSC had not been widely researched for the moment. From the practice point of view, we expect this conceptual model can contribute to mitigate the managerial difficulties associated with reuse and facilitate a wider spread of reuse practices in 
real production-distribution systems.

The framework comprises three main building blocks: common problems observed in reuse CLSC (fleet shrinkage, significant investment, limited visibility), basic information requirements (metrics) needed to deal with these problems (cycle time, return rate, inventory on-hand at each location of the network) and the six managerial issues that practitioners have to expect to face when confronted with a reuse CLSC. Regarding the solutions (orange and blue arrows in figure 4) that have been proposed to some of these issues, we analyzed the control strategies aiming at the reduction of fleet shrinkage and the promotion of articles rotation in the system. Depending on the situation at hand, some control strategies will be more suitable than others. We also proposed a methodology for deciding how many RA need to be in circulation in the network. An aspect to highlight is that this method can be used either in star and multi-depot networks. Fleet size calculation is a design decision to be adopted for the first time during the set-up of the reusable articles system. This decision is also to be revisited when structural changes in RA's demand and cycle time distribution take place (redesign context). In addition, as noted in issue 5.4, lost or damaged articles have to be replaced by new articles purchases in order to maintain the adequate "capacity" of the fleet (fleet size maintenance). We have pointed out in the final section of the chapter further research opportunities regarding inventory control policies aiming at the definition of the optimal purchasing policies for replacing lost or damaged reusable articles in the fleet. 


\section{Chapter 6}

\section{The impact of using the equal}

\section{exchange recovery strategy in reuse CLSC}

\subsection{Introduction}

A wide range of companies employ nowadays reusable articles in their supply chain networks. The introduction of reusable articles is motivated by a search of efficiency: firms tend to reduce costs, as well as the amount of waste, associated with their manufacturing and logistical operations. The sustainability paradigm is expected to increase in the following years the number of applications in which reusable articles are involved in, given their contribution to the economical and environmental sustainability of production-distribution systems. In Chapter 4, we have a presented a typology which includes under the reusable articles term not only the "traditional" reusable elements linked with packaging, but also those items where the article reused is the product itself (rental cars, bikes, surgical instruments, service tools,...). As was explained in chapter 4 , the reusable articles term involves:

- Returnable transport items (RTI), basically load carriers or distribution items, such as pallets (road, train and air cargo), racks for automobile engines or crates (beer, bread, flowers, postal services). 
- Reusable packaging materials (RPM), including:

1. containers: such as glass bottles in the soft drink industry (to be delivered through HORECA channel), cylinders for liquids (LPG) or pressurized gases (medical oxygen), kegs in the beer industry or special containers in the chemical industry.

2. Packaging elements in direct contact with the product itself: special boxes for medical equipment or for wind farms spare parts.

- Reusable products, such as rental cars, public rental bikes systems, surgical instruments, service tools, $\ldots$

Reusable articles constitute a type of closed-loop supply chain (CLSC) that has been designated in this dissertation as "reuse CLSC". As in any other CLSC, a main design issue in reuse CLSC is to ensure a steady return flow (Guide and van Wassenhove, 2001) that enables the company to fulfil the demand of RA. Therefore, when designing the organization of a reuse CLSC, a strategy or set of strategies have to be chosen and implemented in the system in order to avoid as much as possible loss, theft or alterative usage of RA, as well as to promote its rapid circulation in the network. These are some of the managerial issues that have been identified and discussed in the conceptual model presented in Chapter 5. In that chapter, we analysed the following recovery strategies as a solution to the operational problems of controlling and improving the return rate and cycle times of reusable articles. These recovery strategies, which are characterized with more detail in section 5.6 include (a) deposit, (b) rental, (c) account management with periodical payments, (d) equal exchange (swapping), (e) immediate retrieval, (f) direct return after use. The three former strategies ( $a, b, c)$ are mainly based in an economic incentive for return whereas the three latter strategies $(d, e, f)$ are based in "physical" restrictions imposed to the system in order to assure RA return. A final recovery control strategy which does not rely on economic or physical incentives, but on supply network relationships, is to force users' accountability for the return of reusable articles. As our field studies showed, mixed strategies are also possible in practice (deposit and equal exchange, account management and equal exchange, direct return after use and rental,... )

The research conducted until now on closed-loop supply chains has not deeply dealt with the impact that these recovery strategies have in reusable articles return flows (c.f. section X.X, 
Related work). Incentives for product recovery in the general framework of reverse logistics are addressed in De Brito et al. (2005) and Flapper (2003); some of the tools they enumerate can be directly applied in the narrower context of reuse CLSC. Dubiel (1996), Flapper (1996), Fleischmann (2003, section 3.5) or Breen (2006) also refer to some strategies to stimulate the desired behaviour of partners in the particular case of RTI, but limit themselves either to list possible strategies or to briefly characterize them, but they do not model the impact that these strategies can have in the behaviour of customers and suppliers.

In this chapter, we focus on the impact of one particular recovery strategy which is widely used in practice (c.f. section 2 for a justification of this statement), the so-called equal exchange recovery strategy, which consists of the swapping of the same number of full-empty or newold units at the moment of the delivery: the customer is required to return exactly $n$ used (empty/old) RA as a condition to be delivered with $n$ as-new (full/new) RA.

The general aim of this chapter is to measure in terms of cost the impact of the equal exchange recovery strategy from both the customer and supplier point of view. The research question that is dealt with in the chapter is: in which situations is the equal exchanges recovery strategy more suitable? When it is not?

In order to achieve this aim, a two-level decision problem is considered. The optimal behaviour of both the customer and the supplier has been formalized using two Mixed-Integer Linear Programming (MILP) models. Both models are subject to the equal exchange recovery strategy. First, a model representing the point of view of the customer is put forward. The output of this first model is the optimal set of orders for the customer, who aims at minimizing his total relevant costs over the planning horizon T. In the so-called "customer model", only the costs incurred by customer are considered. The output of the first model is used as input for the second model, the so-called "supplier model". This model aims at minimizing the total relevant costs, from the supplier point of view, over the same planning horizon. In this model the supplier is confronted to the customer demand determined in the first model. It does not matter for the supplier model how the customer orders were determined in the first stage of the decision problem, they are taken as given values. Given this demand, the optimal reconditioning and transport plans, taking into account only the relevant costs for the supplier, are determined. 
The general aim of the chapter can be broken down in the following specific objectives:

- To characterize the equal exchanges policy and to position the research problem put forward in this chapter in scientific literature.

- To develop a MILP model from the customer point of view.

- To develop a global MILP model integrating the customer and the supplier point of view.

- To assess the performance of the equal exchange recovery strategy through a series of numerical experiments.

- To compare the results obtained for the equal exchange recovery strategy with the results from alternative recovery strategies.

The chapter is organized as follows. In section 2, we address the characteristics of the equal exchange recovery policy and we position our paper among the related literature in the areas of CLSC of RTI and repair inventory control models with a new-for-old exchange of spare parts. In section 3 we present the model representing the point of view of the customer. We go on in section 4 to introduce the model representing the complete supplier-customer system from the point of view of the supplier. In section 5, carry out a numerical analysis to asses the performance of the equal exchanges policy under different scenarios (different levels of seasonality) and we benchmark it with other recovery policies. Finally, in section 6 , we present our conclusions and future developments.

\subsection{Literature review}

\subsubsection{Characteristics of the equal exchange recovery strategy}

The equal exchange of new-for-old (or full-for-empty, as is also known when referring to packaging elements) recovery policy has received a variety of names in literature: one-for-one system (Breen, 2006), full-for-empty swapping (Roseneau et al., 1996; Twede and Clarke, 2004; Johansson and Hellström, 2007), full-for-empty switch (Hellström and Johansson, 2010), direct replacement (Flapper, 1996), "new for old" (Flapper, 2003) or direct old-for-new exchange 
(Fleischmann, 2003). All these authors refer to the recovery strategy consisting of the following rule to be observed by supply network partners: at the moment of delivery of an order, the customer has to return as many reusable articles (RA) as the number of RA being delivered in the new order. However, there is not an standard term in literature for referring to this policy.

Therefore, we put forward the use of the term "equal exchange" and propose the following definition :

Recovery strategy used in practice in closed-loop supply chains of reusable articles consisting in the following rule to be observed by supply network partners: at the moment of delivery, the customer is requiered to return exactly $n$ units of used $R A$ in order to receive an order of $n$ units of as-new $R A$.

Note that this definition can be applied to all the three types of RA put forward in this thesis: RTI, RPM and RP. The words as-new and used can be replaced by full and empty respectively, in the case of packaging elements, or sterile and contaminated in the case of some reusable products, such as surgical instruments.

The equal exchange strategy is a quite extended control mechanism in reuse CLSC. From our interaction with companies using RA, we found this strategy to be widely extended in practice, especially in the context of packaging articles (RPM and RTI of medium and low value). We have contrasted the use of the equal exchange recovery in the following case studies (Chapter 4): industrial and medical gases industry (cylinders, case \#1), liquefied petroleum gases LPG industry (cylinders,case \#2), roll cages in the horticultural industry (Flora Holland, case \#6). Moreover, this recovery strategy also appears frequently in other case studies published in the academic literature: roll containers in the diary manufacturer Arla Foods (Johansson and Hellström, 2007), reusable containers and racks in the automotive industry used for suppliers to directly deliver in the assembly line (Roseneau et al., 1999; Twede and Clarke, 2004, Volvo case), bottle crates and bottle pallets in a company in the beverage industry (Kärkkäinen et al., 2004), beer kegs in a brewery (Breen, 2006), soft drink glass bottles to be delivered in the HORECA channel (Del Castillo and Cochran, 1996, Privé et al., 2006), pallets in the consumer goods industry (Ilic et al., 2009). High value RTI (maritime containers, railcars), as well as RP (bikes, cars, surgical instrumentation,...) rely as typical physical incentive on direct return 
after use.

The equal exchange policy results advantageous because it constitutes a simple mechanism for preventing losses (no administrative efforts are required) and also because its application simplifies transport organization integrating forward and reverse flows. Vehicle routing is done attending to forward flows and empty RA are returned in the backhauls of delivery routes (using both legs of the vehicle route generally leads to transport cost savings). Capacity constraints in the vehicle usually lead to restrict the number of articles that can be recovered to the number of articles delivered (having left room in the vehicle). This issue is part of the rationale for using the equal exchange recovery strategy.

However the equal exchange strategy also has a number of disadvantages. First, in this chapter we postulate that equal exchanges policy is not suitable for RA which requirements heavily fluctuate. This is the case of RA linked with products showing a marked seasonality in its demand patterns, such as beer, LPG or medical oxygen: during the high season the customer will be willing to place larger orders but their consumption is restricted because of not having enough old/empty articles to give in exchange. On the other hand, articles left after a peak in sales cannot be returned before the next peak. Therefore, the equal exchanges strategy in seasonal products requires a container fleet size wider than strictly necessary.

Other disadvantage of the equal exchange strategy is related to the exceptions to be made the first time a customer is delivered, as no old/empty RA are available to be exchanged in that case. Moreover, the policy has to be complemented with other economic incentives in order to encourage customers to return old/empty articles if they decide not to buy the product again. Another disadvantage is related to the fact that with the equal exchange policy, the RA return flows pass through all the stages (echelons) of the forward supply chain. In the case of supply chain networks with a high number of intermediaries, cycle time will be negatively affected by the use of this strategy, as some stages cannot be by-passed in order to obtain shorter lead times for returns.

On the contrary, the equal exchanges strategy may notably be useful in the case of just-intime (JIT) deliveries and is reported to be used in the automotive sector for reusable containers exchange between suppliers and the assembly line (Rosenau et al., 1996, Twede and Clarke, 2004, Volvo case). JIT systems work well in environments with an even demand pattern, which 
seem to be the most suitable to equal exchange recovery strategy.

The models put forward and solved in this chapter will enable us to confirm the statements postulated in this subsection, regarding the suitability of the equal exchanges strategy in different industrial situations.

\subsubsection{Positioning the research problem: related work}

The research conducted until now on closed-loop supply chains has not deeply dealt with the impact that recovery strategies have in reusable articles return flows. Incentives for product recovery in the general framework of reverse logistics are addressed in De Brito et al. (2005) and Flapper (2003); some of the tools they enumerate can be directly applied in the narrower context of reuse CLSC. Dubiel (1996), Flapper (1996), Fleischmann (2003, section 3.5) or Breen (2006) also refer to some strategies to stimulate the desired behaviour of partners in the particular case of RTI, but limit themselves either to list possible strategies or to briefly characterize them, but they do not model the impact that these strategies can have in the behaviour of customers and suppliers. To the best of our knowledge, this is the first attempt done in academic literature in order to check the impact that the use of one particular recovery strategy can have in the performance of a closed system with return flows.

Somme common characteristics can be found between the problem we research in this chapter and the body of literature related with parts batching in the context of repair services, such as Deneijer and Flapper (2005). In this paper, new service parts are in the vans of service engineers and when a breakdown appears, an exchange of a defective spare part by a new spare part takes place. However, the situation is not exactly the same in both problems. First difference is that no exceptions arise in the service parts problem (parts are always taken back) while with packaging elements an exception has to be made in the first delivery. Second, the order lot-size in the context of repair at the customer locations is usually one (or the number of spare parts required to solve the problem) whereas with packaging elements the lot-size is typically bigger than one. Another difference is that breakdowns appear randomly, unexpectedly. In the case of packaging elements, the demand is, at least, predictable. Finally, it should be emphasized that the objectives of an equipment replacement model or a spare parts model are different to the ones in RA (especially packaging elements and containers systems). In repair, salvage value 
of the old spare part is important. In RTI and RPM, such salvage value is not an objective of managers. Their focus is in minimizing the investment in new units of packaging.

\subsection{Problem conceptualization}

\subsubsection{The two-level decision problem description}

Figure 6-1 depicts the simplified supply chain network considered in this chapter. For the sake of simplicity, only one supplier and one customer are considered. The reusable article considered in this decision problem are containers used to distribute an specific product, such as medical oxygen or LPG. In the reminder of the paper we will focus in a closed-loop supply chain of containers in order to make our reasoning clearer. However, the results we will obtain can be extended without loss of generality to any other type of RA (RTI, RPM or RP) as the dynamics of the models we put forward are independent from the particular characterisitics of the product involved. The focus of these dynamics is on the limits that are imposed to the system by the recovery policy used.

In the closed-loop supply chain depicted in Figure 6-1, two different flows are considered. The forward flow concerns full containers that travel from supplier to customer The contents (i.e. gas) is consumed at the customer and the resulting empty containers follow a reverse flow from the customer to the supplier. At the supplier facility, empty containers are reconditioned and filled again in order to be ready for a new use cycle. All the processes considered in the network: filling, forward transit from supplier to customer, product consumption and reverse transit from customer to supplier take a lead time of one period. In both the customer and the supplier an inventory of full and empty containers is kept.

Note that in this simplified network no container losses due to theft or irrepairable damage are considered. Reconditiong operations involving a higher complexity (in terms of lead time) than filling, such as hydraulic tests (c.f. section $\mathrm{X}$ in chapter 4) or repair are not considered either. However, the external supply of new containers for delivering the customer is explicitly considered in the model. New containers for the delivering the orders of the new customer can only be bought once, at the beginning of the planning horizon. This situation is compatible with the very long delivery time for new containers experienced in practice (Wyld, 2009, case\#1 


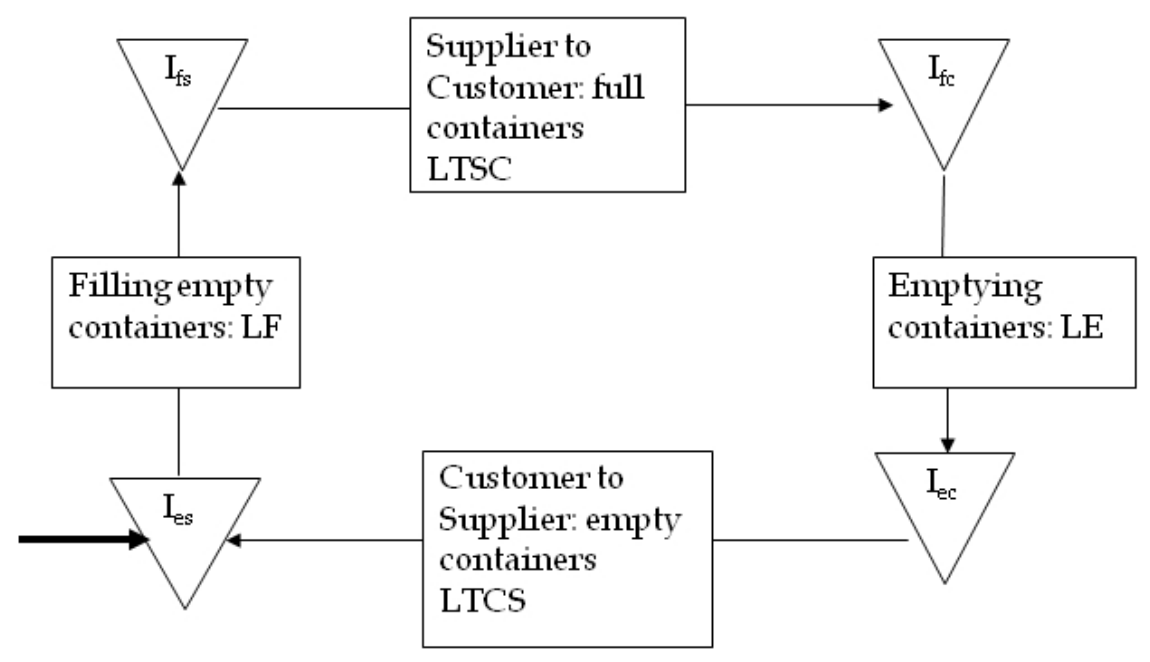

Figure 6-1: The simplified container network. Own development.

MedGas, case \#2 LPG). The bold printer arrow at the left hand side bottom in Figure 6-1 denotes the external supply of new empty containers at the supplier's facility.

As was explained in the Introduction section, a two-level decision problem is put forward in this chapter. First,a MILP model will be used to obtain the optimal set of orders from the point of view of the customer. Second, the output of the first model is used as input for a second MILP model representing the system from the supplier point of view. The optimal filling and transport plans over the considered planning horizon, when the supplier is confronted to the customer demand obtained from the first model, are the results of this second model.

Both MILP models put forward in this chapter use discrete time intervals. The discretization of time used for models' formulation is represented in 6-2. Order placement and deliveries can only take place at instants $i, i=-1,0,1, \ldots, T, T+1$. We refer to the time elapsing between instant $t-1$ and instant $t$ as period $t$. The demand at the customer corresponding to time period $t$.is denoted by $D(t)$.

\subsubsection{Model assumptions}




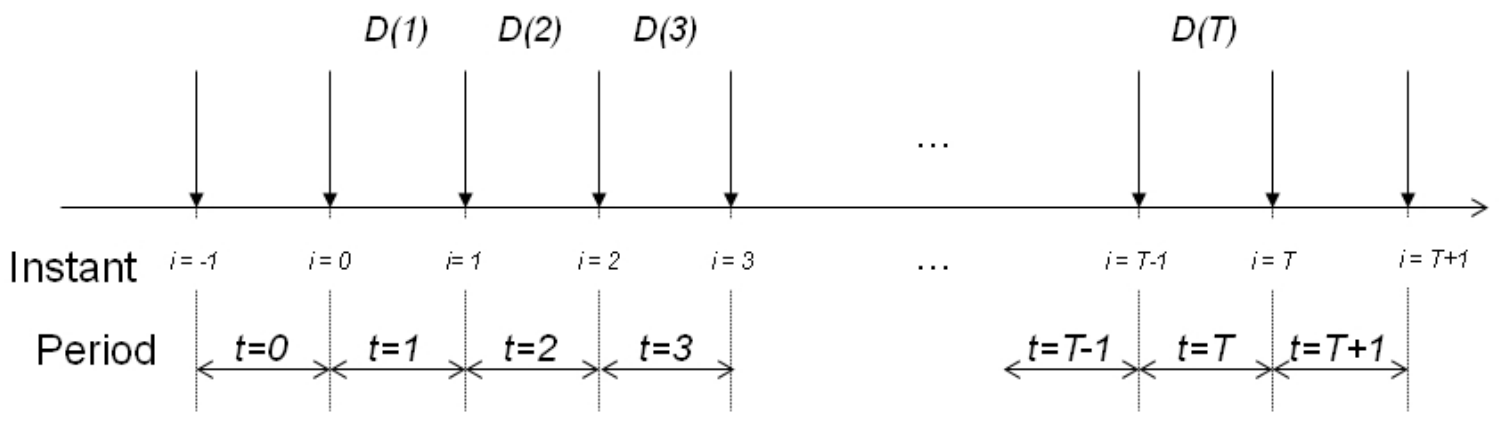

Figure 6-2: Periods definition. Own development.

\section{- General assumptions:}

- 1 supplier - 1 customer

-1 product

- Product distributed in a container

- Product in container does not deteriorate.

- Container does not deteriorate.

- The equal exchange recovery strategy works as follows:

- Customer orders are subject to the following general rule: the supplier will deliver $n$ full containers (previously ordered by the customer) only if the customer is able to give back, at the moment of delivery, exactly the same amount ( $n$ units) of empty containers.

- An exception to the general rule applies to the first time a customer is delivered (instant $t=0$ ): the customer order is delivered without the need of returning the same amount of used/empty RA.

- Another exception to the general rule is considered in the last period. At the end of the planning horizon, all the (potential) full and empty containers remaining at 
the customer will be retrieved by the supplier. Empty and full containers at the customer directly at the beginning of period $T+1$ are collected and transported to the supplier in order to be collected by the third party collecting all containers at the supplier directly at the beginning of period $T+2$. The supplier pays for the collection of the containers at the customer directly at the beginning of period $T+1$.

\section{- Customer demand:}

- Customer demand is deterministic and known at the beginning of the planning horizon.

- Demand spans over a planning horizon of $\mathrm{T}$ periods, from $\mathrm{D}(1)$ to $\mathrm{D}(\mathrm{T})$.

- Customer demand in a time period is an integer number of containers $(0,1,2, \ldots)$, so partial consumption of one container is not considered.

- All demand always has to be fulfilled immediately (no backlogs nor lost sales allowed).

\section{- Lead times:}

- The lead time for RA reception in the forward logistics flow is 1 period. Hence, $\mathrm{RA}$ ordered at the beginning of a time period $t$ (instant $t-1$ ) are received at the beginning of the next time period (instant $t$, beginning of time period $t+1$ ). In other words, an order issued at the beginning period $t$ is delivered at the beginning of period $t+1$, just before demand in period $t+1$ starts. Note that at the moment of delivery, $n$ full containers would be handed to the customer while exactly $n$ empty containers would be retrieved.

- The lead time for RA reconditioning (filling) is also 1 period: empty containers enter the filling process at the beginning of period $t$ (instant $t-1$ ) and exit as full containers at the end of the period (instant $t$ ). This full containers can be transported to the customer directly during period $t+1$ and become available at the customer at the beginning of period $t+2$.

- The lead time for RA use (consumption / emptying) by the customer also takes 1 period, i.e. containers used (emptied) during period $t$ can be collected at the beginning of period $t+1$ (instant $t$ ) when filled containers are delivered. 
- The lead time for RA return transportation (reverse logistics) is $\mathbf{1}$ period: empty containers collected at the beginning of period $t$ at the customer arrive directly at the beginning of period $t+1$ at the supplier.

\section{- Objective functions:}

- Customer goal is to satisfy demand against the lowest undiscounted cost.

- Supplier goal is to satisfy demand against the lowest undiscounted cost.

\section{- Costs and system's limitations.}

We consider the following costs and limits in the system:

\section{- Transport and ordering costs. Customer and Supplier.}

* Fixed ordering cost for customer and supplier, independent of quantity ordered. The fixed ordering cost in the case of supplier is linked with the set up cost of forward and reverse transport. In the case of the customer is linked to the administrative workload for ordering.

* Variable transport cost (to be paid by the supplier), depends linearly on the number of containers to be transported.

* Variable ordering cost (to be paid by the customer), depends linearly on the number of containers ordered. Is the purchase price to be paid by the customer for the contents (the product).

\section{- Container stock keeping (holding) costs. Customer and Supplier.}

* Container stock keeping cost for customer and supplier includes opportunity cost for contents and container, and the cost related to actual storage.

* In addition, the customer stock keeping cost includes the container rental fee to be paid each day he has the containers at his inventory (account management with periodical payments).

* No container storage space restrictions at the customer (ilimited storage capacity at customer). 
* No container storage space restrictions at the supplier (ilimited storage capacity at supplier)

- Reconditioning (filling) costs. Supplier

* Filling costs are neglectable.

* The production of the contents (.e.g., gas) can be decoupled from the fill process.

* Infinite fill capacity.

* There is always enough product to fill whatever quantity of containers.

* Containers returned to the supplier can directly be reused. Any cleaning or repair operations require a neglectable time. No loss of containers due to unrepairable damage or theft is considered.

- Fleet acquisition costs. Supplier.

* New containers can be bought only once (e.g. due to a very long delivery time (Wyld, 2009)), at the beginning of the planning horizon.

\subsection{Customer model}

In this section, the model for optimal ordering from the point of view of the customer is formulated. Firstly, the list of variables and the list of parameters of the customer model are provided.

Next, the sequence of events taking place in a generic time period $t$ is described It should be noted that the first time period $(t=0)$ and the last time period $(t=T)$ constitute exceptional periods and they are characterized accordingly.Finally, the MILP model formulation (objective function and contraints) is introduced and explained.

\subsubsection{List of variables. Customer model}

- $O(t)$ : number of full containers ordered directly at the beginning of period $t$ and delivered directly at the beginning of period $t+1$.

- $Y_{o c}(t)$ : binary variable indicating whether the customer places an order in period $t$. $\left(Y_{o c}(t)=1\right.$ : customer orders directly at the beginning of period $t ; Y_{o c}(t)=0$ : customer 
does not order in period $t$ ).

- $I_{f c}(t)$ : on hand stock of full containers at the customer at the beginning of period $t$ just after the delivery of full containers in period $t$.

- $I_{e c}(t)$ : on hand stock of empty containers at the customer at the beginning of period $t$ just after the retrieval of empty containers in period $t$.

\subsubsection{List of parameters. Customer model.}

- $D(t)$ : number of full containers emptied by the customer during period $t$.

Period $t$ demand occurs between the (potential) moment of delivery of full containers at the beginning of period $t$ and the (potential) moment of delivery of full containers at the beginning of period $t+1$. The actual demand for the product at the customer is assumed to be zero or a natural number of full containers in each time period. Demand elapses between periods 1 to $T$, e.g. $D(0)=D(T+1)=0$. The reader is referred to subsection 6.3.2, where assumptions related to customer demand were listed.

- $C_{o c}$ : fixed ordering cost for the customer per order, independent of the number of full containers ordered.

- $p(t)$ : price that the customer has to pay for the contents of 1 container when ordered directly at the beginning of period $t$ (variable ordering cost).

- $C_{h e c}$ : cost for the customer for having 1 empty container at the beginning of a period, just after the full containers ordered for this period have been delivered.

- $C_{h f c}$ : cost for the customer for having 1 full container at the beginning of a period just after the full containers ordered for this period have been delivered.

\subsubsection{Sequence of events. Customer model}

Figure 6-3 represents the sequence of events taking place in a given time period of the planning horizon. The generic time period $t$ elapses throughout instant $i=t-1$ and instant $i=t$. 


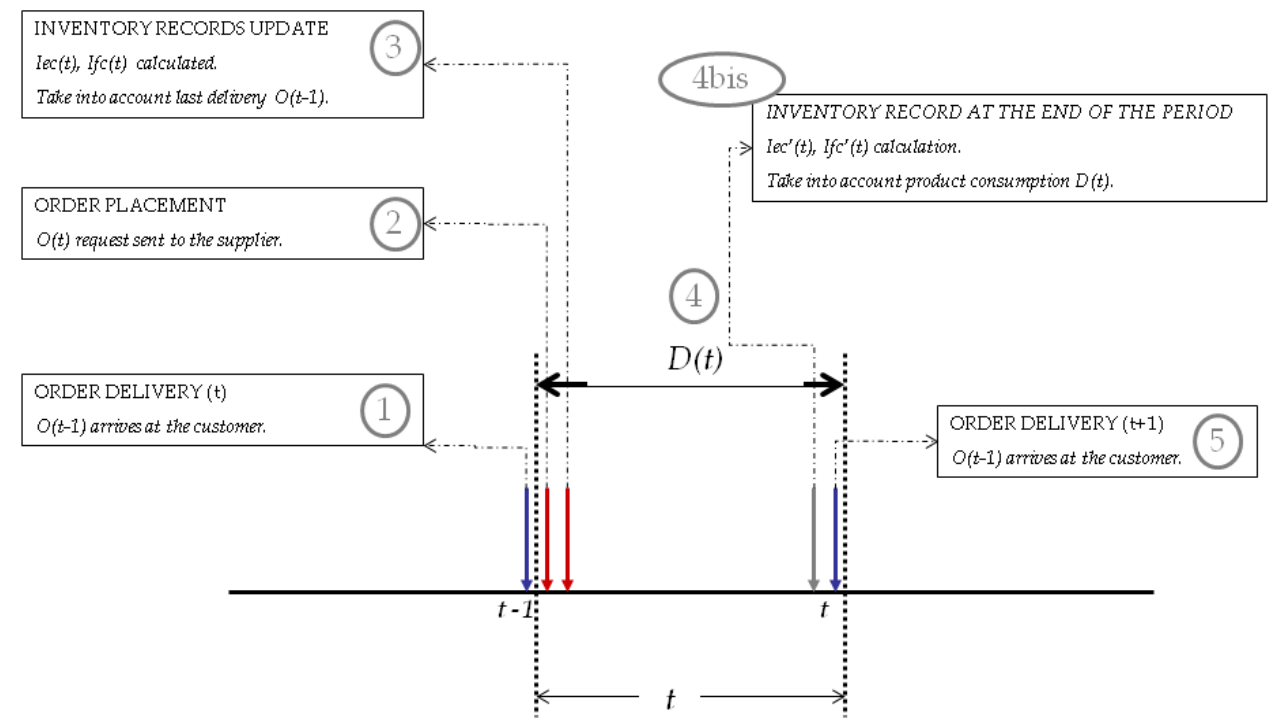

Figure 6-3: Event sequence in a generic time period $t$. Customer model. Own development.

Instant $t-1$ is the beginning of period $t$; instant $t$ is the end of period $t$ (and the beginning of period $t+1)$. We use the notation prima to distinguish between inventory levels registered at the beginning of the period $\left(I_{f c}(t), I_{e c}(t)\right)$, and inventory levels recorded at the end of the period $\left(I_{f c^{\prime}}(t), I_{e c}(t)\right)$. Only the inventory levels recorded at the beginning of a period are included in model formulation. However, $I_{f c}(t)$ and $I_{e c}(t)$ are used for the sake of clarity in this subsection for explaining the sequence of events to be observed in time period $t$.

Note that $I_{f c}(t)$ and $I_{e c}(t)$ record the inventory at the beginning of a period, just after deliveries and shipments take place. $I_{f c}(t)$ and $I_{e c}(t)$ record the inventory at the end of the period, when product consumption has been completed, but just before the forecoming delivery corresponding to period $t+1$.

1. Order delivery $(t)$ : The order $O(t-1)$, placed at the beginning of the preceding period (period $t-1$;instant $i=t-2$ ) is delivered at the customer at instant $i=t-1$. Note that the quantity ordered in a previous period can be equal to 0 . Order delivery increments the inventory of full containers in $O(t-1)$ quantity (equation (1)), while the inventory of empty containers has to be decremented in the same amount (equation (2)), due to the 
equal exchange recovery strategy.

$$
\begin{aligned}
& I_{f c}(t)=I_{f c}(t-1)+O(t-1) \\
& I_{e c}(t)=I_{e c}(t-1)-O(t-1)
\end{aligned}
$$

2. Order placement: Customer places the order $O(t)$, to be delivered at the beginning of next period (period $t+1$, instant $t$ ). It is at instant $t-1$ when the decision on the $O(t)$ quantity is taken.

3. Inventory records update: After delivery, the new on hand inventory of full $\left(I_{f c}(t)\right)$ and empty $\left(I_{e c}(t)\right)$ containers at the customer is registered (use equations (1) and (2)) and the price to be paid for containers rental cost during period $t$ is calculated. The updated inventories take into account the last delivery of containers.

4. Product consumption: Throughout period $t$, demand $D(t)$ is satisfied (demand is always fulfilled). Contents consumption decrements the inventory of full containers (eq. 3) and increments in the same amount the inventory of empty containers (eq. 4). Therefore, the inventory levels of full and empty containers at the end of a period are given by equations (3) and (4).

$$
\begin{aligned}
& I_{f c^{\prime}}(t)=I_{f c}(t)-D(t)=I_{f c^{\prime}}(t-1)+O(t-1)-D(t) \\
& I_{e c^{\prime}}(t)=I_{e c}(t)+D(t)=I_{e c^{\prime}}(t-1)-O(t-1)+D(t)
\end{aligned}
$$

5. Order delivery $(t+1)$ : The order $O(t)$ placed at the beginning of period $t$, is delivered. To be noted that, regardless of the quantity ordered, the maximum amount of containers that can be delivered in $t$ is the inventory on hand of empty containers at the end of period, i.e. $I_{e c} \prime(t)$, due to the equal exchanges recovery strategy. The next period sequence of events starts at this step: the order corresponding to next period $O(t+1)$ is placed, the new on hand inventories $\left(I_{f c}(t+1), I_{e c}(t+1)\right)$ are calculated, etc.

The first time period, $t=0$, constitute a special period, because the first delivery of containers is an exception with respect to the equal exchange policy. Figure 6-4 depicts the event 


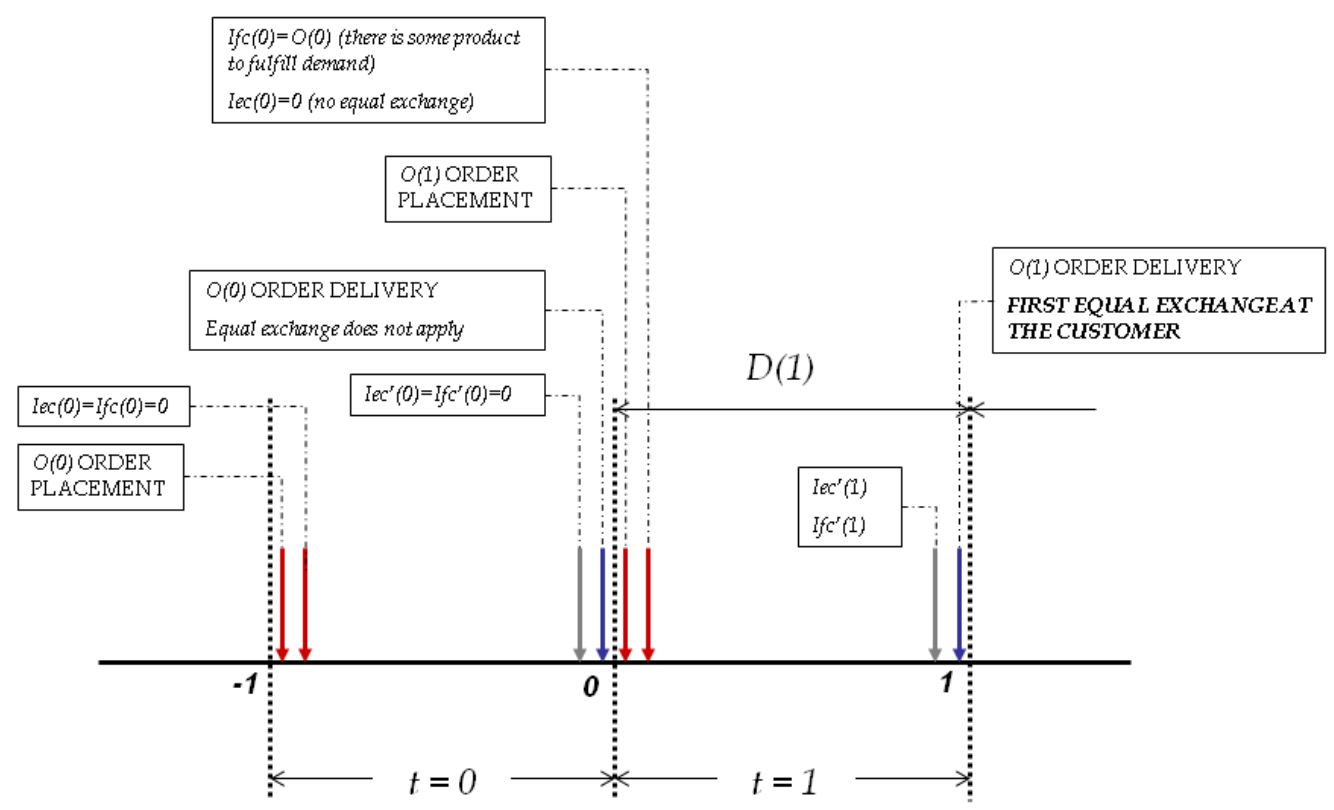

Figure 6-4: Event sequence time period $t=0$. Customer model. Own development.

sequence happening in period $t=0$. The customer starts with no inventory at all of empty nor full containers $\left(I_{e c}(0)=I_{f c}(0)=0\right)$. The first order is placed at instant $i=-1$ and is delivered at instant $i=0$. In this first delivery no empty containers are given in exchange (the equal exchange recovery strategy does not apply to the first delivery), so $I_{e c}(1)$ keeps at 0 level. Product consumption starts in period $t=1$ with $D(1)$. The subsequent deliveries, starting with the delivery of $O(1)$ onwards are subject to the equal exchange strategy.

The final time periods, $T$ and $T+1$, are also special periods. The last period with demand is $T$. The last order is placed in period $T-1$ (instant $i=T-2$ ) and delivered at the beginning of period $T$ (instant $i=T-1$ ). Period $T$ is subject to the same constraints as the rest of periods, except for $O(T)=0$. The inventory at the customer in period $T+1$ is retrieved by the supplier at the end of the planning horizon (instant $i=T$ ) in an special trip (launched at the supplier during period $T$ and arriving at the customer at the beginning of period $T+1$. This special trip aims at retrieving all the containers (full and empty) remaining at the customer at the end of the planning horizon. 


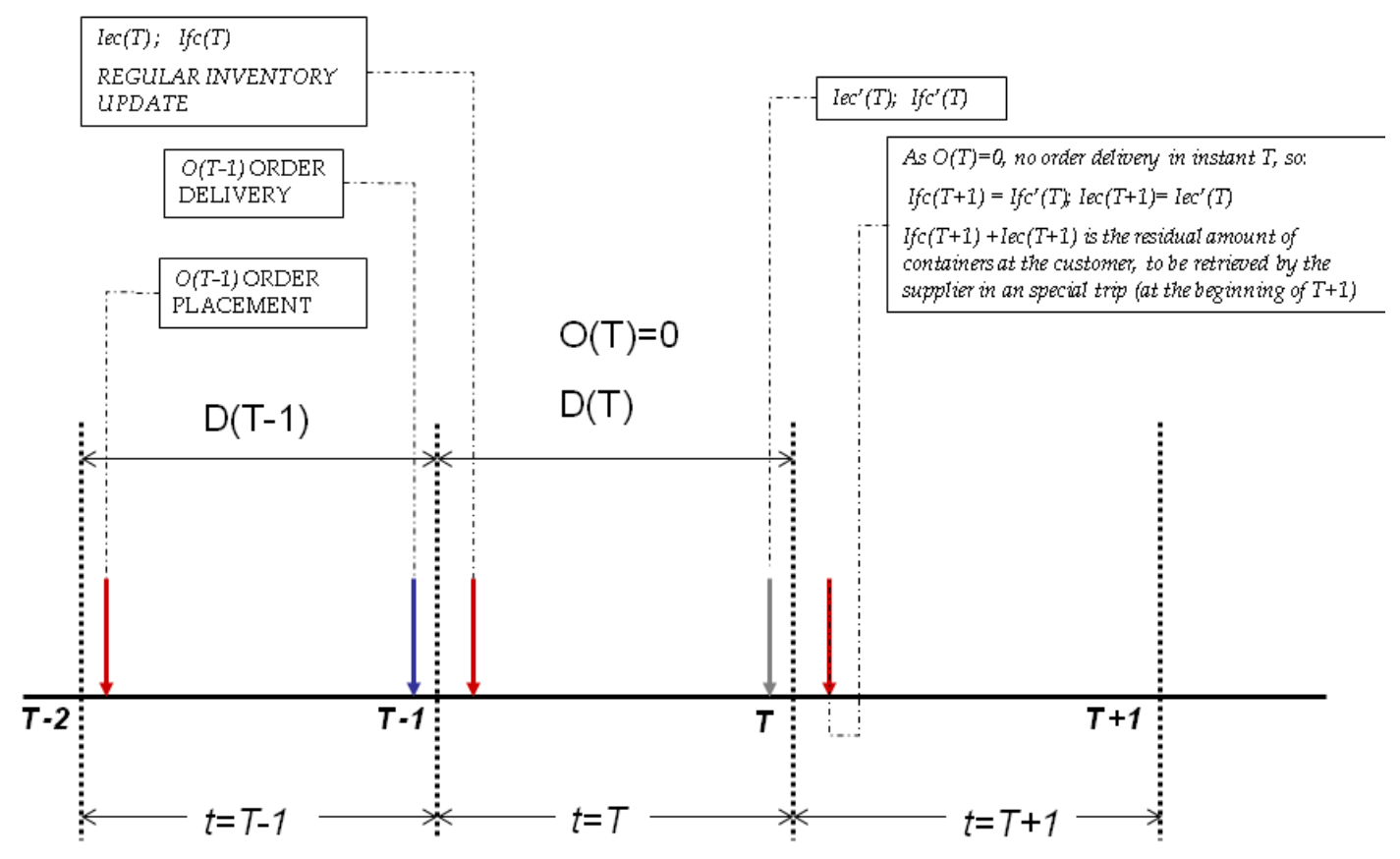

Figure 6-5: Event sequence time periods $T$ and $T+1$. Customer model. Own development. 


\subsubsection{Customer model formulation}

The customer model aims at obtaining the optimal set of orders $\mathrm{O}(\mathrm{t})$ under the point of view of the customer.

Objective: Minimize total undiscounted relevant cost over the planning horizon $\mathrm{T}$ Objective function:

$$
\sum_{t=0}^{T+1}\left\{C_{o c} Y_{o c}(t)+p(t) O(t)+C_{h e c} I_{e c}(t)+C_{h f c} I_{f c}(t)\right\}
$$

Non-negative conditions of the variables and special periods values:

$$
\begin{array}{clrl}
Y_{o c}(t) & \in\{0,1\} & \forall t \quad \mid \quad t=0, \ldots T-1 \\
O(t) & \geq 0 & \forall t \quad \mid \quad t=0, \ldots T-1 \\
I_{e c}(t) \geq 0 & \forall t \quad \mid \quad t=\mathbf{2}, \ldots T+1 \\
I_{f c}(t) \geq 0 & \forall t \quad \mid \quad t=1, \ldots T+1 \\
Y_{o c}(T)=0, \quad Y_{o c}(T+1)=0, \quad O(T)=0, \quad O(T+1)=0 \\
I_{e c}(0)=0, \quad I_{f c}(0)=0, \quad I_{e c}(1)=0
\end{array}
$$

\section{Constraints:}

$$
\begin{array}{rlrlrl}
O(t) & \leq 10^{4} Y_{o c}(t) & \forall t & \mid & t=0, \ldots T-1 \\
I_{f c}(t) & \geq D(t) & \forall t & \mid & t=1, \ldots T+1 \\
I_{f c}(t) & =I_{f c}(t-1)-D(t-1)+O(t-1) & \forall t & \mid & t=1, \ldots T+1 \\
I_{e c}(t) & =I_{e c}(t-1)+D(t-1)-O(t-1) & & \forall t & \mid & t=\mathbf{2}, \ldots T+1
\end{array}
$$


Equation (6.1) shows the objective function, where the first term indicates the fixed ordering cost, the second term denotes the purchase cost, the third term reflects the cost for stock keeping of empty containers for the customer, whereas the fourth term represents the stock keeping cost related to full containers. Costs span throughout all the planning horizon.

The next block of constraints (equations (6.2) to (6.7)) show the non-negative conditions of the variables, as well as the values taken by the variables that are fixed in the special periods. As indicated above, the last period with orders is $T-1$, so constraints group (6.6) models this fact. Constraints (6.7) provide the set up values for the inventory variables.

Next, we have the block of real constraints. Constraint (6.8) models the equal exchange recovery strategy: customer orders of full containers are limited by the amount of empty containers available at the instant of delivery.The formulation of constraint (6.8) is the result of linearizing the following equation ((1)). Equation (1) applies to all the periods when the equal exchange policy is observed (from $t=1$ to $t=T-1$ ):

$$
O(t) \leq Y_{o c}(t) \cdot\left[I_{e c}(t)+D(t)\right] \quad \forall t \quad \mid \quad t=1, \ldots T-1
$$

which is transformed into two equations:

$$
O(t) \leq 10^{4} \cdot Y_{o c}(t) \quad \forall t \quad \mid \quad t=1, \ldots T-1
$$

and

$$
O(t) \leq I_{e c}(t)+D(t) \quad \forall t \quad \mid \quad t=1, \ldots T-1
$$

However, the latter equation $((3))$ is not required, as it is included in the model via constraints (6.4) and (6.11). Therefore, constraint (6.8) corresponds to equation (2) In addition, we expand the period in which constraint (6.8) applies to $t=0$. In this way, the fixed ordering cost for the customer is activated also for the first delivery $(t=0)$. Ending with $T+1$ instead of with $T-1$ in (6.8) would enable us to delete the restrictions $O(T)=O(T+1)=0$ in (6.6).

Constraint (6.9) is required to assure that demand is fulfilled in all periods. In the general assumptions of the model, it was stated that all demand always has to be fulfilled immediately (no backlogs nor lost sales allowed). This restriction applies to all the periods where $I_{f c}$ variable 
is left free.

Constraints (6.10) and (6.11) represent the dynamics of the inventory system: mass balances of empty and full containers inventory taking into account product consumption in each period (demand) and orders delivery. Note that constraint (6.11) only applies from period $t=2$ onwards: in the delivery corresponding to period $t=1(O(0))$ the equal exchange policy does not apply, as the customer has still no empty containers to give in exchange. It should also be remarked that both constraints (6.10) and (6.11) run until period $t=T+1$. In that period, $I_{f c}(T+1)$ and $I_{e c}(T+1)$ represent the residual amount of full and empty containers at the customer at the end of the planning horizon. This residual amount is to be retrieved by the supplier in an special trip at the end of the planning horizon.

\subsection{Supplier model}

In the previous section we have presented the customer model. The output for this MILP model is the set of optimal orders to be placed from the point of view of the customer, $O(t) t \in$ $\{0 \ldots T-1\}$.

In this section, we model the optimal behaviour of the supplier. We use as input the optimal set of orders delivered by the customer model. The output of the supplier model will be the production plan (the quantitities to be filled in each period) as well as the transport plan (the quantities to be delivered and collected in each period). Following the same section organization delivered in section 6.4, firstly the list of variables and the list of parameters of the supplier model are provided. Next, the sequence of events taking place in a generic time period $t$ in the supplier model is described ( $t=0$ and $t=T+1$ constitute exceptional periods). Finally, the MILP supplier model formulation (objective function and constraints) is introduced and explained.

\subsubsection{List of variables. Supplier model.}

- $F(t)$ : number of empty containers filled during period $t$.

- $C S(t)$ : number of containers in transit during period $t$ from the customer to the supplier 
(collected at the customer directly at the beginning of period $t$ and delivered at the supplier directly at the beginning of period $t+1$, assuming that the transit takes 1 period).

- $I_{f s}(t)$ : on hand stock of full containers at the supplier at the beginning of period $t$ just after the shipment of full containers to the customer in period $t$ (instant $i=t-1$ ).

- $I_{e s}(t)$ : on hand stock of empty containers at the supplier at the beginning of period $t$ just after the reception of empty containers from the customer in period $t$ (instant $i=t-1$ ).

- $Y_{o s}(t)$ : binary variable indicating whether the supplier arranges transport in period t. $\left(Y_{o s}(t)=1\right.$ : supplier arranges transport during period $t ; Y_{o s}(t)=0$ : supplier does not arrange transport in period $t$ ).

- $N$ : number of containers acquired by the supplier at the beginning of period $t=-1$ in order to serve the customer.

\subsubsection{List of parameters. Supplier model.}

- $C_{a}$ : cost for acquiring 1 new container.

- $C_{f}$ : cost for filling 1 container.

- $C_{o s}$ : fixed transport cost for the supplier, independent of the number of full containers transported.

- $C_{t s c}$ : cost for transporting 1 container from the supplier to the customer.

- $C_{t c s}$ : cost for transporting 1 container from the customer to the supplier.

- $C_{\text {hes }}$ : cost for having 1 empty container at the supplier at the beginning of a period just after empty containers from the customer (potentially) arrive at the supplier.

- $C_{h f s}$ : cost for having 1 full container at the supplier at the beginning of a period just after the (potential) shipment of full containers to the customer.

- $S C(t)$ : number of full containers in transit from the supplier to the customer in period $t$ (shipped to the customer directly at the beginning of period $t$ and delivered at the 


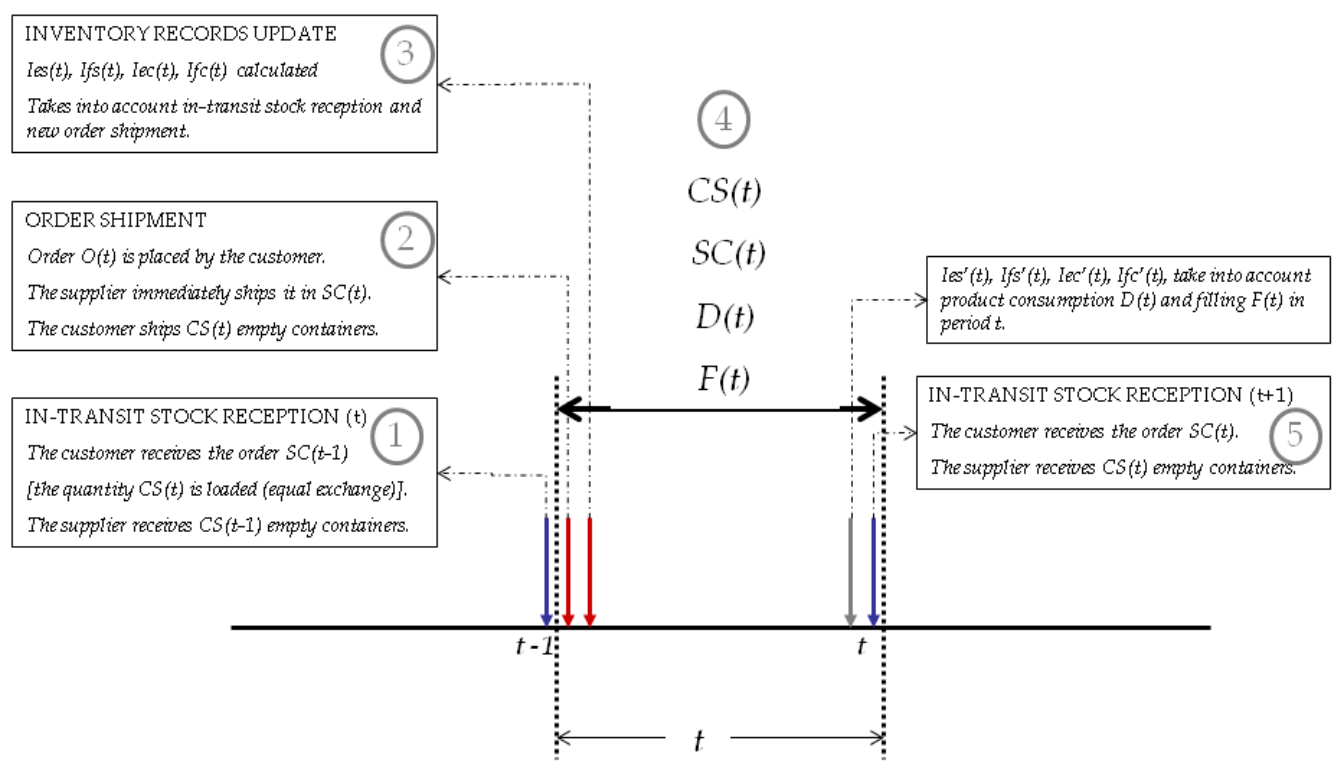

Figure 6-6: Event sequence in a generic time period $t$. Supplier model. Own development.

customer directly at the beginning of period $t+1$ assuming the transit takes 1 period only).

\subsubsection{Sequence of events. Supplier model}

As was done in the customer model, in the supplier model the generic time period $t$ elapses throughout instant $t-1$ and instant $t$. Inventory levels registered at the beginning of the period (after orders reception and orders shipment) are denoted without the notation prima $\left(I_{f s}(t), I_{e s}(t), I_{f c}(t), I_{e c}(t)\right)$, whereas the inventory levels at the end of the period (instant $t$, after filling and product consumption but before next order delivery) are denoted with prima $\left(I_{f s} \prime(t), I_{e s}(t), I_{f c}(t), I_{e c} \prime(t)\right)$. Only the variables without prima are included in the model, but in this subsection $I_{f s} \prime(t), I_{e s} \prime(t), I_{f c} \prime(t)$ and $I_{e c} \prime(t)$ are used for the sake of clarity in explaining the sequence of events to be observed in time period $t$. The sequence of events followed in a generic time period is depicted in Figure 6-3.

1. In-transit stock reception ( $t)$ (Order delivery): The order $S C(t-1)$, placed and shipped 
at the beginning of the precedent period (period $t-1$ ) arrives at the customer with the full containers in-transit. Due to the equal exchange recovery strategy, the same amount of empty containers are loaded in $C S(t)$ variable to be shipped to the supplier In addition, the empty containers in transit during period $t-1, C S(t-1)$ are received at the supplier. Equations (1), (2) and (3) reflect how the inventory of full and empty containers at the customer and the inventory of empty containers at the supplier are modified by in-transit containers reception

$$
\begin{aligned}
I_{f c}(t) & =I_{f c^{\prime}}(t-1)+S C(t-1) \\
I_{e c}(t) & =I_{e c}(t-1)-C S(t) \\
I_{e s}(t) & =I_{e s} \prime(t-1)+C S(t-1)
\end{aligned}
$$

2. Order placement and shipment: The customer places the order $O(t)$ and the supplier immediately ships $S C(t)$ (the reader is reminded that $O(t)=S C(t)$ ). On the other side of the supply chain, a shipment of $C S(t)$ empty containers is shipped from the customer to the supplier. The stock in transit in $S C(t)$ and $C S(t)$ will be delivered to the customer and to the supplier at the beginning of period $t+1$ (instant $t$ ).

3. Inventory update registration: After deliveries and shipments, the on hand inventories at the supplier and the customer are registered $\left(I_{f s}(t), I_{e s}(t), I_{f c}(t), I_{e c}(t)\right)$ for period $t$ cost calculations (stock keeping costs at the supplier and the customer (the latter stock keeping cost includes the rents to be paid by the customer for containers usage).

4. Product consumption and filling: Throughout period $t$, demand $D(t)$ is satisfied (demand is always fulfilled) and $F(t)$ containers are (re)filled. Contents consumption increments the inventory of empty containers at the customer (eq. 1) and decrements in the same amount the inventory of full containers at the customer (eq. 2). Simmetrically, the filling process increments the inventory of full containers at the supplier (eq. 4) whereas the 
inventory of empty containers at supplier is decremented in the same amount (eq. 3).

$$
\begin{aligned}
I_{e c}(t) & =I_{e c}(t)+D(t)=I_{e c}(t-1)-C S(t)+D(t) \\
I_{f c} \prime(t) & =I_{f c}(t)-D(t)=I_{f c^{\prime}}(t-1)+S C(t-1)-D(t) \\
I_{e s} \prime(t) & =I_{e s}(t)-F(t) \\
I_{f s} \prime(t) & =I_{f s}(t)+F(t)
\end{aligned}
$$

During period $t, S C(t)$ full containers are in transit from the supplier to the customer and $C S(t)$ empty containers are in transit from the customer to the supplier.

5. In-transit stock reception $(t+1)$ (Order delivery): A new period $(t+1)$ starts with the reception of the orders in transit during period $t, S C(t)$ and $C S(t)$, followed by the subsequent sequence of events: new order placement and shipment, new inventories registration, etc.

Figure 6-7 depicts the sequence of events in the initial time periods. The first positive demand (potentially) happens at period $t=1$. Full containers need to be available at the supplier to be shipped at the beginning of period $t=0$ so that they can become available at the customer at the beginning of period $t=1$. Hence, the supplier needs to start the filling process during period $t=-1$. The first delivery of containers at the customer takes place at the end of period $t=0$. This period is exceptional because the equal exchange policy is not applied in this particular delivery. In the subsequent deliveries (from the end of period $t=1$ onwards), the customer will already have an inventory of empty containers to be retrieved in each delivery and the equal exchange strategy will be applied.

Figure 6-8 depicts the sequence of events at the final periods of the planning horizon. Demand is (potentially) positive until period $t=T$. Therefore, the last period in which filling will take place is (potentially) $t=T-2$. At the beginning of period $t=T-1$ (instant $T-2$ ) the last order for full containers is placed and shipped, so $S C(T-1)$ is potentially positive whereas $S C(T)=0$. The last order of full containers is in transit during period $T-1$ and do follow the equal exchange strategy. Therefore, the customer receives the last order of full containers at the begining of period $t=T$ (instant $T-1$ ) and the corresponding empty containers are in transit 


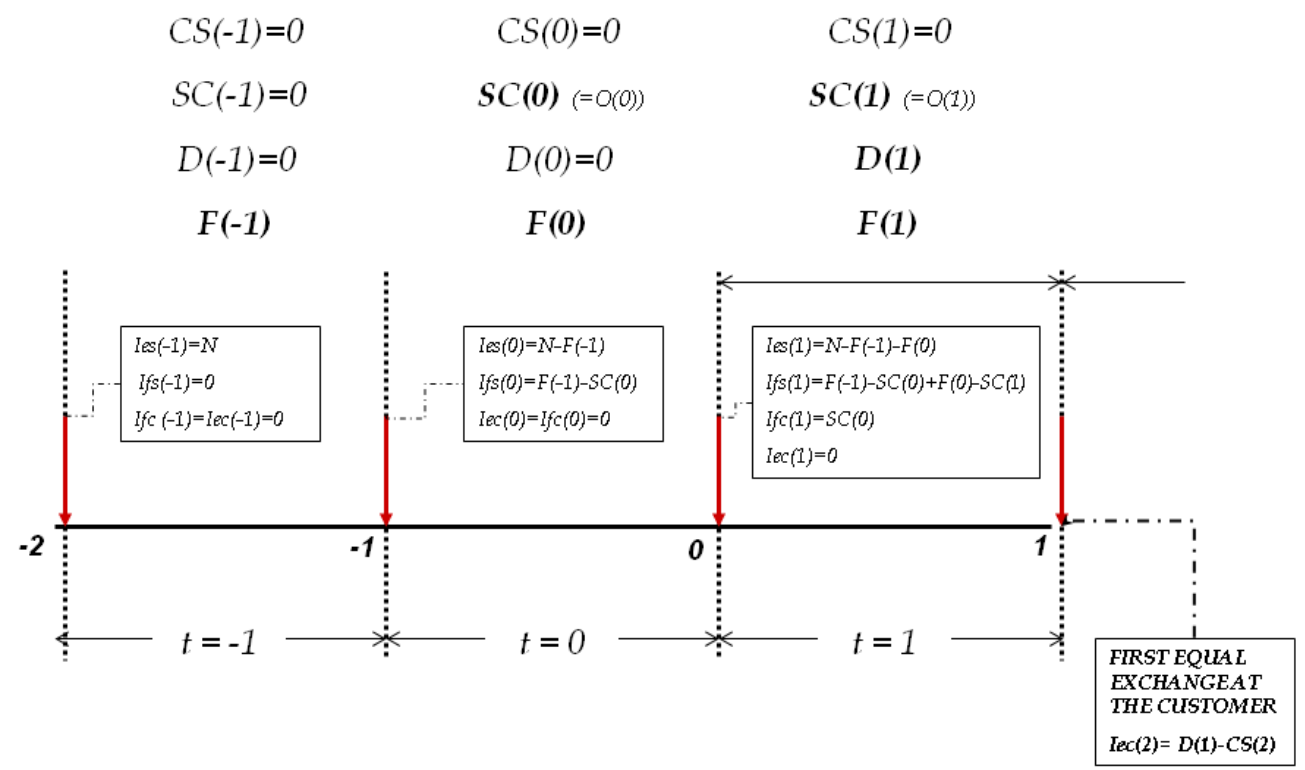

Figure 6-7: Event sequence initial time periods of the planning horizon. Supplier model. Own development.

during period $T(C S(T)=S C(T-1)$ is potentially positive). Finally, also at the beginning of period $t=T$ (instant $T-1$ ) a last special trip is launched from the supplier to the customer, not for delivering new full containers, but in order to retrieve all remaining containers (full and empty) at the customer at the end of the planning horizon (instant $T$, end of period $t=T$ ). In this round trip, the supplier-to-customer part of the journey is an empty-leg $(S C(T)=0)$, whereas the return trip is charged with all the remaining inventory at the customer at the end of the planning horizon $(C S(T+1)=\operatorname{Iec}(T)+I f c l(T))$. If a $t=T+2$ period existed, all the variables would be assigned a null value in that period.

\subsubsection{Supplier model formulation}

First of all, it should be noted that in the supplier model, under the assumptions made, $\{S C(t), t=0, \ldots, T-1\}$ are input variables (parameters), given by: 


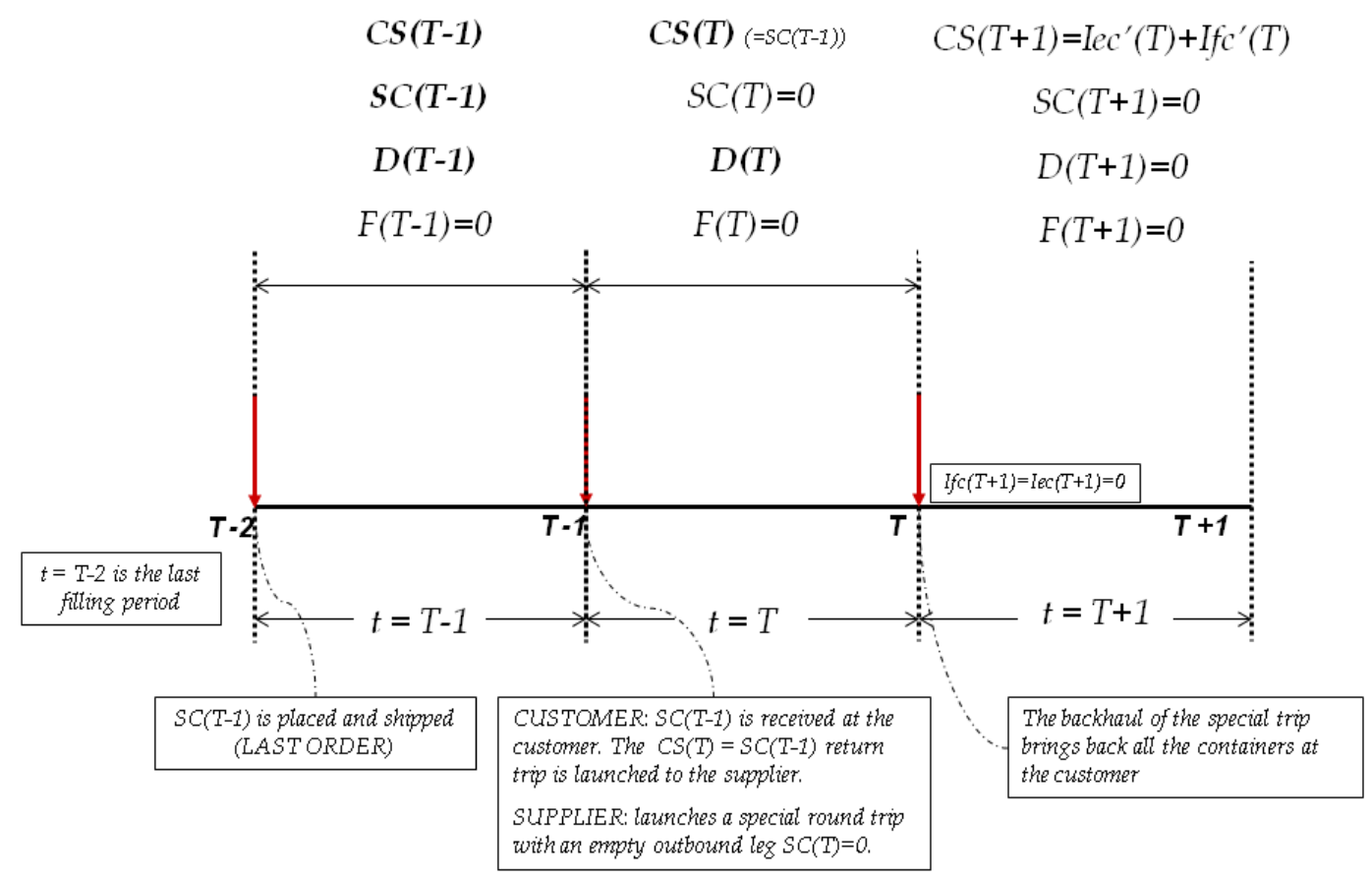

Figure 6-8: Event sequence at the end of the planning horizon. Supplier model. Own development. 


$$
\begin{aligned}
S C(t) & =O(t) \quad \forall t \quad \mid \quad t=0, \ldots T+1 \\
S C(-1) & =0, \quad S C(T)=0, \quad S C(T+1)=0
\end{aligned}
$$

Equation (6.12) links the customer model presented in subsection 6.4.4 and the supplier model we introduce in the current subsection.

Objective: Minimize total undiscounted relevant costs over the planning horizon $\mathrm{T}$ Objective function:

$C_{a} N+\sum_{t=-1}^{T+1} C_{f} F(t)+\sum_{t=-1}^{T+1}\left\{C_{o s} Y_{o s}(t)+C_{t s c} S C(t)+C_{t c s} C S(t)\right\}+\sum_{t=-1}^{T+1}\left\{C_{h e s} I_{e s}(t)+C_{h f s} I_{f s}(t)\right\}$

Non-negative conditions of the variables and special periods values:

$$
\begin{aligned}
& F(t) \geq 0, \\
& \forall t \quad \mid \quad t=-1, \ldots T-2 \\
& Y_{\text {os }}(t) \in\{0,1\}, \\
& \forall t \quad \mid \quad t=0, \ldots T \\
& C S(t) \geq 0, \\
& \forall t \quad t=\mathbf{2}, \ldots T \\
& I_{e s}(t) \geq 0, \\
& \forall t \quad \mid \quad t=0, \ldots T+1 \\
& I_{f s}(t) \geq 0, \\
& \forall t \quad \mid \quad t=0, \ldots T+1 \\
& I_{e c}(t) \geq 0, \\
& \forall t \quad \mid \quad t=0, \ldots T \\
& I_{f c}(t) \geq 0, \\
& \forall t \quad \mid \quad t=0, \ldots T
\end{aligned}
$$




$$
\begin{gathered}
F(T-1)=0, \quad F(T)=0, \quad F(T+1)=0 \\
Y_{o s}(-1)=0, \quad Y_{o s}(T+1)=0 \\
C S(-1)=0, \quad C S(0)=0, \quad C S(1)=0 \\
I_{e c}(T+1)=0, \quad I_{f c}(T+1)=0 \\
I_{f s}(-1)=0, \quad I_{e s}(-1)=N, \quad I_{f c}(-1)=0, \quad I_{e c}(-1)=0,
\end{gathered}
$$

Filling by supplier:

$$
\begin{gathered}
F(-1) \geq S C(0) \\
F(t) \leq I_{e s}(t), \forall t \quad \mid \quad t=-1,0,1, \ldots T-2
\end{gathered}
$$

Ordering and transport:

$$
\begin{gathered}
C S(t)=S C(t-1) \quad \forall t \quad \mid \quad t=\mathbf{2}, \ldots T \\
S C(t) \leq 10^{4} Y_{o s}(t) \quad \forall t \quad \mid \quad t=0, \ldots T-1 \\
C S(T+1)=I_{e c}(T)+I_{f c}(T) \\
C S(T+1) \leq 10^{4} Y_{o s}(T)
\end{gathered}
$$

\section{Inventory:}

$$
S C(t) \leq I_{f s}(t-1)+F(t-1) \quad \forall t \quad \mid \quad t=0, \ldots T-1
$$

Mass balances: 


$$
\begin{gathered}
I_{f s}(t)=I_{f s}(t-1)+F(t-1)-S C(t) \quad \forall t \quad \mid \quad t=0, \ldots \mathbf{T}+\mathbf{1} \\
I_{e s}(t)=I_{e s}(t-1)-F(t-1)+C S(t-1) \quad \forall t \quad \mid \quad t=0, \ldots \mathbf{T}+\mathbf{1} \\
I_{f c}(t)=I_{f c}(t-1)-D(t-1)+S C(t-1) \quad \forall t \quad \mid \quad t=0, \ldots T \\
I_{e c}(t)=I_{e c}(t-1)+D(t-1)-C S(t) \quad \forall t \quad \mid \quad t=0, \ldots T
\end{gathered}
$$

Equation (6.14) shows the objective function, where the first term indicates the fleet acquisition cost (to be paid only once, at the beginning of the planning horizon), the second term denotes the filling cost and the third term reflects the transport cost, which decomposes in other three subterms: the first subterm indicates the fixed transport cost, to be paid every time a shipment to the customer is lauched, whereas the second and third subterm reflect the variable transport costs in each trip leg (from supplier to customer and viceversa). Finally, the fourth term in the objective function represents the stock keeping costs related to empty and full containers at the supplier.

The first block of constraints (equations (6.15) to (6.26)) show the non-negative conditions of the variables, as well as the fixed values taken by the variables in the special periods. Customer demand spans from period $t=0$ to period $t=T$, so the last order is placed in period $T-1$. Therefore, the last period with filling is period $T-2$, so zero containers will be filled in periods $T-1, T$, and $T+1$ (constraints (6.22)).In addition, orders of full containers are (potentially) shipped to the customer in time periods spanning from $t=0$ to $t=T-1$. In $t=T$, the special trip for retrieving all containers at the customer is launched. Therefore, in periods $t=-1$ and $t=T+1$ it is not possible to launch a shipment (constraints (6.23)).

Constraints (6.24) and (6.17) are a consequence of the fact that the first retrieval of empty containers at the customer (equal exchange recovery strategy) takes place at the beginning of period $t=2$. Hence, $C S(t)$ is a variable from period 2 onwards (constraint (6.17)). The values taken by $C S(t)$ for $t=-1, t=0$ and $t=1$ are provided in (6.24). Constraints (6.25) 
force to retrieve all remaining containers at the customer at the end of the planning horizon. Constraints (6.26) provide the set up values of the inventory variables.

Next, we have the blocks of real constraints. Constraints (6.27) and (6.28) refer to the filling process: as all demand has to be fulfilled immediately, the quantity filled in the first period has to cover at least the demand reflected in the first order (constraint (6.27)); in addition, the quantity of containers to be filled in a period is limited by the on hand inventory of empty containers avaliable at the supplier in that period (6.28). This constraint applies to all periods where there is a (potential) filling process.

Constraints from (6.29) to (6.32) refer to the ordering and transport process. Constraint (6.29) ensures the application of the equal exchange policy, so it is only effective from period 2 onwards. Constraint (6.30) is used to activate the fixed transport cost to be paid every time a shipment is launched from supplier to customer (and back to the supplier). The restriction spans all the periods in which potentially a "regular" shipment can take place (from 0 to $T-1$ ).

In period $T$, a special shipment is lauched from the supplier in order to retrieve all the remaining stock of full and empty containers at the customer at the end of the planning horizon. This fact is reflected in constraints (6.31) and (6.32), that result from the linearization of equation $(*)$ :

$$
C S(T+1)=Y_{o s}(T) \cdot\left[I_{e c}(T+1)+I_{f c}(T+1)\right]
$$

This equation can be transformed into two constraints:

- on the one hand, $C S(T+1) \leq 10^{4} Y_{o s}(T) \Longleftrightarrow$ constraint (6.31).

- and on the other hand, $C S(T+1)=I_{e c}(T+1)+I_{f c}(T+1) \quad \Longleftrightarrow \quad$ constraint (6.32). It should be noted that the final formulation proposed in (6.32) stems from the following reasoning: 


$$
\begin{gathered}
\underbrace{C S(T+1)=I_{e c}(T)+I_{f c}(T)=I_{e c}(T)+D(T)+I_{f c}(T)-D(T)=I_{e c}(T)+I_{f c}(T)}_{\Downarrow} \\
C S(T+1)=I_{e c}(T)+I_{f c}(T)
\end{gathered}
$$

An interesting result highlighted by this equation is that the total inventory at the customer (sum of full and empty containers) at the beginning of a period equals the total inventory at the end of the period. Although the sum remains constant throughout the period, the proportion of full and empties changes depending on the value of demand $D(t)$. This result applies to customer inventory for all periods. In the particular case of the end of the planning horizon, the total inventory to be retrieved at the beginning of period $t=T+1(C S(T+1))$ is the total inventory at the end of the precedent period $\left(I_{e c^{\prime}}(T)+I_{f c}(T)\right)$ due to the fact that in instant $i=T$ there are no new deliveries of containers.

The next block is constraint (6.33), which represents the inventory limit of the system: the maximum amount that can be shipped in each period to the customer is the available on hand inventory of full containers at the beginning of the period. This restriction spans to all the periods where there is (potentially) a shipment.

Finally contraints (6.34) to (6.37) represent the mass balances between empty and full containers in both the customer and the supplier. The inventories of full and empty containers at the supplier (Constraints (6.34) and (6.35)) take into account the filling process and the shipment from and to the customer. They span until period $T+1$ because in the last period the inventory at the supplier is still updated with the last shipment retrieving all the remaining containers at the customer. The inventories at the customer (Constraints (6.36) and (6.37)) take into account product consumption and shipments from and to supplier. In the final period $T+1$, after the retrieval of all remaining inventories, the on hand stock of full and empty containers at the customer should be 0 . 


\subsection{Alternative equal exchange control strategy}

Up to now in this chapter, the impact of an strict equal exchange control strategy (requiring to return exactly $n$ units of used RA in order to receive an order of $n$ units of as-new RA) has been analyzed In subsection 6.2.1., we postulated the disadvantages of this strict equal exchange control strategy in the case of RA which requirements heavily fluctuate. The objective in this section is to check if a relaxation of the equal exchange condition can lead to a better performance of the customer-supplier system when confronted to uneven demands For doing so, firstly an alternative equal exchange control strategy is put forward; next, the customer and supplier models are reformulated under the alternative control strategy. Thirdly, numerical experiments are carried out with the new models in order to compare the impact of the two equal exchanges control strategies on system performance.

\subsubsection{Alternative control strategy description}

The so-called strict equal exchange recovery strategy used up to this section in the chapter imposed the following constraint to customer orders: the supplier will deliver $n$ full containers only if the customer is able to return at the moment of delivery exactly the same amount ( $n$ units) of empty containers.

Hereafter, we consider the situation where empty containers can only be returned when a delivery of full containers takes place (i.e., returns can only take place at the moment of delivery). However, the quantity to be returned once transportation has been set up is free: the customer is entitled to return whichever quantity of empty containers in the backhaul leg of the trip. In this situation, it is possible to receive 10 full containers and return only 1 empty container, or to receive 1 full container and return 10 empty containers. The only restriction is that containers can only be returned when an order delivery takes place. The last period of the planning horizon remains an exception to this rule, as in this last period all containers remaining at the customer are collected by the supplier. The alternative recovery strategy is called from now on relaxed equal exchange recovery strategy.

To determine the effect of the relaxed equal exchange recovery strategy, only some slight changes have to be made to the two-level decision model (MILP models) presented above in 
this chapter. These changes are detailed in the following subsection.

\subsubsection{Models reformulation}

Figure 6-9 compares the decision variables under the strict and relaxed equal exchange recovery strategy. Under an strict equal exchange recovery strategy, the customer model used as input a deterministic and known demand throughout the planning period. The customer MILP model provides as output the optimal ordering strategy that minimizes customer's fixed and variable ordering and stock-keeping costs. The number of containers to be returned in each period is not a decision variable in the strict equal exchange recovery strategy, because it will be determined by the quantity of full containers ordered in each period. Afterwards, the output of the customer model $(O(t) \equiv S C(t))$ is used as input for the supplier model for obtaining the set of filling orders and the number containers that minimize supplier's costs.

Within the relaxed equal exchange recovery strategy, the customer has to decide not only how many full containers is going to order in each period, but also how many empty containers are going to be returned within each delivery. Therefore, the output of the new customer model has to be twofold: $O(t)$ and $C S(t)$. Next, both $O(t) \equiv S C(t)$ and $C S(t)$ are entered as parameters in the supplier model.

\section{Changes in Customer Model}

We refer the reader to the customer model presented in subsection 6.4.4. The changes to be done taking this formulation as a basis are described below.

In the non-negative conditions of the variables and special periods values block (constraints 6.2 to 6.7 ), a new variable with its corresponding special periods values has to be added.

$$
\begin{aligned}
& C S(t) \geq 0, \quad \forall t \quad \mid \quad t=\mathbf{2}, \ldots T \\
& C S(0)=0, \quad C S(1)=0
\end{aligned}
$$

In the constraints block, restrictions (6.8), (6.9) and (6.10) are kept unaltered. Restriction 

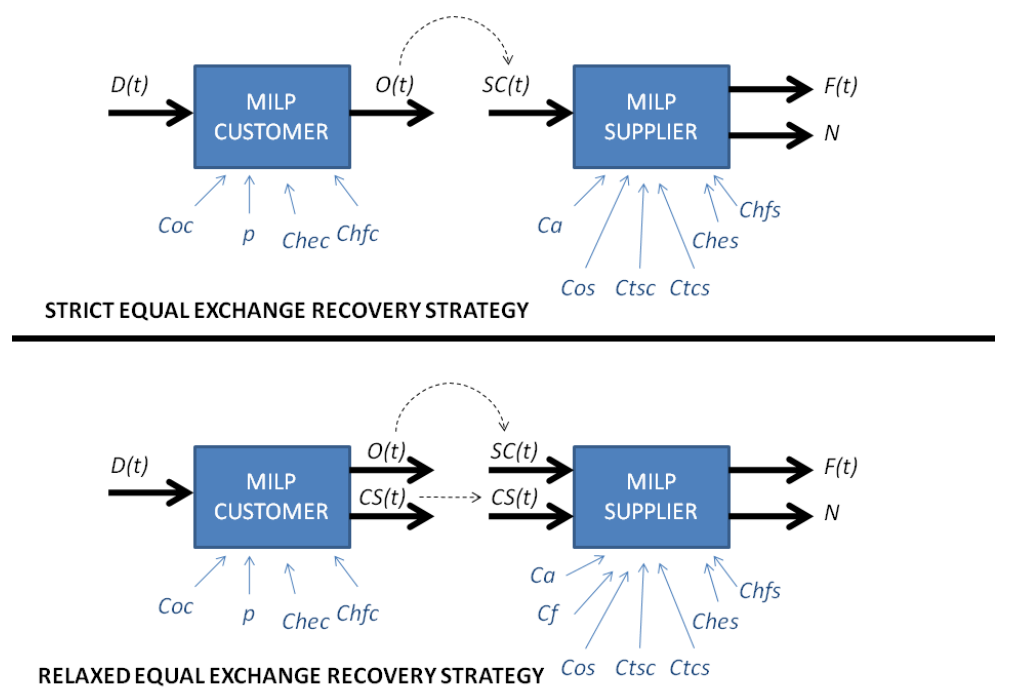

Figure 6-9: Decision variables in the two alternative two-level decision models. Own development.

(6.11) is replaced by (6.40) in order to take into account the new decision variable $C S(t)$ in the empty containers mass balance:

$$
I_{e c}(t)=I_{e c}(t-1)+D(t-1)-C S(t), \quad \forall t \quad \mid \quad t=\mathbf{2}, \ldots T
$$

The new restriction only runs to period $T$, as $C S(T+1)$ is a special trip. The mass balance of empty containers in the last period is therefore constraint (6.41):

$$
I_{e c}(T+1)=I_{e c}(T)+D(T)
$$

In addition, three new restrictions have to be added to the constraints block. Constraint (6.42) limits the maximum amount of empty containers to be returned in each period by the available number of empty containers at the customer at the end of the previous period. Constraint (6.43) limits empty containers recovery to the periods when the delivery of an order of full containers takes place (note the time-lag between $C S(t)$ and $Y_{o c}(t)$, due to the delivery lead 
time of 1 period). Finally, constraint (6.44) reflects the fact that all remaining full and empty containers at the customer are retrieved in a special trip at the end of the planning horizon.

$$
\begin{aligned}
C S(t) & \leq I_{e c}(t-1)+D(t-1), \quad \forall t \quad \mid \quad t=\mathbf{2}, \ldots T \\
C S(t) & \leq 10^{4} \cdot Y_{o c}(t-1), \quad \forall t \quad \mid \quad t=\mathbf{2}, \ldots T \\
C S(T+1) & =I_{e c}(T+1)+I_{f c}(T+1)
\end{aligned}
$$

\section{Changes in Supplier Model}

The main change in the supplier model consists of transforming variable $C S(t)$ in an input parameter. This translates in the following changes.in the supplier model formulated in subsection 6.5.4.

First, in the non-negative conditions of the variables and special periods values block, expressions (6.17) and (6.17) are to be deleted.

In the ordering and transport constraints block, restrictions (6.29) and (6.31) are also to be deleted. Ordering and transport is completely determined by decision output of the customer model. However constraints (6.30) and (6.32) are left in order to activate $Y_{o s}(t)$ when a transport is set-up by the supplier.

\subsection{Numerical experiments}

Once the customer and supplier models have been formalized either for the strict and the relaxed equal exchange recovery strategy, different numerical experiments have been carried out in order to achieve the main goal of this chapter: analyze the impact of the equal exchange recovery strategy on the economical performance of the system.

Models formulation was first implemented in AIMMS 3.9. An Excel interface was programmed for the four models in order to feed each model with the corresponding data and extract the results obtained when the models were run. The use of these interfaces facilitates transferring the output of the customer model to the input data of the supplier model. The solver used was CPLEX 12.1. 


\subsubsection{Experimental design}

The numerical experiments were arranged in the following three phases:

- Stage 1. The effect of demand pattern: the equal exchange strategy confronted to different demands

- Stage 2. The effect of cost structures: the equal exchange strategy confronted to different cost structures

- Stage 3. Comparison with the alternative policy.

\section{Stage 1. The effect of demand pattern}

The goal of this phase is to quantify how the equal exchange recovery strategy performs when confronted to different demand conditions. During these experiments, all costs parameters were kept fixed with a constant value of 1 (base case) in order to isolate costs variation effect on the system. In this first stage, only the effect of demand is to be tested.

Six different demand patterns have been designed for the experiments. The month has been selected as time period. This can be done without loss of generality, as models are formulated for a generic time period that can also be identified with days, weeks, etc. The average per period demand in each demand pattern is roughly 60 , though how consumption is distributed throughout time is different in each case. Non-zero demand spans along 24 periods, i.e. a 2-year planning horizon is considered. Longer or shorter planning horizons would have also been possible. The six demand patterns are as follows:

- Demand 1 (D1) - Even demand

- Demand 2 (D2) - Monotonically increasing demand

- Demand 3 (D3) - Monotonically decreasing demand

- Demand 4 (D4) - Even demand with a "jump".in the middle (step up)

- Demand 5 (D5) - Smoothly oscillating demand (first peak, then valley) 
- Demand 6 (D6) - Sharply oscillating demand 


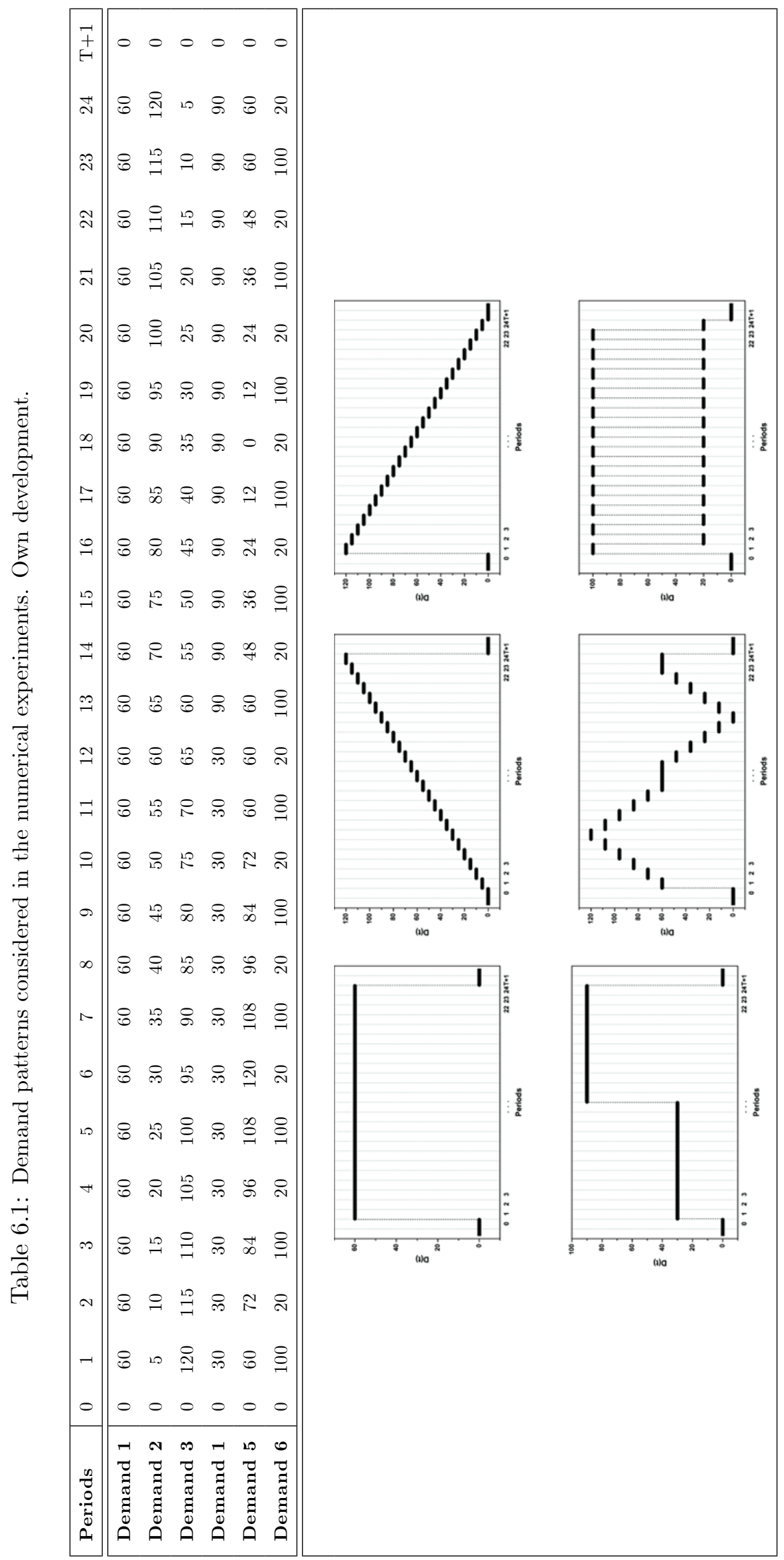


The reversed versions of D4, D5 and D6 were also initially included for being tested in the experimental design. The reversed D4 pattern starts with an even demand of 90 units for 12 periods that suddenly decreases to 30 units (even demand with a "jump" in the middle (step down)). The reversed D5 pattern is a smoothly oscillating demand (first valley, then peak) whereas the reversed D6 is a sharply oscillating demand starting in a valley value. Nevertheless the results obtained with reversed D4, D5 and D6 did not substantially differ from those of their counterparts, so for the sake of simplicity, these extra 3 demand patterns have been discarded from experiments discussion.

Table 6.1 provides the values assigned to $D(t)$ parameter in each period during the experiments and its graphical representation.

\section{Stage 2. The effect of different cost structures}

In this second phase, the goal is to assess how different cost structures impact upon the behavior of the customer and the supplier under the equal exchange strategy. Therefore, all the experiments of this second phase are carried out considering the same demand pattern, which is the even demand D1 presented in the previous phase. The results obtained in this phase are compared with the base case of D1, already carried out in phase 1, where all costs parameters are set at value 1.

Although the supplier defines the delivery-collection strategy, the customer ordering behavior leads the system. Therefore, the experimental design seeks to show that customer costs (ordering costs and stock keeping costs) will be the most leading for the flows in the system. However, this assumption has to be checked with the results from the model. The design also intends to test the impact on system behavior of other cost factors that practitioners typically consider relevant, such as the stock keeping cost of empty containers for the customer (in relationship with the value of the contents) or the structure of the transport costs borne by the supplier (mainly fixed or variable transport costs). These hypotheses emerge from the case studies that have been previously presented in this dissertation.

In phase 2, the following experiments were considered:

- Cost Experiment 1 (CE1): Customer fixed ordering costs vs. Customer stock keeping costs 
- Cost Experiment 2 (CE2): Value of the contents vs. Value of the container

- Cost Experiment 3 (CE3): Variable transport costs vs. Fixed transport costs

CE1: Customer fixed ordering costs vs. Customer stock keeping costs In this experiment, the objective is to test how the proportion between ordering and stock keeping costs impacts customer behavior.

Two main different situations are considered:

- High fixed ordering cost $\left(C_{o c}\right)$, low stock keeping cost $\left(C_{h e c}\right.$ and $\left.C_{h f c}\right)$.

- Low fixed ordering cost, high stock keeping cost.

Both situations are compared with the base case, where the proportion between ordering and stock keeping costs is $1: 1\left(C_{o c}=1 ; C_{h e c}=1 ; C_{h f c}=1\right)$. The value set considered in this experiment is summarized in Table 6.2.

Table 6.2: Cost values for Cost Experiment 1 (CE1). Own development

\begin{tabular}{|c|l|c|c|}
\hline \multicolumn{2}{|c|}{ Customer Fixed Ordering Cost $\left(C_{o c}\right)$} & \multicolumn{2}{|c|}{ Customer Stock Keeping Cost $\left(C_{h e c}, C_{h f c}\right)$} \\
\hline \hline \multirow{2}{*}{ HIGH $C_{o c}$} & $\begin{array}{l}\text { Value 1: } C_{o c}=200 \\
\text { Value 2: } C_{o c}=1000 \\
\text { Value 3: } C_{o c}=10000\end{array}$ & LOW $C_{h e c}, C_{h f c}$ & $C_{h e c}=C_{h f c}=1$ \\
\hline \hline LOW $C_{o c}$ & $C_{o c}=1$ & HIGH $C_{h e c}, C_{h f c}$ & $\begin{array}{l}\text { Value } 1: C_{h e c}=C_{h f c}=100 \\
\text { Value 2: } C_{h e c}=C_{h f c}=1000 \\
\text { Value } 3: C_{h e c}=C_{h f c}=10000\end{array}$ \\
\hline
\end{tabular}

CE2: Value of the contents $v s$. Value of the container In this experiment, the aim is to check the effect of the relationship between the value of the contents and the value of the container on the behavior of customer and supplier. The difference in value of contents and container is considered through different stock keeping costs for full and empty containers both in the customer and the supplier. Three different scenarios are considered, as shown in Table 6.3 . 
CE3: Variable transport costs $v s$. Fixed transport costs In this experiment, the aim is to test if supplier behavior is conditioned by the structure of transport costs. Variable transport costs can be assumed when the setup cost for a trip is negligible compared to the aggregated cost of transporting containers units. Transport costs can be considered mainly.fixed when the cost of moving one unit can be approximated by 0 when compared with the setup cost of one trip. Table ??provides the costs used in the two scenarios considered for this experiment.

Table 6.3: Cost values or Cost Experiment 2 (CE2). Own development

\begin{tabular}{|c|c|c|}
\hline $\begin{array}{c}\text { SCENARIO 1 } \\
\text { Packaging value is greater than } \\
\text { contents value }\end{array}$ & $C_{h f c}=C_{h f s}=1$ & $\begin{array}{c}\text { Contents has neglectable value compared } \\
\text { to packaging,so full and empty } \\
\text { containers have similar holding costs } \\
\text { (e.g. oxygen cylinders) }\end{array}$ \\
\hline \hline $\begin{array}{c}\text { Contents value is greater than } \\
\text { packaging value }\end{array}$ & $C_{h f c}=C_{h f s}=100$ & $\begin{array}{c}\text { Full containers are much more } \\
\text { valuable than empty containers } \\
\text { (holding costs vary accordingly) } \\
\text { (e.g. pallets containing luxury cosmetics) }\end{array}$ \\
\hline \hline $\begin{array}{c}\text { SCENARIO 3 } \\
\text { Contents and packaging have }\end{array}$ & $C_{h f c}=C_{h f s}=2$ & $\begin{array}{c}\text { Full containers value roughly doubles } \\
\text { empty containers value } \\
\text { (holding costs vary accordingly) }\end{array}$ \\
similar values & $C_{h e c}=C_{h e s}=1$ & (e.g. pallets containing paper for recycling) \\
\hline
\end{tabular}

Stage 3. Comparison with the alternative policy The goal of this phase is to compare the performance of the strict equal exchange recovery strategy and the relaxed alternative.

Regarding demand pattern, the six demand series designed for phase 1 (D1, D2, D3, D4, D5 and D6) were also used as input for the alternative models presented in subsection 6.6. An additional demand pattern D7 was also used in this phase in order to test if it would be optimal for the customer to order full containers just for the possibility of getting rid of empty containers lingering in their stock.

\subsubsection{Calculations}

For each numerical experiment, the Excel interface generates two tables: one corresponding to the results of customer model and another one corresponding to the results of the supplier model. All the tables generated during the numerical experiments stage are provided in Appendix I. 
Hereafter, some figures are provided as sample tables in order to guide the reader through the structure of the tables. Figure 6-10 depicts the table result of executing the solver for the customer model under the strict equal exchange recovery strategy. The top part of Figure 6-10 table shows the input parameters introduced into the customer model: demand pattern $D(t)$ and customer objective function parameters $C_{o c}, p(t), C_{h e c}, C_{h f c}$. The bottom part of the table represents the output provided by the customer model: ordering behavior of the customer $O(t)$, other output variables $\left(Y_{o c}(t), I_{e c}(t), I_{f c}(t)\right)$ and the value of the objective function.

Likewise, Figure 6-11 depicts the results obtained from the supplier model under the equal exchange recovery strategy. The top part of the table shows the input parameters introduced in the supplier model. Note that $O(t)$ input line corresponds to Figure 6-10 output line. The output part of Figure 6-11 table is divided in two parts, the upper one corresponding to the output variables $\left(F(t), Y_{o s}(t), C S(t), \ldots\right)$ and the lower one corresponding to the costs incurred in the objective function.

Numerical experiments with the alternative equal exchange recovery strategy result in similar Excel tables for customer and supplier models (Figures 6-12 and 6-13). However, note the main difference between the models corresponding to each strategy: in the strict equal exchange recovery strategy, $C S(t)$ are decision variables in the supplier model (output line in Figure 611 ), whereas within the alternative recovery strategy $C S(t)$ are decision variables directly in the customer model. The tables for the alternative policy show a new output line added to the customer table (Figure 6-12) while the $C S(t)$ output line in the supplier model is transformed in an input line in Figure 6-13. 


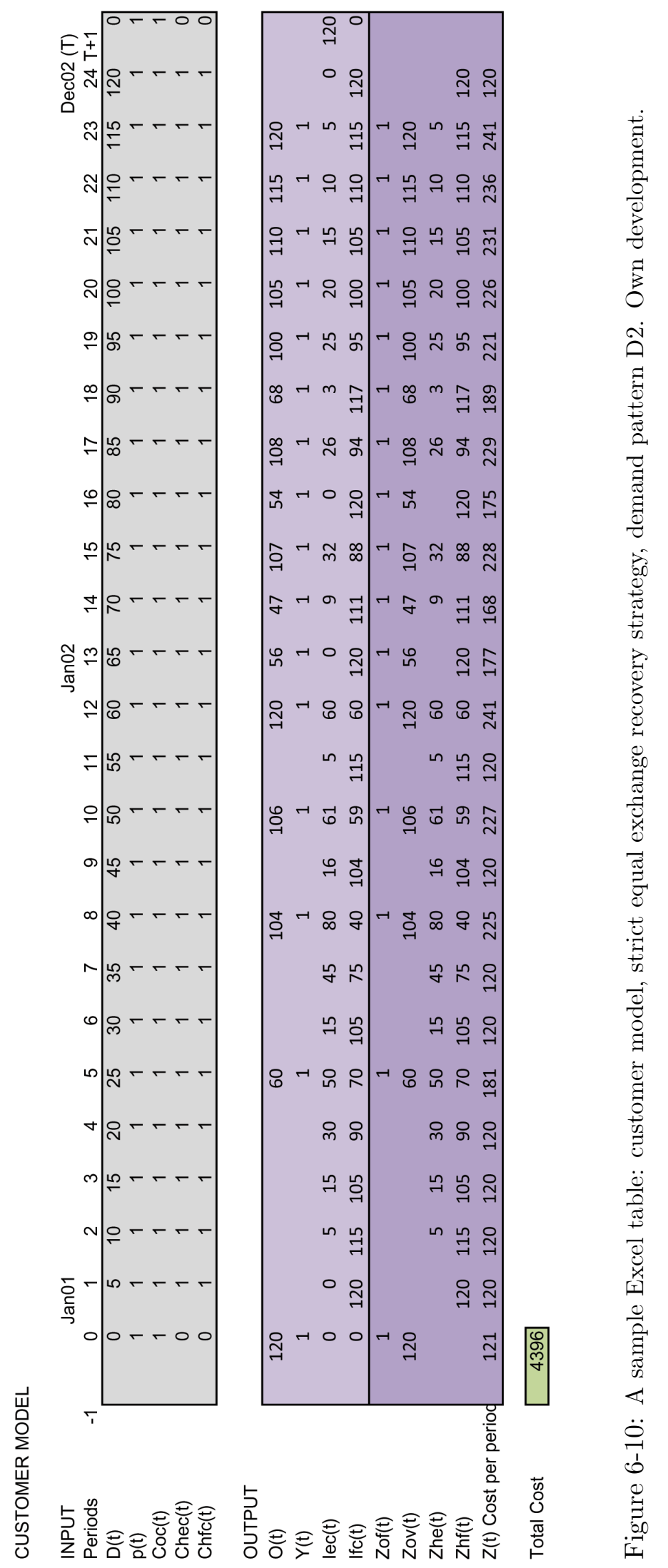



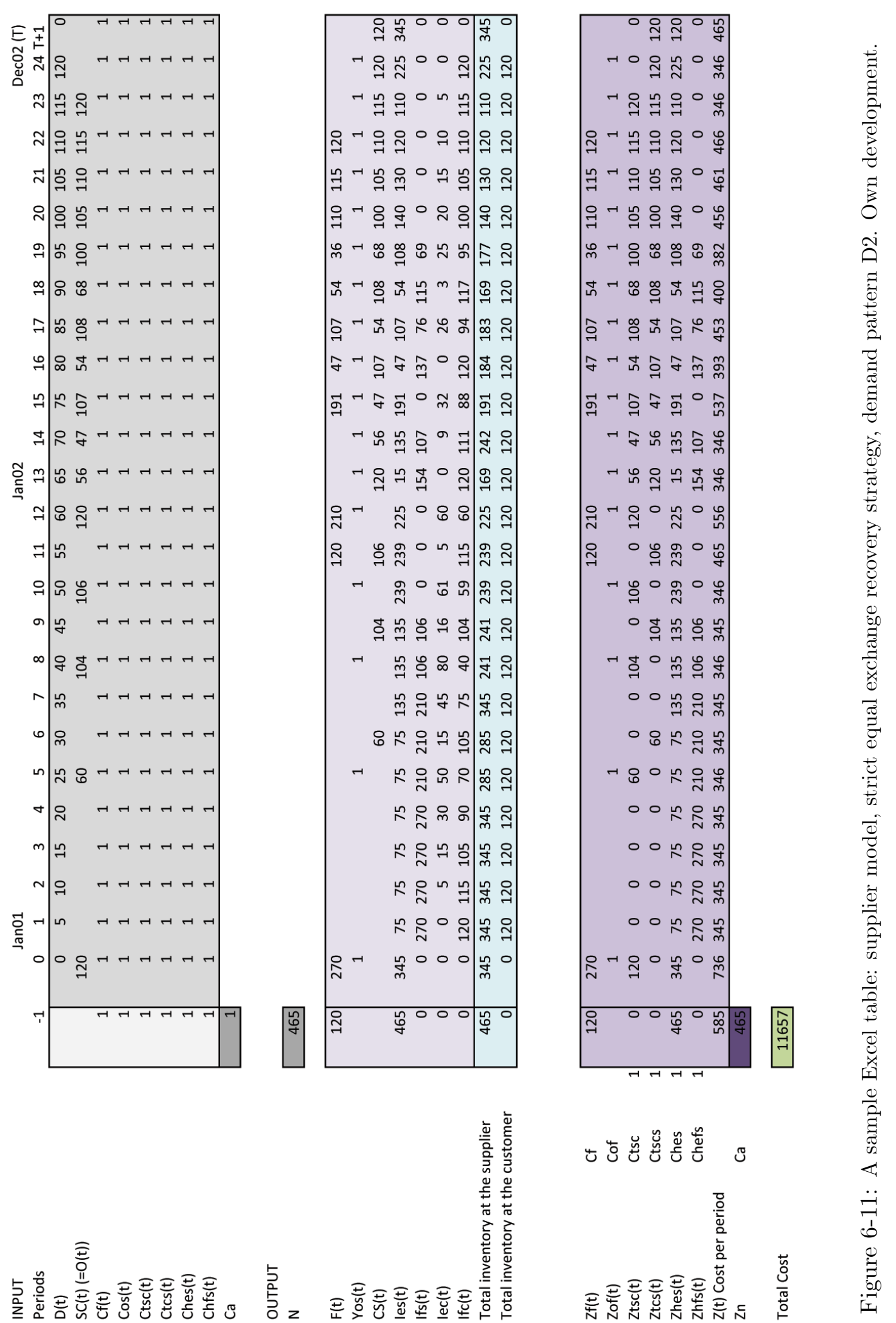

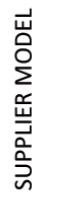

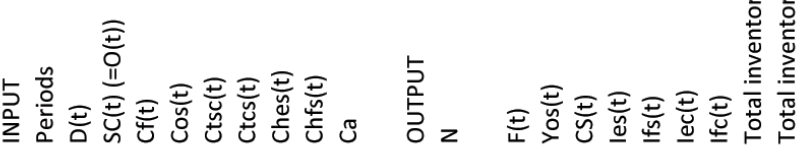




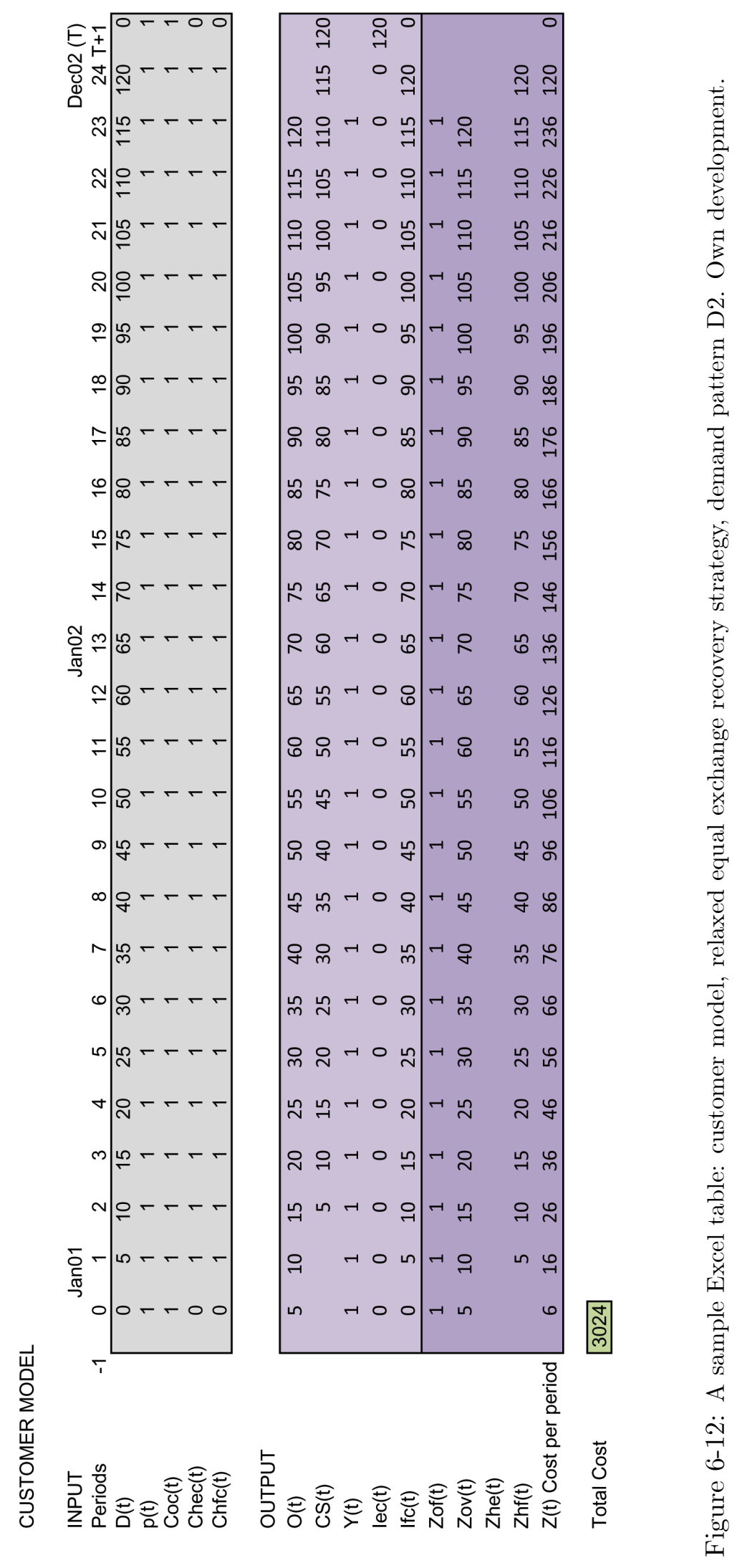



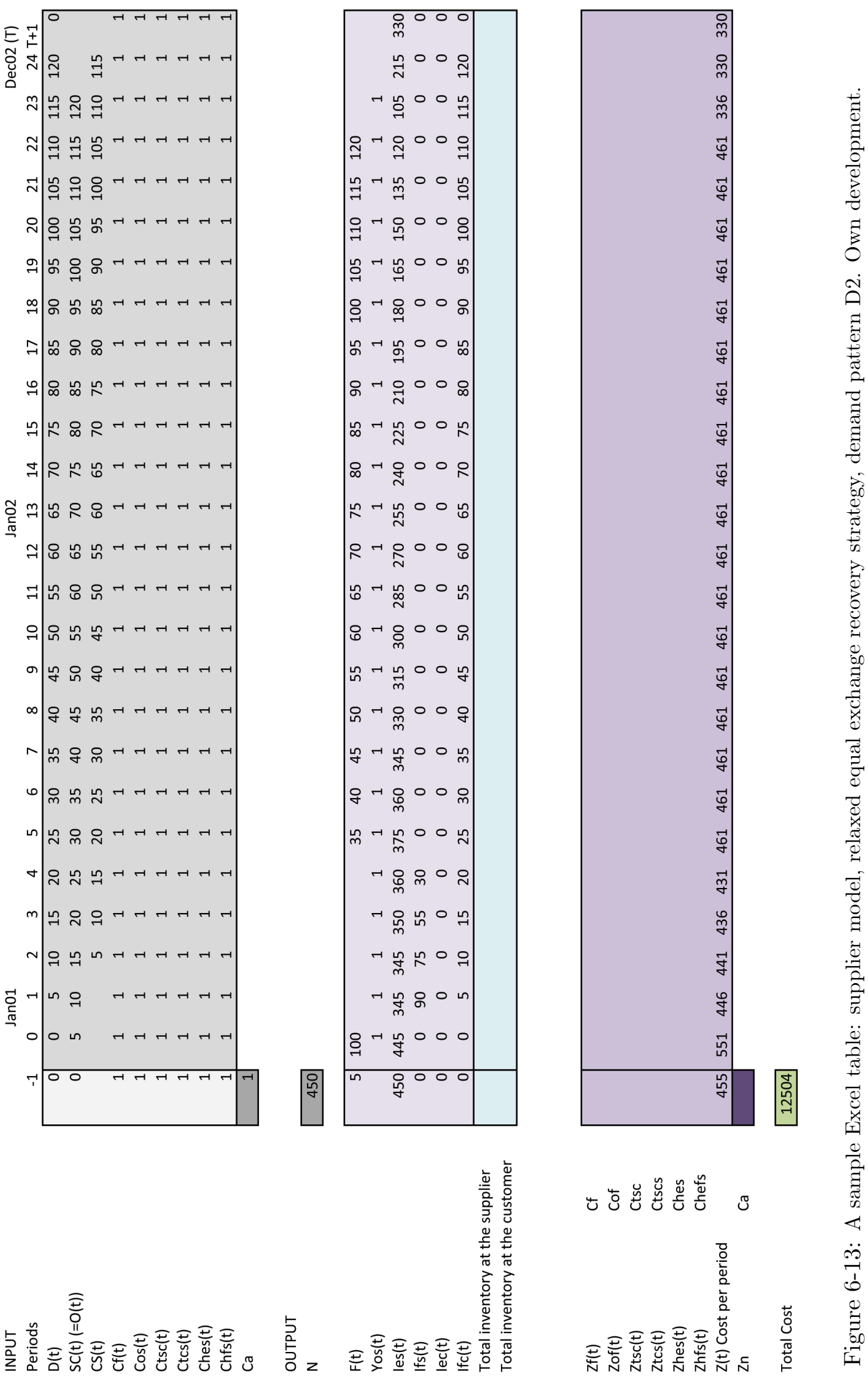

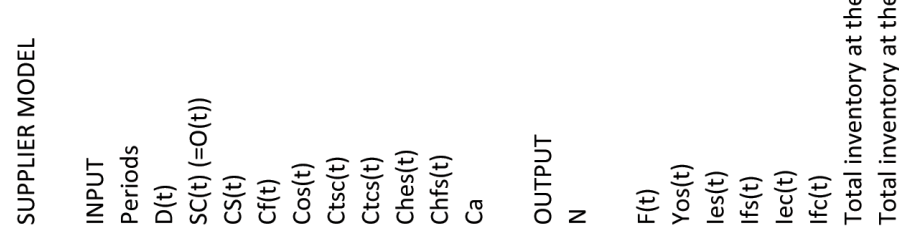




\subsubsection{Results analysis}

The results obtained in the first stage of the numerical experiments are summarized in Tables 6.5 and 6.6 .

As the graphics show, the type of demand pattern confronted by the customer clearly impacts the ordering behavior of the customer and therefore, the costs borne by the supplier.

As expected, the best results with the strict equal exchange policy are obtained when demand presents low variation (level demand, D1, JIT case). The worse results are obtained when the customer is confronted to demands such as D2 (increasing trend), D5 (smoothly oscillating demand) or D3 (decreasing trend), that imply a higher degree of variation. To be noted also that in case of even demand (JIT case, D1) the equal exchange recovery strategy requires a fleet size of exactly four times the demand to be fulfilled in each period, which is coherent with four one-period lead times to complete the whole loop in the system: filling, full transport, consumption, empty transport. This is also coherent with the fleet sizing methodology proposed in Chapter 5. Note also that demand patterns with variation (D2, D3, D5) require larger fleet sizes, as the fleet size has to be dimensioned for the peak value of demand The fact that demands that show a higher degree of variation require a fleet size which is roughly four times the peak demand value is also to be remarked. Likewise, demands D4 and D6 behave almost like two "combined" even demands and they require a smaller fleet size.

Regarding demand patterns, as expected, given the restrictions imposed upon the customersupplier system (no backlogs allowed, etc.), the customer will have to order at the beginning of the planning horizon the peak value of demand in order to have enough empty containers to swap when the order of full containers for fulfilling that demand will have to be delivered. This translates in higher stock keeping costs for the customer. In addition, this finding in the model makes clear one of the disadvantages of the strict equal exchange policy: in the presence of sudden demand peaks, the system organization is not immediately responsive (new deliveries require empty containers in exchange that in case of a demand peak will probably not be available at the customer when required). 


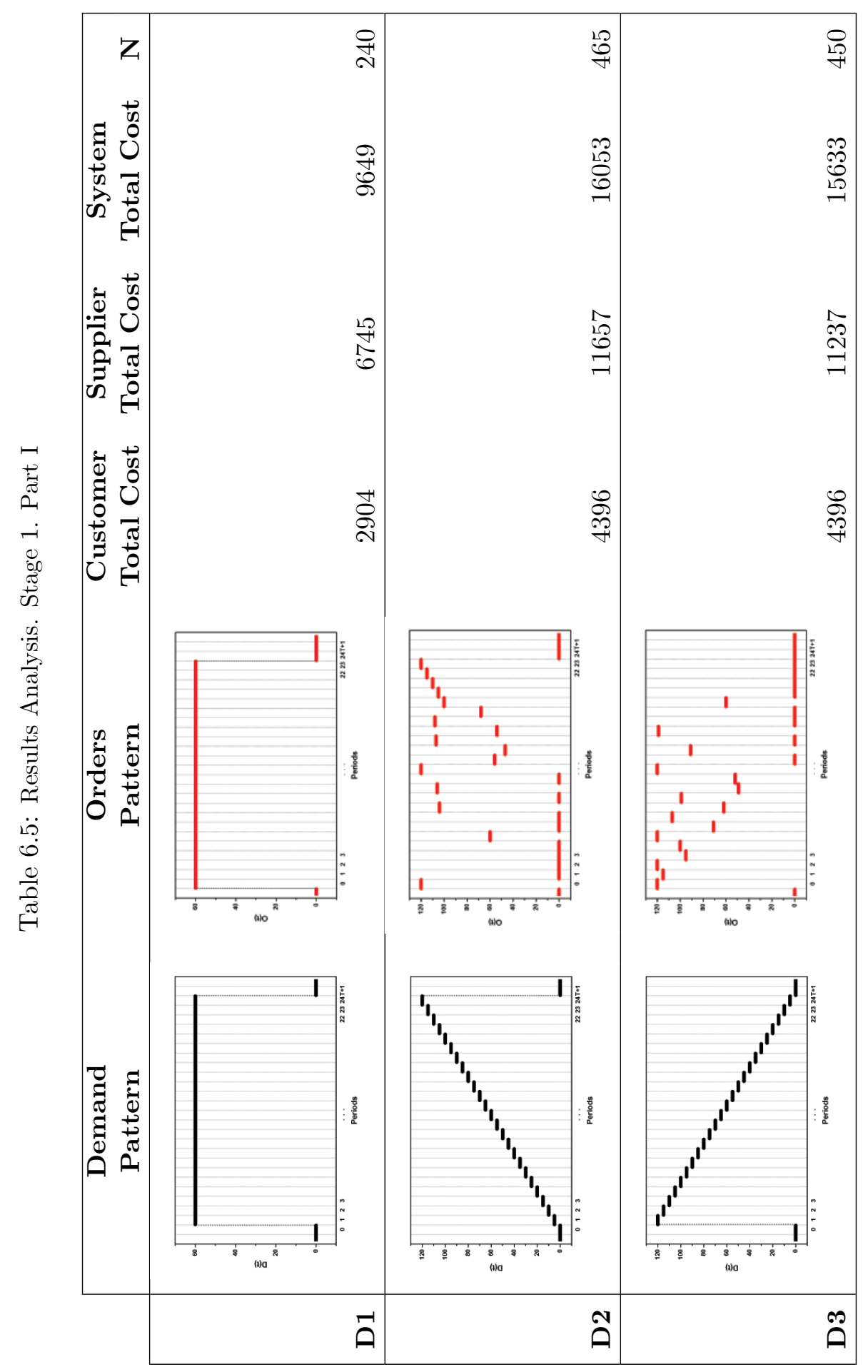




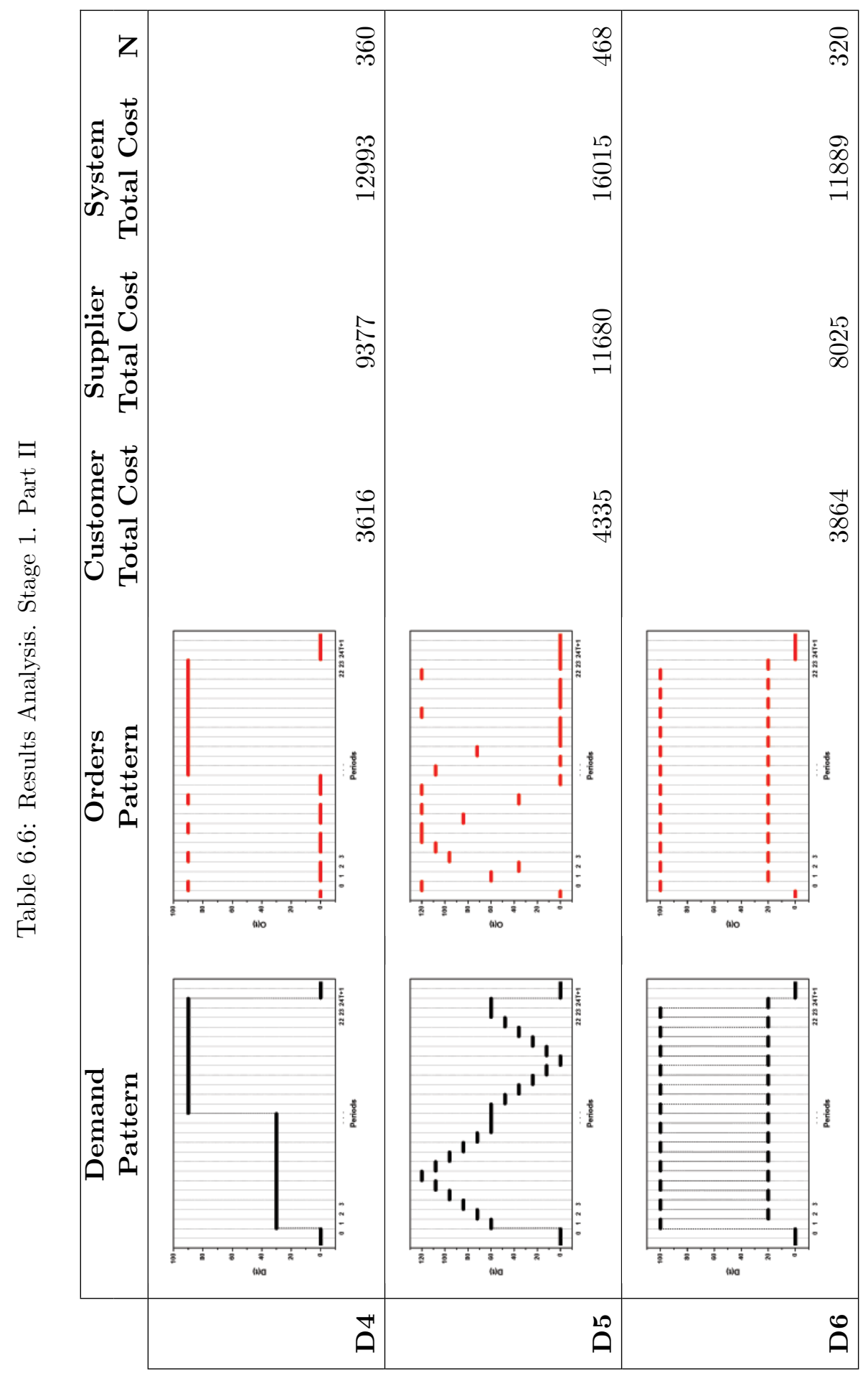




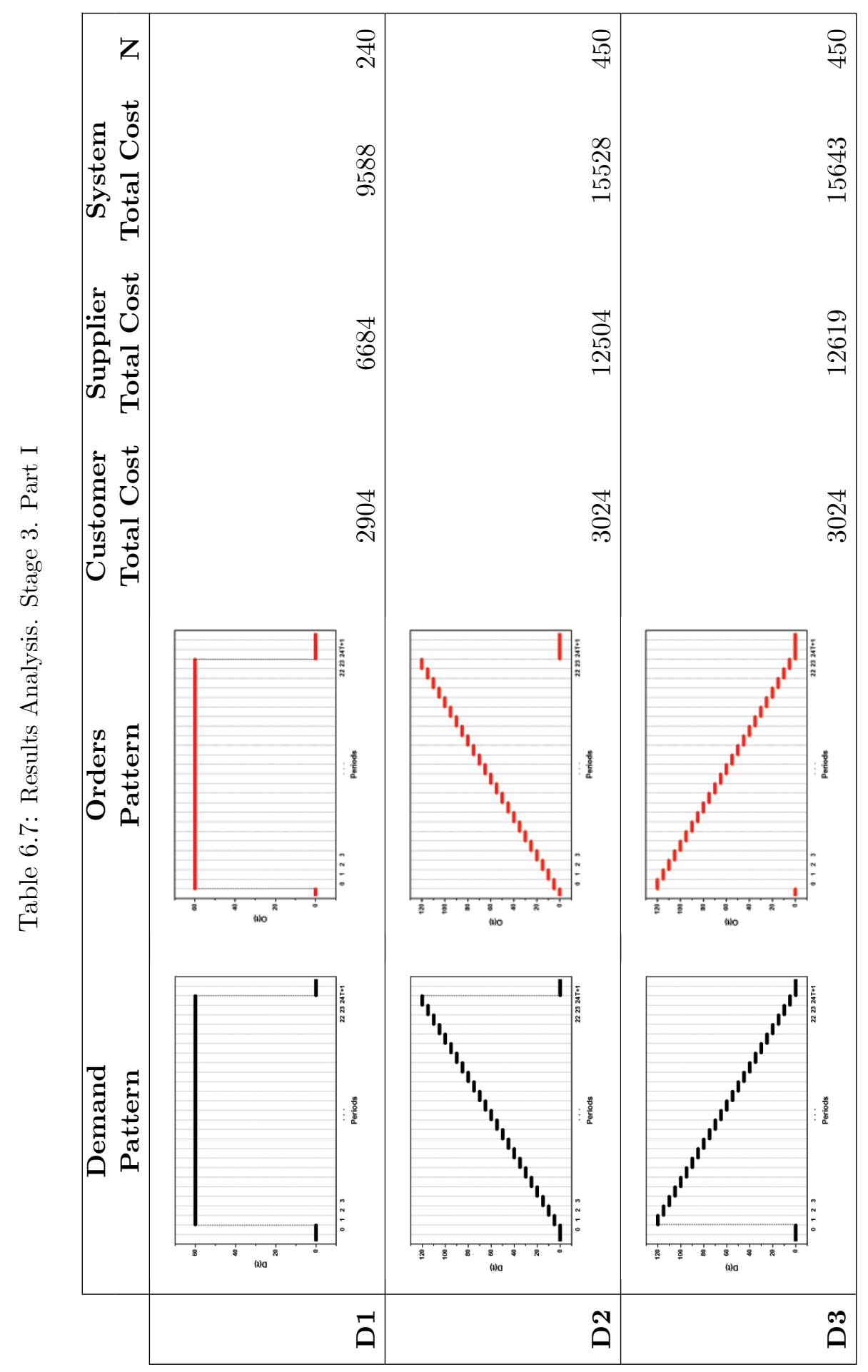




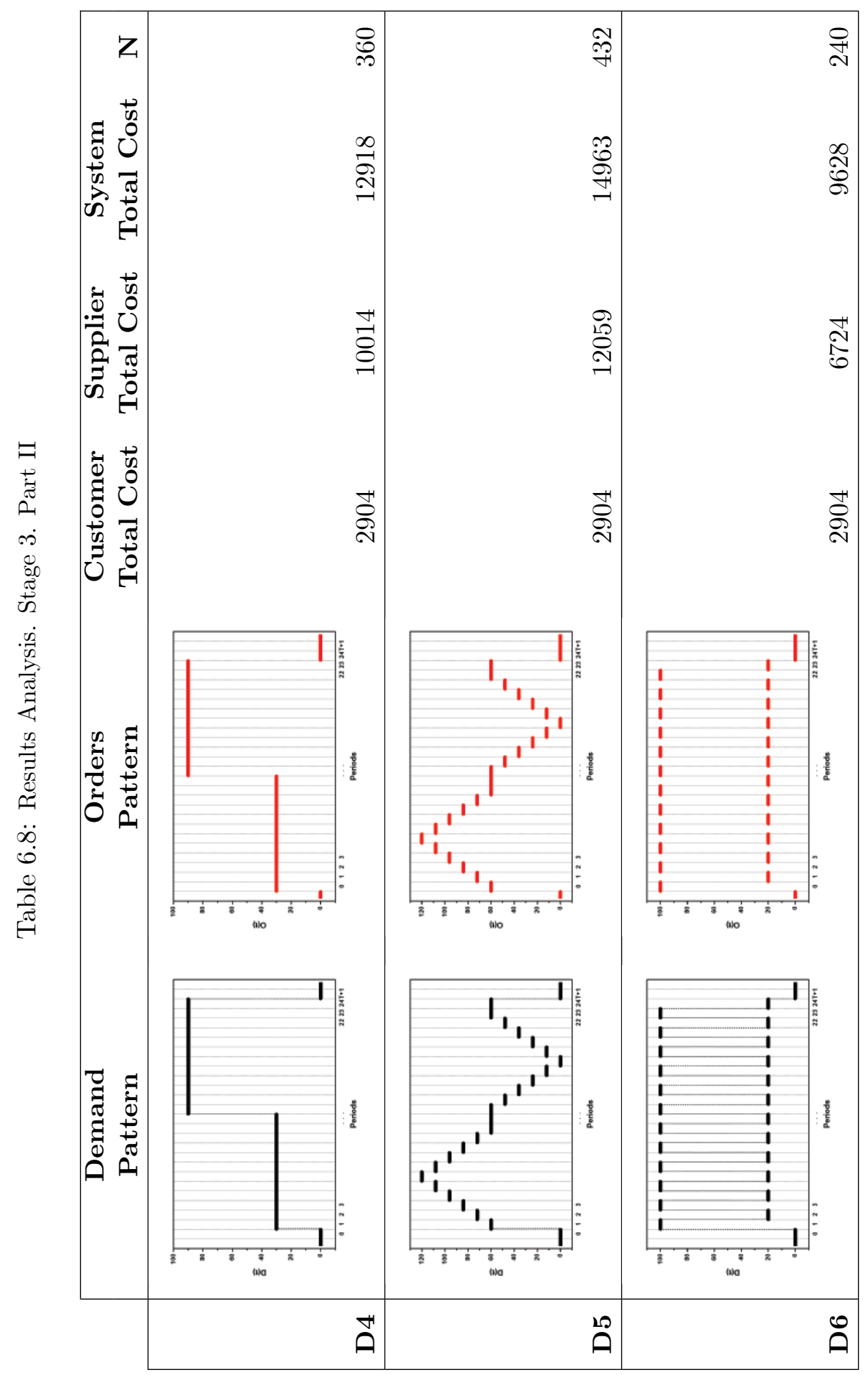




\subsection{Conclusions}

In this chapter we have studied the impact of the equal exchange recovery strategy of the economical performance of both the customer and the supplier. The main conclusions obtained after developing and solving a two-stage decision problem including a customer and a supplier model are as follows. First, the main factor to be considered in this type of situations is demand pattern. Given that no backlogs are allowed, demand fulfillment is the main driver that conditions customer behavior and therefore, supplier behavior as well. Second, we observed that different cost structures have a limited effect on system behavior, especially when compared to the clear effect of different demand patterns. Third, the equal exchange control strategy works better in case of even demand (typical JIT case). Seasonal demands or highly variable demand result in higher total costs due mainly to higher acquisition costs for the required fleet (fleet has to be dimensioned for the peaks). This results need to be compared with alternative policies that enable to discern how to achieve lower total costs for highly variable demands. 


\section{Chapter 7}

\section{Conclusions, original contributions and future research lines}

In this final chapter we recapitulate the research project presented in this dissertation. First, the more relevant learnings and observations resulting from the overall research goal and from our complete PhD trajectory are summarized. Next, more specific conclusions stemming from each of the dissertation objectives are summarized. These two points encompass section 7.1 of this chapter, devoted to the $\mathrm{PhD}$ dissertation conclusions. In the Original Contributions section (section 7.2), we highlight the aspects of this dissertation that constitute a net advance in scientific knowledge. Finally, a $\mathrm{PhD}$ thesis is nothing but the first research project in a researcher professional path. As in any other research project, the expected outcome is not only to provide one step forward in academic knowledge, but to raise meaningful questions that point out directions for further advancements. Therefore, the opportunities for further research that emerge as a result of this thesis are remarked in section 7.3 (Future Research Lines).

\subsection{Conclusions of this PhD dissertation}

\section{BLOCK ONE: CONCLUSIONS ABOUT THE RESEARCH GOAL AND THE COMPLETE PhD TRAJECTORY}

The core research goal of this dissertation was to develop a management model for closedloop supply chains of reusable articles. The model comprises two main parts: problems identi- 
fication and solutions proposal; and intends to be useful for practitioners confronted with the management of a reuse CLSC. In the first part of the model, the main issues that will have to be dealt with in reusable articles systems were identified and integrated. This part of the research used a bottom-up approach: through our past professional experience and the additional field studies we have developed during our $\mathrm{PhD}$ trajectory in close contact with industry, we arrived to the conceptual model proposed in Chapter 5 (figure 5-3). Besides, as engineers or applied scientists, our research is meaningful insofar as scientific knowledge is used or applied to solve practical problems. Hence, this dissertation would have been incomplete if solutions had not been proposed to the managerial issues identified in figure 5-3 (second part of the model). At this point, we came back to academic literature (and to business practice, through our case studies) to analyze to what extent the different issues identified in our model had been dealt with by other researchers or by practitioners. We found that the development degree for each issue was variable: while some issues had been reasonably well solved (e.g. balance inventories between depots), other issues had been scarcely addressed (e.g. fleet size calculation). We also found issues that, though pertaining to well-established clusters of knowledge in closed-loop supply chain research, are not well solved in the particular case of reuse (e.g. inventory control models for defining purchase policies for new reusable articles). For the two latter types of issues, we proposed some solutions and tools mixing either qualitative and quantitative approaches. For instance, the methodology we put forward in chapter 5 departs from an approximate yardstick depicting the relevant variables that are to be considered (fleet size, demand, cycle time) and the relationship that links them. Through a qualitative argumentation, we develop a method for obtaining "from the field" the required information and properly applying it. In this soft reasoning, pieces of formal modeling or quantitative reasoning are embedded, such as the use of transfer function models (time-series analysis) to draw articles cycle time characteristics from aggregate issues and returns data. We also used pure formal reasoning for building and solving the MILP models that we used to evaluate the performance of the equal exchange recovery control strategy (a particularly extended strategy) when confronted to different types of demand patterns. Building this model would have not been possible or meaningful without the previous work of conceptualizing from reality the situation at hand and the main aspects to be considered. 
Once we have presented an overall view of the research process that has been traced in this thesis, we focus on each of the objectives that have been dealt with in the dissertation in order to present the main learnings and insights stemming from them.

BLOCK TWO: CONCLUSIONS RELATED TO EACH RESEARCH OBJECTIVE

Objective 1. To explore/survey and structure the field of reverse logistics and closed-loop supply chains in order to provide a general understanding of this subarea of supply chain management.

The $\mathrm{PhD}$ research project started with a systematic review of the body of literature pertaining to the fields of reverse logistics (RL) and closed-loop supply chains (CLSC). Conference proceedings, key monographs, previous $\mathrm{PhD}$ dissertations on the topic and scientific articles published in journals (included in related subject categories, such as Industrial Engineering, Manufacturing Engineering, Operations Research \& Management Science, Transportation, Management) were reviewed. As a result, an overall understanding of this subarea of Operations Management that theoretically frames our research was acquired. This result has been presented in Chapter 2. In this chapter, we introduced how the reverse logistics concept has evolved throughout the last years: from an initial notion focused on the materials flow "sense" (direction), to a more restricted concept in the nineties mainly related only to environmental (basically recycling) issues. In the next decade, the term reverted to the original concept, focusing in the sense of the material flow, regardless of its purpose. During the last decade, the reverse logistics notion has evolved to be integrated in the broader concept of closed-loop supply chains, that emphasizes the need of considering the forward and reverse flows in supply chain networks with a holistic perspective. The links of RL and CLSC with other border disciplines such as waste management, green supply chain management, industrial ecology and eco-efficiency have also been explored.

A basic pillar to understand the RL and CLSC fields is to acknowledge the fact that the reverse flow encompasses a wide variety of different activities, each of them having its particular characteristics. It is also important to understand that reverse flows can be classified depending on different criteria, such as: 1) the level of disassembly undergone by the product in the recovery process; 2) in which stage of product life-cycle the return occurs; 3) the drivers that 
motivate the existence of the return flow. Some possible typologies are the following:

- Regarding criteria type 1 (level of disassembly), CLSCs can be classified in: direct reuse or resale, repair, refurbishing, remanufacturing, cannibalization, recycling.

- Regarding criteria type 2 (product life-cycle stage for returns), two possible typologies are found. First typology encompasses production-related returns (e.g. defectives rework), distribution-related returns (e.g. commercial returns), use-related returns (e.g. repair), end-of-use returns (e.g. trade-in after lease), end-of-life returns (e.g. recycling). An alternative typology includes end-of-life (EoL) returns, end-of-use returns (EoU), commercial returns and reusable items.

- Regarding criteria type 3 (drivers), CLSC can be classified in: economic profit-driven (profit), environmental legislation driven (planet), corporate social responsibility-driven (people).

Finally, a wide range of decision-making problems that typically arise in RL and CLSC were presented and classified according to their strategic, tactical or operational nature.

The achievement of Objective 1 enabled us to learn that RL and CLSC are still in their infancy as academic disciplines, especially when compared with the enormous amount of scientific literature focusing in the forward supply chain. However, some types of reverse flows or some particular decision problems have been studied in more depth by the academic community while others remain fairly unexplored. In particular, one reverse flow type that shows a high scarcity of academic research are closed-loop supply chains involving direct reuse of products.

Objective 2. To position the research problem addressed in this thesis in the general body of RL and CLSC literature

After accomplishing Objective 1, an overall understanding of CLSC and RL fields was acquired. In this second objective, we went from generals to specifics, sharpening the scope of our research and positioning it in the general body of literature of RL and CLSC. This objective has been mainly accomplished in section 3.2 of Chapter 3 .

The focus of this thesis is centered in closed-loop supply chains of reusable articles (reuse CLSC). In this part of the research, the edges of our understanding of "reuse CLSC" were 
defined: we identified three main features (represented in Figure 3-1) that enable to distinguish reuse CLSC from other types of CLSC, such as remanufacturing or commercial returns types. First feature is the level of disassembly or disaggregation required in product recovery activities. In reuse CLSC, the product is reintroduced in the forward supply chain without undergoing any disassembly process, but just simple reconditioning operations, such as cleaning, filling, etc. Second feature is that the term reuse CLSC used in this dissertation refers to products that are reintroduced in the original forward supply chain or a similar one. Sales cannibalization in the primary market due to an enlargement of the secondary market is retained out of the scope of this thesis. Third feature refers to the fact that in reuse CLSC, articles are mobile assets that constitute a shared resource in the supply chain network. In order to perform the function for which the article is designed, it has to be some stages, articles remain out of the control of the original owner.

The literature review carried out within this objective revealed that, in spite of the contribution of reuse CLSC to the environmental and economical sustainability of production and distribution systems, this type of CLSC has not been widely researched for the moment. Besides, our interaction with organizations dealing with reusable articles unveiled that management of reuse CLSC is not straightforward. Both factors (scarce academic knowledge on the topic and managerial difficulties on the practitioners' side) motivate this research project on CLSC of reusable articles and steers this research to take off by a field exploration of the problem at hand.

Objective 3. To develop a methodological framework for research in the Operations Management area, and to elaborate the particular methodological approach used in this thesis.

Methodological aspects in the Operations Management (OM) area are acquiring a growing importance. However, given its short trajectory as an academic discipline, the OM community is still lacking an agreed-upon set of research methods and techniques. In this part of the research project, several methodologies frequently used in OM area were reviewed (namely, case study research, action research, survey research and quantitative modeling). Then, a comparative analysis was carried out in order to detect which methodology or set of methodologies are more suitable to address a particular type of research question. In addition, the four methods were 
positioned in the different stages of the scientific knowledge creation cycle (conceptualization, formal modeling, model solving, implementation). Some methodologies are more suitable for new theories and ideas generation whereas others are much more powerful for theory testing.

During this part of the research several interesting conclusions were drawn. First conclusion is that OM researchers have at hand a variety of techniques and tools to tackle manifold OM problems in different levels of scientific elaboration. Nevertheless, the main conclusion extracted from our analysis is the complementariness of the different techniques. The four approaches analyzed in this research are not to be considered as disjoint alternatives, but rather as complementary approaches that the researcher has at hand in order to create new knowledge. The more appropriate research methods and tools depend on the problem at hand and the objectives of the research project. Therefore, researchers in OM will need to handle several techniques, if not all of them, in order to address scientific problems with the most appropriate method (or combination of methods) in each case.

In addition, the use of several complementary research methodologies for addressing the same scientific problem is highly recommended. This approach, known as triangulation of methods, enables to reaffirm the coherence and internal validity of the research. If the results and conclusions obtained through the different methods are coherent, research bias due to the method used are expected to be under control. The triangulation approach can also be applied to other dimensions of the research project, such as researchers and data. In essence, all these approaches aim at controlling bias and its application provide more robust and reliable research results.

All the knowledge accumulated during Objective 3 accomplishment has been condensed in the general methodological framework put forward in section 3.3. The framework encompasses the selection guide outlined in Table 3.1 and the research cycle model depicted in Figure 3-3. This framework, which can be applied to any research project in the OM area constitute one of the net contributions of this $\mathrm{PhD}$ thesis to academic knowledge.

Objective 3 also aims at elaborating the particular methodological approach to be used in this thesis. Two "ingredients" are required for this purpose. First ingredient is within objective 2 , where the research problem to be addressed in this dissertation was defined. This problem pertains to a specific subdiscipline of the OM area. Second ingredient is found within the first 
part of objective 3, where a framework for choosing the research methodology in OM area was developed. Therefore, the two elements required for providing a methodological choice to this thesis are now present. Given the novelty of reuse CLSC, an initial exploratory study in the field (case studies) seemed more than necessary. Once the reuse phenomena was better understood and structured, in the solutions proposal phase, new techniques (mainly with a quantitative focus) could be applied. The design of the research project presented in this dissertation covers most stages represented in the scientific knowledge creation cycle depicted in Figure 3-3: conceptualization, formal modeling, model solving, and, partially, implementation (validation of the conceptual model by practitioners involved in the case studies).

The two aims pertaining to Objective 3 have been accomplished in Chapter 3, and more specifically in sections 3.3 and 3.4 .

Objective 4. To elaborate six own development case studies carried out in real industrial settings on which the theories and concepts proposed in this thesis are grounded through inductive reasoning.

In order to develop new theory on reuse CLSC, six case studies were developed in close contact with industrial partners. Case studies sampling was not random but theoretical: two case studies deal with reusable articles of RTI type (Shopping Carts, Flora Holland); two case studies deal with RPM type (Medgas and LPG); another two case studies deal with RP type (Erasmus MC and Service tools). Structured case study reports were built after the completion of each case. The structured arrangement of the information collected within each case eased further comparisons of the empirical evidence provided by the cases. All this empirical information has been later used to generate new knowledge and theories through the use of grounded theory approach.

Objective 5.To sharpen the reusable articles concept definition and to propose a typology for reusable articles classification, providing an integrated view of RTI, RPM and RP.

The accomplishment of objective 2 led us to conclude that empirical research on reusable articles management is quite scarce. Academic knowledge on reuse CLSC is fragmented and scattered and only considers some particular situations in which reuse is involved. Based on the case studies carried out as a result of objective 4, we proposed in this thesis a definition 
and a typology for reusable articles, namely Returnable Transport Items (RTI), Reusable Packaging Materials (RPM) and Reusable Products (RP). The first type encompasses tertiary and secondary packaging materials used mainly as distribution items. Typically standardized, RTI are not in direct contact with the real product (the contents). RPM type comprises primary packaging materials in direct contact with the contents, and therefore, their standardization is rendered more complex due to technical or marketing-related reasons. Finally, we also consider a third category, Reusable Products (RP), where the article reused is the product itself and not a packaging element. Conventional wisdom in general CLSC frameworks, such as Thierry et al. (1995), Flapper et al. (2005) or Krikke et al. (2004), only include packaging elements at item-level reuse activities (mainly distribution items and, at most, toner cartridges or reusable cameras). However, as this research has shown, a product can also be reused at item-level disassembly degree without cannibalizing sales in the primary market, if the product has been designed for durability and hence, for reuse. Several examples of RP are provided throughout the dissertation: surgical instruments, service tools, bikes in public rental systems... To the best of our knowledge, this is the first time that this integrated view has been given to the set RTI, RPM and RP. This integrated view under the "reusable articles" term has the special interest that enables to extend results (models, best practices, frameworks, ... ) obtained from one category to the others. The definition and typology of reusable articles term constitutes a second net contribution to knowledge derived from this $\mathrm{PhD}$ dissertation.

Other important results obtained within this objective are the identification of the main features that characterize reuse CLSC (including the particular aspects of their return flow) and the identification of two different physical flow structures in this context (star and multidepot networks). Objectives 4 and 5 have been mainly developed in Chapter 4 .

Objective 6. To elaborate a conceptual model that synthesizes the common problems detected in reusable articles systems, the basic information and metrics required to deal with this set of problems and the managerial issues that practitioners will specifically encounter in the context of reuse.

As a result of the gap detected in literature concerning reusable articles, a framework (conceptual model) that synthesizes the main aspects involved in the management of a reuse CLSC is developed within this objective. The model contributes to a better understanding of the main 
factors that make the management of a reuse closed-loop supply chain more complex than the management of the classical one-way supply chain (use-and-dispose model).

The conceptual model comprises three building blocks: common problems, basic information requirements (metrics) and management issues. The foundations on which the three building blocks are laid on are the case studies developed within objective 4. The first building block, common problems, includes aspects such as fleet shrinkage, significant investment and limited visibility. The second building block, basic information requirements (metrics) needed to deal with the common problems encompasses three variables: cycle time, return rate, inventory onhand at each location of the network. Finally, six managerial issues that practitioners have to expect to face when confronted with a reuse CLSC are identified, namely:

- Define fleet size dimension

- Control cycle time and promote articles rotation

- Control return rate and prevent shrinkage

- Define purchase policies

- Plan and control reconditioning

- Balance inventories between depots

This six managerial issues involve interesting opportunities for researchers in $\mathrm{OM}$ and $\mathrm{OR} / \mathrm{MS}$ areas. Once the issues have been identified and the decision-making aspects involved in each issue structured, different quantitative approaches and techniques can be used to address the issues. Some issues have been reasonably well solved in literature or in practice, whereas other issues do not actually show a clear approach for addressing them. For instance, Issue 6: Balance inventories between depots, can be fairly addressed with dynamic stochastic linear programming models within the classical transportation formulation. In the dissertation several academic and practical examples of the use of these models have been provided. On the other hand, Issue 1. Fleet size dimension has not been directly addressed in literature and constitutes an opportunity for contributing with new knowledge to the OM literature.

Objective 7. To propose several solutions to some managerial issues, such as an analysis of different recovery control strategies, a methodology for determining the 
reusable articles feet size in star networks and the corresponding replenishment purchasing policies.

For three managerial issues not having been actually solved neither in practice nor in academia, we proposed some solutions (orange and blue arrows in figure 5-3). More precisely, two solutions have been fully developed in this dissertation. The foundations for the development of an additional solution are laid down in this document, though for this third solution, it is not possible to claim a "complete" development and constitute an element of further research.

The first solution consists of analyzing a set of control strategies aiming at the reduction of fleet shrinkage and the promotion of articles rotation in the system. Depending on the situation at hand, some control strategies will be more suitable than others. The second solution is the methodology proposed in this dissertation for deciding how many RA need to be in circulation in the network. An aspect to highlight is that this method can be used either in star and multi-depot networks. Fleet size calculation is a design decision to be adopted for the first time during the set-up of the reusable articles system. This decision is also to be revisited when structural changes in RA's demand and cycle time distribution take place (redesign context). In addition, as noted in issue 5.7, lost or damaged articles have to be replaced by new articles purchases in order to maintain the adequate "capacity" of the fleet (fleet size maintenance). This last aspect motivates the development of a third solution.

The problem addressed in this third solution deals with the purchasing policies to be established in order to replace irreparably lost or damaged articles (operational issue). Can optimal purchasing policies be derived from specific inventory control models? Although this solution requires further elaboration, in this dissertation the problem at hand and the corresponding literature gap have been identified. Some possible approaches or approximations on how to deal with this problem have been pointed out in this document.

Objectives 6 and 7 have been mainly developed within chapter 5 .

Objective 8. To elaborate and solve a mixed-integer linear programming (MILP) model to quantitatively analyze the impact of different recovery control strategies on reusable articles management.

Within this last objective, the focus is centered in one particular control strategy that was studied as an outcome of the objective 7 . The main conclusions obtained after developing and 
solving a two-stage decision problem including a customer and a supplier model are as follows. First, the main factor to be considered in this type of situations is demand pattern. Given that no backlogs are allowed, demand fulfillment is the main driver that conditions customer behavior and therefore, supplier behavior as well. Second, we observed that different cost structures have a limited effect on system behavior, especially when compared to the clear effect of different demand patterns. Third, the equal exchange control strategy works better in case of even demand (typical JIT case). Seasonal demands or highly variable demand result in higher total costs due mainly to higher acquisition costs for the required fleet (fleet has to be dimensioned for the peaks). This results need to be compared with alternative policies that enable to discern how to achieve lower total costs for highly variable demands.

\subsection{Original contributions}

In this section the net original contributions to academic knowledge achieved in this thesis are listed and briefly explained. They constitute a modest one step forward in current scientific knowledge. Each original contribution has been more widely elaborated in the corresponding objective conclusions.

The first original contribution is the methodological framework for research in the OM area that resulted from objective 3. The framework has been developed to be used in any research project pertaining to OM area and is not specific of RL or CLSC topics. This methodological framework provides a selection guide that facilitates the choice of the research methodology depending on the research questions arising at project design level. Besides, the methodological choice can also be influenced by the place of the four main research methodologies within the cycle for generation of scientific knowledge in OM (Conceptualization - Formal modeling - Model Solving - Implementation). Some methodologies are more suitable for theory generation activities (bottom-up, inductive approach) whereas others perform better for theory testing (top-down, deductive approach). The research questions, as well as the methods used, will depend on the advancement degree achieved by the OM community on a scientific topic. All this aspects can be interesting for other OM researchers starting a new research project.

The second original contribution of this thesis is the integrated view of RTI, RPM 
and RP resulting from objective 5. A definition of the "reusable articles" term and a typology highlighting similarities (and also differences) between the three categories have been put forward. This integration and conceptualization of the reusable articles term enables to use the principle "study for one, results for all" within the three categories. Results can be generalized between categories, subject to the limitations also expressed in dissertation. The generalization approach, enabled by this contribution, can accelerate the generation of knowledge about reusable articles in general. The models, best practices, frameworks, ... described in the body of literature about RTI (which, although scarce, is the more abundant in the three types of reusable articles) can be extended to other reuse situations involving RPM or RP.

The third original contribution generated in this thesis is the conceptual model that integrates the managerial aspects arising in reuse CLSC (Figure : common problems, basic information requirements (metrics), managerial issues). This contribution intends to be useful from the practical point of view. Practitioners can use the framework for identifying the main aspects in which they have to focus on and also for recognizing the relationships established between the different building blocks of the framework. In addition, the model is also useful from the academic point of view. Some managerial issues identified in the model have not been actually well solved in the academic literature. Classical one-way logistics decision-models do not suit many times the particular characteristics of reuse closed-loop supply chains, where most demand is fulfilled with the returned products. Our conceptual model represent one step forward in structuring the reusable articles field and can facilitate further quantitative modelizations of logistical decisions involving reusable articles.

The different solutions that have been proposed in this dissertation to some managerial issues detected in the conceptual model also constitute net advancements on academic knowledge. Therefore, the fourth original contribution of this $\mathrm{PhD}$ dissertation is the methodology elaborated for fleet size calculation $(\mathbf{N})$. This methodology is valid either for star and multi-depot networks. Based on a yardstick that establishes the relationship between the three variables involved in the problem (namely fleet size, reusable articles demand, and cycle time) the methodology aims at obtaining from the field the necessary information, with sufficient accuracy level, in order to derive the number of articles required in circulation in a given system. 
The fifth original contribution to knowledge is the identification and analysis of the different control strategies that can be used in closed-loop supply chains of reusable articles. The strategies have been classified in three groups: economical recovery incentives; non-economical recovery incentives; users' accountability. The importance of establishing the appropriate incentives in supply chains using shared resources is highlighted by this contribution.

Finally, the sixth net contribution to knowledge is the two-stage decision model elaborated and solved in Chapter 6. The model encompasses two MILP models representing the optimal behavior of the supplier and the customer. Not only has the model been useful to discern the situations in which the equal exchange recovery strategy is not adequate. In addition, the model which has been implemented using AIMMS, CPLEX and Excel, can be used as Decision Support System (DSS) in the corporate world in order to decide on the acquisition of new reusable articles when a new customer enters the system. The specific demand pattern of each particular customer can be explicitly considered within this model.

\subsection{Future research lines}

Two main opportunities for further research emerge as a result of our $\mathrm{PhD}$ research project.

The first further research opportunity has already been pointed out in the conclusions pertaining to Objective 7 (Solutions Proposal). In this part of the research, an additional unsolved problem in reuse CLSC has been identified. This problem is linked to the definition of optimal purchasing policies for replacing lost or damaged articles in the fleet. The foundations that trigger this further research point have been elaborated in Section 5.7. In thePhD dissertation we already provide some ideas on how a solution to this issue could be developed. However, the full solution needs to be further elaborated and is what we propose as one further development of this research.

A second further research line is linked with Radio Frequency Identification Systems (RFID). This type of technology opens new possibilities in the management of reusable articles. RFID is expected to provide wider visibility in the unobservable part of the supply chain. A few implementation case studies have already been developed. How the new data can be used to 
leverage a better management of reusable articles also constitute an element of further research. 


\section{Bibliography}

[1] Aberdeen Group (2004), RFID-enabled Logistics Asset Management Benchmark Report, Aberdeen Group, Boston, MA.

[2] Ackoff, R.L., Sasieni, M.W.(1968). Fundamentals of Operations Research. New York: Wiley.

[3] Ackoff, R.L. (1971). "Towards a System of Systems Concepts". Management Science, vol. 17 (11), Theory Series, pp.661-671.

[4] Andreu Abela, J., García-Nieto, A., Pérez Corbacho, A.M. (2007). Evolución de la Teoría Fundamentada como técnica de análisis cualitativo. Madrid: Centro de Investigaciones Sociológicas (CIS). Cuadernos Metodológicos.

[5] Atasu, A., Guide, V. D. R., and Van Wassenhove, L. N. (2008). Product reuse economics in closed-loop supply chain research. Production and Operations Management, 17(5):483-496.

[6] Barba Gutiérrez, Y. (2009). Herramientas para la toma de decisiones estratégicas y operativas en la cadena de suministro inversa. PhD dissertation. Supervisor: Adenso Díaz. Universidad de Oviedo.

[7] Box, G.E.P. y Jenkins, G.M. (1976). Time Series Analysis: Forecasting and Control. Holden-Day, San Francisco, CA.

[8] Bojkow, E. (1991). Basic considerations on the calculation of the trippage number for returnable containers. Packaging Technology and Science, 4(6):315-331.

[9] Breen, L. (2006). "Give me back my empties or else! A preliminary analysis of customer compliance in reverse logistics practices (UK)", Management Research News, 29 (9), pp.532-551. 
[10] BRIDGE (2007). Returnable transport items: The market for EPCglobal applications. Brussels: Building Radio frequency IDentification solutions for the Global Environment.

[11] Bryson, L. (2005). Brewers, do you know where your kegs are? Solving the problem of disappearing cooperage. The New Brewer, September-October, pp.30-35. [Available on-line]: www.brewersassociation.org

[12] Buchanan, D. J. and Abad, P. L. (1998). Optimal policy for a periodic review returnable inventory system. IIE Transactions, 30(11):1049-1055.

[13] Carrasco-Gallego, R., Ponce-Cueto, E., Dekker, R. (2009a). A framework for closed-loop supply chains of reusable articles. Econometric Institute Report EI2009-21. [Available on-line]: http://publishing.eur.nl/ir/repub/asset/16707/EI2009-21.pdf

[14] Carrasco-Gallego, R., Ponce-Cueto, E. (2009b). Forecasting the returns in reusable containers' closed-loop supply chains. A case in the LPG industry. In:Proceedings of the 3rd International Conference on Industrial Engineering and Industrial Management. Barcelona-Terrassa, September 2-4, pp. 311-320.

[15] Carrasco-Gallego, R., Ponce-Cueto, E. (2009c) "Case studies on the adoption of radiofrequency identification (RFID) systems in Spanish companies". In: 16th International Annual EurOMA Conference. 14-17 June, Göteborg, Sweden.

[16] Carter, C.R., Ellram, L.M. (1998). Reverse logistics: a review of the literature and framework for future investigation. Journal of Business Logistics, 19(1), 85-102.

[17] Churchman, C.W. (1961). Prediction and optimal decision. Philosophical issues of a science of values. Englewood Cliffs, NJ: Prentice-Hall Inc.

[18] Coughlan, P., Coughlan, D. (2002). "Action Research for Operations Management". International Journal of Operations \& Production Management, Vol. 22 (2), pp.220-240.

[19] Crainic, T.G., Gendreau, M., Dejax, P. (1993), "Dynamic and stochastic models for the allocation of empty containers", Operations Research, 41 (1), pp.102-126.

[20] Dantzig, G.B.(1963). Linear Programming and Extensions. Princeton University Press. 
[21] Davis, L.E., Cherns, A.B.(eds.) (1975).The Quality of Working Life. V1: Problem, Prospects and the State of the Art. \& V2: Cases and Commentary. New York: The Free Press.

[22] Debo, L.G., Toktay, L.B., Van Wassenhove, L.N. (2005). Market Segmentation and Product Technology Selection for Remanufacturable Products. Management Science, 51 (8), pp.1193-1205.

[23] De Brito, M.P. and Dekker, R. (2003), "Modelling product returns in inventory control - exploring the validity of general assumptions", International Journal of Production Economics, 81-82, pp. $225-241$.

[24] De Brito M.P., Dekker, R. and Flapper, S.D.P.(2005), "Reverse Logistics: a review of case studies", in: Fleischmann, B. and Klose, A. (eds.) Distribution Logistics, advanced solutions to practical problems. Springer-Verlag, Berlin.

[25] De Brito, M.P. and Van der Laan, E. (2009), "Inventory control with product returns: The impact of imperfect information", European Journal of Operational Research, 194 (1), pp. 85-101.

[26] Dekker, R., Fleischmann, M., Inderfurth, K. and Van Wassenhove, L.N. (2004) (eds), Reverse logistics. Quantitative models for closed-loop supply chains. Springer.

[27] De la Fuente Aragón, M.V. (2003). Propuesta de modelo integrado para la gestión de las cadenas de suministro directa e inversa. Aplicación a una empresa del sector metal-mecánico. PhD dissertation. Supervisor: Lorenzo Ros McDonnell. Escuela Técnica Superior de Ingeniería Industrial. Universidad Politécnica de Cartagena.

[28] Del Castillo, E., Cochran, J.K. (1996). "Optimal Short Horizon Distribution Operations in Reusable Container Systems", Journal of the Operational Research Society, 47, 1, pp. 48-60.

[29] DeCroix, G. A. and Zipkin, P. H. (2005). Inventory management for an assembly system with product or component returns. Management Science, 51(8):1250-1265.

[30] DeCroix, G., Song, J.-S., and Zipkin, P. (2005). A series system with returns: Stationary analysis. Operations Research, 53(2):350-362.

[31] DeCroix, G. A. (2006). Optimal policy for a multiechelon inventory system with remanufacturing. Operations Research, 54(3):532-543. 
[32] Dong, J.X. and Song, D.P. (2009). Container fleet sizing and empty repositioning in liner shipping systems. Transportation Research Part E: Logistics and Transportation Review, 45(6):860-877

[33] Dubiel, M. (1996), "Costing Structures of Reusable Packaging Systems", Packaging Technology and Science, 9, pp. 237-254.

[34] Duhaime, R., Riopel, D., Langevin, A. (2001). "Value Analysis and Optimization of Reusable Containers at Canada Post". Interfaces, 31, 3, pp 3-15.

[35] Edelstein, M. and Melnyk, M. (1977). The pool control system. Interfaces, 8(1) :21-36.

[36] Eisenhardt, K. M. (1989). Building theories from case study research. Academy of Management Review, vol. 14 (4), pp. 532-550.

[37] Ellram, L.M. (1996). The use of the case study method in logistics research. Journal of Business Logistics, 17 (2), pp. 93-XX.

[38] Emery, F., Trist, E. (1965) "The Causal Texture of Organizational Environments" Human Relations, vol. 18, pp. 21-32.

[39] Emery, F., Trist, E. (1972). Towards a Social Ecology: Contextual Appreciations of the Future in the Present. London: Plenum Publishing Corporation.

[40] Emery, F., Thorsrud, E. (1976). Democracy at Work. Leiden: Martinus Nijhoff Social Sciences Division.

[41] EPAL (2010). European Pallet Association www.epal-pallets.org . Accessed on May 2010.

[42] Erera, A.L., Morales, J.C., and Savelsbergh, M. (2009). Robust optimization for empty repositioning problems. Operations Research, 57(2):468-483.

[43] Fernández Quesada, I. (2004). Análisis De La Logística Inversa En El Entorno Empresarial: Una Aproximación Cualitativa. PhD dissertation. Supervisor: David de la Fuente García. Facultad de Ciencias Económicas y Empresariales. Universidad de Oviedo.

[44] Ferrer, G., Ketzenberg, M.E., (2004). Value of information in remanufacturing complex products. IIE Transactions, 36(3): 265-277. 
[45] Filippini, R. (1997). Operations management research: some reflections on evolution, models and empirical studies in OM. International Journal of Operations \& Production Management, vol. 17 (7), pp.655.

[46] Fink, A. and Reiners, T. (2006). Modeling and solving the short-term car rental logistics problem. Transportation Research Part E: Logistics and Transportation Review, 42(4):272-292.

[47] Flapper, S.D.P. (1996). "One-way or reusable distribution items?", in: Proceedings of ICIMPRO'96, International Conference on Computer Integrated Manufacturing in the Process Industries, 3-4 June, Eindhoven, The Netherlands.

[48] Flapper, S.D.P., van Nunen, J.A.E.E., van Wassenhove, L.N. (eds), (2005), Managing Closed-Loop Supply Chains. Berlin: Springer.

[49] Fleischmann, M., Krikke, H.R., Dekker, R. and Flapper, S.D.P. (2000), "A characterisation of logistics networks for product recovery", Omega, 28, pp.653-666.

[50] Fleischmann, M. (2001). Quantitative models for reverse logistics. Berlin: Springer.

[51] Fleischmann, M., Kuik, R., Dekker, R. (2002), "Controlling inventories with stochastic item returns: A basic model", European Journal of Operational Research, 138 (1), pp. 63-75.

[52] Fleischmann, M., Kuik, R. (2003). On optimal inventory control with independent stochastic item returns. European Journal of Operational Research, 151(1):25-37.

[53] Fluensee (2010). Case study: Keg tracking at New Belgium Brewery. Available on line [visited on May 2010]: http://www.fluensee.com/downloads/Case_Study_NBB_Keg_Tracking.pdf

[54] Forrester, J.W. (1961). Industrial Dynamics. Cambridge, MA: MIT Press.

[55] Forza, C. (2002). Survey research in operations management: a process-based perspective. International Journal of Operations \& Production Management, vol. 22 (2), pp. 152-194.

[56] Frohlich, M.T. (2002). Techniques for improving response rates in OM survey research. Journal of Operations Management, vol. 20, pp.53-62.

[57] Frosch, R.A., Gallopoulos, N.E. (1989). Strategies for Manufacturing. Scientific American, 261 (3), 144-152. 
[58] Geyer, R., Van Wassenhove, L. N., and Atasu, A. (2007). The economics of remanufacturing under limited component durability and finite product life cycles. Management Science, 53(1):88-100.

[59] Ginter, P. M., Starling, J. M. (1978). Reverse distribution channels for recycling. California Management Review 20, 73-82.

[60] Glaser, B., Strauss, A. (1967). The discovery of grounded theory: strategies of qualitative research. London: Wiedenfeld and Nicholson.

[61] Glaser B. (1992), Basics of Grounded Theory Analysis. Emergence vs Forcing. Mill Valley, CA: Sociology Press.

[62] Goh, T.N. and Varaprasad, N. (1986). "A statistical methodology for the analysis of the Life-Cycle of Reusable Containers", IIE Transactions, 18, pp. 42-47.

[63] González Torre, P. (2002). Análisis Del Ciclo De Logística Inversa En El Sector Del Vidrio Hueco Industrial. PhD dissertation. Supervisors: Esteban Fernández y Adenso Díaz. Facultad de Ciencias Económicas y Empresariales. Universidad de Oviedo.

[64] González Torre, B.A. (2005). Modelo para la determinación de la estrategia de fin de vida de los productos dentro del enfoque del diseño para el medio ambiente. PhD dissertation. Supervisor: Adenso Díaz. Escuela Politécnica Superior de Ingeniería de Gijón. Universidad de Oviedo.

[65] Guide, V. D.R. and Srivastava, R. (1997). Repairable inventory theory: Models and applications. European Journal of Operational Research, 102(1):1-20.

[66] Guide, V.D.R. and Van Wassenhove, L.N. (2001), "Managing product returns for remanufacturing", Production and Operations Management, 10 (2), pp. 142-155.

[67] Guide, V.D.R. and Van Wassenhove L.N. (2002). "The reverse supply chain". Harvard Business Review, 80 (2), pp. 25-26.

[68] Guide, V.D.R. and Van Wassenhove, L.N.(2003), "Business Aspects of Closed-Loop Supply Chains",in: Guide, V.D.R. and Van Wassenhove, L.N.(2003), Business Aspects of Closed-Loop Supply Chains, Canergie Mellon University Press. 
[69] Guide, V.D.R., Van Wassenhove, L.N. (2009). The evolution of closed-loop supply chain research. Operations Research, 57(1):10-18.

[70] Guiltinan, J. P., Nwokoye, N. G. (1975). Developing distribution channels and systems in the emerging recycling industry. International Journal of Physical Distribution 1, 28-38.

[71] Guintini, R., Andel, T. (1994) Track the coming, goings and costs of returnables. Transportation \& Distribution, 35 (7): 55-60.

[72] Gummesson, E. (2000). Qualitative Methods in Management Research. $2^{a}$ edición. Thousand Oaks, CA: Sage.

[73] Hax, A.C. (2007). Evolución del pensamiento académico en la Gestión de Organizaciones: una reflexión personal. Discurso de investidura como Doctor Honoris Causa por la Universidad Politécnica de Madrid.

[74] Hellström, D. (2009). The cost and process of implementing RFID technology to manage and control returnable transport items. International Journal of Logistics Research and Applications: A Leading Journal of Supply Chain Management, 12(1):1-21.

[75] Heese, H.S. (2007). Inventory record inaccuracy, double marginalization, and RFID adoption. Production and Operations Management, 16(5):542-553.

[76] Herbst, P.G. (1974). Socio-technical design. Strategies in multidisciplinary research. London : Tavistock Publications.

[77] Herren, H. (1973) The distribution of empty wagons by means of a computer. Rail International, 4, 1005-1010.

[78] Hertz, A., Schindl, D., and Zufferey, N. (2009). A solution method for a car fleet management problem with maintenance constraints. Journal of Heuristics, 15(5):425-450.

[79] Hill, P. (1976). Towards a New Philosophy of Management. A study of the company development programme at Shell UK Ltd. Revised reprint. Essex: Gower Press, Bowker Publishing Company.

[80] Ignizio, J.P. (1976). Goal programming and extensions. London: Heath Lexington Books. 
[81] Ilic, A., Ng, J., Bowman, P., and Staake, T. (2009). The value of RFID for RTI management. Electronic Markets, 19(2):125-135.

[82] Inaba, T. (2008). Value of sparse RFID traceability information in asset tracking during migration period. In: IEEE International Conference on RFID, pages 183-190. Las Vegas, April 16-17.

[83] Inderfurth, K. (1997). Simple optimal replenishment and disposal policies for a product recovery system with leadtimes. OR Spectrum, 19(2):111-122.

[84] International Society for Industrial Ecology (2007). < http://www.is4ie.org >

[85] Jankowick, A.D. (1991). Business Research Projects for Students. Londres: Chapman and Hall.

[86] Jelinski, L.W., Graedel, T.E., Laudise, R.A., McCall, D.W., Patel, C.K.N. (1992) Industrial Ecology: Concepts and Approaches. Proceedings of the National Academy of Sciences USA 89(3), 793-797.

[87] Johansson, O. and Hellström, D. (2007), "The effect of asset visibility on managing returnable transport items", International Journal of Physical Distribution and Logistics Management, 37 (10), 799-815.

[88] Jordan, W.C. and Turnquist, M.A. (1983). A stochastic, dynamic network model for railroad car distribution. Transportation Science, 17(2):123-145.

[89] Kantorovich, L.V. (1939) Matematicheskie metody ovganizatsii i planirovania proizvodstva. (Mathematical Methods of Organizing and Planning Production), Leningrad State University. (en ruso). Reimpreso en 1960 en Management Science, (en inglés), vol. 6 (4), pp.366-422.

[90] Kator, C. (2008). Pallet basics. Modern Materials Handling, 63 (5), pp.28.

[91] Kärkkäinen, M., Ala-Risku, T., Herold, M. (2004), "Managing the rotation of reusable transport packaging - a multiple case study", in: 13th International Working Seminar on Production Economics, Innsbruck, February 16-20.

[92] Karlsson, C. (2002). Guest editorial. International Journal of Operations and Production Management, vol. $22(2)$, pp. 141-147. 
[93] Kelle, P. and Silver, E.A. (1989a), "Forecasting the Returns of Reusable Containers", Journal of Operations Management, Vol.8, No.1, pp. 17-35.

[94] Kelle, P. and Silver, E.A. (1989b), "Purchasing Policy of New Containers Considering the Random Returns of Previously Issued Containers", IIE Transactions, 21 (4), pp.349-354.

[95] Ketzenberg, M.E., van der Laan, E., and Teunter, R.H. (2006). Value of information in closed loop supply chains. Production and Operations Management, 15(3):393-406.

[96] Kiesmüller, G.P. and Van der Laan, E.A. (2001), "An inventory model with dependent product demands and returns", International Journal of Production Economics, 72 (1), pp. 73-87.

[97] Koh, S., Hwang, H., Kwon-Ik, S., and Chang-Seong, K. (2002). An optimal ordering and recovery policy for reusable items. Computers \& Industrial Engineering, 43(1-2):59-73.

[98] Kopicki, R.J., Berg, M.J., Legg, L., Dasappa, V., Maggioni, C. (1993). Reuse and recycling: reverse logistics opportunities. Council of Logistics Management, Oak Brook, IL.

[99] Kotzab, H. (2005). The role and importance of survey research in the field of Supply Chain Management. En: Kotzab, H., Seuring, S., Müller, M., Reiner,G. (eds.). Research Methodologies in Supply Chain Management. Heidelberg : Physica-Verlag (Springer).

[100] Krikke, H., LeBlanc, I., Van de Velde, S. (2004), "Product modularity and the design of closed-loop supply chains", California Management Review, 46(2), pp. 23-39.

[101] Kroon, L. and Vrijens, G. (1995) "Returnable containers: An example of reverse logistics". International Journal of Physical Distribution \& Logistics Management, 25 (2), pp.56-68.

[102] Kulkarni, A., Ralph, D., and McFarlane, D. (2007). Value of RFID in remanufacturing. International Journal of Services Operations and Informatics, 2(3):225-252.

[103] Lambert, D.M., Stock, J.R. (1981). Strategical Physical Distribution Management.

[104] Law, A.M., Kelton, W.D. (1991). Simulation modeling and analysis. 2nd ed. McGrawHill.

[105] Lewin, K. (1946). Action Research and Minority Problems. Journal of Social Issues, 2(4): 34-46. 
[106] Martínez-Sala, A.S., Egea-López, E., García-Sánchez, F., and García-Haro, J. (2009). Tracking of returnable packaging and transport units with active rfid in the grocery supply chain. Computers in Industry, 60(3):161-171.

[107] Malhorta, M.K., Grover, V. (1998). An assessment of survey research in POM: from constructs to theory. Journal of Operations Management, vol. 16, pp. 407-425.

[108] McDonough, W., Braungart, M. (2002). Cradle to cradle. Remaking the way we make things. North Point Press.

[109] McFarlane, D., Sheffi, Y. (2003). The impact of automatic identification on supply chain operations. The International Journal of Logistics Management, 14(1):1-17

[110] McKerrow, D. (1996), "What makes reusable packaging systems work?", Logistics Information Management, 9 (4), pp.39-42.

[111] Meredith, J.R., Raturi, A., Amoako-Gyampah, K., Kaplan, B. (1989). Alternative research paradigms in operations. Journal of Operations Management, vol. 8 (4), pp.297-326.

[112] Miles, M. y Huberman, A.M. (1984). Qualitative data analysis. Beverly Hills, CA: Sage Publications.

[113] Misra., S.C. (1972). Linear programming of empty wagon disposition, Rail International, 3, pp. $151-158$.

[114] Mitroff, I.I., Betz, F., Pondy, L.R., Sagasti, F. (1974). "On Managing Science in the Systems Age: two schemas for the study of science as a whole systems phenomenon". Interfaces, vol. 4 (3), pp. 46-58.

[115] Mollenkopf, D., Closs, D., Twede, D., Lee, S., Burgess, G. (2005), "Assessing the viability of reusable packaging: a relative cost approach", Journal of Business Logistics, 26 (1), pp. 169-197.

[116] Momberg, W. (2009). Remanufacturing at Volkswagen AG. In: 9th Internatonal Workshop on Closed-Loop Supply Chain Management. Braunschweig-Wolfsburg (Germany), September 17-19.

[117] Murphy, P. (1986) "A Preliminary Study of Transportation and Warehousing Aspects of Reverse Distribution". Transportation Journal, Summer 1986, pp. 12-21. 
[118] Murphy, P.R., Poist, R.P. (1989). Management of Logistical Retromovements: An Empirical Analysis of Literature Suggestions, Transportation Research Forum, pp. 177-84.

[119] Nachtmann, H., Waller, M., Rieske, D. (2010). The impact of point-of-sale data inaccuracy and inventory record data errors. Journal of Business Logistics, 31 (1), pp. 149-158.

[120] Ortega Mier, M. (2008). Utilización de métodos cuantitativos para el análisis de problemas de localización en logística inversa. PhD dissertation. Supervisor: Joaquín Delgado Hipólito. Universidad Politécnica de Madrid

[121] Pankratz, A. (1991). Forecasting With Dynamic Regression Models. New York: Wiley.

[122] Pohlen, T.L., Farris II, M. (1992). Reverse logistics in plastic recycling. International Journal of Physical Distribution \& Logistics Management, 22(7), 35-47.

[123] Ponce, E, Prida, B. (2004). La logística de aprovisionamientos para la integración de la cadena de suministros. Madrid: Prentice-Hall

[124] Popper, K.R. (1934). La lógica de la investigación científica. Madrid: Tecnos

[125] Powell, W.B. (1986). A stochastic model of the dynamic vehicle allocation problem. Transportation Science, 20(2):117-129.

[126] Privé, J., Renaud, J., Boctor, F., Laporte, G. (2006). Solving a vehicle-routing problem arising in soft-drink distribution. The Journal of the Operational Research Society, 57 (9):1045-1052.

[127] Raiffa, H. (1968). Decision Analysis. Introductory lectures on choices under uncertainty. AddisonWesley.

[128] Raman, A., De Horatius, N., and Ton, Z. (2001). Execution: the missing link in retail operations. California Management Review, 43(3):136-154.

[129] Regulation (EC) No. 178/2002 of the European Parliament and of the Council of 28 January 2002 laying down the general principles and requirements of food law, establishing the European Food Safety Authority and laying down procedures in matters of food safety, Official Journal of the European Communities, L 31, 1.2.2002, pp. 1-24. 
[130] Rekik, Y., Sahin, E., and Dallery, Y. (2008). Analysis of the impact of the RFID technology on reducing product misplacement errors at retail stores. International Journal of Production Economics, 112(1):264-278.

[131] Rekik, Y., Sahin, E., and Dallery, Y. (2009). Inventory inaccuracy in retail stores due to theft: an analysis of the benefits of RFID. International Journal of Production Economics, 118(1):189-198.

[132] Richter, K. (1996). The extended EOQ repair and waste disposal model. International Journal of Production Economics, $45(1-3), 443-448$.

[133] Rogers, D. S., Tibben-Lembke, R. S. (1999). Going Backwards: Reverse Logistics: Trends and Practices. Reverse Logistics Executive Council, Pittsburgh, PA.

[134] Rosenau, W.V., Twede, D., Mazzeo, M.A, Singh, S.P. (1996), "Returnable/reusable logistical packaging: A capital budgeting investment decision framework", Journal of Business Logistics, 17 (2), pp.139-165.

[135] Rubio Lacoba, S. (2003). El Sistema De Logística Inversa En La Empresa: Análisis y Aplicaciones. PhD dissertation. Supervisors: Tomás Bañeguil y Albert Corominas. Universidad de Extremadura.

[136] Rubio, S., Miranda, F.J., Chamorro, A., Valero, V. (2009), "Implementing a reverse logistics system: a case study", International Journal of Procurement Management, 2 (4), pp. 346-357.

[137] Rudi, N., Pyke, D.F., Sporsheim, P.O. (2000), "Product Recovery at the Norwegian National Insurance Administration”, Interfaces, 30 (3), pp. 166-179.Sagasti, F.R., Mitroff, I.I. (1973). Operations Research from the viewpoint of general systems theory. Omega, vol. 1 (6), pp. 695-709.

[138] Sahin, E. (2004). A qualitative and quantitative analysis of the impact of AutoID technology on the performance of supply chains. Ph.D. Thesis, Ecole Centrale Paris.

[139] Schlaifer, R. (1969). Analysis of decisions under uncertainty. McGraw-Hill.

[140] Schrady, D.A. (1967). A deterministic inventory model for reparable items. Naval Research Logistics Quarterly, 14(3):391-398.

[141] Sheffi, Y. (2004). RFID and the innovation cycle. The International Journal of Logistics Management, 15(1):1-10. 
[142] Sherbrooke, C.C. (1968). Metric: A multi-echelon technique for recoverable item control. Operations Research, 16(1):122-141.

[143] Soto Zuluaga, J.P. (2005). Reverse logistics: models and applications. PhD dissertation. Supervisor: Helena Ramalhinho. Departament d'Economia i Empresa, Universitat Pompeu Fabra.

[144] Strauss A.and Corbin J.M. (1990), Basics of Qualitative Research: Grounded Theory Procedures and Techniques. Thousand Oaks, CA: Sage.

[145] Stock, J.R. (1992), Reverse Logistics. Oak Brook, IL: Council of Logistics Management

[146] Stock, J.R. (1998). Development and implementation of reverse logistics programs. Council of Logistics Management, Oak Brook, IL.

[147] Susman, G., Evered, R. (1978). An assessment of the scientific merits of action research. Administrative Science Quarterly, vol.23, pp.582-603.

[148] Swinkels, J. and Van Esch, C.F.A.(1998), "Retourverpakkingen en omloopsnelheden" (Return packaging and turnover rates), in: Goor, A.R., Flapper, S.D.P., Clement, C. (eds.), Handboek Reverse Logisitics, Deventer, The Netherlands: Kluwer. (in Dutch)

[149] Teunter, R. (2004). Lot-sizing for inventory systems with product recovery. Computers \& Industrial Engineering, 46(3):431-441.

[150] The Kalundborg Center for Industrial Symbiosis (2010), http://www.symbiosis.dk/

[151] Thoroe, L., Melski, A., Schumann, M. (2009) The impact of RFID on management of returnable containers. Electronic Markets, 19, pp. 115-124.

[152] Thierry, M., Salomon, M., Van Nunen, J., van Wassenhove, L.N. (1995). "Strategic Issues in Product Recovery Management". California Management Review, vol. 37, 2, pp. 114-135.

[153] Toktay, L.B., Wein, L.M., and Zenios, S.A. (2000). Inventory management of remanufacturable products. Management Science, 46(11):1412-1426.

[154] Toktay, L.B., van der Laan, E. A., and de Brito, M.P. (2004). Managing product returns: the role of forecasting. In: Dekker, R., Fleischmann, M., Inderfurth, K., and van Wassenhove, L.N., (eds.), Reverse logistics. Quantitative models for closed-loop supply chains. Springer. 
[155] Turnquist, M.A., Jordan, W.C. (1986). Fleet sizing under production cycles and uncertain travel times. Transportation Science, 20(4):227-236.

[156] Twede, D., Clarke, R. (2005). Supply chain issues in reusable packaging. Journal of Marketing Channels, 12(1):7-26.

[157] Trist, E., Bamforth, W. (1951). Some social and psychological consequences of the long wall method of coal-getting. Human Relations, vol. 4, pp. 3-38.

[158] Van Dalen, J., van Nunen, J.A.E.E; Wilens, C.M. (2005). The chip in crate: the Heineken case. In: Flapper, S.D.P.; van Nunen, J.A.E.E.; van Wassenhove, L.N. (eds). Managing Closed-Loop Supply Chains. Berlin: Springer.

[159] Van Dalen, J., van Nunen, J.A.E.E. (2009) Modelling the turnaround behaviour of product carriers in the presence of highly-frequent information. Working paper. Erasmus University of Rotterdam.

[160] Vliegen, I.M.H. and Van Houtum, G.J. (2009), "Approximate evaluation of order fill rates for an inventory system of service tools", International Journal of Production Economics, 118, pp. $339-351$.

[161] Voss, C., Tsikriktsis, N., Frohlich, M (2002). "Case Research in Operations Management". International Journal of Operations and Production Management, vol. 22 (2), pp. 195-219.

[162] White, W.W. (1972). Dynamic transshipment networks: An algorithm and its application to the distribution of empty containers. Networks, 2(3):211-236.

[163] Woodward, J. (1965), Industrial Organization: Theory and Practice. Oxford University Press.

[164] Wyld, D.C. (2009). The reverse logistics of beer: combating keg theft by better managing the "float" in the very unique supply chain for draft beer. Reverse Logistics Magazine, 17: 16-19.

[165] Witt, C.E. (2000). Are reusable containers worth the cost? Transportation and Distribution, 41 (9), pp. 105-108.

[166] Yin, R.K. (1984). Case Study Research. Design and Methods. Newbury Park, CA: Sage Publications. 
[167] Young, R.R., Swan, P.F., and Burn, R.H. (2002). Private railcar fleet operations: The problem of excessive customer holding time in the chemicals and plastics industries. Transportation Journal, $42(1): 51-59$.

[168] Yuan, X. and Cheung, K. L. (1998). Modeling returns of merchandise in an inventory system. OR Spectrum, 20(3):147-154.

[169] Zeleny, M. (1975). Multiple Criteria Decision Making. Springer-Verlag. 